\title{
THE MOLECULAR PHARMACOLOGY OF PATEAMINE A
}

\author{
By \\ James Henry Matthews
}

\begin{abstract}
A thesis
submitted to the Victoria University of Wellington in fulfillment of the requirements for the degree of

Doctor of Philosophy

in Biomedical Science
\end{abstract}

Victoria University of Wellington 
This thesis is dedicated to the memory of George Albert Matthews

My proud father 


\section{Abstract}

Pateamine $\mathrm{A}$ is a cytotoxic terpenoid isolated from the marine sponge Mycale hentscheli that induces apoptosis in mammalian cell lines and is growth inhibitory to yeasts and fungi, yet shows no inhibitory action in prokaryotes. The targets of pateamine in mammalian cell lines were isolated and identified using a combination of affinity chromatography and mass spectrometry, putative targets included the DEAD-Box helicase eIF4A family of proteins, $\beta$-tubulin and actin. In vitro assessment of tubulin and actin polymerization showed pateamine was able to affect them only at high micromolar concentrations, whereas the effect on eIF4A in vitro was shown by others to occur at nanomolar concentrations. Additionally, pateamine was shown to inhibit cap-dependent protein synthesis in vivo, suggesting eIF4A as a primary target. The generation of a pateamine resistance-conferring mutation in the yeast eIF4A encoding gene TIF1, suggested further that eIF4A is a primary target in both mammalian and yeast cells, and allows the speculation of the position of the binding site for pateamine on the N-terminal lobe of eIF4A and the proposal of potential covalent interaction between this drug and its target. Given the size of the DEAD-Box helicase family, all of which share considerable homology with the eIF4As, FAL1 especially which is essential for rRNA maturation, a chemogenomic screen was performed in an attempt to establish the breadth of functional interactions of pateamine. The results of hierarchical clustering of these screen results suggest that pateamine has a mode-of-action distinct from other compounds screened previously, despite its effect on protein synthesis it failed to cluster with any other protein synthesis inhibitors regardless of their separate mechanisms, though, as a class, protein synthesis inhibitors were not found to form a discrete cluster in any of the variations of cluster analysis performed. Functional analysis, by GO term enrichment, of the genes whose deletions are hypersensitive to pateamine indicates that deletions of genes involved in numerous aspects of RNA metabolism affect pateamine sensitivity, however clear results regarding the involvement of FAL1 or any other non-eIF4A target in pateamine's mode-of-action were not found. 


\section{Acknowledgements}

First and foremost I must acknowledge my parents George and Yvonne Matthews without whose support emotionally, mentally and financially I would have never completed this work. Thank you for your patience, it's been a long road but it's finally found an end... for now. My primary supervisor Dr Paul Teesdale-Spittle who has been an endless source of inspiration, good ideas and a calming voice, lord knows I've needed calming at times. Thank you for your patience and believing me in me even when I probably didn't, and thank you for letting me take this project where I felt it should go, you allowed me to develop as a researcher, and taught me there is almost always information in data, even if it is ugly data that I cannot stand the sight of. Thanks to my secondary supervisor Dr Peter Northcote, who provided the pateamine, (or at least his grad students, cheers Joanna and others), but who also provided wise advice more than once.

A heart-felt thanks to Prof Paul Atkinson, without whose vision the chemical-genetics lab would not exist, you are an inspiration to all of us, there are not many that would undertake a research program in which we had no previous experience, you are to be admired. Without your influence I would not have been exposed so many of the things that now bring me so much joy... and frustration, thank you for allowing me to start to develop a way of thinking that I hope allow me to be an effective scientist and researcher for as many years as you have been. To Dr David Maass, you are a strange man, but shooting the shit with you also helped me develop how I think about things now, you are an invaluable member of not only our lab but the department and University as a whole, keep asking the shitty questions.

To Drs John Miller, Alan Clark, Bill Jordan, Darren Day and Jim McIntosh, you were the ones who taught me and piqued my interest in all of this, thank you for always having an open door and indulging my ignorance on multiple occasions. I thank all of the graduate students past (very past in some cases) and present, for putting up with my rants, but also for allowing me to help you where I could, through helping you (and watching what didn't work...) I have learnt more that I would have done otherwise, keep on trucking Vero, if I can finally finish so you can too. Finally, to the girly, I don't know where to start, or finish, but I carry it too. 


\section{Table of Contents}

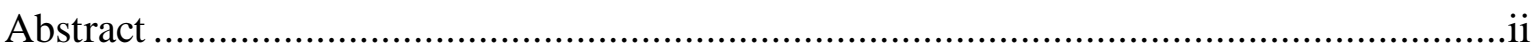

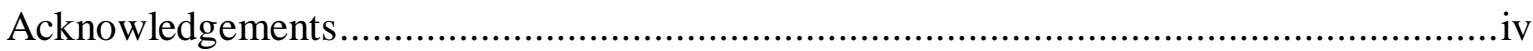

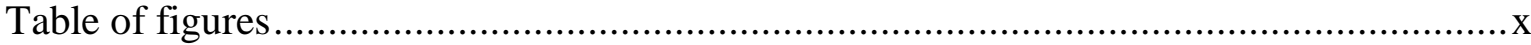

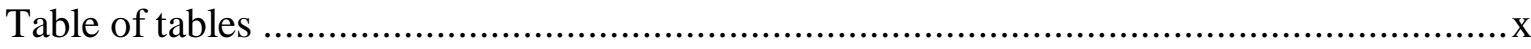

Table of supplementary files .....................................................................................

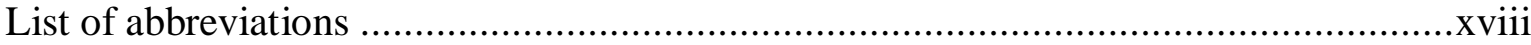

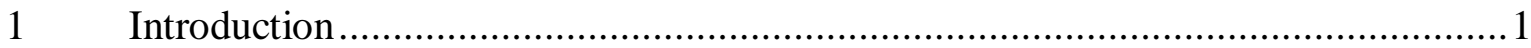

$1.1 \quad$ Drug mechanism and mode-of-action ..............................................................

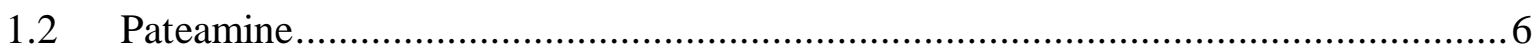

1.3 The eIF4A family of DEAD-box helicases ........................................................... 11

$1.4 \quad$ Eukaryotic translation and protein synthesis inhibitors .......................................... 17

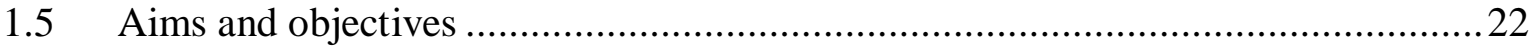

2 Affinity isolation of the cellular target of pateamine ............................................23

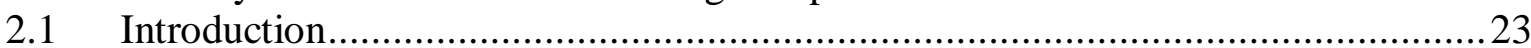

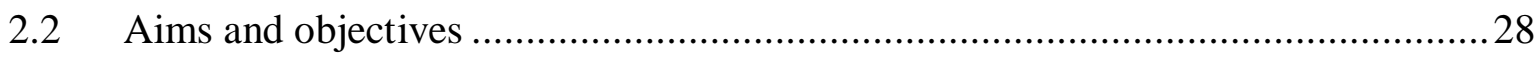

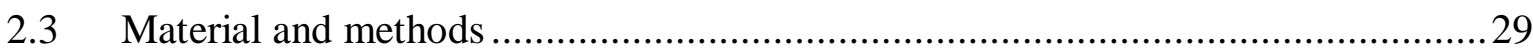

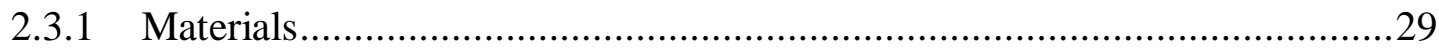

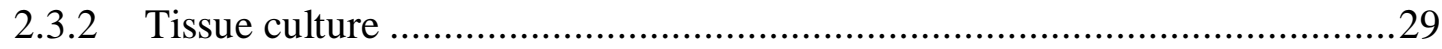

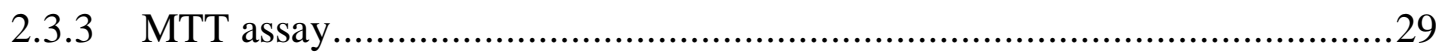

2.3.4 Pateamine affinity resin generation ..........................................................

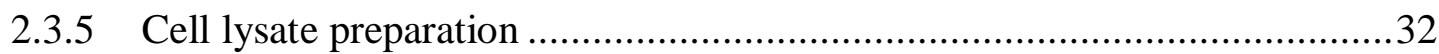

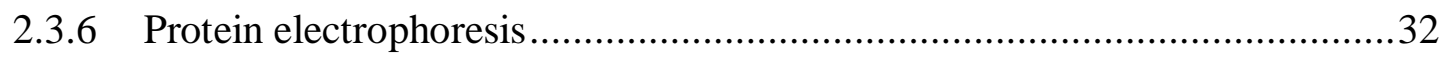

2.3.7 Isolation of pateamine binding proteins.......................................................3

2.3.8 Peptide mass fingerprinting......................................................................

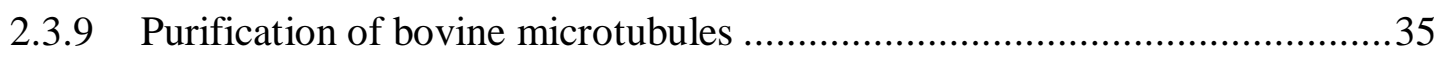

2.3.10 Tubulin polymerization assay ......................................................................36

2.3.11 Pyrene-actin microfilament polymerization assay ………………….............37

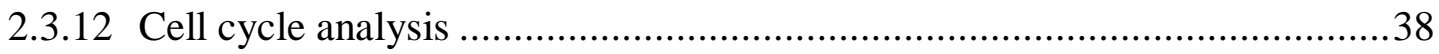

2.3.13 Annexin V binding assay ………………………................................... 38 


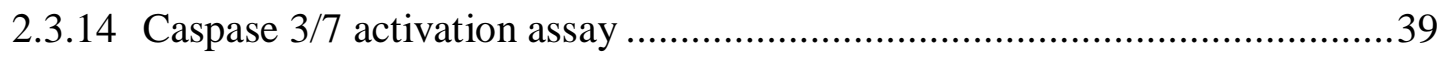

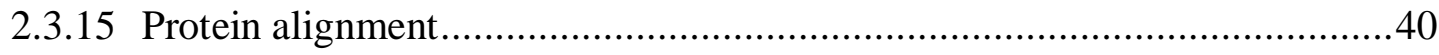

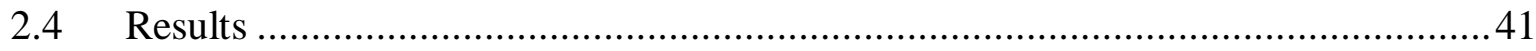

2.4.1 Pateamine is cytotoxic to cultured cells ...................................................41

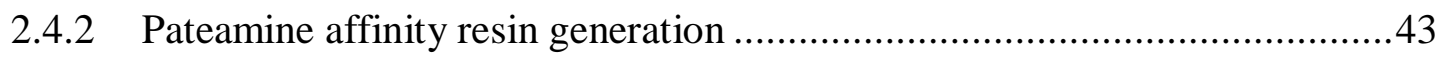

2.4.3 Pateamine binding protein isolation and elution ..................................4

2.4.4 Identification of putative pateamine binding proteins by peptide mass

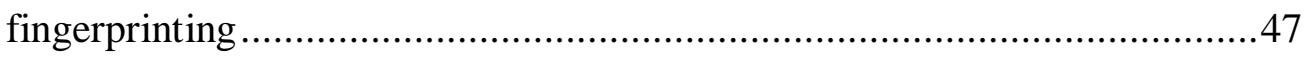

2.4.5 Pateamine displays duel effects on in vitro microtubule polymerization......52

2.4.6 High concentrations of pateamine disrupt polymerization of rabbit $\alpha$-actin in

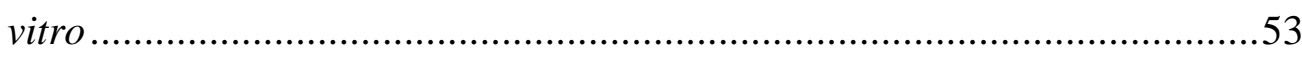

2.4.7 Pateamine does not specifically disrupt cell cycle progression ...................56

2.4.8 Pateamine cytotoxicity is irreversible ................................................6

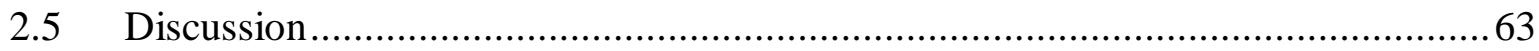

2.5.1 Putative target proteins isolated from human cell lines ...........................63

2.5.2 Protein $1-\beta$-tubulin ...................................................................6 65

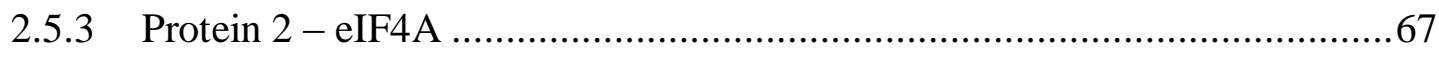

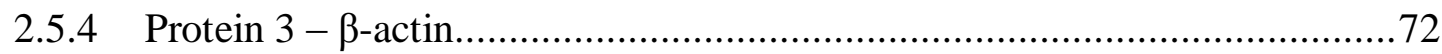

2.5.5 Irreversibility of pateamine-induced cytotoxicity .................................. 74

2.5.6 Mammalian pateamine targets..................................................... 75

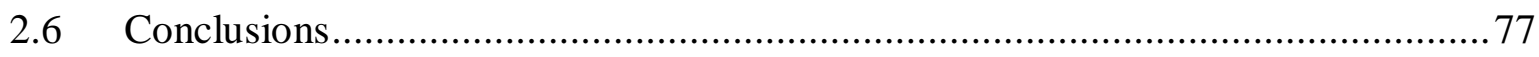

3 The generation and characterization of pateamine resistant yeast ........................ 78

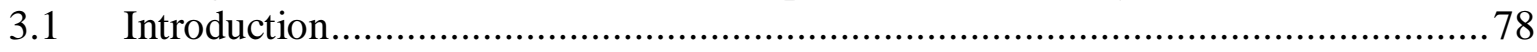

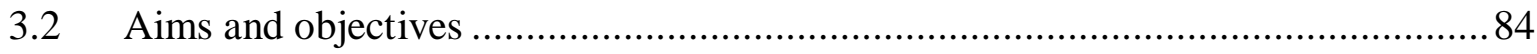

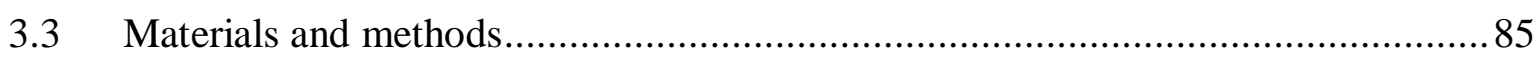

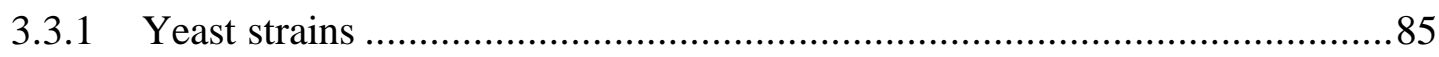

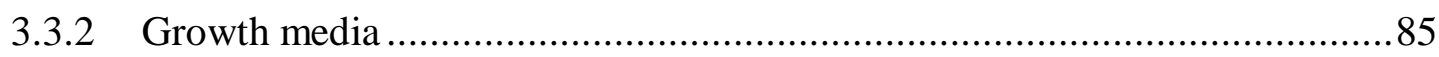




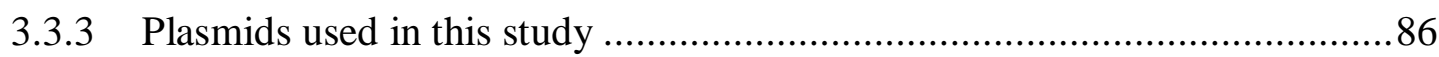

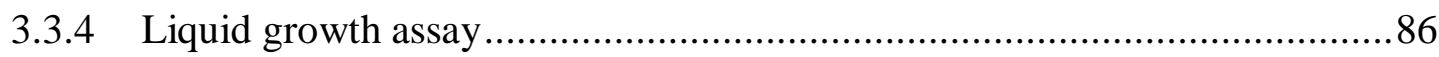

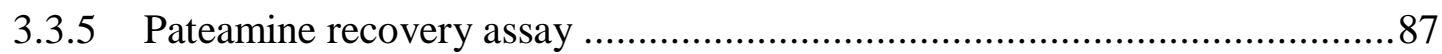

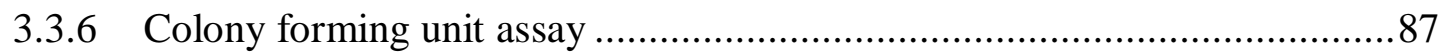

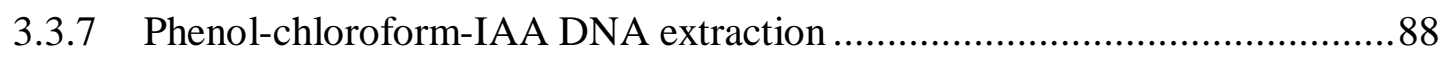

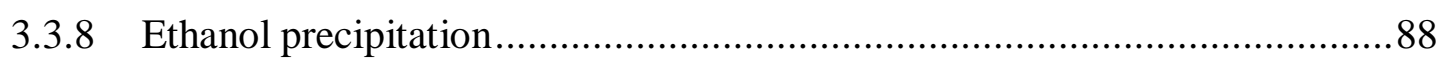

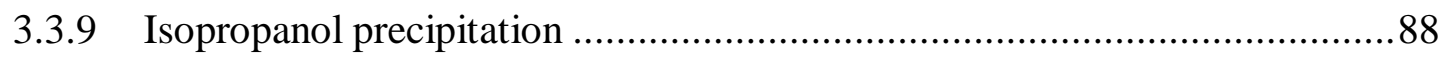

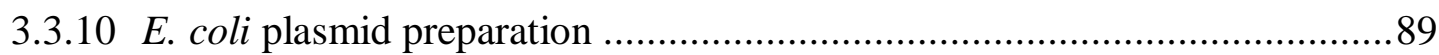

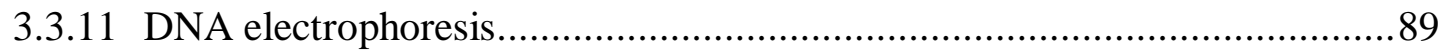

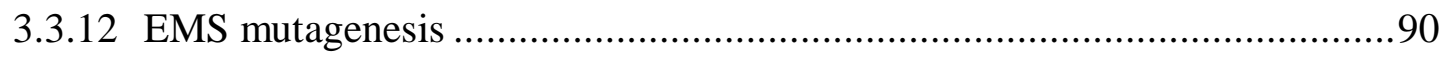

3.3.13 S. cerevisiae plasmid preparation ...................................................... 90

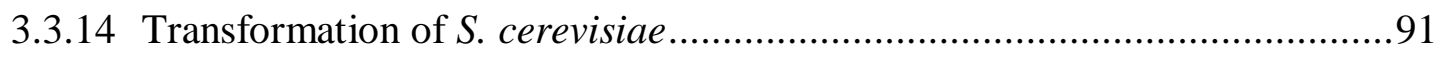

3.3.15 TIF1-TAP plasmid digestion and purification ......................................92

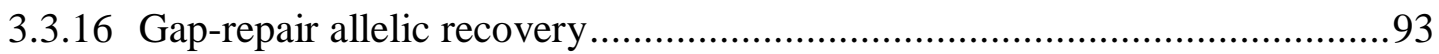

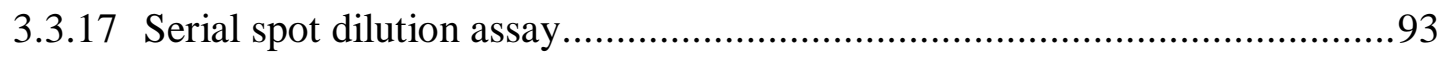

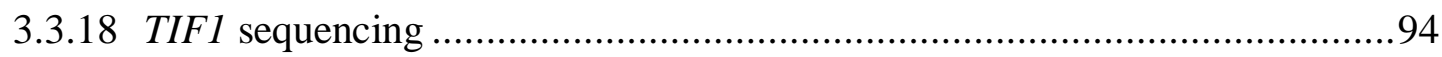

3.3.19 De novo protein and RNA synthesis assay ............................................94

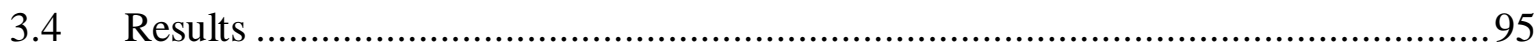

3.4.1 Pateamine reversibly inhibits the growth of $S$. cerevisiae .........................95

3.4.2 Multi-drug resistance pump and ergosterol pathway deletions sensitize to

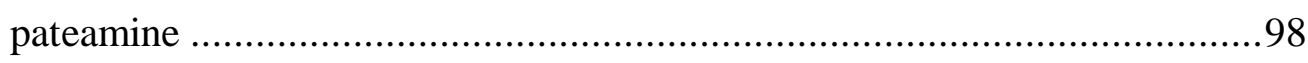

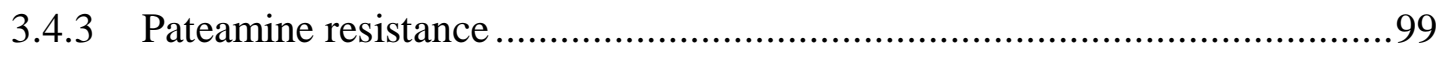

3.4.4 Gap repair-mediated recovery of tif1 allele .........................................100

3.4.5 Sequencing of tif1 allele reveals a single point mutation .........................103

3.4.6 Pateamine inhibits protein and RNA synthesis in yeast ......................... 103

3.4.7 Predicting a putative pateamine binding site ....................................... 105

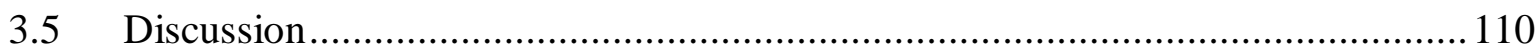


3.5.1 Pateamine inhibits the growth of yeast in a but does not kill them 110

3.5.2 Multi-drug resistance pump and ergosterol pathway deletions sensitize to pateamine

3.5.3 Pateamine resistance 112

3.5.4 Gap repair mediated recovery of tif1 allele. 113

3.5.5 Sequencing of tif1 allele reveals a single point mutation 114

3.5.6 Pateamine inhibits protein and RNA synthesis in yeast 115

3.5.7 Putative pateamine binding site on eIF4A 116

3.6 Conclusions 118

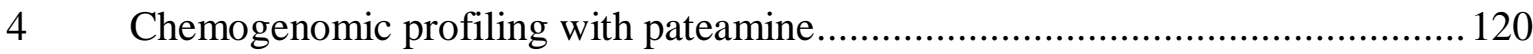

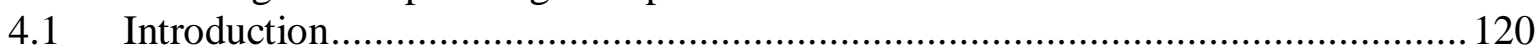

4.1.1 The heterozygous deletion library ................................................ 121

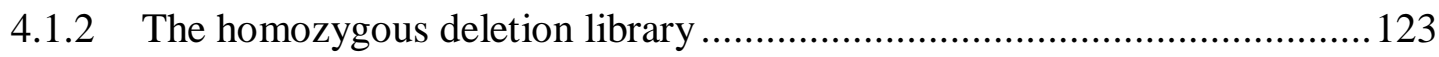

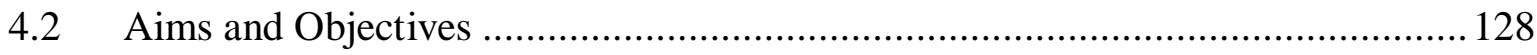

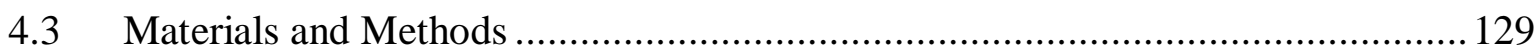

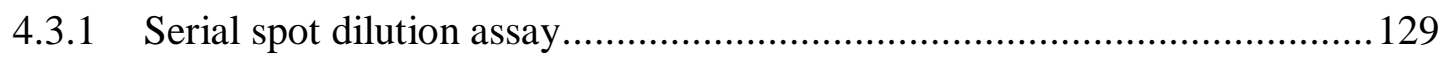

4.3.2 Pateamine haploid hyper-sensitivity screen ........................................ 129

4.3.3 Confirmation of altered pateamine sensitivity ......................................130

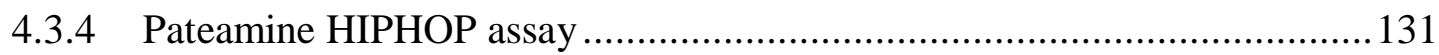

4.3.5 Functional enrichment analysis ....................................................... 131

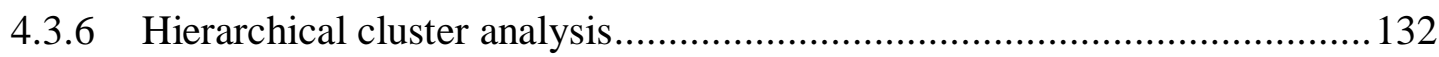

4.3.7 Protein synthesis inhibitor sensitive strain overlap ...............................133

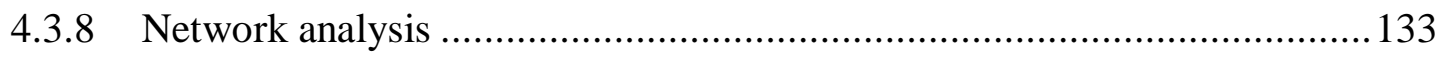

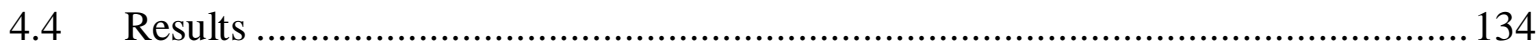

4.4.1 eIF4F component sensitivity to pateamine ......................................... 134

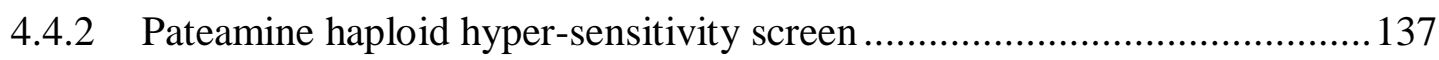

4.4.3 Heterozygous essential gene deletion library results.............................139 
4.4.4 Homozygous deletion library screen results ....................................... 144

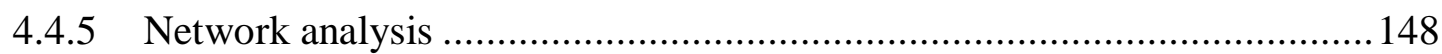

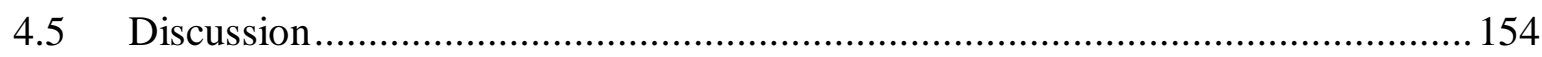

4.5.1 eIF4F component deletion fitness in the presence of pateamine.................154

4.5.2 FAL1 haploinsufficiency in the presence of pateamine ...........................156

4.5.3 Homozygous deletion library screens............................................. 157

4.5.4 Haploinsufficiency profiling of pateamine ......................................... 162

4.5.5 Interactions of pateamine with other proposed targets ........................... 163

4.5.6 Pateamine-hit interaction network analysis ....................................... 164

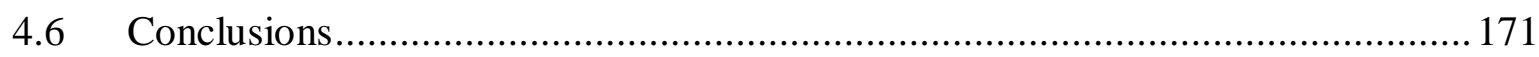

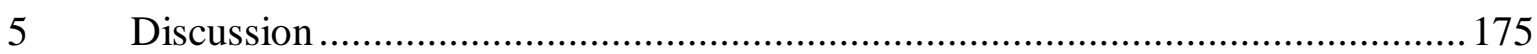

5.1 Pateamine targets the eIF4A helicase family in mammalian cell lines ................ 175

5.2 Pateamine targets yeast eIF4A ........................................................... 180

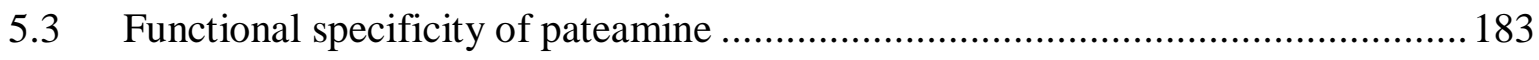

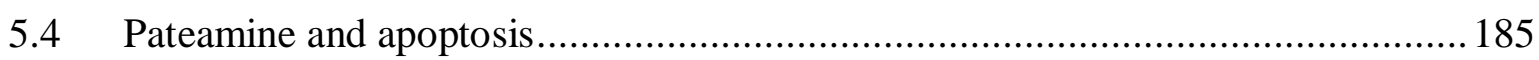

5.5 Models of pateamine action................................................................. 188

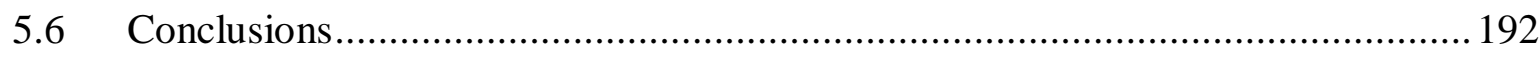

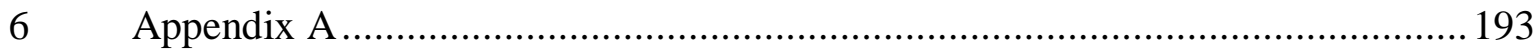

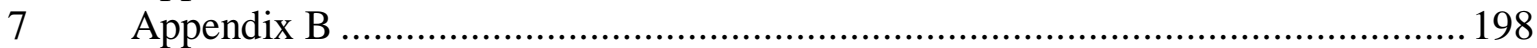

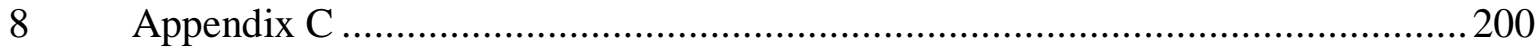

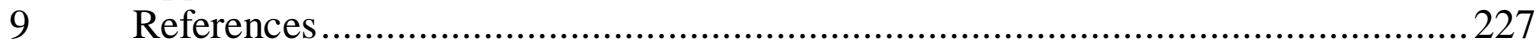




\section{Table of figures}

Figure 1.1 The structure of pateamine A........................................

Figure 1.2 The role of eIF4A in cap-dependent translation initiation....................13

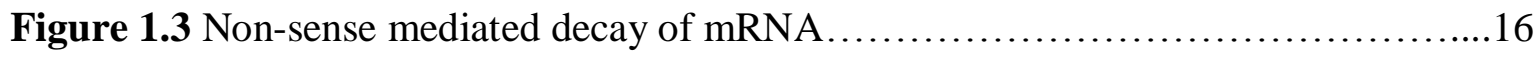

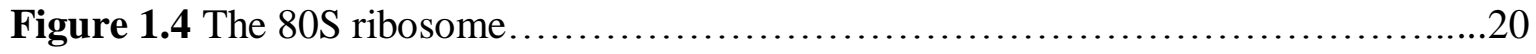

Figure 2.1 Pateamine cytotoxicity dose-response curves.........................42

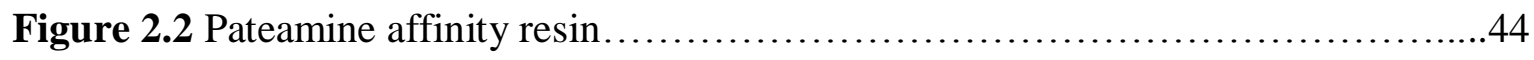

Figure 2.3 Isolation of cellular pateamine targets by affinity chromatography ...........46

Figure 2.4 Pateamine affinity chromatography specificity of interaction...............47

Figure 2.5 MALDI mass spectrum acquired from gel band two....................49

Figure 2.6 eIF4AIII isolated by pateamine affinity chromatography ..................50

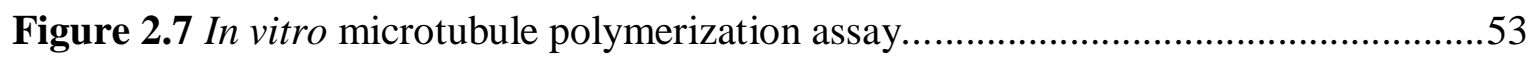

Figure 2.8 In vitro microfilament polymerization assay ...........................55

Figure 2.9 Cell cycle distribution in the presence of pateamine ....................................57

Figure 2.5 Chronic exposure to pateamine activates caspase 3/7 and causes a loss of

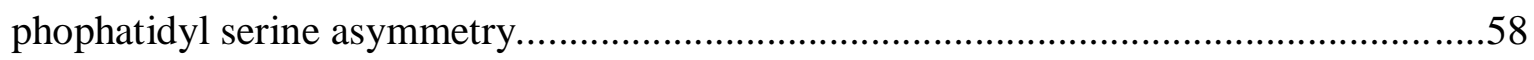

Figure 2.6 Pateamine dose-response in the presence of the pan-caspase inhibitor

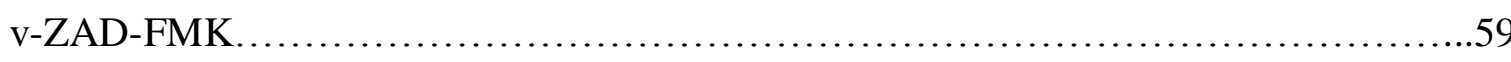

Figure 2.12 Pateamine withdrawal MTT assay ......................................................61

Figure 2.13 Activation kinetics of caspase 3/7 by pateamine by flow cytometry............ 62

Figure 3.1 Yeast dose-response experiments..................................96

Figure 3.2 Growth inhibition recovery assay...................................97 
Figure 3.3 Colony forming unit assay.....

Figure 3.4 Serial spot dilution assay of strains deficient in ergosterol pathway components and the Pdr5p drug efflux pump.

Figure 3.5 PAR clone resistance to pateamine confirmation by serial spot dilution.

Figure 3.6 Large BG1805 plasmid fragment production by restriction digestion. 101

Figure 3.7 Clones bearing gap-repaired TIF1 plasmids recovered from PAR1-5 clones confer pateamine resistance to the $\Delta t i f 2, \Delta e r g 6$ strain

Figure 3.8 Pateamine resistance is not due to the $U R A 3$ selection marker presence 102

Figure 3.9 Recovered pBG1805-PAR1 - 5 amino acid sequence alignment with wild-type TIF1......

Figure 3.10 Pateamine inhibits in vivo macromolecule synthesis in yeast. 104

Figure 3.11 Potential pateamine binding site proposition by sequence alignment. 107

Figure 3.12 eIF4AIII bound to RNA abstracted from the crystal structure of the EJC....109

Figure4.1 Serial spot dilution assay of eIF4F component deletion strains 135

Figure 4.2 Pateamine sensitivity of the heterozygous $\Delta$ fall deletion strain.

Figure 4.3 Heterozygous diploid (HIP) pateamine screen results hierarchically clustered with the essential heterozygous deletion screen dataset from Hillenmeyer et al 144

Figure 4.4 Homozygous diploid (HOP) pateamine screen results hierarchically clustered with the essential heterozygous deletion screen dataset from Hillenmeyer et al. ... 147

Figure 4.5 Homozygous diploid (HOP) pateamine screen results hierarchically clustered with the homozygous deletion screen dataset from Parsons et al. 148 
Figure 4.6 Sub-network one is enriched for processes related to RNA polymerase II related transcription, translation, tRNA metabolism and protein ubiquitination.

Figure 4.7 Sub-network two is enriched for processes related to RNA transport, mitosis, transcription, DNA repair and vacuolar acidification.

Figure 4.8 Sub-network three is enriched for large and small ribosome subunits, ribosome biogenesis, regulation of transcription and translation initiation

Figure 5.1 Pateamine mechanism model one

Figure 5.2 Pateamine mechanism model two 190

Figure 6.1 Replicate MTT assay dose response curves for HeLa, SH-SY5Y, and HL-60 cell lines.

Figure 6.2 Mass spectra close-up images 194

Figure 6.3 Close up of spectrum acquired from gel band two 195

Figure 6.4 Mass spectrum acquired from gel band three. 196

Figure 6.5 LDS-PAGE of purified bovine tubulin. 196

Figure 6.6 Multiple amino acid sequence alignment of actin 197

Figure 7.1 Replicate tritiated leucine and tritiated uridine incorporation dose-response curves.

Figure 7.2 TPG and TLG sequences are able to assume the same conformation

Figure 7.3 Conformational differences in RNA bound and apo structures

Figure 8.1 Complete clustergram resulting from the hierarchical clustering of pateamine HIP screens with the essential heterozygous screen data from Hillenmeyer et al 2008.

Dataset 1 was clustered using the centered Pearsons distance metric.... 201

Figure 8.2 Complete clustergram resulting from the hierarchical clustering of pateamine HIP screens with the essential heterozygous screen data from Hillenmeyer et al 2008.

Dataset 1 was clustered using the uncentered Pearsons distance 202 
Figure 8.3 Complete clustergram resulting from the hierarchical clustering of pateamine HIP screens with the essential heterozygous screen data from Hillenmeyer et al 2008.

Dataset 2 was clustered using the centered Pearsons distance metric..... .203

Figure 8.4 Complete clustergram resulting from the hierarchical clustering of pateamine HIP screens with the essential heterozygous screen data from Hillenmeyer et al 2008.

Dataset 2 was clustered using the uncentered Pearsons distance metric. 204

Figure 8.5 Complete clustergram resulting from the hierarchical clustering of pateamine HIP screens with the essential heterozygous screen data from Hillenmeyer et al 2008. Dataset 3 was clustered using the centered Pearsons distance metric..... .205

Figure 8.6 Complete clustergram resulting from the hierarchical clustering of pateamine HIP screens with the essential heterozygous screen data from Hillenmeyer et al 2008.

Dataset 3 was clustered using the centered Pearsons distance metric .206

Figure 8.7 Complete clustergram resulting from the hierarchical clustering of pateamine HIP screens with the essential heterozygous screen data from Hillenmeyer et al 2008. Dataset 4 was clustered using the Jaccard distance metric

Figure 8.8 Complete clustergram resulting from the hierarchical clustering of pateamine HOP screens with the homozygous diploid screen data from Hillenmeyer et al 2008.

Dataset 1 was clustered using the centered Pearsons distance metric. .208

Figure 8.9 Complete clustergram resulting from the hierarchical clustering of pateamine HOP screens with the homozygous diploid screen data from Hillenmeyer et al 2008.

Dataset 1 was clustered using the uncentered Pearsons distance metric. .209

Figure 8.10 Complete clustergram resulting from the hierarchical clustering of pateamine HOP screens with the homozygous diploid screen data from Hillenmeyer et al 2008.

Dataset 2 was clustered using the centered Pearsons distance metric. 210

Figure 8.11 Complete clustergram resulting from the hierarchical clustering of pateamine HOP screens with the homozygous diploid screen data from Hillenmeyer et al 2008.

Dataset 2 was clustered using the uncentered Pearsons distance metric. 211 
Figure 8.12 Complete clustergram resulting from the hierarchical clustering of pateamine HOP screens with the homozygous diploid screen data from Hillenmeyer et al 2008.

Dataset 3 was clustered using the centered Pearsons distance metric. 212

Figure 8.12 Complete clustergram resulting from the hierarchical clustering of pateamine HOP screens with the homozygous diploid screen data from Hillenmeyer et al 2008.

Dataset 3 was clustered using the uncentered Pearsons distance metric. 213

Figure 8.13 Complete clustergram resulting from the hierarchical clustering of pateamine HOP screens with the homozygous diploid screen data from Hillenmeyer et al 2008.

Dataset 4 was clustered using the Jaccard distance metric. .214

Figure 8.15 Complete clustergram resulting from the hierarchical clustering of pateamine HOP screens with the homozygous diploid screen data from Parsons et al 2006 was clustered using the centered Pearsons distance metric. 215

Figure 8.16 Complete clustergram resulting from the hierarchical clustering of pateamine HOP screens with the homozygous diploid screen data from Parsons et al 2006was clustered using the uncentered Pearsons distance metric and average linkage method....216

Figure 8.17 Complete clustergram resulting from the hierarchical clustering of pateamine HOP screens with the homozygous diploid screen data from Parsons et al 2006 was clustered using the uncentered Pearsons distance metric and average linkage method....217

Figure 8.18 Pateamine hypersensitive and haploinsufficient gene deletion network.....218

Figure 8.19 Pateamine screen hit interactions with other hits.... .219

Figure 8.20 Sub-network five .220

Figure 8.21 Sub-network six. 221

Figure 8.22 Sub-network seven. 222

Figure 8.22 Synthetic lethal and negative genetic interactions present in the SGD database for yeast eIF4A encoding genes TIF1 and TIF2 and the closely related FAL1. .223 


\section{Table of tables}

Table 2.1 Summary of cytotoxicity assay results for pateamine sensitive cell lines

Table 2.2 Summary of ProFound search results for putative pateamine binding proteins...51

Table 2.3 Summary of curve parameters for z-VAD-FMK inhibited MTT assays.........59

Table 2.4 P-values for selected points in the pan caspase inhibited MTT assay

Table 2.5 Summary of caspase 3/7 activation kinetics in HeLa cells

Table 4.1 Top-ten haploinsufficient strains from four pateamine HIP replicates and their $\log _{2}$ ratio scores 140

Table 7.1 Summary statistics for leucine and uridine incorporation assays 198

Table 8.2 Pearson correlation of heterozygous deletion set HIP screen results. .200

Table 8.3 HIP screen overlaps in hit and GO term enrichment. .200

Table 8.4 Pearson correlation of homozygous deletion set HOP screen results 207

Table 8.5 Contribution of pateamine screen data to MCODE clusters. .223

Table 8.6 Descriptions of genetic interactions used in network analysis .224

Table 8.7 Descriptions of physical interactions used in network analysis. 225 


\section{Table of supplementary files}

\section{Supplementary File 1}

Sheet 1 MTT assay raw data

Sheet 2 Peptide mass fingerprinting search results for HeLa cells

Sheet 3 Peptide mass fingerprinting search results for HL-60 cells

Sheet 4 Peptide mass fingerprinting search results for SH-SY5Y cells

Sheet 5 Theoretical trypsin digests of human b-tubulin, actin and eIF4A isoforms

Sheet 6 Tubulin polymerization assay results

Sheet 7 Actin polymerization assay results

Sheet 8 Caspase 3 and Annexin V assay results

\section{Supplementary File 2}

Sheet 1 Pateamine haploid screen results

Sheet 2 Haploid screen overlap with protein synthesis inhibitors

Sheet 3 Pateamine HIP screen results

Sheet 4 HIP screen top-ten hit lists

Sheet 5 HIP screen overlap with protein synthesis inhibitors

Sheet 6 Pateamine HOP screen results

Sheet 7 HOP screen overlap with protein synthesis inhibitors

Sheet 8 MCODE results

Sheet 9 HOP and haploid screen overlap

\section{Supplementary File 3}

Sheet 1 GO term enrichments for Pateamine hypersensitive haploid deletion after MDS removal

Sheet 2 GO term enrichments for Pateamine hypersensitive haploid deletion overlap with other protein synthesis inhibitor datasets after MDS removal

Sheet 3 GO term enrichments for Top-ten HIP hits

Sheet 4 GO term enrichments for HIP screen 1

Sheet 5 GO term enrichments for HIP screen 2

Sheet 6 GO term enrichments for HIP screen 3

Sheet 7 GO term enrichments for HIP screen 4

Sheet 8 GO term enrichments for hits from 3 of 4 HIP screens

Sheet 9 GO term enrichments for HIP screen 1 overlap with other protein synthesis 
inhibitor datasets

Sheet 10 GO term enrichments for HIP screen 2 overlap with other protein synthesis inhibitor datasets

Sheet 11 GO term enrichments for HIP screen 4 overlap with other protein synthesis inhibitor datasets

Sheet 12 GO term enrichments for HIP screen 3 of 4 overlap with other protein synthesis inhibitor datasets

Sheet 13 GO term enrichments for HOP screen 1

Sheet 14 GO term enrichments for HOP screen 1 overlap with other protein synthesis inhibitor datasets

Sheet 15 GO term enrichments for MCODE sub-network 1

Sheet 16 GO term enrichments for MCODE sub-network 2

Sheet 17 GO term enrichments for MCODE sub-network 3

Sheet 18 GO term enrichments for MCODE sub-network 4

Sheet 19 GO term enrichments for MCODE sub-network 5

Sheet 20 GO term enrichments for MCODE sub-network 6

Sheet 21 GO term enrichments for MCODE sub-network 7

Sheet 22 GO term enrichments for MCODE sub-network 8

Sheet 23 GO term enrichments for compiled list of all pateamine screen hits 


\section{List of abbreviations}

MDS

MSG

4E-BP

5 -UTR

ATP

$\mathrm{ddH}_{2} \mathrm{O}$

DEAE

DMSO

DTT

$\mathrm{EC}_{50}$

EDTA

EGTA

eIF4A

eIF4B

eIF4E

eIF4F

eIF4G

EJC

EMS

FCS

FKBP12

GO

GTP

$\mathrm{HCV}$

HEPES

HIP

HOP

$\mathrm{IC}_{50}$

IFN $\gamma$

IL-2

IRES

KanR

LCV
Multi-drug sensitizing

Monosodium glutamate

4E binding protein

5 -untranslated region

Adenosine triphosphate

Distilled, deionized water

Diethylaminoethyl cellulose

Dimethyl sulfoxide

Dithiothreitol

Effective concentration 50

Ethylene diamine tetra acetic acid

Ethylene glycol tetra acetic acid

Eukaryotic initiation factor $4 \mathrm{~A}$

Eukaryotic initiation factor $4 \mathrm{E}$

Eukaryotic initiation factor $4 \mathrm{E}$

Eukaryotic initiation factor $4 \mathrm{~F}$

Eukaryotic initiation factor $4 \mathrm{G}$

Exon-exon junction complex

Ethyl methane sulfonate

Foetal calf serum

FK506 binding protein 12

Gene ontology

Guanosine triphosphate

Hepatitis $\mathrm{C}$ virus

$\mathrm{N}$-(2-hydroxyethyl)-piperazine-N'-2-ethanesulfonic acid

Haploinsufficiency profiling

Homozygous profiling

Inhibitory concentration 50

Interferon gamma

Interleukin 2

Internal ribosome entry site

Kanamycin resistance cassette

Lymphocyte viability assay 
LDS

MALDI-MS Matrix assisted laser desorption ionisation mass

spectrometry

MAPK

MDS

mHIP

MLR

MTT

NatR

ncRNA

NMD

OD

ORF

PAGE

PBS

PCR

PEG

PenStrep

PIPES

PTC

RPM

RT-PCR

$\mathrm{SD}$

SDS

SGD

TBE

TCA

TE

TFA

THF

TOF

TOR

XIAP
Mitogen activated protein kinase

Multi-drug sensitizing

Multi-drug haploinsufficient

Mixed lymphocyte reaction

3-(4,5-dimethylthiazol-2-yl)-2,5-diphenyltetrazolium

bromide

Nourseothricin resiatnce cassette

Non-coding RNA

Non-sense mRNA decay

Optical density

Open reading frame

Polyacrylamide electrophoresis

Phosphate buffered saline

Polymerase chain reaction

Polyethylene glycol

Penicillin-Streptomycin

Piperazine-1,4-bis(2-ethanesulfonic acid)

Premature termination codon

Revolutions per minute

Real time polymerase chain reaction

Synthetic dropout

Sodium dodecyl sulfate

Saccharomyces Genome Database

Tris, boric acid, EDTA

Trichloroacetic acid

Tris, EDTA

Trifluoracetic acid

Tetrahydrofuran

Time-of-flight

Target of rapamycin

$\mathrm{X}$-linked anti-apoptotic protein 


\section{Introduction}

\subsection{Drug mechanism and mode-of-action}

A bio-active small molecule, or drug, is a chemical entity that elicits a specific response in a biological system. While a vast array of chemical entities are able to elicit a response in biological systems only a subset of these can be considered drug-like compounds due to the lack of specific responses elicited by other compounds. For instance, many organic solvents may have effects in biological systems that are non-specific, e.g. methanol causes dehydration, increased permeability of the plasma membrane and non-specific cross-linking of cellular proteins. While this is an effect on a biological system it cannot be called a specific one. In the 1870's Paul Erlich proposed that specific staining by chemical dyes occurs due the interaction between the dye and a cellular structure and John Newport Langley proposed there was some structure in nerves capable of specifically interacting with pilocarpin and atropine (Maehle, Prull et al. 2002). This is what is meant by a specific response, that is, those responses that are mediated by the physical interaction between a small molecule and a specific biological structure or structures.

In general, drug-like compounds interact with cellular macromolecules: proteins, nucleic acids, carbohydrates and lipids, with the majority of characterized bio-active compounds targeting proteins. In the case of proteins these interactions are usually non-covalent, mediated by hydrogen bonds, electrostatic, hydrophobic and van der Waals interactions between the small molecule and the target. The interaction between a drug and its target (especially those that are protein targets) can be viewed in a similar way to the relationship between enzymes and their substrates. An initial binding event occurs between a portion of the compound and the target, which become a higher affinity interaction according to the 
"induced fit" theory (Koshland 1994). That is after the initial binding, both the small molecule and the target protein induce a conformational change in each other that leads to greater complementarily between the compound and its binding site on the protein. This is exemplified in the case of small molecule chaperones that allow correct protein folding of a nascent polypeptide in situations where the protein is likely to fold incorrectly (Arakawa, Ejima et al. 2006).

Covalent interactions between small molecules and proteins also occur but they are much less common and often involve nucleophilic attack by an enzyme on reactive electrophilic centres of the small molecule. For instance the epoxide moiety is fumagillin attacked by a nucleophilic amino acid side chain present at its binding site on methionine aminopeptidase 2 (Sin, Meng et al. 1997). Often the nucleophilic attack is an integral part of the mechanism by which that enzyme performs its function, for instance irreversible protease inhibitors (Sabido, Tarrago et al. 2009). However, covalent drug-protein adducts can be formed with non-enzymatic protein targets also. Bioactive molecules targeting lipids tend to do so via non-covalent interactions also, e.g. nystatin interacts with ergosterol reversibly (Bastide, Jouvert et al. 1982; Richman-Boytas and Parks 1989). However, irreversible interactions with DNA are common with agents that target it specifically, for instance DNA alkylating agents (Vanduuren 1988). While most bioactive compounds can be separated into those that target proteins, nucleic acids or lipids exclusively, on occasion a compound may target a non-protein structure through a protein that acts directly on the that target, as is the case with etoposide where the target could viewed as being the complex of topisomerase II and DNA (Liu, Hsiung et al. 1994). 
The identity of the structure targeted by a small molecule and how the function of that target is perturbed by the compound constitutes that compound's mode-of-action or mechanism. These terms are commonly used interchangeably however there is a subtle difference between them. The mode-of-action of a compound is often a broad categorization, for instance, DNA alkylating agents, protein synthesis inhibitors, and cholesterol lowering drugs. These classifications can be useful to describe what the compound does in broad terms, but they often do not contain enough information to say exactly how this effect is achieved. The mechanism of a drug on the other hand specifies the cellular structure targeted by the compound, how its function is changed and how that alters the performance or the phenotype of the biological system in the presence of the compound; all of the information required to describe exactly what the compound does.

Understanding detailed mechanisms of a compound's action is becoming more important as the search for specific drugs with high efficacy and low incidence of side effects increases. In the case of therapeutic drugs this knowledge may lead to the rational or semirational design of new drugs that emulate the action of previous drugs while potentially having fewer side-effects or greater efficacy. This is especially true for antibiotic, antifungal, anti-viral and anti-neoplastic drugs that are particularly prone to a loss of efficacy due to the development of resistance by the intended target (White, Marr et al. 1998; Walsh 2000; Gottesman 2002; Sarafianos, Hughes et al. 2004). Knowledge of the target and mechanism of a drug can aid in the understanding of how side-effects occur as well as the design of the drugs with fewer side effects. Side-effects, as with the desired effect of a drug, are also mediated by interaction with cellular structures, however it must be ascertained whether the side-effects noted are due to the interaction with more than one target, or with one target whose exact function depends on the environment in which it exists, e.g. difference in function in different cell types. It is becoming more apparent that 
the function, in the context of the cell, of any one gene, or the protein or RNA it encodes, is dependent on the other genes that are being expressed in that cell type, therefore the downstream consequence of perturbing one target in different cell types may well differ.

In the case of non-therapeutic compounds, e.g. toxins, mechanistic knowledge of their action can yield highly useful biological probes that can lead to a greater understanding of the function of their targets. This aspect is becoming particularly important with the rise of chemical genetics which, in part, attempts to understand biological phenomena by identifying compounds that alter the occurrence of that phenomenon. The premise of the chemical-genetic approach is that small molecules can emulate genetic mutations, that is, an inhibitor of an enzyme is functionally analogous to a loss of function mutation in the gene that encodes that enzyme (Piggott and Karuso 2004). The reverse also holds, where some mutations can cause an increase in the activity of the protein product. Small molecules can also be found to stimulate the function of their target; admittedly they are underrepresented in the literature but that may be due to the manner in which drugs have been sought rather than the likelihood of their existence.

This is analogous to classical reverse genetics approaches, where mutants are sought with altered phenotypes. Once found, the mutation is identified and the role of that gene in the phenotype of interest is characterized. Chemical genetics can greatly accelerate the discovery of compounds that alter phenotypes, but linking this back to the gene/targets responsible for this alteration remains a significant challenge. When approaching gene function from a purely genetic angle the information is retained in the sequence of DNA, on the other hand the conditional mutation that a drug or bioactive compound emulates is transient and unable to be amplified, and is therefore more difficult to characterize. 
However the advantage of using chemical mimics of genetic mutations is that they allow an assessment of temporal gene function; when the interaction is reversible they can be added, removed and titrated; and the timing of addition can be altered. Due to this emulation of conditional mutants, bioactive compounds allow access to essential gene functions that are difficult to study in a purely genetic manner. From a systems biology point of view the broader the phenotype that a compound induces the more can be learned about its target, also the more different phenotypes induced by the compound the better, as this allows for a more complete assessment of the targets function.

Hence, small molecules can be used to study the function of their target in a complete biological system, and the consequence of altering that function, but this requires knowledge of their target. Another way in which small molecules can illuminate target function is by understanding the nature of the physical interaction between the small molecule and its target. The function of a protein is defined by its structure, which is in turn defined by its amino acid sequence. Biologically active small molecules physically interact with proteins and change their function. This must mean that small molecule binding alters either protein structure, for example through altering conformation or shifting the balance within ensembles of conformations, or its ability to associate with other proteins or substrates, in the case of enzyme inhibitors. Therefore, an appreciation of the way in which the protein structure changes upon small molecule binding should provide evidence of the structure-function relationship of that protein.

By linking the target of a compound with phenotypes that treatment with that compound induces or suppresses, biologically active small molecules are potentially incredibly powerful tools in understanding how biological systems work from the molecular to the 
cellular level. However, without an understanding of the nature of these effects at both a molecular and cellular level, their use as biological probes is limited, as are the inferences that can be drawn by their use. It is often the case, however, that there is a little knowledge concerning the action of the small molecule on its target and a little knowledge concerning the function of that target so while it is tempting to try and define one without the other, it is inevitable and advantageous that knowledge of the two will co-occur.

\subsection{Pateamine}

Pateamine A (pateamine) is a novel terpenoid natural product isolated in the early 1990's from samples of the marine sponge Mycale hentscheli collected off the south-west coast of the South Island of New Zealand (Figure 1.1). The authors used a bioassay guided isolation approach to identify a $\mathrm{MeOH} / \mathrm{CH}_{2} \mathrm{Cl}_{2}$ (19:1) fraction that was ultimately shown to contain pateamine A (pateamine $\mathrm{B}$ and $\mathrm{C}$ have also been isolated, however they are present in minor amounts, and differ from pateamine A only in the substitution of the tertiary amine at C17). Purified pateamine showed potent growth inhibitory effects on the fungi Candida albicans, Trichophyton mentagrophytes and Cladosporium resinae and cytotoxicity in the murine leukemic cell line P388 $\left(\mathrm{IC}_{50}=0.15 \mathrm{ng} / \mathrm{ml}\right)$, but was significantly less potent in confluent BSC cells $\left(\mathrm{IC}_{50} \sim 300 \mathrm{ng} / \mathrm{ml}\right.$ ) and inactive against prokaryotes tested This suggests that pateamine A may be a eukaryotic specific toxin with selectivity towards rapidly dividing cells (Northcote, Blunt et al. 1991). 


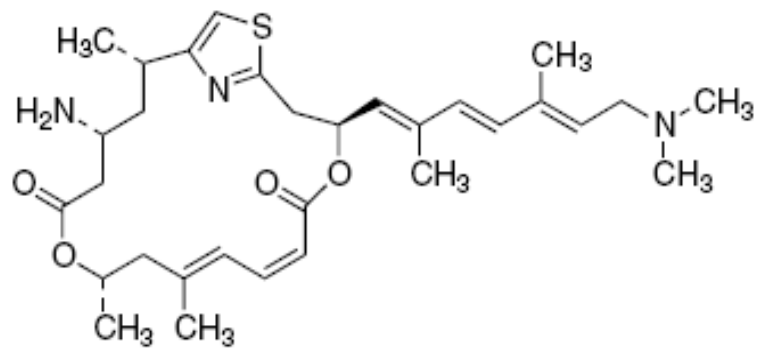

Figure 1.1 The structure of pateamine A.

The total synthesis of pateamine was reported in 1998 (Romo, Rzasa et al. 1998) and synthetic pateamine was used to show a potential immunosuppressive effect in a mouse skin graft rejection assay, where it afforded tolerance of the graft for 15 days after implantation, compared to 10 days for the clinically used immunosuppressive cyclosporine A. In culture pateamine shows at potent $\left(\mathrm{IC}_{50}=2.6 \mathrm{nM}\right)$ effect on T-cell activation in a mixed lymphocyte reaction (MLR) with negligible cytotoxicity (LCV (lymphocyte viability assay)/MLR ratio > 1000), suggesting that pateamine may possess immunosupressive properties similar to that of cyclosporine A.

Further, with the use of a luciferase reporter assay, it was shown that pateamine specifically inhibits the transcription of the pro-inflammatory cytokine interleukin 2 (IL-2) in Jurkat T-cells after stimulation with phorbol-12-myristate-13-acetate (PMA) and ionomycin. During the total synthesis a small number of derivatives were made that showed both the macrocycle and the trienylamine tail were required for the inhibitory nature of pateamine to the IL-2 promoter but that the primary amine withstood derivatisation (both $N$-dexamethasone and $N$-Boc derivatives were active in the assay), suggesting the primary amine may be a site of tolerable modification. Later the same authors confirmed a specific effect on the Jurkat T-cell IL-2 promoter activity using 
RT-PCR and expanded on the range of derivatives made (Romo, Choi et al. 2004). This further structure-activity relationship study reaffirmed the tolerance to $\mathrm{C} 3$ primary amine derivatisation, showing that it could also be completely removed along with the nearby $\mathrm{C} 5$ methyl without a significant loss of activity. On the other hand analogues replacing the C19 - C20 alkene with an alkyne were inactive unless combined with a dienyl tail with aterminal methyl ether instead of the tertiary amine. Interestingly, the terminal methyl ether derivative with the original conjugated diene at C19 - C22 was not active.

Further investigation of the toxic effects of pateamine to mammalian cells revealed the cytotoxic effects of pateamine are due to the induction of apoptosis (Hood, West et al. 2001). In this study the sensitivities of two tumourigenic cell lines (SY5Y and H441 cells) were compared to that of a non-tumourigenic cell line (LLC-PK1). Contrary to the original discovery and isolation report by Northcote et al. where there seemed to be selective toxicity towards the tumourigenic cell line greater than 2000-fold compared to confluent cells, there was no significant difference between the $\mathrm{IC}_{50}$ values of the tumourigenic and non-tumourigenic cell lines in the MTT viability assay. However all cell lines tested where shown to undergo DNA cleavage after a 24 hour treatment of pateamine, suggesting the induction of an apoptotic pathway. Further experiments in the IL-3 dependant 32D cells confirmed the induction of apoptosis by concentration dependent DNA cleavage, and early Annexin $\mathrm{V}$ binding to the cell surface.

Annexin V binds to phosphatidyl serine, normally phophatidyl serine is localized almost exclusively to the inner leaflet of the plasma membrane, an asymmetry maintained by flipase enzymes. In early apoptosis the loss of this asymmetry precedes a loss of membrane integrity, compared to necrotic cell death where the two occur simultaneously (Guimaraes 
and Linden 2004). Pateamine causes a loss of phosphatidyl serine asymmetry, indicated by Annexin $\mathrm{V}$ binding to the cell, before the loss of membrane integrity, indicated by the entry of the fluorophore propidium iodide into the cell. The active analogue DMDApateamine was also found to be approximately 1,000 -fold less potent in its ability to significantly alter the level of intracellular ATP in IMR-90 cells that had been induced to enter quiescence by contact inhibition and serum deprivation (Kuznetsov, Xu et al. 2009), compared to the concentrations that induced cell death in actively dividing cells. This was interpreted by the authors as it being a specific cytotoxin in non-dividing cells, though it must be noted that both of the assays that suggest this specificity are performed with cells grown to very high density, which will alter drug sensitivity in itself.

The potential selectivity of pateamine towards transformed cells was further investigated with use of $32 \mathrm{D}$ cells transfected with plasmids that express the $\mathrm{p} 21^{\text {ras }}$ and bcr/abl oncogenes (Hood, West et al. 2001). The sensitivity of the transfected and non-transfected cells to pateamine was tested with the tetrazolium salt MTT. Respiring cells reduce the yellow MTT to a blue formazan product, making this a common viability assay. As seen previously, pateamine showed little selectivity towards the cells transfected with either of the oncogenes in the MTT assay. However, when cell viability was assessed with trypan blue (a dye that is actively effluxed from living cells), statistically significant differences were seen between the transfected and non-transfected cells at concentrations above $10 \mathrm{nM}$, an effect seen with the protein synthesis inhibitors puromycin, cycloheximide and mycalamide as well as the DNA damaging agent Ara-C. In line with the trypan blue assay results the $\mathrm{p} 21^{\mathrm{ras}}$ and bcr/abl transfected 32D cells were more sensitive to pateamine with respect to Annexin V binding, suggesting these cell lines were more sensitive to apoptosis induction by pateamine. 
The induction of apoptosis occurs through two major pathways, the extrinsic pathway involves activation of membrane bound "death receptors" and the activation of the protease caspase 8 , which in turn activates downstream caspases ultimately leading to DNA cleavage and the formation of apoptotic bodies. The intrinsic pathway on the other hand involves the leakage of cytochrome $\mathrm{C}$ from the mitochondria, and the activation of caspase 9, which then in turn activates downstream effector caspases. It has been shown the pateamine causes the activation of caspase 9 which peaks two hours after exposure and quickly declines, followed a number of hours later by the activation of caspase 8 (Miller, Rouwe et al. 2004). Cross talk between the intrinsic and extrinsic pathways is well established and is thought to be an aspect of the commitment to the completion of apoptosis once induced (Strasser, O'Connor et al. 2000).

Miller, Rouwe et al. (2004) also readdressed the potential immunosuppressive effects of pateamine using both the aforementioned mixed lymphocyte reaction and also $\mathrm{T}$-cells directly stimulated by an anti-CD3 antibody and measuring interferon $\gamma$ (IFN $\gamma$ ), another indicator of T-cell activation. Where Romo et al used the trypan blue exclusion assay as a measure of viability Miller et al. used Annexin V binding to directly assess the early activation of apoptosis rather than membrane integrity, which is still maintained during early apoptosis. The $\mathrm{IC}_{50}$ values for ${ }^{3} \mathrm{H}$-thymidine incorporation (T-cell proliferation), Annexin $\mathrm{V}$ binding (apoptosis) and IL-2 production for pateamine treated MLR were indistinguishable $\left(\mathrm{IC}_{50} \sim 0.5 \mathrm{nM}\right.$ ). Furthermore pateamine failed to selectively inhibit the production of IFN $\gamma$ without causing an equivalent growth inhibition according to the MTT assay. 
In summary, pateamine $\mathrm{A}$ is a novel marine natural product that is potent inducer of apoptosis in the majority of mammalian cell lines tested, with arguable selectivity towards transformed cell lines. While it seems that pateamine specifically decreases the transcription of the IL-2 gene in Jurkat T-cells, it does not seem to decrease the production of the IL-2 protein by isolated splenocytes. Despite the discrepancies that exist in the literature regarding the exact biological activities displayed by pateamine, and perhaps because of them, establishing a mechanism or mode-of-action by which these seemingly diverse effects occur will provide functional evidence for the role of the target of pateamine in apoptosis and IL-2 promoter activity.

\subsection{The eIF4A family of DEAD-box helicases}

The super-family of RNA DEAD-box helicases is highly conserved amongst all species analyzed to date. While members of this family exist in bacteria and archea they are most prevalent in eukaryotic organisms, where they are involved at almost every step of RNA metabolism including, but not limited to pre-mRNA splicing, nuclear export, translation initiation, mRNA decay, ribosome biogenesis and mitochondrial gene expression (Hernandez and Vazquez-Pianzola 2005). The S. cerevisiae and H. sapiens genomes encode 25 and 38 DEAD-box proteins respectively, indicating just how ubiquitous these proteins are. This super-family is defined by numerous distinct enzymes that share significant sequence and structural homology, yet are exquisitely specific to the processes in which they function. The name derives from the presence of a highly conserved D-E-A-D motif which is required for ATP binding and hydrolysis. Specifically, the eIF4A family of proteins are the archetypal DEAD-box RNA helicases representing the minimal sequence required for inclusion in the DEAD-box super-family. All DEAD-box proteins are ATP-dependent RNA helicases and RNA-dependent ATPases, whereby the energy 
from ATP hydrolysis is used to unwind RNA secondary structure or separate complimentary RNA strands (Linder 2006).

The members of eIF4A family represent the two major mechanisms by which DEAD-box RNA helicases function, that is, as a processive helicase, melting RNA secondary structure, or as a RNA anchor where ATP hydrolysis is linked to the release of RNA. They are essential for translation initiation in yeast (Linder and Slonimski 1989) and humans (Gingras, Raught et al. 1999) (yeast eIF4A also known as TIF1/2p and eIF4AI/II respectively), non-sense mediated mRNA decay in humans (eIF4AIII) (Ferraiuolo, Lee et al. 2004), and rRNA processing in yeast (Fallp) (Kressler, de la Cruz et al. 1997). In humans and yeast, eIF4A has an identical role in translation initiation. It is recruited to the 5 -untranslated region (5-UTR) of mRNA, soon after nuclear export, by the scaffolding protein, eIF4G, which directly interacts with both the 5-UTR and the 7-methyl guanine cap-binding protein eIF4E. It has been shown the eIF4A is able to melt mRNA secondary structure in the 5-UTR facilitating the formation of the $43 \mathrm{~S}$ pre-initiation complex and ultimately ribosome recruitment and scanning to the start codon (Sonenberg and Hinnebusch 2009), and that the translation of mRNA with a greater degree of secondary structure in the 5-UTR has a higher requirement for the activity of eIF4A, both in vivo and in vitro (Svitkin, Pause et al. 2001).

While translation initiation is essentially identical in yeast and humans subtle differences exist, for instance in humans eIF4A exists in two forms, free and bound to eIF4G which is bound to eIF4E, the three together known as the eIF4F complex, it is thought that eIF4A may cycle through this complex as a part of its mRNA unwinding function. In yeast only the free, unbound form is present, rather than a stable eIF4F complex consisting of eIF4E, 
eIF4G and eIF4A, that is isolatable by 7-methyl guanosine affinity chromatography in mammalian cells, only eIF4E and eIF4G can be isolated in the way from yeast (Lanker, Muller et al. 1992).

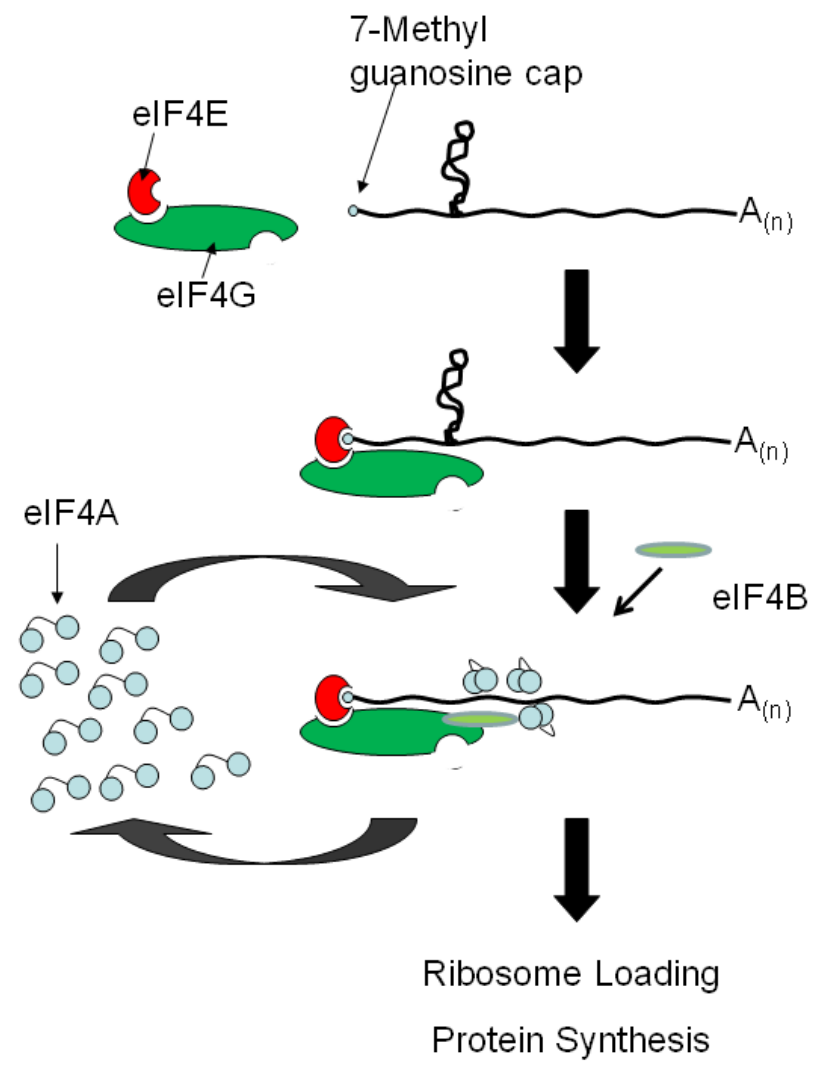

Figure 1.2 The role of elF4A in cap-dependent translation initiation. The 7-methyl guanosine cap is bound by elF4E which interacts with elF4G, which in turn recruits elF4A that unwinds mRNA 5 -UTR structure with the aid of elF4B. Figure adapted from McCarthy, 1998.

This phenomenon may be related to the fact the human eIF4G1 contains two eIF4A binding sites (Korneeva, Lamphear et al. 2001), compared to the yeast eIF4G which has one ( $\mathrm{Li}$, Belsham et al. 2001), and may also be related to the observation that most yeast transcripts have relatively short and unstructured 5-UTR (McCarthy 1998). In both organisms eIF4A is the most abundant translation initiation factor (von der Haar and McCarthy 2002), and its helicase function is augmented by the RNA binding protein eIF4B (Altmann, Wittmer et al. 1995). In isolation eIF4A is a non-processive, bi-directional RNA 
helicase, however, as a part of the eIF4F complex it becomes processive and uni-directional, in the 5 - 3` direction (Rogers, Richter et al. 2001).

Two distinct mechanisms of translation initiation exist, the aforementioned cap-dependent mechanism, which relies on the 5'-methyl guanine cap of mRNA being bound by the eIF4E component of the eIF4F complex and is dependent on the activity of eIF4A, and a cap-independent mechanism. This second mechanisms is dependent on the presence of internal ribosome entry sites (IRES) $3^{`}$ to the cap structure, and often a considerable distance from the cap. These IRES allow the ribosome to being loaded onto the transcript independent of the 5-UTR and cap and have a variable requirement for eIF4A (Jackson, Hellen et al. 2010). IRES have been found in a variety of transcripts, particularly those derived from viral genomes, whereby the host cell's translation machinery is re-routed to translate viral mRNA by compromising the eIF4F complex, particularly through protease mediated partial cleavage of the eIF4G component (Holcik and Sonenberg 2005). However, they have also been found in mRNA encoding eIF4G itself and those encoding anti-apoptotic proteins such as X-linked anti-apoptotic protein (XIAP), amongst others (Johannes and Sarnow 1998). In yeast IRES-containing transcripts are far less prevalent but have been found in genes that are involved in filamentous growth induced in response to nutrient starvation, though it seems there are distinct mechanistic differences from their mammalian, insect and viral counterparts (Gilbert, Zhou et al. 2007).

In contrast to the role of eIF4AI and II in mammalian translation initiation, the closely related protein, eIF4AIII functions in the non-sense mRNA decay (NMD) pathway, and is unable to compensate for eIF4AI/II in vitro or in vivo (Ferraiuolo, Lee et al. 2004). NMD is an mRNA decay pathway responsible for the degradation of transcripts containing a 
premature termination codon (PTC). It is thought this mechanism has evolved to prevent the translation of PTC containing transcripts that would produce truncated proteins that could possibly have deleterious, dominant-negative function thereby compromising the function of the pathways they participate in. These PTCs occur as a consequence of genetic mutations and aberrant splicing reactions and are recognized by the exon-exon junction complex (EJC) and the translational machinery (Hentze and Kulozik 1999).

The EJC is deposited on exon-exon junctions during splicing and are displaced by the translocating ribosome during the pioneer round of translation (Le Hir, Izaurralde et al. 2000). When a PTC is present more than 50 - 55 nucleotides upstream of the final exon-exon junction, that transcript is marked for degradation. The EJC is composed of eIF4AIII, which acts as the mRNA anchoring component, and the proteins Y14, Magoh and MLN51 and serves as a recruitment point for other proteins involved in the degradation of the transcript (Shibuya, Tange et al. 2004). When a PTC is present the EJC signals to the ribosome via Upf3 together with Upf1 and Upf2, and the transcript is degraded (Figure 1.3). Although the mechanistic details concerning the deposition of the EJC are yet to be fully resolved it has been found to involve phosphorylation of Upf1 (Singh, Jakob et al. 2007). eIF4AIII acts as the anchor for this complex by binding the mRNA at the exon-exon Junction in an ATP-dependent manner. Its intrinsic ATPase activity is inhibit by the binding of Y14-Magoh and MLN51 which bind to the interface of the two lobes of eIF4AIII locking it in a position that prevents in from hydrolyzing the bound ATP (Nielsen, Chamieh et al. 2009). In the absence of a PTC the translocating ribosome disrupts this interaction, allowing ATP hydrolysis and the dissolution of the EJC complex (Ishigaki, Li et al. 2001). 


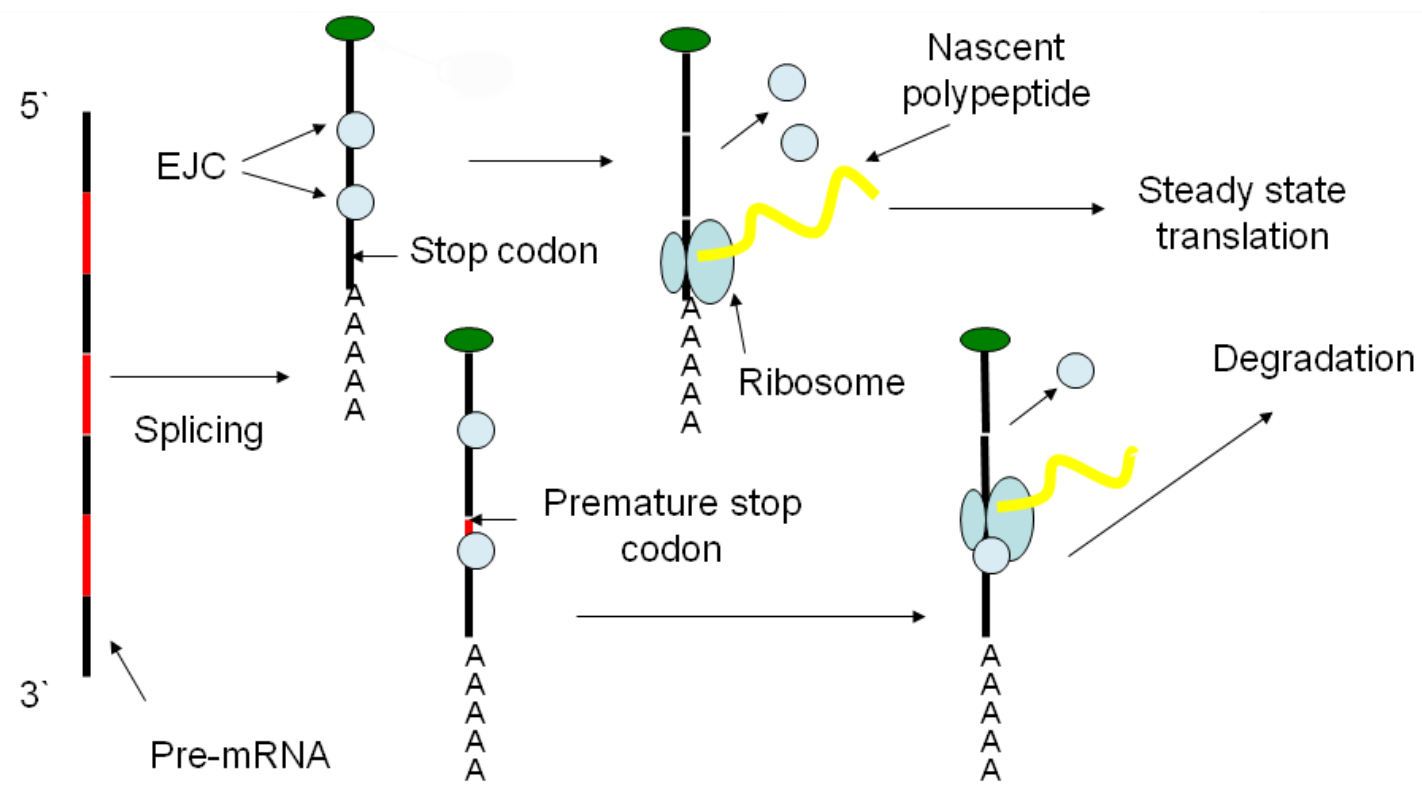

Figure 1.3 Non-sense mediated decay of mRNA. During splicing, the EJC complex (of which elF4AIll is a core member) is deposited on exon-exon junctions. In the absence of a premature stop codon (PTC), the EJC is displaced by the ribosome during the pioneer round of translation and the mRNA is translated. If a PTC is present 50-55 nt upstream of the final exon-exon junction the EJC signals to the ribosome via Upf3 together with Up1 and Upf2, and the transcript is degraded.

In contrast to the NMD pathway present in higher eukaryotes, the pathway in yeast does not involve an EJC, since the majority of yeast transcripts do not contain introns and those that do contain only one (Conti and Izaurralde 2005). Instead, yeast NMD involves the sensation of a PTC by the translation machinery itself and does not involve the closest yeast homologue of eIF4AIII known as Fallp. This protein has also been shown not to compensate for a loss of yeast eIF4A (Tif1/2p) but functions in small ribosome subunit biogenesis, specifically the processing of the $35 \mathrm{~S}$ pre-rRNA and the production of the $18 \mathrm{~S}$ rRNA (Kressler, de la Cruz et al. 1997). Very little is known about the exact mechanism by which Fal1p is recruited to the 35S pre-rRNA transcript or any protein-protein interactions that it may take part in. While there are, for Fallp, database interactions these are derived from large-scale studies and have not been validated. It is unclear whether the role of Fallp 
in $35 \mathrm{~S}$ pre-rRNA processing involves RNA unwinding activity, as in the case of eIF4AI/II and Tif1/2p or simply RNA binding activity as in the case of eIF4AIII.

\subsection{Eukaryotic translation and protein synthesis inhibitors}

Eukaryotic protein translation can be divided into three separate and distinct phases: 1 . Initiation; 2. Elongation; 3. Termination. Each phase is characterized by a specific sequence of events and small molecule inhibitors have been found that specifically inhibit each of initiation and elongation, and others that mimic termination.

Translation initiation is the phase which involves events prior to the positioning of the $80 \mathrm{~S}$ ribosome at the AUG start codon. In eukaryotic organisms there exist two separate mechanisms for translation initiation: cap-dependent and independent, as detailed in Section 1.4. In yeast the predominant mechanism is cap-dependent initiation though there have been some IRES controlled transcripts found (Gilbert, Zhou et al. 2007). Subsequent to the formation of the eIF4F complex and melting of mRNA secondary structure by eIF4A and eIF4B, a pre-assembled 43S pre-initiation complex, consisting of Met-tRNAi (initiator Met-tRNA) and eIFs 1, 1A, 2, 3 and 5, is recruited to the transcript and scans to the AUG start codon, where base-pairing occurs between the start codon and the anticodon of the Met-tRNAi component. The Met-tRNAi is anchored to the rest of the complex by eIF2 with GTP bound, recognition of the start codon causes the scanning to halt, the hydrolysis of GTP and the loss of other associated eIFs, which allows the large (60S) subunit to associate and form the complete $80 \mathrm{~S}$ ribosome ready to accept the appropriate aminoacyl-tRNA into the A-site (Kapp and Lorsch 2004; Sonenberg and Hinnebusch 2009). 
Pateamine is the first characterized specific inhibitor of cap-dependent translation initiation, subsequently the inhibitors silvestrol (Cencic, Carrier et al. 2009) and hippuristanol (Lindqvist, Oberer et al. 2008) have also been shown to inhibit eIF4A by stabilizing and destabilizing the eIF4A-RNA respectively, and hence inhibiting capdependent translation initiation in mammalian cells. Others inhibitors of initiation have also been characterized, for instance 4EGI-1 binds to mammalian eIF4E preventing it from interacting with eIF4G (Moerke, Aktas et al. 2007), ribavirin on the other hand mimics the 7-methyl guanosine cap structure of mRNA preventing the association of eIF4E mRNA (Kentsis, Topisirovic et al. 2004), it has recently been suggested that the apoptosis-inducing compound resveratrol may also target eIF4A (Lomenick, Hao et al. 2009). It can be said that rapamycin also inhibits translation initiation, but it does so indirectly by inhibiting TOR in mammalian and yeast cells, the consequence of this is the phosphorylation of numerous translation initiation factors, preventing cap-dependent translation initiation indirectly (Brazelton and Morris 1996; Crespo and Hall 2002). There has been considerable interest in the use of specific cap-dependent translation inhibitors as anti-neoplastic drugs given the over-expression of numerous eIF4F components in a number of cancers (Lindqvist and Pelletier 2009), and the role of translation initiation as the major point of translational regulation (Sonenberg and Hinnebusch 2009). As of yet there are no characterized inhibitors of the translation of transcripts controlled by eIF4A-independent IRES.

The formation of the $80 \mathrm{~S}$ ribosome positioned over the AUG start codon marks the end of initiation and the beginning of elongation, where polypeptide chain elongation occurs. The $80 \mathrm{~S}$ ribosome has three separate sites, known as the acceptor (A) site which accepts 
incoming aminoacylated tRNA bound by the eukaryotic elongation factor 1A (eEF1A), the peptidyl $(\mathrm{P})$ site, which is the site of peptide bond formation a between the nascent polypeptide chain and the incoming amino acids, and the exit (E) site where deacylated tRNA are allowed to leave after the peptidyl transferase reaction (Figure 1.4). The catalysis of the peptide bond formation only occurs if the incoming tRNA has an anti-codon complementary to the mRNA codon at the A-site. Only after the tRNA and mRNA are translocated to the P-site is another aminoacylated-tRNA allowed to bind to the A-site. The release of the incoming aminoacylated tRNA by eEF1A occurs prior to the hydrolysis of its bound GTP, which only occurs if the anti-codon base-pairs with the codon at the A-site. The release of the deacylated tRNA from the E-site occurs as a result of the translocation of the ribosome to the next codon, this step is catalyzed by eEF2 with the hydrolysis of GTP. In yeasts and fungi there is an additional elongation factor (eEF3), which actively promotes the release of the deacylated tRNA from the E-site, it has been suggested that this activity is intrinsic to the ribosome of other eukaryotes (Kapp and Lorsch 2004). 


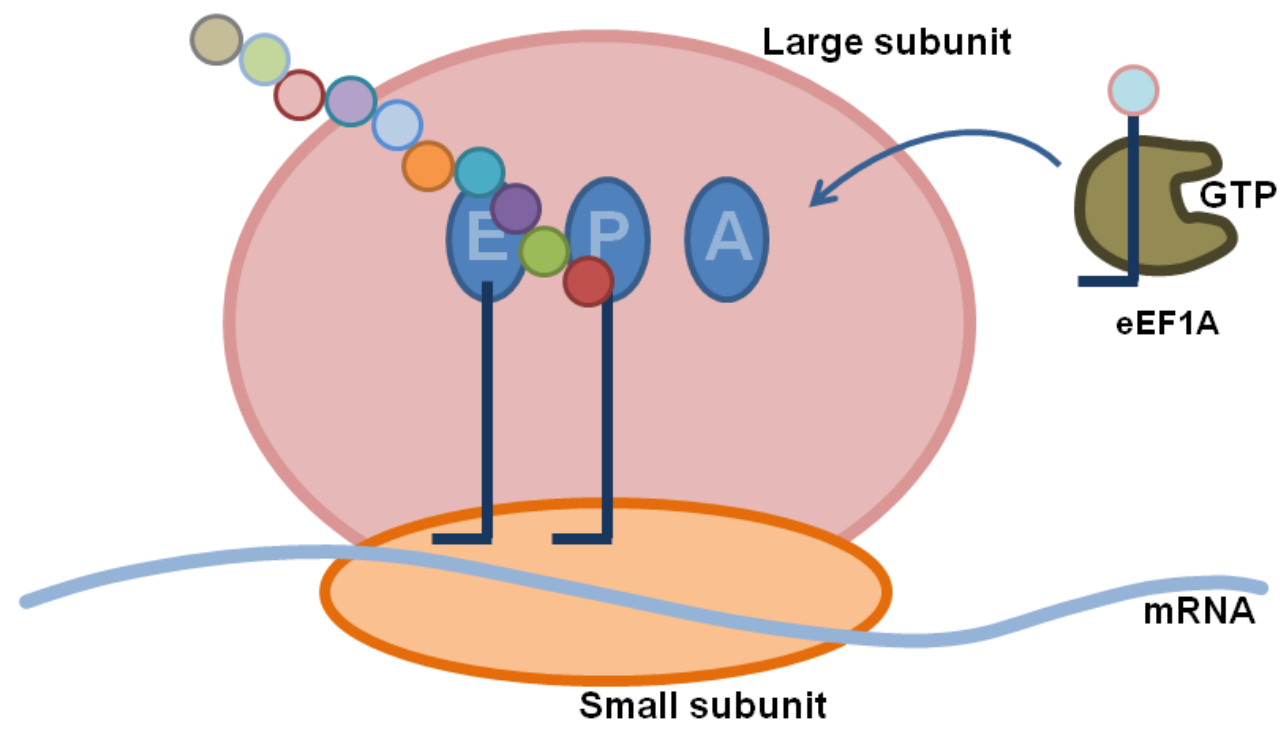

Figure 1.4 The $80 \mathrm{~S}$ ribosome. This cartoon depicts the three main sites within the $80 \mathrm{~S}$ ribosome: The acceptor (A) site, which accepts incoming aminoacylated tRNA bound by eEF1A; the peptidyl (P) site which catalyses the formation of the peptide bond between the incoming amino acid and the polypeptide chain; and the exit $(E)$ site, where deacylated tRNA is able to leave the ribosome.

Protein synthesis inhibitors that target translation elongation are by far the most enumerated and can be divided into those that target the ribosome directly, and those that directly target elongation factors. Those inhibitors that target the ribosome do so by selectively binding to one of a number of different positions (Pestka 1971). Cycloheximide for instance has been shown to directly interact with the ribosome (Stocklein and Piepersberg 1980), preventing translocation and stabilizing translating ribosomes on mRNA (Obrig, Culp et al. 1971). It has been proposed that this occurs via an interaction with the ribosomal E-site and the deacylated tRNA positioned there (Pestova and Hellen 2003; Schneider-Poetsch, Ju et al. 2010). In contrast anisomycin inhibits the peptidyl transferase reaction (Grollman 1967) by interacting with the A-site (Carrasco, Barbacid et al. 1973), and emetine which binds to the small subunit, also stabilizing the ribosome-mRNA interaction (Carrasco, Jimenez et al. 1976). Other inhibitors found to target the ribosome include streptovitacin (Bennett, Ward et al. 1965), verrucarin (Cannon, 
Jimenez et al. 1976) and hygromycin B (Gonzalez, Jimenez et al. 1978) all of which inhibit polypeptide elongation. Didemnin B and sordarin on the other hand have been shown to inhibit elongation by targeting eEF1A (Crews, Collins et al. 1994) and eEF2 (Capa, Mendoza et al. 1998), respectively.

The termination phase of translation results in the release of the polypeptide from the ribosome, this is facilitated by the eukaryotic release factor 1 (eRF1) which promotes the hydrolysis of the peptidyl-tRNA peptide bond when one of the three stop codons is present at the A-site (Traut and Monro 1964). To date there are no known inhibitors of the termination phase of translation, however, puromycin has been shown to cause premature polypeptide chain termination by mimicking the incoming aminoacylated-tRNA and being incorporated into the nascent polypeptide (Rosenbloom, Endo et al. 1976). 


\subsection{Aims and objectives}

The aim of this study is to identify the cellular targets of pateamine and to investigate the breadth of their functional specificity with respect to the phenotypes that this compound has been previously shown to induce. To this end, various complementary approaches are to be employed:

- Initially, potential targets in mammalian cells will be identified using affinity chromatography with a pateamine derivatized affinity matrix.

- The model organism Saccharomyces cerevisiae will be employed to isolate and characterize a pateamine-resistant mutant.

- The recently developed method of chemogenomic profiling using the Saccharomyces cerevisiae gene deletion libraries will be employed to investigate the breadth of target specificity of pateamine. 


\section{Affinity isolation of the cellular target of pateamine}

\subsection{Introduction}

Affinity chromatography is one of the oldest and simplest methods of determining potential target prfoteins for a biologically active compound. This generally involves coupling the compound to a solid phase support, passing a cell lysate or tissue homogenate by the resin and identifying any proteins selectively retained (Leslie and Hergenrother 2008). Early application of this approach was centered on the use of metabolite analogues for the efficient enzyme purification (Lerman 1953; Arsenis and McCormick 1964; McCormick 1965; Arsenis and McCormick 1966), the first use of affinity chromatography to determine a drug target was when the cis-trans peptidyl-prolyl isomerase FK506binding-protein was established as the target of the immunosuppressant FK506 (Harding, Galat et al. 1989). Prior to the advent of mass spectrometry-based protein identification and genome sequencing technology, direct identification of a protein by its sequence was generally limited to N-terminal degradation methods (Henzel, Watanabe et al. 2003), the success of the chemical proteomic approach to identifying drug targets is partially due to advances in this area. In the case of so-called promiscuous compounds, that is those which target a large structurally related protein family, such as protein kinases, or exhibit broad target selectivity, such as staurosporine, the combination of affinity chromatography and mass spectrometry has enabled an appreciation of the breadth of potential drug-target interactions (Knockaert and Meijer 2002; Godl, Wissing et al. 2003). The case of protein kinase inhibitors illustrates the point that many of secondary target interactions will be due to binding site conservation rather than the interaction with a entirely different site (Bantscheff, Scholten et al. 2009). 
Compound immobilization occurs via the coupling of a reactive group, such as an amine or hydroxyl, on the compound with a functionalized affinity resin. Often the affinity resin is a carbohydrate, agarose or sepharose for instance, that has been somehow functionalized, a hydrophilic aliphatic linker is often added which terminates in a reactive functionality, such as an epoxide or $N$-succinamidyl ester (Leslie and Hergenrother 2008); functionalized latex beads have also been used (Shimizu, Sugimoto et al. 2000). Natural products are structurally diverse; often possessing numerous functional groups capable of coupling to the resin (Feher and Schmidt 2003), however, unless a group of congeners with differential biological activity is found, often limited structure-activity-relationship data is available with which to make an informed decision as to the most or least desirable site to couple to. If conjugation to a functional group abrogates binding to the target, affinity purification is impossible or misleading. In cases where coupling does not abrogate binding it is still important to distinguish between specific and non-specific protein binding.

Non-specific binding that occurs due to interactions between proteins and the solid phase support, the hydrophilic linker or the reagent used to block any un-reacted functional groups on the resin can be controlled for by comparison of the proteins retained by a blocked resin with no drug coupled. However, non-specific binding may also be due to high abundance protein interacting with the compound with relatively low affinity, or even a protein interacting specifically or non-specifically with a protein interacting with the compound, such binding events are somewhat more difficult to control for. Where possible, the use of an inactive analogue derivatized resin is the most desirable control (Kaida, Motoyoshi et al. 2007), unfortunately this is often not possible for natural products. Due to the fact that the degree of retention of protein(s) by a compound derived affinity resin is a function of both, the abundance of the protein(s) and their affinity for the compound, relative protein abundance in the eluate is poor indicator of the strength of 
interaction. While specific elution of proteins retained by the resin using free ligand provides an indication of the specificity of interaction it is not always possible owing to the high concentration often required and the low availability and aqueous solubility of a lot of bioactive natural products. For this reason, denaturing methods that presumably remove all protein non-covalently bound to the resin are used, this heightens the need for specificity controls. The strength of the interaction may be qualitatively assessed by observing protein retention subsequent to high or low salt washes. Alternatively a change in $\mathrm{pH}$ may aid in assessing specificity of an interaction but $\mathrm{pH}$ and salt concentration are by no means definitive. The recent use of stable isotope labeling of cellular proteins prior to affinity chromatography has aided in determining non-specific binding (Ong, Schenone et al. 2009).

The in vitro nature of affinity chromatography means the likelihood of purifying the cellular target of a compound using affinity chromatography is dependent upon the nature of the target itself and the nature of its interaction with the compound. It is desirable to mimic the cellular environment that the target exists in as closely as possible when generating the lysate or homogenate to be used, this is impossible for every potential target protein. For instance proteins localized to the lysosome experience a different $\mathrm{pH}$ to those in the cytosol, also in order to solubilize membrane proteins strong detergents are used that may disrupt the interaction between the compound and the target. Generally as a compromise the conditions, $(\mathrm{pH}$, tonicity, etc) in the cytosol are mimicked in the homogenate which often means the exclusion of membrane bound proteins and those with pI $\sim 7.4$, regardless there are some examples of membrane proteins being retained by an affinity resin (Bantscheff, Eberhard et al. 2007; Rix, Hantschel et al. 2007). 
Given these difficulties in establishing absolute target specificity, it is important to treat affinity chromatography only as a screen for potential target proteins which must be verified. Verification of a specific interaction can occur at the level of the physical interaction, for instance with the use of isothermal calorimetry, surface plasmon resonance (Oda, Owa et al. 2003), NMR, or more simply by more traditional receptor binding analysis (Crews, Collins et al. 1994). Evidence of a physical interaction and even an assessment of its strength directly, however, does not necessarily mean it is the target, there must be a functional consequence to the target of drug binding. This is most readily assessed using cell based assays of protein function, or purified target function in an in vitro assay, where available (Brehmer, Godl et al. 2004; Bach, Knockaert et al. 2005; Kaida, Motoyoshi et al. 2007). With the advent of siRNA technology it is possible to assess the role of the putative target of a compound in the phenotype the compound induces in a direct "genetic" fashion (Kotake, Sagane et al. 2007). For instance, if the compound of interest induces apoptosis, the siRNA mediated knockdown of its target is likely to do so also. This approach relies on efficient knockdown of the target protein by the siRNA (below the threshold required for an effect to be seen), but also relies on the protein being inhibited by the compound and that the presence of a drug-bound nonfunctional target is analogous to decreasing target function lowering its abundance. Where this is not the case it may be possible to assess a change in drug sensitivity during knockdown as a form of target verification (Dong, Low et al. 2008). It must not be disregarded that the phenotypic effects of a drug may be due to the combinatorial perturbation of a number of functionally diverse targets, a scenario difficult to assess.

An advantage of affinity chromatography over previous methods, which generally involved tracking a radio-labeled analogue of the compound of interest during a traditional biochemical fractionation, is that the target is physically isolated. Schreiber and co-workers 
in the 1990's used immobilized natural products to purify the cellular receptors for the aforementioned FK506; didemnin B, which inhibits elongation factor $1 \alpha$ (Crews, Collins et al. 1994) and palmitoyl protein thioesterase (Meng, Sin et al. 1998); trapoxin a potent DNA acetylase inhibitor (Taunton, Hassig et al. 1996); the irreversible proteasomal inhibitor lactacystin (Fenteany, Standaert et al. 1995); and myriocin a serine palmitoyltranferase inhibitor (Chen, Lane et al. 1999). Since then the same approach has facilitated the identification of cellular targets for numerous diverse natural products from a variety of sources (Piggott and Karuso 2004; Rix and Superti-Furga 2009; Cheng, Wong et al. 2010). Herein this approach coupled with MALDI-MS peptide mass fingerprinting is applied in order to identify putative cellular targets of pateamine in cultured human cell lines. 


\subsection{Aims and objectives}

The overall aim of this study is to identify the cellular protein targets of pateamine in human cells. To this end, a pateamine affinity resin has been developed to isolate candidate protein targets and mass spectrometry used to identify them. For putative target proteins it has been established whether pateamine has a functional effect on these potential targets in vitro and in cultured human cell lines. 


\subsection{Material and methods}

\subsubsection{Materials}

Samples of pateamine were obtained from the natural product chemistry group of Peter Northcote in the School of Physical and Chemical Sciences, Victoria University of Wellington, and were reported to be of $95-98 \%$ purity as determined by NMR spectroscopy. Pateamine samples were tracked via individual batch number in order to account for anomalous results. Where possible, each study was completed with a single batch. Dry samples were stored at $-20{ }^{\circ} \mathrm{C}$ until use whereby they were dissolved in methanol, ethanol or DMSO (dimethyl sulfoxide). All pateamine solutions were stored at $-80{ }^{\circ} \mathrm{C}$.

\subsubsection{Tissue culture}

HL-60, HeLa and SH-SY5Y cell lines were cultured according to standard tissue culture techniques (Freshney 2005). Briefly, all cell lines were grown in RPMI 1640 (GIBCO) medium supplemented with $10 \%$ foetal calf serum (FCS) and 1\% Penicillin-Streptomycin (PenStrep) in a humidified incubator at $37{ }^{\circ} \mathrm{C}$ and $5 \% \mathrm{CO}_{2}$. HL-60 cells were passaged by ten-fold dilution in fresh medium when the cell density reached $2 \times 10^{5}$ cells $/ \mathrm{ml}$. HeLa and SH-SY5Y cells were passaged after removal by trypsin treatment $(2.5 \mathrm{mg} / \mathrm{ml}$ porcine trypsin in HBSS) after reaching 70\% confluence, and were diluted ten-fold on re-seeding.

\subsubsection{MTT assay}

In all MTT assays (Mosmann 1983), pateamine was serially diluted two-fold in triplicate in RPMI 1640 medium, supplemented with 10\% FCS and 1\% PenStrep, in a tissue culture grade 96-well plate (Greiner Bio-One, Frickenhausen, Germany) to give a final range of 3 
pM to $100 \mathrm{nM}$. For the non-adherent HL-60 cell line pateamine was prepared in $50 \mu \mathrm{l}$ of medium at double the final concentration, then $5 \times 10^{3}$ cells per well were added in $50 \mu 1$ to each well and the plate was incubated for $48 \mathrm{~h}$ in a humidified incubator at $37{ }^{\circ} \mathrm{C}$ and $5 \%$ $\mathrm{CO}_{2}$. For adherent HeLa and SH-SY5Y cell lines, $2 \times 10^{3}$ or $5 \times 10^{3}$ cells respectively were seeded in $100 \mu \mathrm{l}$ of medium per well and were allowed to attach for $18 \mathrm{~h}$, after which the medium was aspirated and replaced with $100 \mu \mathrm{l}$ of fresh media into which pateamine was then serially diluted. The carrier control was $0.1 \%$ ethanol in RPMI 1640 supplemented with $10 \% \quad$ FCS and $1 \%$ PenStrep. After $48 \quad \mathrm{~h}$ incubation, $20 \mu \mathrm{l}$ of 3-(4,5-dimethylthiazol-2-yl)-2,5-diphenyltetrazolium bromide (MTT) (5 mg/ml in PBS (10 mM sodium phosphate, $138 \mathrm{mM}$ sodium chloride, $27 \mathrm{mM}$ potassium chloride, $\mathrm{pH}$ 7.4)) was added and the plate returned to the incubator for $2 \mathrm{~h}$, after which $100 \mu \mathrm{l}$ solubilizer (10\% SDS (sodium dodecyl sulfate), $45 \%$ THF (tetrahydrofuran)) was added and incubated overnight before measuring the absorbance at $570 \mathrm{~nm}$ using an automated plate reader (VersaMax, Molecular Devices, Sunnyvale, CA, USA). The $\mathrm{IC}_{50}$ value was determined using SigmaPlot Ver 10.0 (Systat Software Inc., Richmond, CA, USA) for each individual assay. The results from three independent assays were then averaged and standard errors propagated through standard methods. This procedure was performed with each new batch of pateamine received to assist with batch-to-batch comparison. Assessment of viability in the presence of the pan-caspase inhibitor $\mathrm{z}$-VAD-FMK (Promega Corp., Madison, WI, USA) was performed as with the same concentration range of pateamine with 5,10 or $50 \mu \mathrm{M}$ z-VAD-FMK added, in this case maximum and minimum growth as well as $\mathrm{IC}_{50}$ value were calculated using SigmaPlot Ver 10.0 (Systat Software Inc.). 
The ability of HeLa cells to recover after pateamine treatment and withdrawal was assessed with the MTT assay. Cells were exposed to 10,50 or $100 \mathrm{nM}$ pateamine in RPMI media with $2 \%$ FCS and $1 \%$ PenStrep for $0.25,0.5,1$ and $2 \mathrm{~h}$, after removal by aspiration the cells were washed with warm RPMI media with 10\% FCS and 1\% PenStrep and allowed to recover in the same fresh media. In a non-withdrawal control, the fresh media contained the same concentration as the initial exposure. Cells were allowed to recover for $11 \mathrm{~h}$ in a humidified incubator at $37^{\circ} \mathrm{C}$ and $5 \% \mathrm{CO}_{2}$, after which viability was assessed with the MTT reagent as above.

\subsubsection{Pateamine affinity resin generation}

A pateamine-substituted affinity resin was generated from epoxy-activated Sepharose 6B (GE Health Sciences, Little Chalfont, UK), which was prepared according to the manufacturer's instructions. Briefly, $150 \mathrm{mg}$ of resin was washed with $200 \mathrm{ml}$ double-distilled water followed by $5 \mathrm{ml}$ of methanol. The washed resin was re-suspended in $0.3 \mathrm{ml}$ of methanol containing $13 \mathrm{mg}$ pateamine and $2.5 \mu \mathrm{l}(1.1 \mathrm{eq})$ triethylamine and incubated at $45{ }^{\circ} \mathrm{C}$ with shaking overnight. The resulting yellow resin was washed with three $1 \mathrm{ml}$ aliquots of methanol, then three $1 \mathrm{ml}$ aliquots of double distilled water. To block any un-reacted epoxy groups, the resin was re-suspended in $1 \mathrm{ml}$ of $1 \mathrm{M}$ diethanolamine $\mathrm{pH} 8.0$, and incubated at $45^{\circ} \mathrm{C}$ with shaking for 4 hours, the resin was washed sequentially with three $1 \mathrm{ml}$ aliquots of $0.5 \mathrm{M} \mathrm{NaCl}, 0.1 \mathrm{M}$ sodium acetate $\mathrm{pH} 4.0$ and $0.5 \mathrm{M} \mathrm{NaCl}$, $0.1 \mathrm{M}$ Tris- $\mathrm{HCl} \mathrm{pH} 8.0$, followed by three $1 \mathrm{ml}$ aliquots of double distilled water. Beads were stored at $-20{ }^{\circ} \mathrm{C}$ after lyophilisation. 
To control for non-specific binding of proteins in the cell lysate, a blank control resin was generated by preparing the beads as described above, but re-suspending them in $1 \mathrm{ml}$ of $1 \mathrm{M}$ diethanolamine immediately. The diethanolamine control resin was washed in the same manner as the pateamine resin.

\subsubsection{Cell lysate preparation}

HL-60 cells were grown to $5 \times 10^{5}$ cells $/ \mathrm{ml}$; SH-SY5Y and HeLa cells were grown to approximately $70 \%$ confluence according to method 2.3.2. Cells were harvested by centrifugation or cell scraping, collecting about $1 \times 10^{7}$ cells, washed three times with $20 \mathrm{ml}$ of ice cold PBS (10 mM sodium phosphate, $138 \mathrm{mM}$ sodium chloride, $27 \mathrm{mM}$ potassium chloride, $\mathrm{pH}$ 7.4) and re-suspended in $5 \mathrm{ml}$ cold PBS with Complete Mini Protease Inhibitor tablets (Roche Diagnostics, Mannheim, Germany). Cells were disrupted with 7 - 10 strokes of a tight fitting Dounce homogenizer, Triton X-100 was added to $0.1 \%$ and the homogenate rotated at $4{ }^{\circ} \mathrm{C}$ for $30 \mathrm{~min}$. The homogenate was centrifuged at $100 \mathrm{k}$ rpm for 30 min (SS-34 rotor, Evolution RC, Sorvall, Thermo Fisher Scientific, Waltham, MA, USA) and protein in the supernatant was quantified with the BCA Protein Assay Kit (Thermo Scientific Pierce, Rockford, IL, USA).

\subsubsection{Protein electrophoresis}

All protein electrophoresis, unless otherwise stated, was carried out with the NuPAGE LDS-PAGE system (Invitrogen, Carlsbad, CA, USA) on 4 - 12\% gradient gels under reducing condition in MOPS buffer according to the manufacturer's instructions. After 45 $\min$ at $150 \mathrm{~V}$ the gels were washed with water, fixed $(50 \%$ ethanol $(\mathrm{v} / \mathrm{v}), 2 \%$ orthophosphoric acid (v/v)) and visualized by staining with colloidal Coomassie stain 
(0.05\% Coomassie G-250, 17\% ammonium sulfate (w/v), $2 \%$ orthophosphoric acid (v/v), $34 \%$ methanol (v/v)), followed by de-staining with double-distilled water.

\subsubsection{Isolation of pateamine binding proteins}

To isolate putative pateamine targets, $30 \mu \mathrm{l}$ of pateamine and control resin were equilibrated in $0.5 \mathrm{ml}$ of $0.1 \%$ Triton $\mathrm{X}-100$ in PBS (10 mM sodium phosphate, $138 \mathrm{mM}$ sodium chloride, $27 \mathrm{mM}$ potassium chloride, $\mathrm{pH} 7.4$ ) for 30 min at $4^{\circ} \mathrm{C}$, and washed with another $0.5 \mathrm{ml}$ of $0.1 \%$ Triton X-100 in PBS. The resins were incubated in $1 \mathrm{ml}$ of $1 \mathrm{mg} / \mathrm{ml}$ cell lysate (prepared according to method 2.3.5), with agitation for 30 min at $4{ }^{\circ} \mathrm{C}$. Beads were recovered by centrifugation and washed three times with $0.1 \%$ Triton X-100 in PBS. Bounds proteins were eluted either by the addition of $30 \mu 1$ of $2 x$ LDS-PAGE sample loading buffer (Invitrogen) and incubation at $70{ }^{\circ} \mathrm{C}$ for $10 \mathrm{~min}$, or with $500 \mu \mathrm{M}$ pateamine in $1 \%$ DMSO, $0.1 \%$ Triton $\mathrm{X}-100$ in PBS. A high salt wash was performed with $1 \mathrm{M}$ sodium chloride, $0.1 \%$ Triton $\mathrm{X}-100$ in PBS, and the remaining proteins were eluted with LDS-PAGE loading buffer. A competition assay was performed by adding pateamine (500 $\mu \mathrm{M}$ final concentration) to the cell lysate prior to incubation with the affinity resins. Isolated proteins were separated and visualized on LDS-PAGE gels as described in method 2.2.6.

\subsubsection{Peptide mass fingerprinting}

Samples of the protein of interest were excised from a LDS-PAGE gel with a glass Pasteur pipette, washed twice with MilliQ water, then twice with $100 \mathrm{mM}$ aqueous ammonium bicarbonate with the final wash lasting 10 min. Samples were reduced with $3 \mathrm{mM}$ DTT (dithiothreitol) in $100 \mathrm{mM}$ aqueous ammonium bicarbonate for $20 \mathrm{~min}$ at $60{ }^{\circ} \mathrm{C}$, cooled to room temperature and alkylated with the addition of iodoacetamide to a final concentration 
of at least $6 \mathrm{mM}$, and incubated in the dark for $20 \mathrm{~min}$. Samples were washed with $50 \%$ acetonitrile in $100 \mathrm{mM}$ aqueous ammonium bicarbonate for $20 \mathrm{~min}$, dehydrated with $100 \%$ acetonitrile for $10 \mathrm{~min}$ and lyophilized at room temperature in the speed-vac.

The lyophilized gel pieces were rehydrated with $2 \mu 1$ of $50 \mathrm{mM}$ aqueous ammonium bicarbonate containing $0.1-0.25 \mu \mathrm{g}$ of trypsin for $10 \mathrm{~min}$. Gel pieces were overlaid with $10 \mu \mathrm{l}$ of $50 \mathrm{mM}$ ammonium bicarbonate and incubated at $37^{\circ} \mathrm{C}$ for $3 \mathrm{~h}$. After trypsin digestion, $5 \mu \mathrm{l}$ of $0.2 \%$ trifluoroacetic acid (TFA) in MilliQ water was added and the digest solution removed to a fresh tube, $10 \mu \mathrm{l}$ of a 1:1 mixture of acetonitrile and $0.4 \%$ aqueous TFA was added to the gel pieces and incubated for $30 \mathrm{~min}$; the resulting solution was added to the previously recovered digest solution and replaced with $10 \mu 1$ acetonitrile for 30min, after which this was removed and added to the digest solution which was lyophilized at room temperature in the speed-vac. The lyophilized peptides were dissolved in $10 \mu 10.2 \%$ TFA in MilliQ water and purified with ZipTips-C18 (Millipore, Bedford, MA, USA) according to the manufacturer's instructions. The resulting purified peptides were eluted from the ZipTip-C18 with $2 \mu 150 \%$ acetonitrile, $0.2 \%$ TFA and mixed 1:1 with a saturated solution of a-cyano-4-hydroxy-cinnamic acid in 50\% acetonitrile, $0.2 \%$ TFA, and $1 \mu \mathrm{l}$ was spotted on a MALDI sample plate at room temperature.

Mass spectra were acquired using an Applied Biosystems DEPro MALDI-TOF mass spectrometer (Framingham, MA, USA) in positive ion reflector mode with accelerating voltage $20,000 \mathrm{~V}$, grid voltage $75 \%$ and 180 ns delay time. Peptide masses were calibrated internally using trypsin autolysis peaks. The resulting mass peak list was used to search all eukaryotic species in the NCBI protein database via the ProFound search engine (http://prowl.rockefeller.edu/prowl-cgi/profound.exe) (Zhang and Chait 2000), allowing 
for methionine oxidation and acetamide adducts. A positive identification was achieved when more than five peptide masses were matched covering more than $20 \%$ of the peptide sequence, with a mass error tolerance of $25 \mathrm{ppm}$, and an expectation below 0.01 . This indicates that a similar match would be found approximately once in every 100 similar sized databases that did not contain the sequence that matches the mass spectrometry data supplied.

Theoretical protein digests were performed using the PeptideMass web tool (Wilkins, Lindskog et al. 1997) hosted by the ExPASy proteomics server (Gasteiger, Gattiker et al. 2003) with amino acid sequences obtained from the SWISS-PROT knowledgebase (O'Donovan, Martin et al. 2002). All theoretical digests were achieved by selecting trypsin as the protease, and allowing for partial methionine oxidation and complete acetamide adduct presence.

\subsubsection{Purification of bovine microtubules}

Bovine microtubules were purified from the brain of an adult cow according to the method of Hamel et al. (Hamel and Lin 1981). The fresh brain was weighed after meninges were removed with Kim Wipes and tweezers. The brain tissue was homogenized with a polytron (Kinematica AG, Switzerland) in $1 \mathrm{ml}$ of $0.1 \mathrm{mM}$ GTP (guanosine triphosphate), $1 \mathrm{M}$ monosodium glutamate (MSG) per gram of brain matter. The homogenate was first centrifuged at $21 \mathrm{k} \mathrm{rpm}, 2{ }^{\circ} \mathrm{C}$ for $30 \mathrm{~min}$ (SS-34 rotor, Evolution RC, Sorvall) the supernatant was retained and further centrifuged at $36 \mathrm{k} \mathrm{rpm}$ at $2{ }^{\circ} \mathrm{C}$ for $1 \mathrm{~h}$ (Ti45 rotor, XL-80 Ultracentrifuge, Beckman Instruments Inc, Palo Alto, CA, USA). The supernatant was retained, GTP added to concentration of $0.1 \mathrm{mM}$ and incubated at for $1 \mathrm{~h}$ at $4{ }^{\circ} \mathrm{C}$ with $1 \mathrm{ml}$ of DEAE-Sephacel (Amersham) pre-equilibrated with $0.8 \mathrm{M}$ MSG per $5 \mathrm{ml}$ 
supernatant. The ion exchange resin was washed with five $100 \mathrm{ml}$ aliquots of $1 \mathrm{M}$ MSG with $0.1 \mathrm{mM}$ GTP. Tubulin was eluted with five $40 \mathrm{ml}$ aliquots of $0.1 \mathrm{mM}$ GTP, $1 \mathrm{M} \mathrm{NaCl}, 1 \mathrm{M} \mathrm{MSG}$ with each fraction collected separately. Fractions with an absorbance above $0.5 \mathrm{AU}$ at $280 \mathrm{~nm}$ were pooled and GTP was added to $1 \mathrm{mM}$ followed by $1 \mathrm{~h}$ incubation at $37{ }^{\circ} \mathrm{C}$ to polymerize the microtubules, which were recovered by centrifugation at 36k rpm (Ti45 rotor, XL-80 Ultracentrifuge, Beckman Instruments Inc) at $37{ }^{\circ} \mathrm{C}$ for $1 \mathrm{~h}$. The resulting supernatant was discarded and the pellet was re-solubilized in $1 \mathrm{M}$ MSG with $0.1 \mathrm{mM}$ GTP using a Teflon homogenizer. Insoluble matter was removed by centrifugation at $36 \mathrm{k}$ rpm (Ti45 rotor, XL-80 Ultracentrifuge, Beckman Instruments Inc) at $2{ }^{\circ} \mathrm{C}$ for $30 \mathrm{~min}$. GTP was added to $1 \mathrm{mM}$ followed by incubation at $37{ }^{\circ} \mathrm{C}$ to polymerize the microtubules. The cycle of polymerization-de-polymerization was repeated four times, after which the final pellet was re-solubilized with a Teflon homogenizer, the insoluble matter removed by centrifugation. The protein content of the supernatant was assessed using the BCA protein quantification assay (Pierce) and $10 \mu \mathrm{g}$ of protein was run on a LDS-PAGE gel (Invitrogen) and stained with colloidal Coomassie stain to assess purity. Solubilized microtubules were stored in $0.1 \mathrm{mM} \mathrm{GTP,} 1 \mathrm{M} \mathrm{MSG}, 20 \%$ glycerol at $-80{ }^{\circ} \mathrm{C}$ until use.

\subsubsection{Tubulin polymerization assay}

Purified tubulin was buffer exchanged using G25 Sephadex into polymerization buffer (2 mM ethylene glycol tetraacetic acid (EGTA), $1 \mathrm{mM}$ DTT, $0.1 \mathrm{mM}$ GTP 0.1 M PIPES, $\mathrm{pH}$ 6.9), protein content determined by the BCA method (Pierce) and concentrated centrifugally to $2 \mathrm{mg} / \mathrm{ml}$. The so-formed tubulin solution $(95 \mu \mathrm{l})$ was added to the plate with pateamine in $5 \mu 1$ of $40 \%$ ethanol for final concentrations of 20,100 and $200 \mu \mathrm{M}$ and absorbance at $350 \mathrm{~nm}$ was recorded every $5 \mathrm{~min}$ for $2 \mathrm{~h}$ in a microtitre plate reader 
(VersaMax, Molecular Devices) in kinetics mode, at $37^{\circ} \mathrm{C}$. Ethanol (2\%) was included as a carrier control, colchicine $(20 \mu \mathrm{M})$ and taxol $(20 \mu \mathrm{M})$ were included as controls for microtubule destabilization and microtubule stabilization respectively.

\subsubsection{Pyrene-actin microfilament polymerization assay}

In vitro actin polymerization was assessed using pyrene labeled actin (Kouyama and Mihashi 1981). The Actin Polymerization Biochem Kit (Cytoskeleton Inc, Denver, CO, USA) was used according to the manufacturer's instructions. Briefly, pyrene-actin was reconstituted on ice for $1 \mathrm{~h}$ in A-buffer $\left(0.5 \mathrm{mM}\right.$ DTT, $0.2 \mathrm{mM} \mathrm{CaCl}_{2}, 0.2 \mathrm{mM}$ ATP (adenosine triphosphate), $5 \mathrm{mM}$ Tris- $\mathrm{HCl}, \mathrm{pH} 8.0$ ) at a concentration of $4.3 \mu \mathrm{g} / \mathrm{ml}, 85 \mu \mathrm{l}$ of this solution was added to each well of a black 96-well plate, pateamine was added in $5 \mu 1$ of DMSO for a final concentration range of $25-200 \mu \mathrm{M}, 5 \mu \mathrm{l}$ of DMSO was included as a carrier control. Polymerization was induced by the addition of $10 \mu 1$ of 10 x polymerization inducing buffer (500 mM KCl, $20 \mathrm{mM} \mathrm{MgCl}$, $10 \mathrm{mM} \mathrm{ATP}$ ). Polymerization was monitored on a fluorescent micro-titre plate reader (SpectraMax, Gemini, Molecular Devices) with excitation at $365 \mathrm{~nm}$, monitoring emission at $407 \mathrm{~nm}$ every $5 \min$ for $1 \mathrm{~h}$. Polymerization conditions were modified in the following manner: addition of $0.5 \mathrm{x}$ $(1.8 \mu \mathrm{g} / \mathrm{ml})$ pyrene-actin; addition of $0.25 \mathrm{x}$ polymerization inducing buffer (final concentrations: $12.5 \mathrm{mM} \mathrm{KCl}, \quad 0.5 \mathrm{mM} \quad \mathrm{MgCl}_{2}, 0.25 \mathrm{mM}$ ATP); addition of $0.25 x$ polymerization inducing buffer supplemented with $1 \mathrm{mM}$ ATP, or $2 \mathrm{mM} \mathrm{MgCl}_{2}$; addition of $2 \mathrm{mM}$ EGTA. 


\subsubsection{Cell cycle analysis}

A 24-well plate was seeded with $2 \times 10^{5} \mathrm{HeLa}$ cells and left overnight to attach in a humidified incubator at $37{ }^{\circ} \mathrm{C}$ with $5 \% \mathrm{CO}_{2}$. Cells were treated with $10 \mathrm{nM}$ pateamine in 0.1\% ethanol, RPMI 1640 media supplemented with 10\% FCS and 1\% PenStrep, for $18 \mathrm{~h}$ in a humidified incubator at $37^{\circ} \mathrm{C}$ and $5 \% \mathrm{CO}_{2}$, after which they were harvested with trypsin (according to method 2.3.2), washed twice with $1 \mathrm{ml}$ of PBS (10 mM sodium phosphate, $138 \mathrm{mM}$ sodium chloride, $27 \mathrm{mM}$ potassium chloride, $\mathrm{pH} 7.4$ ) and resuspended in PI buffer $(0.05 \mathrm{mg} / \mathrm{ml}$ propidium iodide, $0.1 \%$ Sodium citrate, $0.1 \% \mathrm{TX}-100)$ and incubated for $30 \mathrm{~min}$ on ice. DNA content was analyzed on the FL2 channel of a FACScan flow cytometer (BD Biosciences), 10,000 cell events were collected and the data were analyzed by CellQuest Pro software (BD Biosciences).

\subsubsection{Annexin V binding assay}

Into each well of a 24-well tissue culture grade plate (Greiner), 5 x $10^{4} \mathrm{HeLa}$ cells (maintained as according to method 2.3.2) were seeded and allowed to attach overnight. Pateamine (10 nM in $0.1 \%$ ethanol, RPMI 1640 media supplemented with $10 \%$ FCS and $1 \%$ PenStrep) or $0.1 \%$ ethanol RPMI 1640 media, supplemented with $10 \%$ FCS and $1 \%$ PenStrep, as control was added and the plate incubated in a humidified incubator at $37^{\circ} \mathrm{C}$ and $5 \% \mathrm{CO}_{2}$ for $3,6,12,18$ or $24 \mathrm{~h}$, after which loose cells were washed off the well surface with media and retained. The remaining attached cells were removed with trypsin, according to method 2.2.2, and added to the previously recovered cells. Cells were washed with three $1 \mathrm{ml}$ aliquots of Annexin $\mathrm{V}$ buffer $\left(150 \mathrm{mM} \mathrm{NaCl}, 5 \mathrm{mM} \mathrm{KCl}, 1.8 \mathrm{mM} \mathrm{CaCl}_{2}\right.$, $1 \mathrm{mM} \mathrm{MgCl} 2,10 \mathrm{mM}$ HEPES, $\mathrm{pH}$ 7.4), re-suspended in $100 \mu \mathrm{l}$ of the same buffer and stained with Annexin-V-Fluos (Roche Diagnostics) according to the manufacturer's recommendations. Cells were then washed with $1 \mathrm{ml}$ of Annexin $\mathrm{V}$ buffer and re-suspended in $100 \mu \mathrm{l}$ of the same buffer. Cell membrane permeability was assessed with 
the addition of $10 \mu \mathrm{g} / \mathrm{ml}$ propidium iodide. Cellular fluorescence was measured using a FACScan flow cytometer (BD Biosciences, Franklin Lakes, NJ, USA), 10,000 cell events were collected, and percentage cell populations were established using CellQuest Pro software (BD Biosciences). An unpaired t-test was performed using SigmaPlot Ver 10.0 (Systat Software Inc.).

\subsubsection{Caspase $3 / 7$ activation assay}

The FAM-DEVD-FMK reagent (FLICA Caspases 3 and 7 Kit, Immunochemistry Technologies LLC, Bloomington, MN, USA) was used according to manufacturer's instructions with minor modifications. Briefly, a 24-well plate was seeded with HeLa cells at $5 \times 10^{4}$ cells per well (maintained as according to method 2.2.2) in $1 \mathrm{ml}$ of RPMI 1640 media, supplemented with 10\% FCS and 1\% PenStrep, and allowed to attach overnight. To asses chronic exposure to pateamine it was added to a final concentration of $10 \mathrm{nM}$ in 0.1\% ethanol in RPMI 1640 media, supplemented with 10\% FCS and 1\% PenStrep, and the plate incubated in a humidified incubator at $37^{\circ} \mathrm{C}$ and $5 \% \mathrm{CO}_{2}$ for $18 \mathrm{~h}$, to asses early caspase 3/7 activation kinetics in the presence of high concentrations of pateamine, it was added to $1 \mu \mathrm{M}$ and cell were harvested after 1,2 and $4 \mathrm{~h}$, after which loose cells were washed off the well surface with media and retained. The remaining attached cells were removed with trypsin and added to the previously recovered cells. Cells were washed with three $1 \mathrm{ml}$ aliquots of fresh media, re-suspended in $30 \mu \mathrm{l}$ of fresh media containing 0.25x FAM-DEVD-fmk and incubated in a humidified incubator at $37{ }^{\circ} \mathrm{C}$ and $5 \% \mathrm{CO}_{2}$ for $1 \mathrm{~h}$. Cells were recovered by centrifugation and washed with $1 \mathrm{ml}$ of apoptosis wash buffer (Immunochemistry Technologies LLC) and re-suspended in $300 \mu 1$ of the same buffer containing $10 \mu \mathrm{g} / \mathrm{ml}$ propidium iodide. Cellular fluorescence was measured using the FACScan flow cytometer (BD Biosciences) 10,000 cell events were collected, and percentage cell populations were established using CellQuest Pro software 
(BD Biosciences). An unpaired t-test was performed using SigmaPlot Ver 10.0 (Systat Software Inc.).

\subsubsection{Protein alignment}

All protein alignments were performed using Matlab Ver 7.8.0.347 (R2009a) (MathWorks, Inc. Natick, MA, USA) with amino acid sequences from the SWISS-PROT knowledgebase (O'Donovan, Martin et al. 2002). Global multiple alignments were peformed with the multalign function, and local pairwise alignments with the swalign function (Smith and Waterman 1981), both part of the bioinformatics toolbox. 


\subsection{Results}

\subsubsection{Pateamine is cytotoxic to cultured cells}

To ensure that the batches of pateamine supplied for this study were of comparable biological activity to samples tested in previous studies, and to account for batch-to-batch variations in purity, the MTT assay was performed with three transformed human cell lines, leukemic HL-60 cells (Gallagher, Collins et al. 1979), cervical epithelial HeLa cells (Scherer and Hoogasian 1954) and the neuroblastoma cell line SH-SY5Y (Biedler, RofflerTarlov et al. 1978). Figure 2.1 contains representative dose-response curves for the three cell lines tested, Table 2.1 contains the mean $\mathrm{IC}_{50}$ values from three independent experiments and shows that pateamine displays similar cytotoxicity in the three cell lines tested here, with $\mathrm{IC}_{50}$ values comparable to previously published literature (Hood, West et al. 2001), additionally the potency of each batch of pateamine was within two standard deviations of these values. These three cell lines were used for subsequent binding protein studies. 


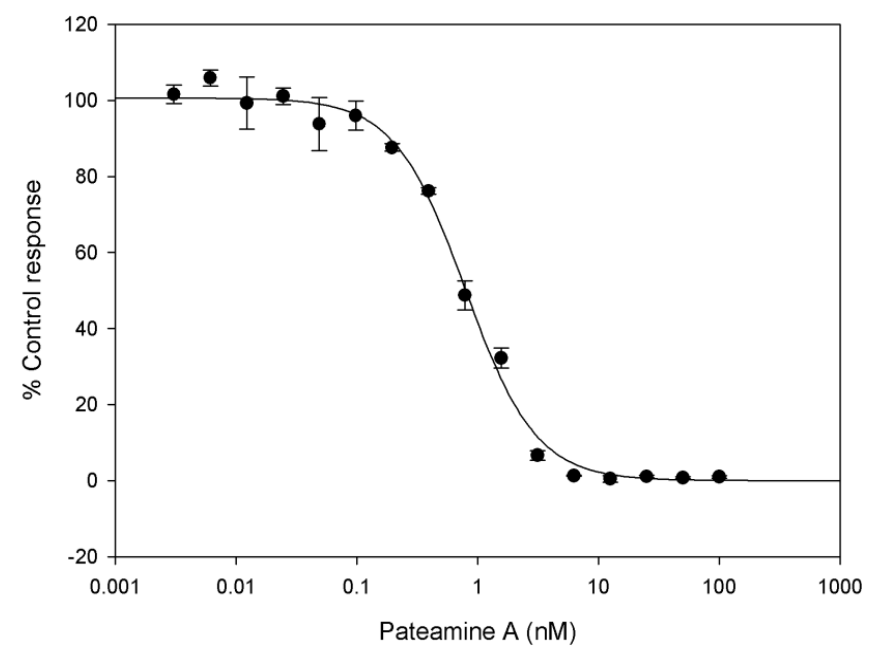

HeLa

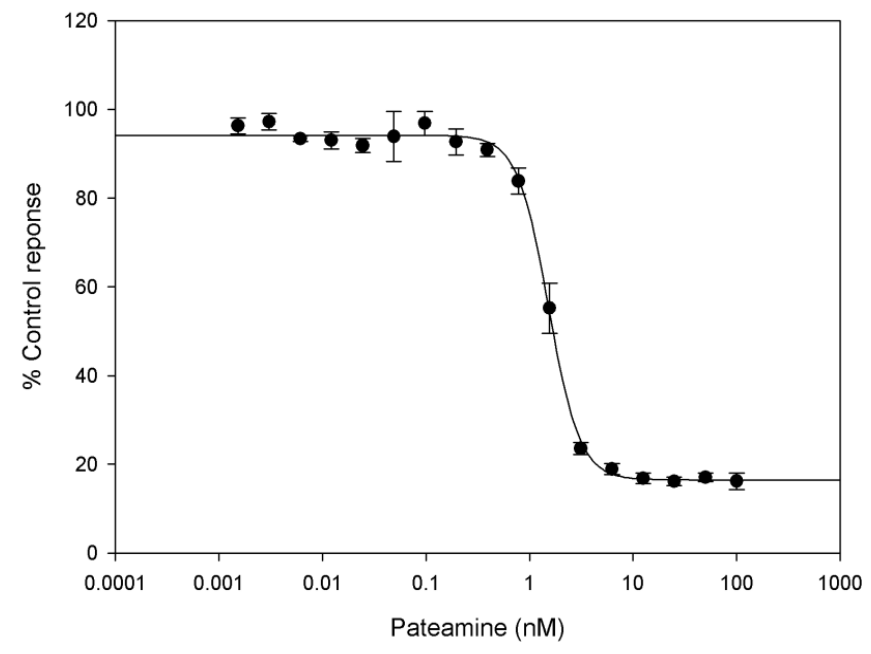

SH-SY5Y

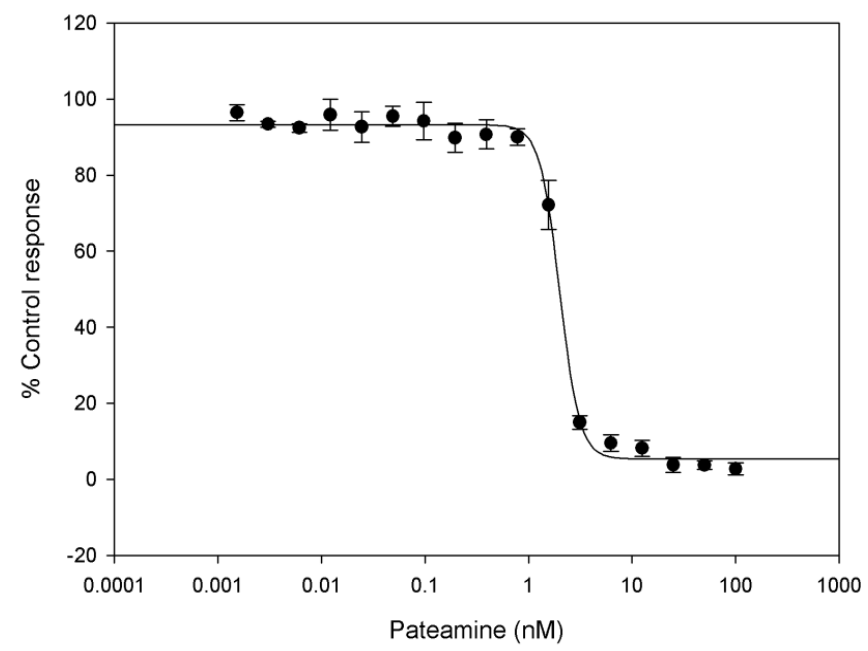

Figure 2.1 Pateamine cytotoxicity dose-response curves. Representative pateamine MTT assay dose-response curves, each cell line was tested in triplicate three times, shown above is a best fit sigmoidal curve for a single assay in triplicate for each cell line. 


\begin{tabular}{|l|l|}
\hline Cell Line & Mean $\mathrm{IC}_{50}$ \\
\hline HL-60 & $1.43 \pm 0.06 \mathrm{nM}$ \\
\hline HeLa & $1.5 \pm 0.04 \mathrm{nM}$ \\
\hline SH-SY5Y & $1.98 \pm 0.08 \mathrm{nM}$ \\
\hline
\end{tabular}

Table 2.1 Summary of cytotoxicity assay results for pateamine sensitive cell lines. The average \pm standard error of three independent MTT dose-response assays performed in triplicate is shown.

\subsubsection{Pateamine affinity resin generation}

The exact mechanism by which the coupling reaction proceeded was not established although it is assumed that it is achieved through the primary amine of pateamine performing a nucleophilic attack on the terminal epoxy-carbon of the affinity resin (Figure 2.2). Direct quantification of the level of substitution was not performed, however after the coupling reaction the resin appeared to be yellow in color and $9 \mathrm{mg}$ of pateamine was recovered from the subsequent methanol washes, indicating approximately $4 \mathrm{mg}$ of pateamine reacted with $120 \mathrm{mg}$ of epoxy-activated Sepharose $6 \mathrm{~B}$, which corresponds to approximately $20 \mu$ mol pateamine per $\mathrm{ml}$ of swollen resin. 


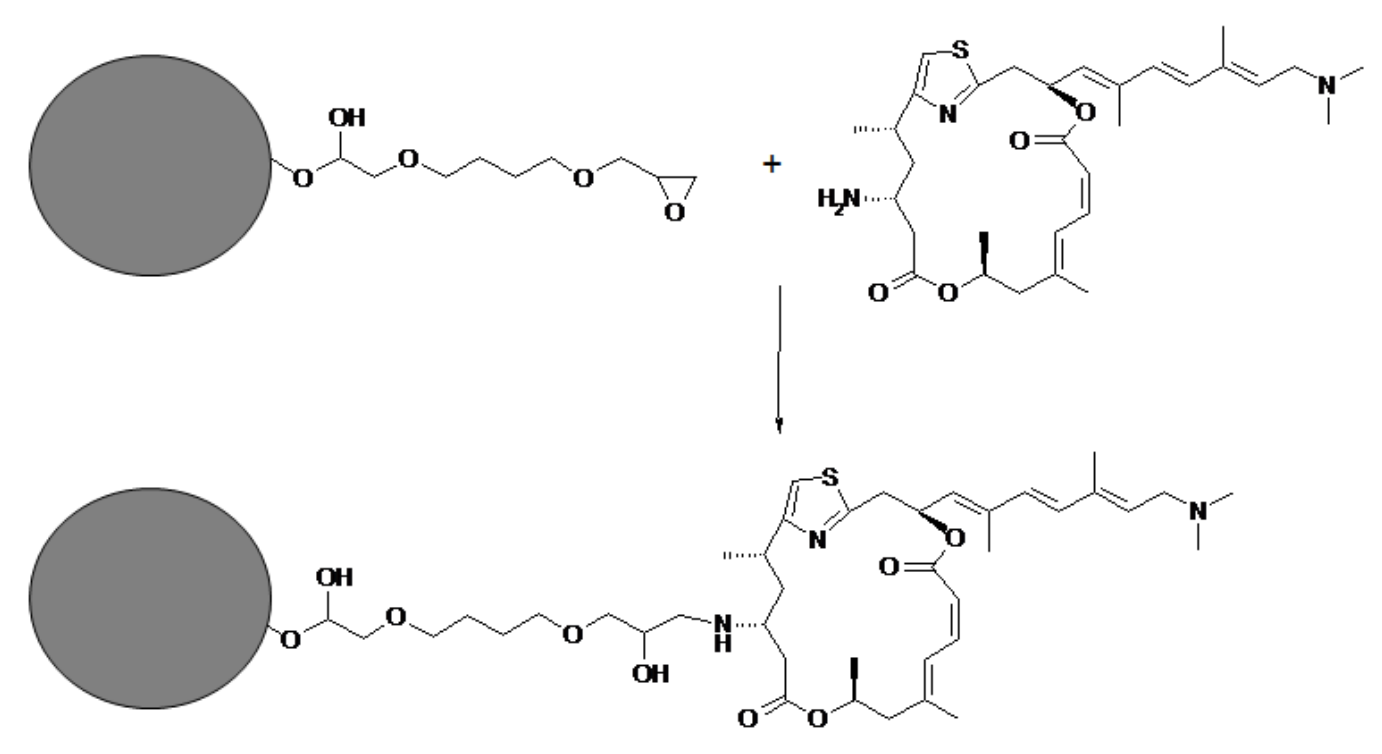

Figure 2.2 Pateamine affinity resin. Immobilization of pateamine onto the epoxy activated Sepharose solid phase is presumed to occur through the C3 primary amine as shown.

\subsubsection{Pateamine binding protein isolation and elution}

Equal amounts of swollen pateamine resin and diethanolamine control resin were used to isolate pateamine binding proteins from HL-60, HeLa and SH-SY5Y cell lysates, the control resin was used to establish non-specific protein-binding to the solid phase and linker regions of the resin. To ensure recovery of all proteins bound by both resins, LDS-PAGE loading buffer was initially used to elute bound protein from the resins. As can be seen in Figure 2.3, three proteins $(1-3)$ were consistently eluted from the pateamine resin that did not appear in the control resin eluates for the three cell lines tested, while other bands specific to each cell line appear, these were not investig ated due to their low amount and lack of representation in all three cell lines. In order to establish the specificity of these proteins for the pateamine resin an attempt to elute these proteins with $500 \mu \mathrm{M}$ pateamine in PBS was made (Figure 2.3a). However, elution with pateamine resulted in a large smear rather than separated and resolved bands on the LDS-PAGE gel. An alternative method to validate the pateamine-specificity of these binding proteins was undertaken by 
adding pateamine $(500 \mu \mathrm{M})$ to the lysate prior to incubation with each of the resins to demonstrate the ability of soluble pateamine to compete with the resin for these binding proteins. Figure $2.3 \mathrm{~b}$ shows the pre-incubation of the HL-60 cell lysate with pateamine prevents the binding of any of the three previously recovered proteins to the pateamine resin. In order to estimate the relative strengths of the binding interactions of these three proteins the resin was washed with $1 \mathrm{M}$ sodium chloride prior to LDS-PAGE loading buffer elution. Figure $2.3 \mathrm{c}$ shows that the high salt wash significantly decreased the amount of bands 1 and 3, but band 2 stained with a similar intensity to that previously observed, a similar pattern of elution was observed when a non-reducing elution with a solution of $7 \mathrm{M}$ urea, $2 \mathrm{M}$ thiourea and 4\% CHAPS (data not shown). 


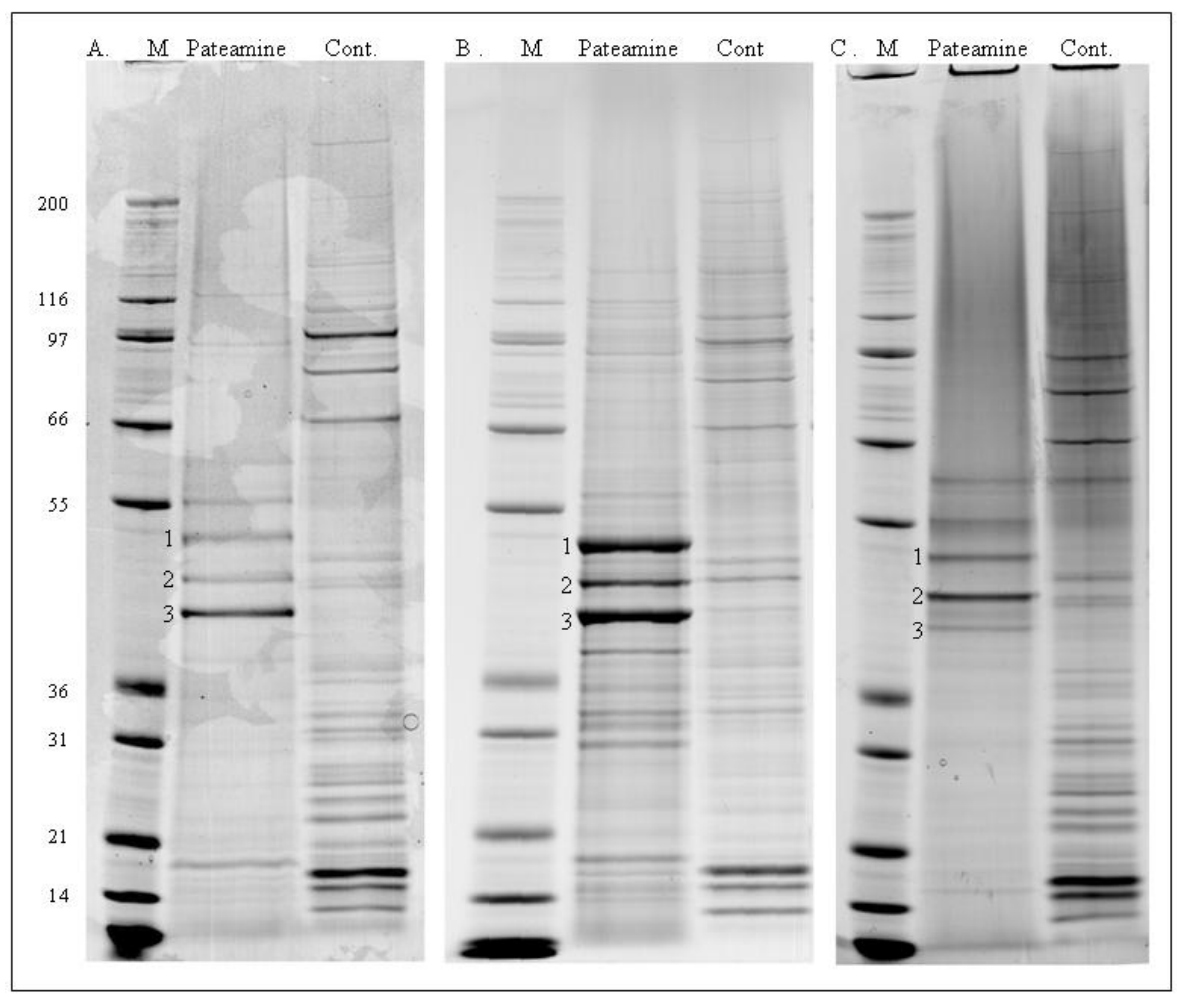

Figure 2.3 Isolation and separation of cellular pateamine targets by affinity chromatography.

Lanes marked M contain molecular weight markers, Pateamine labeled lanes show proteins isolated with pateamine resin and lanes labeled Cont. indicates protein isolated with the control resin. Proteins were isolated from whole cell lysates from three cell lines: A. SH-SY5Y cells; B. HeLa cells; C. HL-60 cells. Bound proteins were eluted from both resins with LDS-PAGE loading buffer (Invitrogen), separated on NuPAGE 4-12\% gradient Bis-Tris gels and run at 200V in MOPS buffer, followed by fixation and staining with colloidal Coomassie. Each gel is a representative of at least two independent isolations, the three bands consistently isolated from all three cell lines are labeled 1-3. 


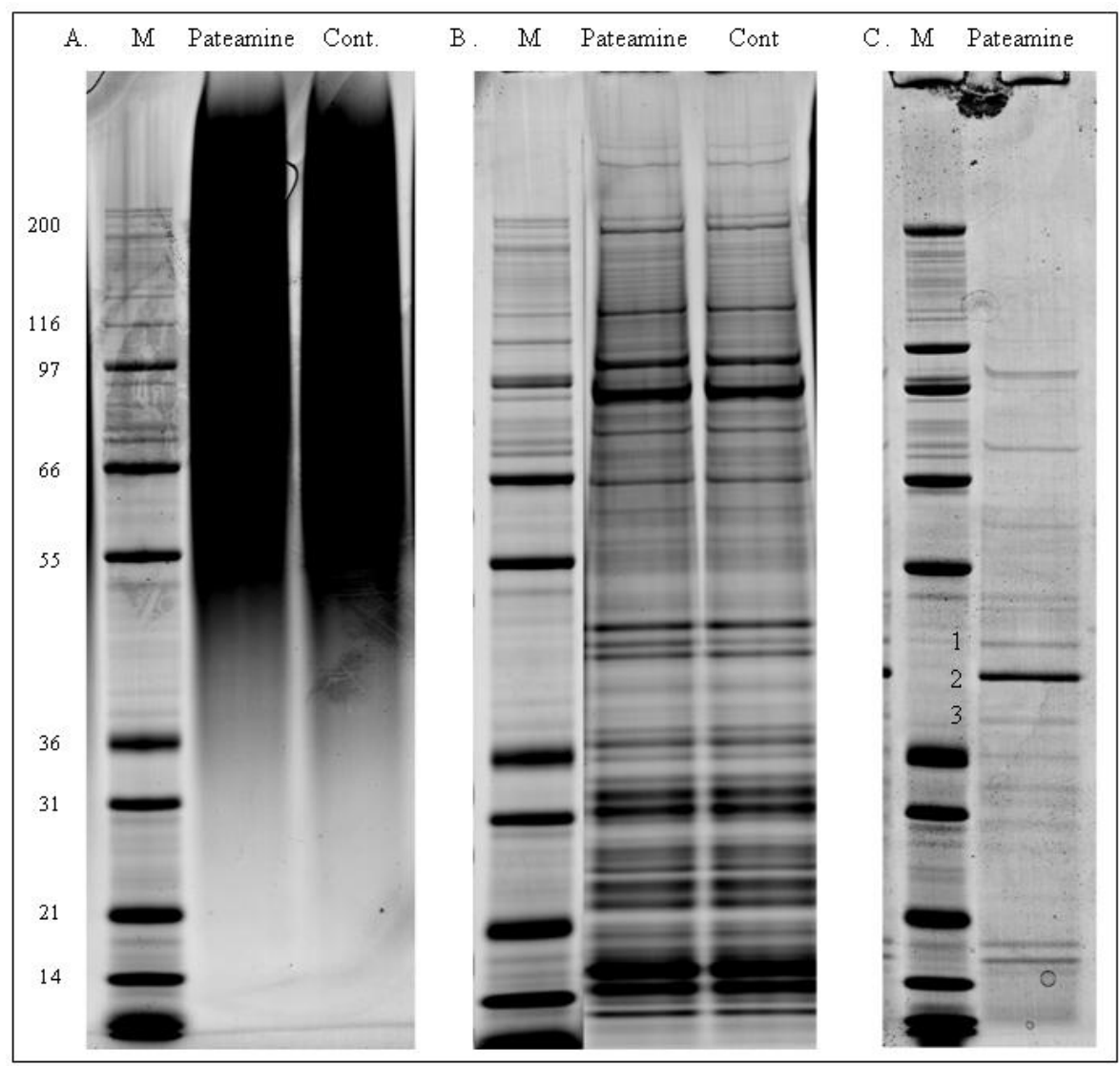

Figure 2.4 Pateamine affinity chromatography specificity of interaction. Lanes marked $M$ contain molecular weight markers, Pateamine labeled lanes show proteins isolated with resin derivatized with pateamine and lanes labeled Cont. indicates protein isolated with the control resin derivatized with diethanolamine. Proteins were isolated from HL-60 cell whole cell lysates and: A. Attempted specific elution with PBS containing $0.1 \%$ Triton $\mathrm{X}-100$ and $500 \mu \mathrm{M}$ pateamine; B. Binding competition with $500 \mu \mathrm{M}$ pateamine followed by elution with LDS-PAGE loading buffer; C. Protein retention by the pateamine affinity resin subsequent to an additional wash step with $1 \mathrm{M}$ sodium chloride, $0.1 \%$ Triton $\mathrm{X}-100,10 \mathrm{mM}$ sodium phosphate $(\mathrm{pH} 7.4)$, proteins remaining were recovered by elution with LDS-PAGE loading buffer.

\subsubsection{Identification of putative pateamine binding proteins by peptide mass fingerprinting}

The three putative pateamine binding proteins $(1-3)$ isolated from each cell line using the pateamine affinity resin were identified by peptide mass fingerprinting after trypsin digestion. Table 2.2 shows a summary of typical results attained for the putative pateamine binding proteins isolated from each cell line after searching the NCBI database with the ProFound search engine, only the first positive hit to a human protein for each search is 
listed for brevity, Sheets 2 - 4, Supplementary File 1 contains full search results for each gel band and cell line. Each positive identification was achieved with at least 7 independent peptides covering at least $27 \%$ of each protein with expectation scores less than 0.0096 .

In all cell lines except SH-SY5Y, binding protein 1 was identified as being a member of the $\beta$-tubulin family with no less than 7 independent peptides covering at least $27 \%$ of the amino acid sequence (Figure 6.6, Appendix A; Sheet2 - 4, Supplementary File 1), it has been reported that there exist at least nine $\beta$-tubulin isotypes in the Homo sapiens, all sharing a very high degree of amino acid sequence similarity (Luduena 1998). A significant portion of this family is present with equal expectancy in the list of hit from the ProFound search, inspection of the spectra used to search the database shows the presence of peptides from at least $5 \beta$-tubulin isotypes (Figure 6.2, Appendix A). Whilst the band 1 from SH-SY5Y was of the same apparent molecular weight as that from the other cell lines, no significant hits were obtained from the mass fingerprinting.

Binding protein 2 isolated from each cell line was identified as eukaryotic initiation factor 4A (eIF4A) with 14 independent peptides covering at least $27 \%$ of amino acid sequence (Tabl2 2.2; Sheets 2 - 4, Supplementary File 1). There exist three isoforms of this protein in the Homo sapiens. Isoforms I and II are approximately $98 \%$ similar, whereas eIF4AIII is approximately $70 \%$ similar to eIF4AI (Linder 2006). 
Figure 2.5 shows a typical spectrum obtained for gel band 2 isolated from the HeLa cell line, and while eIF4AIII does not appear in the list of hits attained using the ProFound search engine (Sheets $2-4$, Supplementary File 1), a closer inspection of this spectrum (Figure 2.6; Figure 6.3, Appendix A) reveals the presence of peptides that are unique to eIF4AIII (see Sheet 5, Supplemenatry File 1) for theoretical tryptic digest results). While MALDI-ToF MS is only semi-quantitative (Dreisewerd 2003), the lower signal intensity of the eIF4AIII specific peptides in the spectrum probably reflective of this protein's lower abundance compared to isoforms I and II (Linder 2003). The presence of eIF4AI, II and III in the pateamine resin eluate obtained from the HL-60 cell line was confirmed by western blot with isoform specific antibodies (Bordeleau, Matthews et al. 2005).

Gel band three was identified as $\beta / \gamma$-actin from each of the three cell lines with at least 9 independent peptides covering at least $30 \%$ of the amino acid sequence and an expectation score no greater than 0.0093 . Due to a lack of unique peptides for either $\beta$ or $\gamma$ actin it is not clear whether one or both isoforms are present in the eluates (Figure 6.4, Appendix A; Sheets 2-4, Supplementary File 1). 


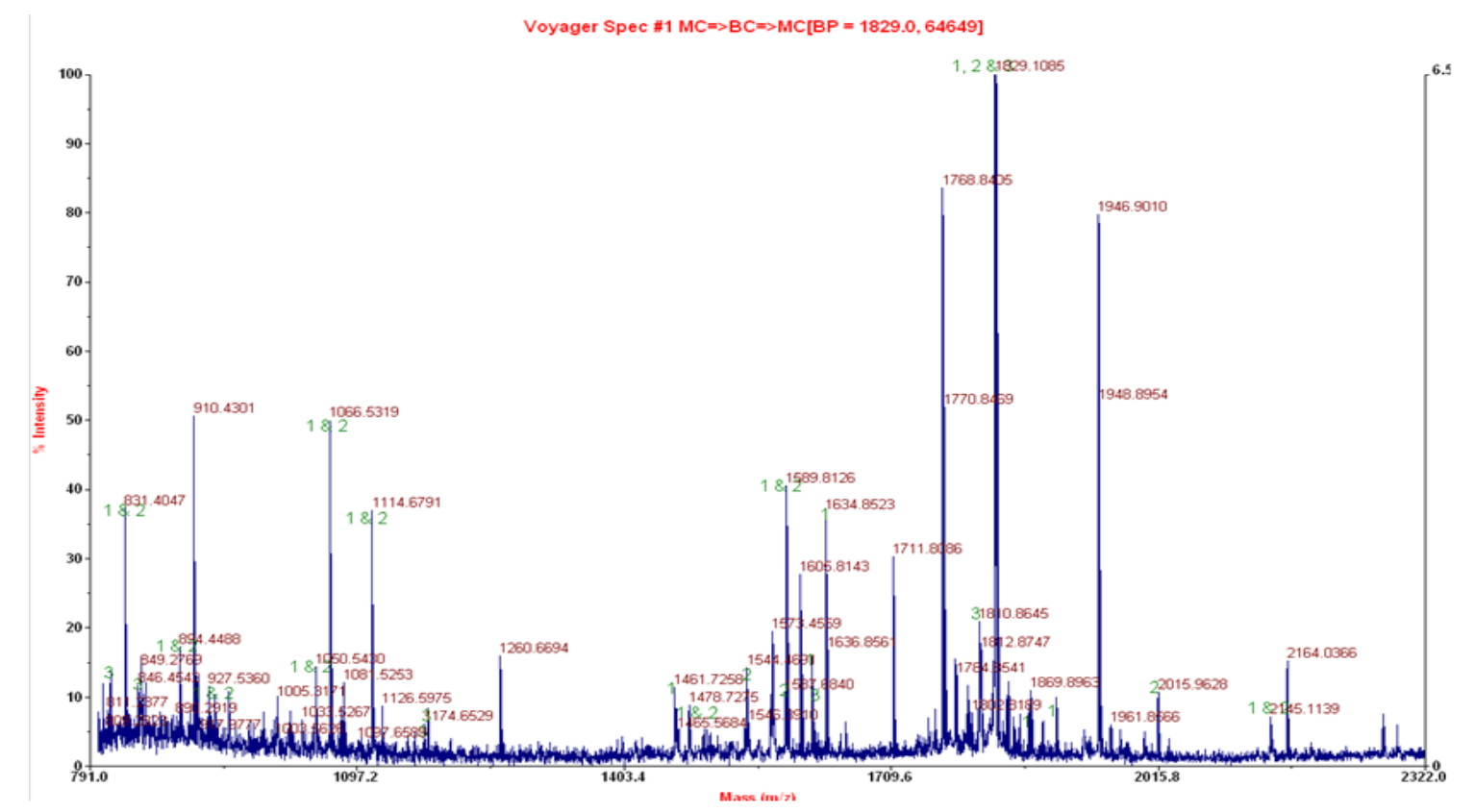

Figure 2.5 MALDI mass spectrum acquired from gel band two from the HeLa cell lysate after digestion with trypsin. Three isoforms of elF4A are retained by the pateamine affinity resin, database searching identified this band as elF4A isoform I and II, peaks with masses corresponding to those from each isoforms including elF4AIII are labeled.

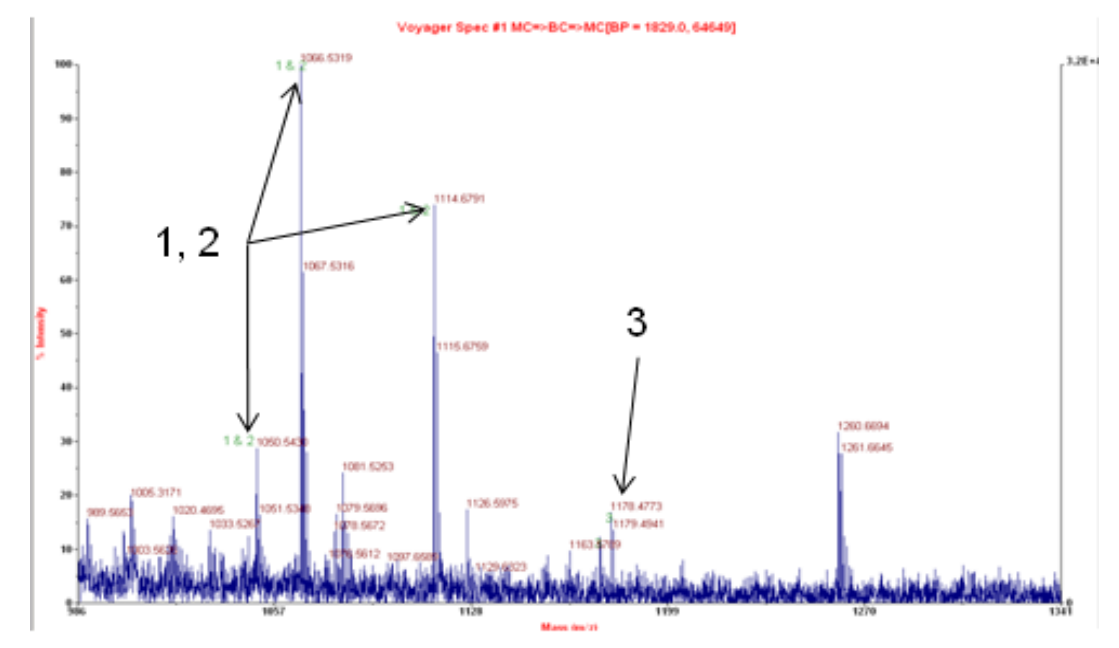

Figure 2.6 elF4Alll isolated by pateamine affinity chromatography. Close up of mass spectrum acquired from gel band two isolated from the HeLa cell lysate shows masses corresponding to peptides found only from the tryptic digest of elF4AIII. Peaks are labeled as described in figure 2.5 


\begin{tabular}{|c|c|c|c|c|c|c|c|}
\hline $\begin{array}{l}\text { Cell } \\
\text { Line }\end{array}$ & Band & Identity & Expectation & $\begin{array}{l}\text { Matched } \\
\text { Peptides }\end{array}$ & $\begin{array}{l}\text { Sequence } \\
\text { Coverage }\end{array}$ & $\begin{array}{l}\text { Predicted } \\
\text { MW }\end{array}$ & $\begin{array}{l}\text { Observed } \\
\text { MW }\end{array}$ \\
\hline \multirow[t]{3}{*}{$\overline{\mathrm{HeLa}}$} & 1 & $\begin{array}{l}\text { gi|29788785| } \\
\text { tubulin, beta [Homo sapiens] }\end{array}$ & $3.6 \times 10^{-3}$ & 7 & $27 \%$ & 50.11 & $50 \mathrm{kDa}$ \\
\hline & 2 & $\begin{array}{l}\text { gi|4503529 } \\
\text { leukaryotic translation initiation factor } 4 \mathrm{~A} \text { isoform } 1 \text { [Homo } \\
\text { sapiens] }\end{array}$ & $4.6 \times 10^{-5}$ & 14 & $31 \%$ & 46.36 & $46 \mathrm{kDa}$ \\
\hline & 3 & $\begin{array}{l}\text { gi|} 15277503 \mid \\
\text { ACTB protein [Homo sapiens] }\end{array}$ & $9.3 \times 10^{-3}$ & 10 & $34 \%$ & 40.54 & $40 \mathrm{kDa}$ \\
\hline \multirow[t]{3}{*}{ HL-60 } & 1 & $\begin{array}{l}\text { gi|2119276| } \\
\text { beta-tubulin - human (fragment) }\end{array}$ & $9.6 \times 10^{-3}$ & 9 & $27 \%$ & 49.38 & $50 \mathrm{kDa}$ \\
\hline & 2 & $\begin{array}{l}\text { gi }|4503529| \\
\text { eukaryotic translation initiation factor } 4 \mathrm{~A} \text { isoform } 1 \text { [Homo sapiens] }\end{array}$ & $1.2 \times 10^{-6}$ & 14 & $33 \%$ & 46.36 & $46 \mathrm{kDa}$ \\
\hline & 3 & $\begin{array}{l}\text { gi|15277503| } \\
\text { ACTB protein [Homo sapiens] }\end{array}$ & $6.8 \times 10^{-3}$ & 11 & $34 \%$ & 40.54 & $40 \mathrm{kDa}$ \\
\hline \multirow{3}{*}{$\begin{array}{l}\text { SH- } \\
\text { SY5Y }\end{array}$} & 1 & No significant hits & NA & & NA & NA & $50 \mathrm{kDa}$ \\
\hline & 2 & $\begin{array}{l}\text { gi }|4503529| \\
\text { eukaryotic translation initiation factor } 4 \mathrm{~A} \text { isoform } 1 \text { [Homo sapiens] }\end{array}$ & $6.7 \times 10^{-5}$ & 14 & $33 \%$ & 46.36 & $46 \mathrm{kDa}$ \\
\hline & 3 & $\begin{array}{l}\text { gi|15277503| } \\
\text { ACTB protein [Homo sapiens] }\end{array}$ & $3.7 \times 10^{-3}$ & 9 & $30 \%$ & 40.54 & $40 \mathrm{kDa}$ \\
\hline
\end{tabular}

Table 2.2 Summary of ProFound search results for putative pateamine binding proteins. Each assignment was achieved at least twice for each cell line and protein, reported is representative results for each protein band, for brevity the first database entry for each search is reported. See method 2.3.8 for an explanation of the expectation score. 


\subsubsection{Pateamine displays duel effects on in vitro microtubule polymerization}

An in vitro microtubule polymerization assay was performed to assess whether pateamine could affect the polymerization of tubulin. To this, end tubulin was isolated and purified to approximately 95-99\% purity (Figure 6.5, Appendix A) from bovine brain grey matter, and the effect of pateamine on its ability to polymerize was assessed by measuring the increase in turbidity (indicating polymerization) and compared to taxol and colchicine which are known to enhance (Lopes, Miller et al. 1997) and inhibit (Borisy and Taylor 1967) microtubule formation respectively. Figure 2.7 shows that high concentrations $(100-200 \mu \mathrm{M})$ of pateamine seem to significantly enhance tubulin polymerization, although even at $200 \mu \mathrm{M}$, the rate of microtubule formation is lower than that achieved with $20 \mu \mathrm{M}$ taxol. In contrast, a lower concentration $(20 \mu \mathrm{M})$ seems to prevent polymerization to a similar level to that achieved by the same concentration of colchicine (See Sheet 6, Supplementary File 1 for raw data). 


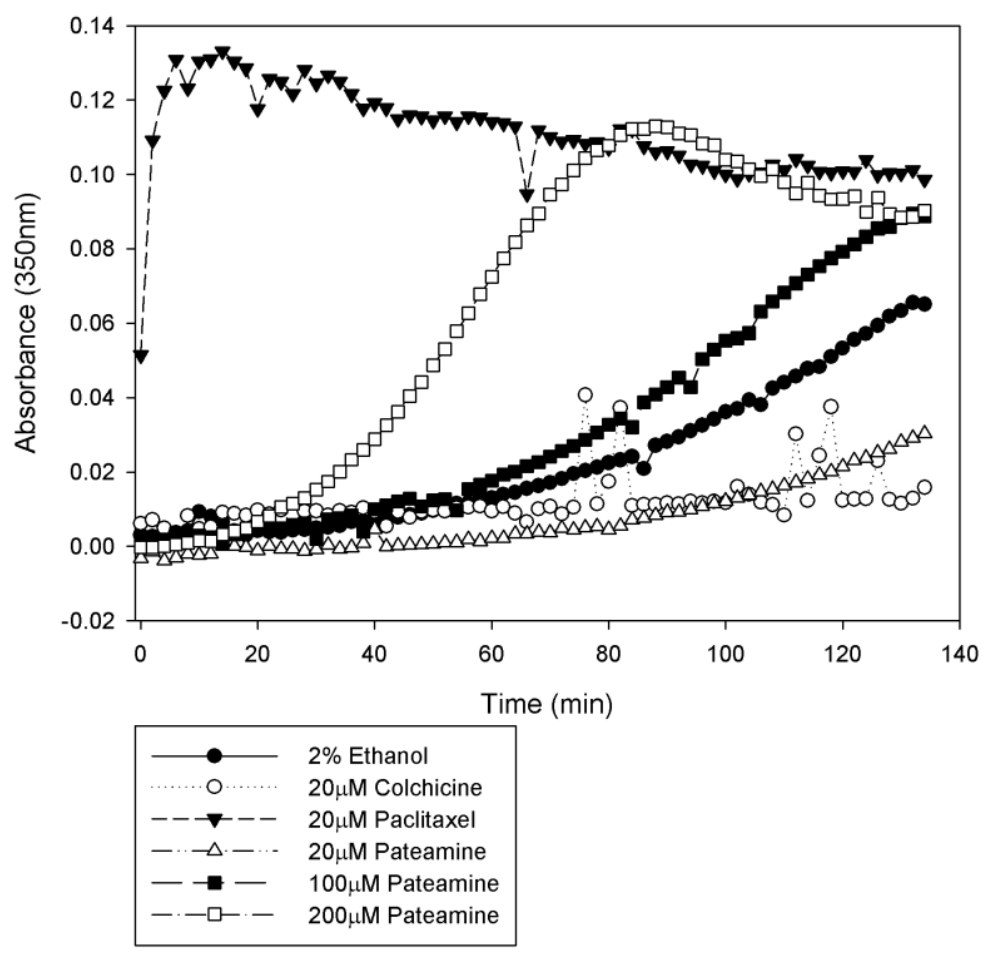

Figure 2.7 In vitro microtubule polymerization assay. Purified bovine tubulin polymerization was monitored in a microtitre plate at $37^{\circ} \mathrm{C}$ by measuring absorbance at $350 \mathrm{~nm}$ in the presence of the indicated drugs, or $2 \%$ ethanol as a carrier control. Pictured is a representative of at least three independent assays.

\subsubsection{High concentrations of pateamine disrupt polymerization of rabbit $\alpha$-actin in vitro}

Fluorescently labeled rabbit $\alpha$-actin was used to assess the in vitro effect of pateamine on microfilament formation due to the commercial availability of the reagent and the similarity between rabbit $\alpha$-actin and human $\beta$ and $\gamma$-actin (Figure 6.6, Appendix A). Figure 2.8a shows that pateamine causes dose dependant suppression of both the initial rate of actin polymerization and the maximum fluorescence intensity attained at concentrations comparable to those that seem to stabilize microtubule polymerization; this was only seen after the addition of ATP (data no shown). In contrast to microtubule polymerization, where it appears pateamine has a duel effect, stabilizing or destabilizing depending on the concentration, microfilament polymerization is suppressed at all concentration of 
pateamine tested. When the concentration of actin in the assay is halved (Figure 2.8b) pateamine inhibits both the initial rate and maximum fluorescence proportionally, whereas decreasing the concentration of the polymerization buffer fourfold (Figure 2.8c) causes an increase in the level of suppression of these parameters. Supplementation of the depleted polymerization buffer with $1 \mathrm{mM}$ ATP (Figure 2.8d) has no effect on the suppression of the initial rate of polymerization and maximum fluorescence by pateamine, whereas when the depleted polymerization buffer is supplemented with $2 \mathrm{mM} \mathrm{Mg}^{2+}$ (Figure 2.8e) a higher level of suppression of these parameters occurs. When the assay is performed in the presence of 2 mM EGTA (Figure 2.8f) abrogation of inhibitory effects of pateamine on the both the initial rate of polymerization and the total fluorescence are observed (see sheet 7 , Supplementary File 1). 
A
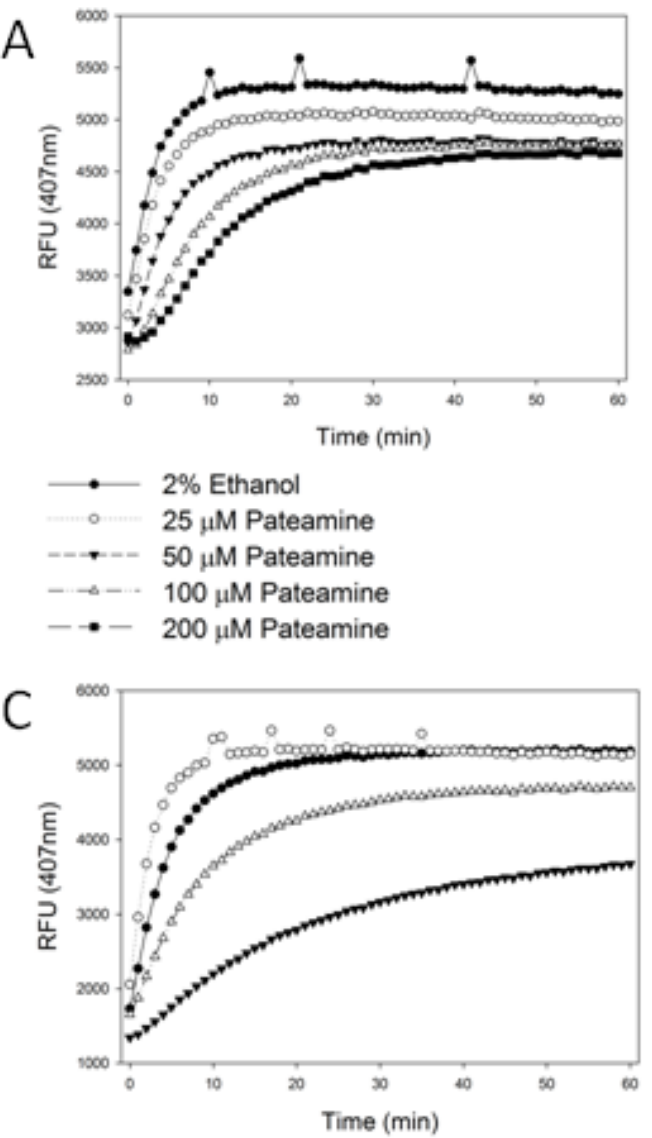

- $25 \mu \mathrm{M}$ Pateamine, 1x polymerization buffer

- $2 \%$ Ethanol, $1 \times$ polymerization buffer

-.-- $25 \mu \mathrm{M}$ Pateamine, $0.25 \mathrm{x}$ polymerization buffer

$\ldots-2 \%$ Ethanol, $0.25 x$ polymerization buffer

E

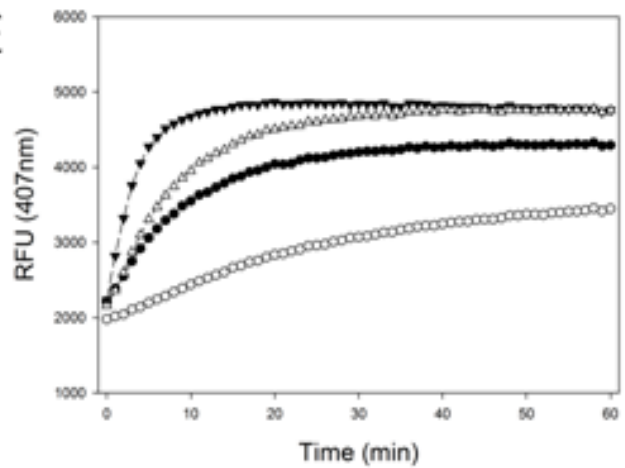

- $2 \%$ Ethanol, $0.25 x$ polymerization buffer $25 \mu \mathrm{M}$ Pateamine, $0.25 \mathrm{x}$ polymerization buffer $2 \%$ Ethanol, $0.25 x$ polymerization buffer, $2 \mathrm{mM} \mathrm{Mg}^{2+}$

$25 \mu \mathrm{M}$ Pateamine, $0.25 \mathrm{x}$ polymerisation buffer $2 \mathrm{mM} \mathrm{Mg}^{2+}$

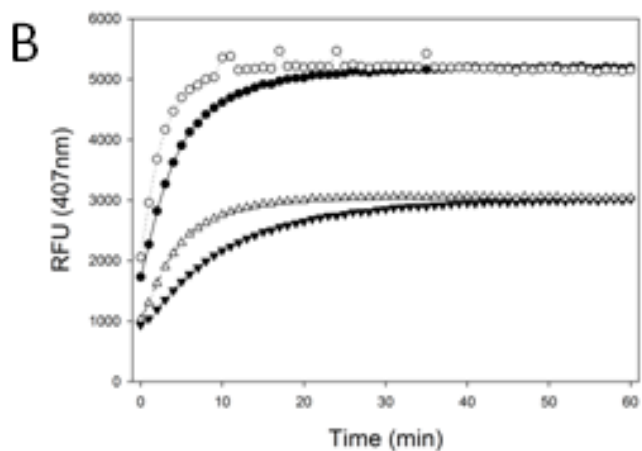

- $25 \mu \mathrm{M}$ Pateamine, 1x pyrene-actin $2 \%$ Ethanol, $1 x$ pyrene-actin

$\ldots+\cdots \mathrm{M}$ Pateamine, $0.5 \mathrm{x}$ pyrene-actin

_. $2 \%$ Ethanol, $0.5 x$ pyrene-actin

D

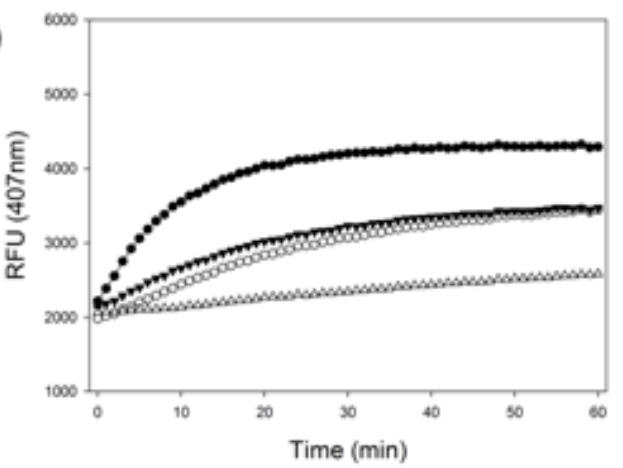

- $2 \%$ Ethanol, $025 x$ polymerization buffer $50 \mu \mathrm{M}$ Pateamine, $025 \mathrm{x}$ polymerization buffer

-- $2 \%$ Ethanol, $0.25 x$ polymerization buffer, $1 \mathrm{mM}$ ATP

$-\infty-50 \mu \mathrm{M}$ Pateamine, $0.25 \times$ polymerization buffer, $1 \mathrm{mM}$ ATP
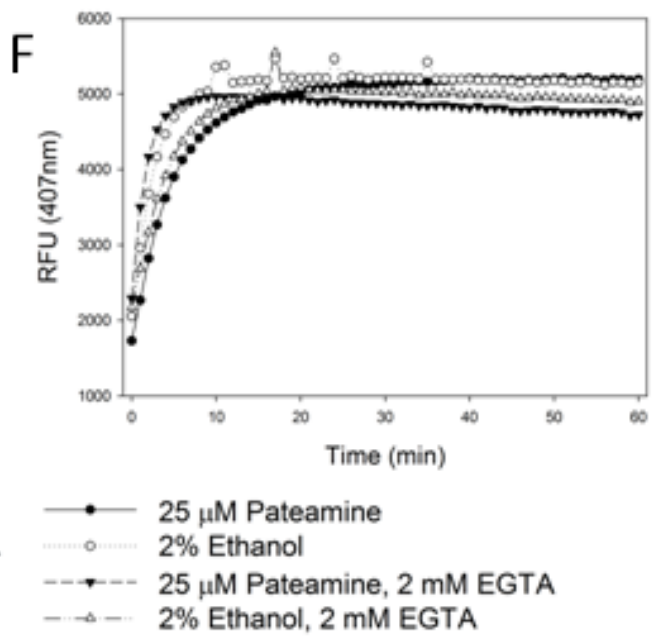

Figure 2.8 In vitro microfilament polymerization assay. Pyrene labeled rabbit $\alpha$-actin polymerization in the stated conditions was monitored by fluorescence, $2 \%$ ethanol was used as a carrier control. A. Standard assay conditions. B. 0.5x actin assay. C. $0.25 x$ polymerization buffer assay. D. ATP re-supplementation assay. E. $\mathrm{Mg}^{2+}$ re-supplementation assay. F. EGTA addition assay 


\subsubsection{Pateamine does not specifically disrupt cell cycle progression}

Given the well established roles of both the actin microfilaments and tubulin microtubules in mitosis (Lodish 2003), and the observation that drugs that target these proteins tend to cause a change in the distribution of cells across the cell cycle (Lopes, Miller et al. 1997; Usui, Kazami et al. 2004; Lee and Keng 2005), the effects of pateamine on cell cycle progression was carried out using flow cytometry. As Figure 2.9 shows, rather than an increase in the number of cells with $4 n$ DNA (corresponding to those cells at the $\mathrm{G}_{2} / \mathrm{M}$ phase transition), as would be expected with a compound that affects tubulin function (Hood, West et al. 2002), or an increase in the number of cell with $8 \mathrm{n}$ or 16n DNA (corresponding to cells unable to complete cytokinesis) as would be expected with a compound that inhibits actin function (Usui, Kazami et al. 2004), pateamine caused a statistically significant increase in the amount of small debris in the sub- $\mathrm{G}_{1}$ region (unpaired t-test, $\mathrm{P}<0.0003$ ), possibly corresponding to an increase in apoptotic bodies. Consistent with this result and previous literature (Hood, West et al. 2001), Figure 2.8 shows that $10 \mathrm{nM}$ pateamine is able to induce statistically significant caspase $3 / 7$ activation (unpaired t-test, $\mathrm{P}<0.0015$ ) and causes a statistically significant loss of phophatidyl serine asymmetry (unpaired t-test, $\mathrm{P}<0.003$ ) after $18 \mathrm{~h}$ exposure confirming that the increase in sub- $\mathrm{G}_{1}$ sized debris is due to the induction of apoptosis. Consistent with the role of caspase activation in the cytotoxicity of pateamine, co-treatment with the pan-caspase inhibitor z-VAD-FMK, alters the response of HeLa cells to pateamine treatment (Figure 2.11). Table 2.4 illustrates that simple $\mathrm{IC}_{50}$ values can be misleading. Whilst high concentrations of the pan-caspase inhibitor modestly lowers the $\mathrm{IC}_{50}$ value for pateamine, as might be expected, it is noticeable that this treatment with z-VAD-FMK results in a significant increase in the level of survival relative to control at high pateamine concentrations, denoted by the minimum value in Table 2.3. Thus unexpectedly, it can be seen that the pan-caspase inhibitor actually provides significant protection against pateamine. The inhibitory effect on the maximum response in the presence of the $50 \mu \mathrm{M} \mathrm{z-VAD-FMK}$ 
suggests decreased viability or MTT response (i.e. respiration) at this concentration of the pan-caspase inhibitor in the absence of pateamine.

HL 60 Cell Cycle Analysis

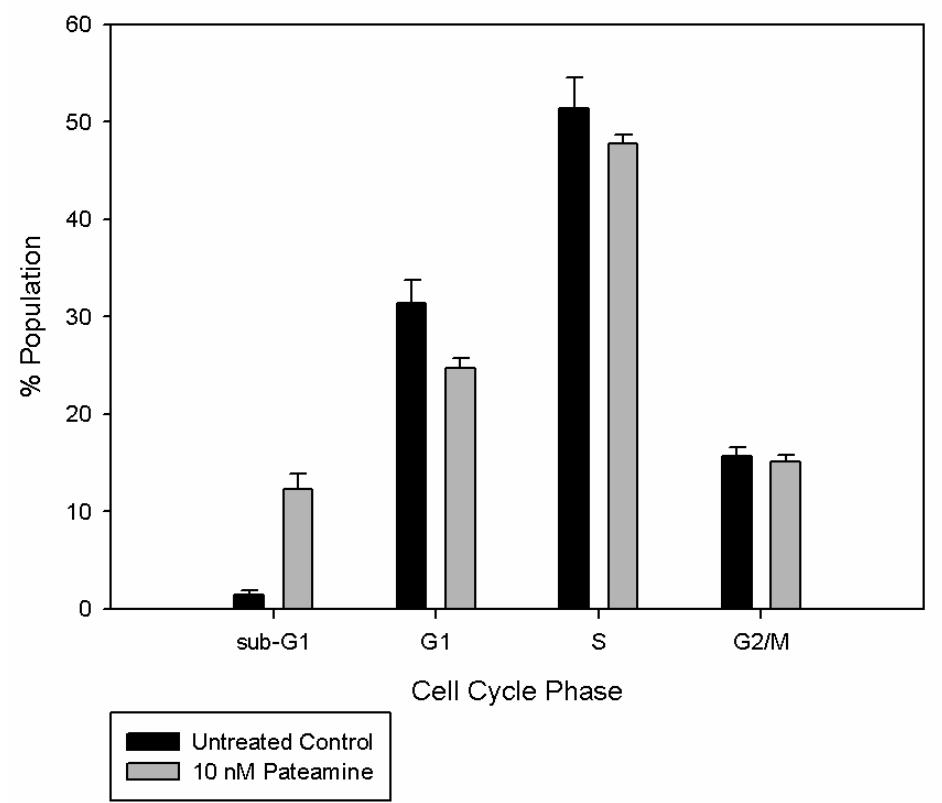

Figure 2.9 Cell cycle distribution in the presence of pateamine. HL-60 cells were treated for 18 h with $10 \mathrm{nM}$ pateamine in RPMI media supplemented with $10 \%$ FCS. Cells were washed, membranes permeabilized and DNA stained with propidium iodide. DNA content was measured by flow cytometry and the control cell samples were used to identify cell cycle stages. The increase in sub $G_{1}$ population is statistically significant ( $p<0.0003$, unpaired t-test) whilst the decrease in the $\mathrm{G}_{1}$ or $\mathrm{S}$ phase was not significant (Sheet 8, Supplementary File 1). 


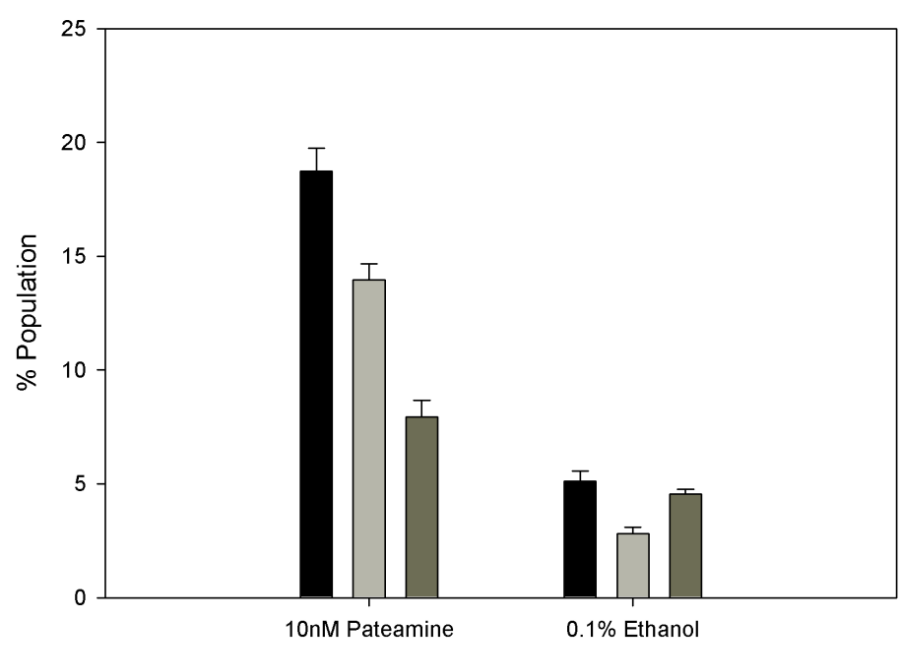

Caspase 3 Positive
$\square$ Caspase 3 Positive, PI Permeable
$\square$ PI Permeable

Annexin V Binding Assay

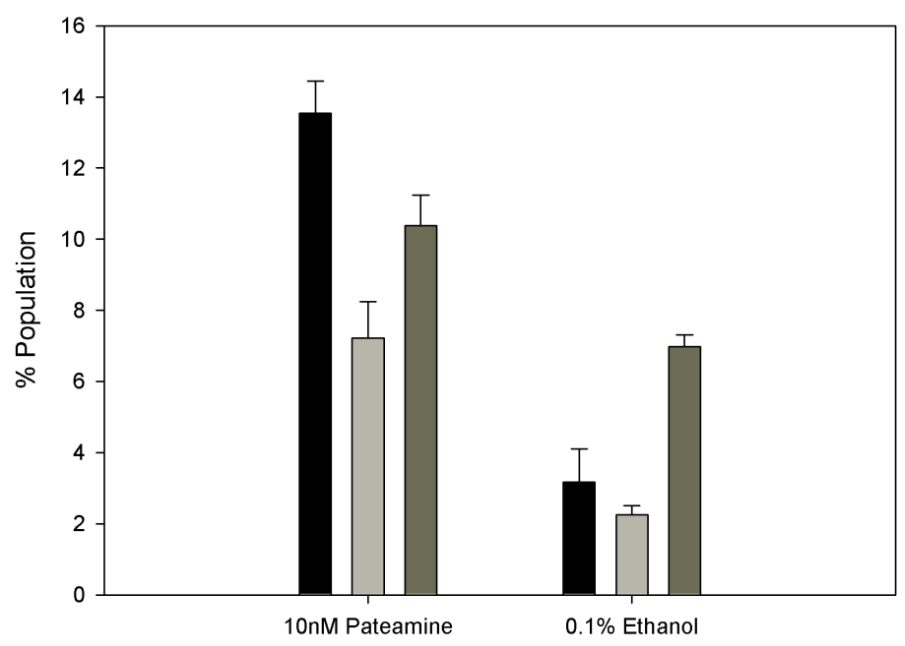

Annexin $V$ Positive

Annexin V Positive, PI Permeable

PI Permeable

Figure 2.10 Chronic exposure to pateamine activates caspase $3 / 7$ and causes a loss of phophatidyl serine asymmetry. HL-60 cells were treated for $18 \mathrm{~h}$ with $10 \mathrm{nM}$ pateamine in RPMI media supplemented with 10\% FCS then stained with propidium iodide (PI positive) and either: A. Caspase $3 / 7$ specific FLICA probe (Caspase $3 / 7$ positive); or B. FITC-Annexin $V$ conjugate (Annexin $\mathrm{V}$ positive). Flow cytometry was used to measure cellular fluorescence, $0.1 \%$ ethanol in RPMI media supplemented with 10\% FCS was used as a carrier control. Each of the three cell population labeled above was significantly enriched in the pateamine treated samples $(P<0.003$, unpaired t-test). Cells indicated as only PI permeable were negative for caspase 3 or annexin V. 


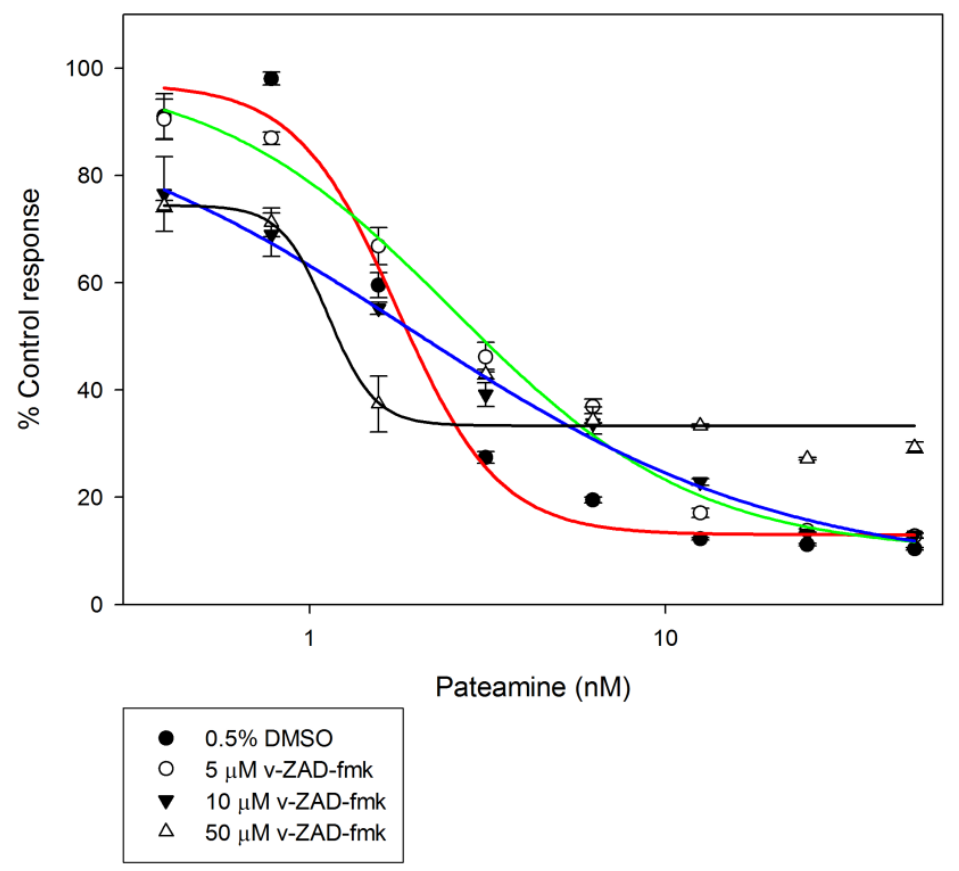

Figure 2.11 Pateamine dose-response in the presence of the pan-caspase inhibitor v-ZAD-FMK. HeLa cells, Red: 0.5\% DMSO as carrier control, Green: $5 \mu \mathrm{M}$ v-ZAD-fmk, Blue: $10 \mu \mathrm{M}$ z-VAD-FMK, Black: $50 \mu \mathrm{M}$ z-VAD-FMK.

\begin{tabular}{|l|l|l|l|l|}
\hline z-VAD-FMK $(\mu \mathrm{M})$ & 0 & 5 & 10 & 50 \\
& & & & \\
\hline Minimum value & $13.00 \pm$ & $9.74 \pm$ & $6.16 \pm$ & $33.36 \pm$ \\
& 1.65 & 3.11 & 7.20 & 1.54 \\
\hline Maximum value & $97.12 \pm$ & $99.90 \pm$ & $96.22 \pm$ & 74.44 \\
& 3.02 & 5.95 & 18.83 & \pm 3.50 \\
\hline IC $_{50}$ Value & $1.77 \pm$ & $2.54 \pm$ & $1.93 \pm$ & $1.13 \pm$ \\
& 0.10 & 0.33 & 0.88 & 0.16 \\
\hline
\end{tabular}

Table 2.3 Summary of curve parameters for Z-VAD-FMK inhibited MTT assays. 


\begin{tabular}{|l|l|}
\hline Pateamine $(\mathrm{nM})$ & P-value \\
\hline 50 & $5.53 \times 10^{-5}$ \\
\hline 25 & $1.58 \times 10^{-6}$ \\
\hline 12.5 & $5.66 \times 10^{-7}$ \\
\hline
\end{tabular}

Table 2.4 P-values for selected points in the pan caspase inhibited MTT assay (Figure 2.). An unpaired t-test was performed with each data point at each pateamine concentration in the $50 \mu \mathrm{M}$ z-VAD-FMK treated curves, relative to the untreated pateamine data point.

\subsubsection{Pateamine cytotoxicity is irreversible}

Following observations that the inhibitory effect of pateamine on protein synthesis was irreversible (Bordeleau, Matthews et al. 2005), as is the formation of stress granules (Dang, Kedersha et al. 2006), the reversibility of pateamine induced cytotoxicity was investigated. As seen in Figure 2.12, a short exposure of $15 \mathrm{~min}$ to $100 \mathrm{nM}$ pateamine is enough to cause more than $60 \%$ cytotoxicity after $11 \mathrm{~h}$ recovery, when this exposure time is increased to $30 \mathrm{~min}$ the MTT response is indistinguishable from constant exposure for $11.5 \mathrm{~h}$, as is exposure to $50 \mathrm{nM}$ pateamine for $2 \mathrm{~h}$. This suggests pateamine induced cytotoxicity is irreversible at concentrations comparable to those that irreversibly inhibit protein synthesis and induce stress granule formation. To establish whether this irreversibility is due to the rapid activation of caspase $3 / 7$ its activation kinetics to $1 \mu \mathrm{M}$ pateamine were established (Method 2.3.14). Figure 2.13 and Table 2.5 show that statically significant proportions of the $1 \mu \mathrm{M}$ pateamine treated population has active caspase $3 / 7$ after $2 \mathrm{~h}$ of exposure. 


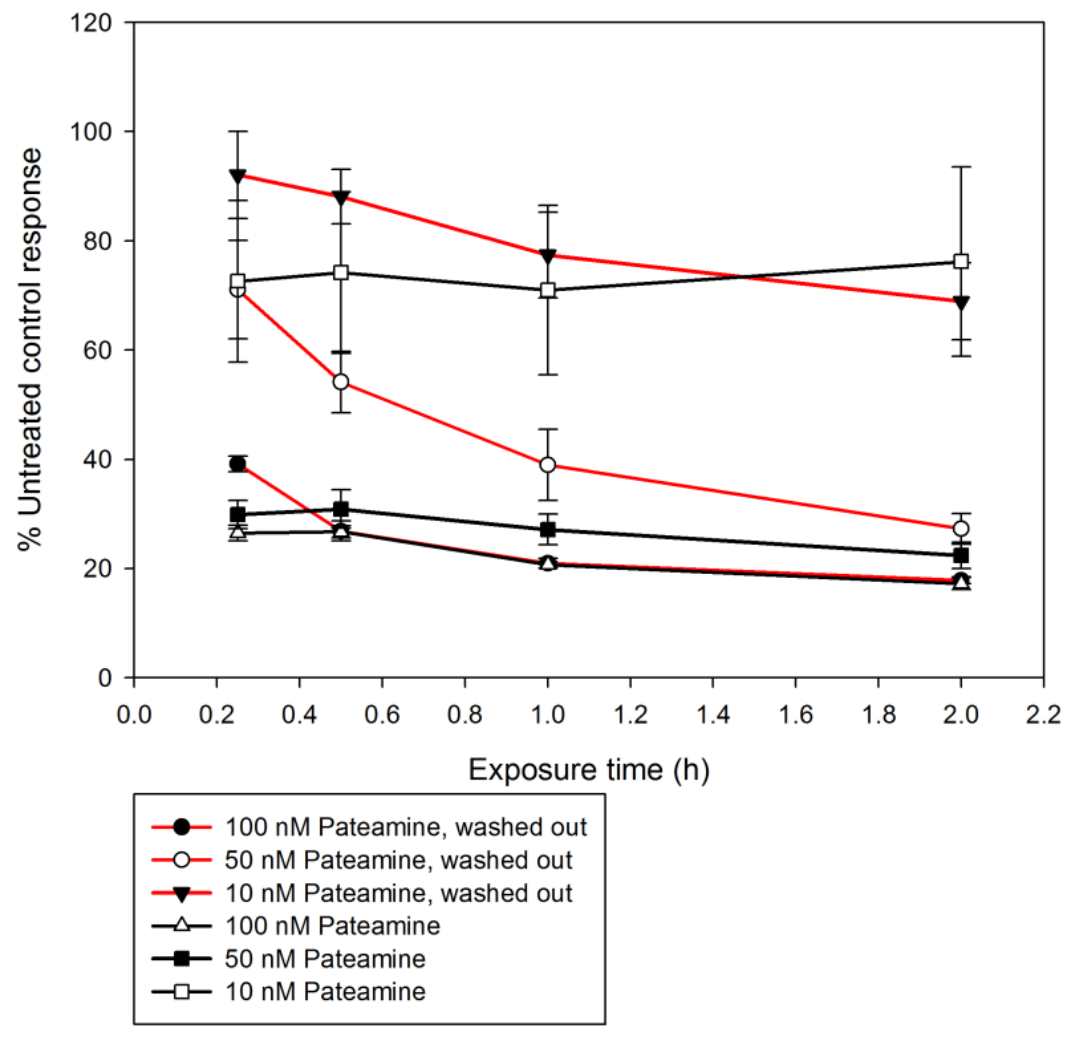

Figure 2.12 Pateamine withdrawal MTT assay. HeLa cells were exposed to pateamine for the indicated times and then removed, washed with warm media and allowed to recover for $10 \mathrm{~h}$ in fresh media (red lines) for or media containing the same concentration of pateamine as initially exposed to (black lines). MTT reagent was used to assess viability which is expressed relative to untreated control cell response. The assay was performed in triplicate three times, average data is presented and error bars correspond to compounded standard deviation across three independent experiments. 


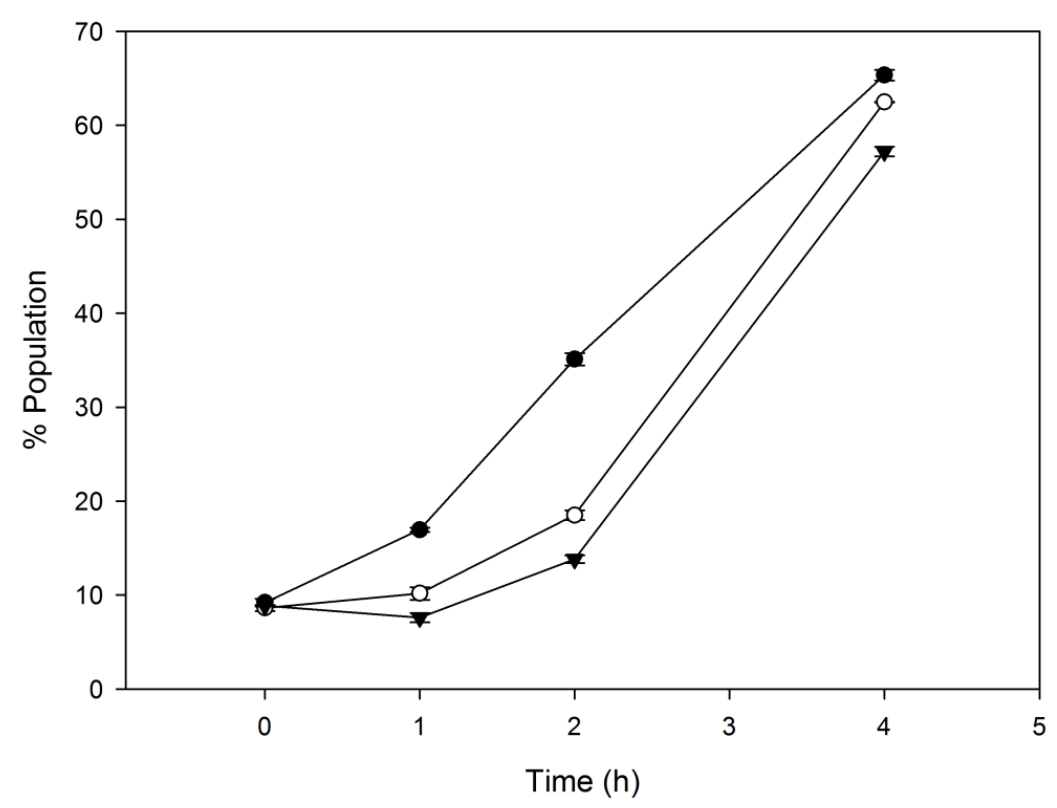

Figure 2.13 Activation kinetics of caspase $3 / 7$ by pateamine by flow cytometry. Performed in HeLa cells over four hours after treatment with $1 \mu \mathrm{M}$ pateamine, expressed as the percentage of the total treated population, cells with activated caspase $3 / 7$ were detected with the use of a fluorescent alkylating probe for caspase 3/7. The assay was performed in triplicate three times, average data is presented and error bars correspond to compounded standard deviation across three independent experiments, see Table for summary statistics.

\begin{tabular}{|l|l|l|l|l|}
\hline Time $(\mathrm{h})$ & 0 & 1 & 2 & 4 \\
\hline Mean $(\%)$ & 8.90 & 11.58 & 22.48 & 61.67 \\
\hline Standard Deviation & 0.36 & 4.21 & 9.69 & 3.59 \\
\hline P-value & & 0.07491 & 0.0007 & $<0.00001$ \\
\hline
\end{tabular}

Table 2.5 Summary of caspase 3/7 activation kinetics in HeLa cells. Measurements were taken over four hours after treatment with $1 \mu \mathrm{M}$ pateamine. Assay was performed by flow cytometry and a fluorescent alkylating probe for caspase $3 / 7$. The experiments were performed three times in triplicate, mean cell percentages with active caspase $3 / 7$ and standard deviations are shown, $\mathrm{P}$-values were assessed by means unpaired t-test with comparison to time $0 \mathrm{~h}$. 


\subsection{Discussion}

\subsubsection{Putative target proteins isolated from human cell lines}

Upon commencement of these experiments the nature of the cellular target of pateamine was unknown, given that the majority of drug targets are proteins it was reasoned that the target of pateamine would be also In order to isolate putative pateamine protein targets from whole cell lysates of HL-60, HeLa and SH-SY5Y cells, a pateamine derivatized affinity resin was generated using epoxy-activated Sepharose. The primary amine at C3 is the most reactive functional group on the molecule and several analogues derivatized at this position retain significant biological activity (Romo, Rzasa et al. 1998). This group and the methyl group at C5 are dispensable for activity (Romo, Choi et al. 2004), hence it was presumed that coupling to the affinity resin through the $\mathrm{C} 3$ amine group would not abrogate binding to potential targets. Proteins retained by the affinity resin were separated using LDS-PAGE and visualized after staining the gels with colloidal Coomassie. For reasons undetermined it was not possible to specifically elute bound proteins from the affinity resin with aqueous pateamine (Figure 2.4a), although non-selective binding of pateamine to protein surfaces at the high concentration tested could result in disrupted and variable association with dodecyl sulphate, leading to the lack of resolution observed. Thus the elution of both specific and non-specific binding proteins was achieved with LDS-PAGE loading buffer. A control resin consisting of the epoxy-activated Sepharose coupled with diethanolamine was used to determine non-specific protein retention by the solid phase. The HL-60, HeLa and SH-SY5Y cell lines were used in an attempt to control for non-specific binding to the solid phase that is specific to each cell line; these were used as they are all comparably sensitive to pateamine (Figure 2.1).

Consistent isolation of three proteins (Figure 2.3) not retained by the control resin from each of the three cell lines was achieved. While other, different bands are also visible in the 
pateamine resin lanes from each cell line they were generally at lower abundance, varied between experiments and often related to proteins found in the control lane. For example, the band prominent at approximately 55 and $60 \mathrm{kD}$ in panes $\mathrm{A}$ and $\mathrm{C}$ of Figure 2.3 are cytokeratin and a fragment of cytokeratin respectively. In each case, cytokeratin or a fragment of it was represented in the control resin. For this reason, only those that were retained from all three whole cell lysates were considered potential targets. Although elution with aqueous pateamine was not possible (Figure 2.4a), the binding of all three proteins to the pateamine affinity resin was prevented by the addition of pateamine to cell lysate prior to the affinity purification (Figure 2.4b) suggesting specific retention of all three. Proteins 1 and 3 were significantly reduced in abundance subsequent to the resin being subjected to a high salt wash (Figure 2.4c) which may suggest a lower affinity interaction than with protein 2 , or at least an interaction mediated predominantly by ionic interactions.

Peptide mass fingerprinting was used to identify proteins 1 - 3. Each protein was digested with trypsin and the masses of the resulting peptide fragments determined using MALDI-MS, these masses were used to search the NCBI database for potential hits. Except for protein 1 isolated from the SH-SY5Y whole cell lysate, significant hits for all three proteins from each cell lines were attained (Table 2.2). Protein 1 isolated from the HL-60 and HeLa whole cell lysates was identified as $\beta$-tubulin, protein 2 from all three cell lines was identified as eIF4A, and protein 3 from all three cell lines was identified as $\beta$ actin. Each of these proteins is highly expressed in the majority of cell types (Duncan and Hershey 1983; Nielsen and Trachsel 1988; Williams-Hill, Duncan et al. 1997; Luduena 1998; Lodish 2003), however there seems to be little sequence similarity between them though they all bind and hydrolyse ATP or GTP. 


\subsubsection{Protein 1 - $\beta$-tubulin}

Microtubules are a major cytoskeletal component present in all eukaryotic cells and are essential for chromosome separation during mitosis and vesicular trafficking during interphase. They consist predominantly of heterodimers comprised of tightly associated $\alpha$ and $\beta$-tubulin subunits arranged in a head-tail fashion into proto-filaments, a polymerized microtubule consists of 13 - 15 proto-filaments forming a tubular structure. The free $\alpha / \beta$-tubulin heterodimer bind two molecules of GTP one of which is hydrolyzed after incorporation into a microtubule (Nogales 2001). Microtubules are a common target for a number of cytotoxic compounds; the tubulin subunits were in part characterized due the ability to bind to radioactively labeled colchicine, a potent anti-inflammatory isolated from Colchicum autumnale, that destabilizes microtubules, and is cytotoxic to cultured cells (Borisy and Taylor 1967). More specifically the $\beta$-tubulin subunit is directly targeted by the vinca alkaloids, taxane and epothilone classes of compounds. These compounds, which include a number of well established clinical anti-neoplastic agents, alter the polymerization dynamics of microtubules, stabilizing or destabilizing the polymerized form (Jordan and Wilson 2004; Singh, Rathinasamy et al. 2008). A number of marine natural products have been found to alter microtubule polymerization. These include peloruside A, also isolated from the sponge Mycale hentscheli which is cytotoxic, stabilizes the polymerized form of microtubules both in vivo and in vitro and causes cell cycle arrest the at $\mathrm{G}_{2} / \mathrm{M}$ phase checkpoint (Hood, West et al. 2002).

Of the $14 \beta$-tubulin isoforms encoded by the human genome peptides from at least five we present in the mass spectra obtained from protein 1 from HeLa whole cell lysate (Appendix A). Pateamine appears to be able to promote bovine microtubule polymerization in vitro, albeit at a concentration approximately 100,000 fold higher than those required for cytotoxicity and with differing kinetics to that of taxol (Figure 2.5). Generally, microtubule 
stabilizing drugs that are cytotoxic at low nanomolar concentrations are effective in an in vitro assay tubulin polymerization assay at low micromolar concentrations (Jordan, Toso et al. 1993; Bollag, McQueney et al. 1995; Ter Haar, Kowalski et al. 1996; Hood, West et al. 2002; Pryor, O'Brate et al. 2002). Conversely a concentration of pateamine ten-fold lower than those observed to enhance microtubule polymerization seems to prevent polymerization in an analogous manner to colchicine (Figure 2.5). Dynamic microtubule function is required during mitosis; microtubules grow from the centriole to attach to the centromere of each chromosome facilitating equatorial alignment of each chromosome and the subsequent separation after the loss of sister chromatid cohesion. Subsequent to chromosome separation the microtubules must be depolymerized to allow the new nuclear envelope to form. Taxol and colchicines for instance, prevent progression through the $\mathrm{G}_{2} / \mathrm{M}$ phase checkpoint of the cell cycle to $\mathrm{G}_{1}$ phase and hence causing an increase in the number of cells containing 4n DNA, a hallmark of microtubule perturbing agents (Honore, Pasquier et al. 2005). Pateamine did not cause an increase in the number of HeLa cells with 4n DNA (Figure 2.9), instead an increase in the sub- $\mathrm{G}_{1}$ population was observed. Which, given the increase in the number of cells that stain positive with Annexin $\mathrm{V}$ and have active caspase 3/7 (Figure 2.10), both indicators of apoptosis (Strasser, O'Connor et al. 2000), can be presumed to be cellular debris or apoptotic bodies resulting from the induction of apoptosis rather than a specific cell cycle effect.

This absence of a subset of cells blocked at the $G_{2} / M$ checkpoint indicates that, whilst alteration of microtubule dynamics is a potential mode of action of pateamine and occurs at a concentration equivalent to that of colchicine, it is unlikely to be pateamine's primary mode of action. The observed apoptosis in the absence of significant changes in the ratios of $\mathrm{G}_{1}, \mathrm{~S}$ and $\mathrm{G}_{2} / \mathrm{M}$ cell populations indicates an alternative primary mode of action. 


\subsubsection{Protein 2 - eIF4A}

Members of the eIF4A (eukaryotic initiation factor 4A) family are ATP-dependent, RNA helicases (Grifo, Tahara et al. 1983) and are the archetypal DEAD-box helicase. These, and the related DEXD/H box family members are characterized by seven highly conserved amino acid motifs that have been implicated in their RNA remodeling role (Linder 2006). There are three members of the eIF4A family in humans: eIF4AI and eIF4AII show $90-95 \%$ amino acid similarity and are both cytoplasmically localized and are involved in translation initiation as a part of the eIF4F complex (Grifo, Tahara et al. 1983; Yoder-Hill, Pause et al. 1993); eIF4AIII is approximately $70 \%$ similar to eIF4AI, is a nucleocytoplasmic shuttling protein and does not compensate for the loss of eIF4AI in an in vitro translation system but is required for non-sense mediated mRNA decay (NMD) as a part of the exon-junction complex (EJC) (Li, Imataka et al. 1999; Chan, Dostie et al. 2004; Ferraiuolo, Lee et al. 2004; Palacios, Gatfield et al. 2004; Shibuya, Tange et al. 2004).

The recruitment of the ribosome to the newly exported mRNA transcript is the rate limiting step in protein synthesis and represents a major point of post-transcriptional regulation. In eukaryotes there are two major pathways of translation initiation: Cap-dependent and internal ribosome entry site-mediated initiation. In cap-dependent initiation, in which the 5 7-methyl guanine cap structure of the mRNA transcript is first bound by the eIF4F complex. eIF4F is comprised of: eIF4E, which bind directly to the cap structure; eIF4G which acts a scaffolding proteins binding eIF4E, the mRNA transcript and eIF3 (Sonenberg, B. et al. 2000). The eIF4G protein also recruits eIF4AI/II (hereon referred to as eIF4AI). With the help of eIF4B and eIF4H, eIF4AI prepares the transcript for ribosome scanning by removing secondary structure in the 5 -UTR immediately proximal to the cap. Both free eIF4A and eIF4F are required for cap-dependent translation initiation, and it is 
thought that eIF4A cycles through the eIF4F complex as RNA unwinding occurs (Ray, Lawson et al. 1985; Pause, Methot et al. 1994; Svitkin, Pause et al. 2001). In contrast, internal ribosome entry site (IRES) mediated translation initiation occurs in a fashion that is independent of the 5 cap structure (Sonenberg, B. et al. 2000). Different IRES elements have differing requirements for the aforementioned initiation factors, for instance initiation at the hepatitis $\mathrm{C}$ virus (HCV) IRES is not dependant on eIF4AI activity, whereas at the encephalomyocarditis virus IRES it is dependent on both eIF4G and eIF4AI (Pestova, Shatsky et al. 1998).

The mass spectrum acquired for protein band 2 identified as eIF4AI showed the presence of peptides that were unique to all three eIF4A isoforms (Figures 2.5 and 2.6), the retention of eIF4AI and eIF4III by the pateamine affinity resin was confirmed by Western blot (Bordeleau, Matthews et al. 2005). Protein band 2 was less affected by the high salt washing during the affinity isolation suggesting a more stable interaction with the resin than protein bands 1 and 3 (Figure 2.4). Consistent with the notion of eIF4AI as a cellular target of pateamine was its identification in a high throughput screen for translation (Novac, Guenier et al. 2004). A bicistronic mRNA transcript was prepared in vitro bearing firefly and renilla luciferase whose translation is dependent on the 5 7-methyl guanine cap or the HCV IRES respectively. This was used in an in vitro translation extract as a multiplexed assay used to screen for compounds that act as initiation specific and general translation inhibitors.

Further work showed pateamine as able to rapidly inhibit protein synthesis in HeLa cells with an $\mathrm{IC}_{50}$ of $5 \mathrm{nM}$ and prevented the formation of the $48 \mathrm{~S}$ pre-initiation complex and subsequent polysomes, suggesting cellular targeting of eIF4AI. In vitro, pateamine was 
shown to stimulate the ATP binding and ATP hydrolytic activity of purified murine eIF4AI in an RNA dependent manner, and RNA binding was stimulated even in the absence of ATP. Furthermore, the RNA and ATP binding abilities of the eIF4F complex were not perturbed by pateamine. The helicase activity of eIF4AI in the presence of pateamine was also stimulated in a manner dependant on ATP. It seems this effect is specific to the eIF4A family of proteins as the closely related DEAD-box helicase Ded1p from S. cerevisiae (Struhl 1985) is not stimulated by pateamine.

Additionally, pateamine has no effect in an in vitro splicing assay, further evidence of eIF4A specificity as splicing involves between 7 and 13 DEXD/H box helicases (Bordeleau, Matthews et al. 2005; Linder 2006). Using a biotinylated pateamine derivative and streptavidin beads Low et al. confirmed the ability for pateamine to purify eIF4AI from HeLa whole cell lysate, as well as confirming the inhibitory effect on protein synthesis and polysome formation, and the stimulatory effects on the purified protein previously noted. They also noted that over-expression of eIF4AI in HeLa cells led to a modest but significant increase in resistance to pateamine in a cellular proliferation assay, and that pateamine treatment caused the aggregation of eIF4AI into stress granules, both suggestive of cellular targeting of at least eIF4AI by pateamine (Low, Dang et al. 2005).

Additional to the western blot analysis of the eluate of from the pateamine resin that showed the presence of eIF4AIII (Bordeleau, Matthews et al. 2005), biotinylated pateamine was also shown to interact with eIF4AIII (Dang, Low et al. 2009) and its ATPase activity is also stimulated the desamino- desmethyl- analogue of pateamine (Low, Dang et al. 2007). In vivo $0.5-1 \mu \mathrm{M}$ pateamine is able inhibit NMD through stabilization of the interaction between the EJC and mRNA, which inhibits the degradation of a premature 
termination codon (PTC) containing transcript. The inhibitory effect on NMD is independent of the effect of pateamine on translation initiation (Dang, Low et al. 2009). The NMD pathway functions to degrade mRNA transcripts that contain a PTC more than 50-55 nucleotides upstream of the final exon-exon junction. Translation of these transcripts may lead to the production of a truncated, partially or completely non-functional, protein product. A PTC can be present in a transcript due to non-sense or frame-shift mutations, or because of errors during transcription or splicing (Sonenberg, B. et al. 2000).

After an intron is removed from a transcript the EJC is deposited on the resulting exon-exon junction. This complex is dynamic in nature, its core components in mammals are eIF4AIII, Y14, Magoh and MLN51 (Le Hir, Izaurralde et al. 2000; Le Hir, Gatfield et al. 2001). The role of eIF4AIII in the EJC is to mediate the interaction between the transcript and the rest of the EJC components, the interaction with MLN51 inhibits its ATPase activity fixing it to the exon-exon junction (Bono, Ebert et al. 2006). In this way, eIF4AIII functions in a distinctly different manner to eIF4AI, which hydrolyses ATP in order to unwind RNA. The exact mechanism by which a PTC containing transcript is detected and marked for degradation has not been fully elucidated but it involves the recruitment of the proteins Upf1-3 (Tange, Nott et al. 2004) to the EJC and functioning ribosomes (Carter, Doskow et al. 1995), suggesting that detection occurs during the pioneer round of translation. Knockdown of eIF4AIII by siRNA inhibits the degradation of a PTC containing transcript by preventing the deposition of the EJC on the exon-exon junction (Ferraiuolo, Lee et al. 2004). Pateamine most likely inhibits NMD by preventing the removal or dissolution of the EJC complex during the pioneer round of translation (Dang, Low et al. 2009). 
Although it seems pateamine is the first compound characterized to specifically inhibit NMD, hippuristanol, a polyhydroxysteroid isolated from the coral Isis hippuri, and resveratrol have also been shown to target eIF4AI and cap-dependent protein synthesis (Bordeleau, Mori et al. 2006; Lomenick, Hao et al. 2009). Although it is not clear whether eIF4AIII and NMD are also affected, these compounds are also, albeit weakly, cytotoxic. A considerable number of other inhibitors of protein synthesis have been discovered, as discussed in section 1.3.

These compounds are typically toxic to cultured cell lines, for instance: cycloheximide binds to the translocating ribosome during polypeptide elongation causing it to stall (Alessenko, Boikov et al. 1997; Lemaire, Andreau et al. 1999; Tang, Lahti et al. 1999; Kageyama, Kusano et al. 2002); puromycin which binds to the A-site on the 80 S ribosome and causes premature polypeptide termination (Carter, Doskow et al. 1995); anisomycin inhibits the peptidyl transferase activity of the 80S ribosome (Grollman 1967; Kageyama, Kusano et al. 2002). Didemnin B on the other hand has been shown to inhibit polypeptide elongation by inhibiting elongation factor $1 \alpha(\mathrm{EF} 1 \alpha)$ (Sir Deshpande and Toogood 1995; Baker, Grubb et al. 2002), and reveromycin A targets isoleucyl tRNA synthetase inducing apoptosis in osteoclasts (Woo, Kato et al. 1999). Despite the fact protein synthesis inhibition is a verified mode of inducing apoptosis, the simultaneous siRNA mediated knockdown of eIF4AI and eIF4AII does not appear to have a significant effect on viability HeLa cells over $48 \mathrm{~h}$, perhaps due to the existence of IRES controlled anti-apoptotic proteins (Holcik and Korneluk 2000; Miyamoto, Machida et al. 2002; Van Eden, Byrd et al. 2004), whereas an $85 \%$ reduction in eIF4AIII by siRNA appears to reduce cell number over (Ferraiuolo, Lee et al. 2004). 


\subsubsection{Protein 3 - $\beta$-actin}

A ubiquitous cytoskeletal protein, $\beta$-actin, is one of 6 isoforms of actin found in humans, it polymerizes to form filamentous structures known as microfilaments, which provides the plasma membrane with structural integrity, facilitate cytoplasmic membrane bound vesicular transport and fulfills an essential role in cytokinesis and cell migration and motility (Fenteany and Zhu 2003; Rao and Li 2004). Microfilaments are targeted by a number of cytotoxic agents, for instance the latrunculins were originally isolated from the sea sponge Latrunculia rnagnifca and are potent destabilizers of microfilament polymerization and induce apoptosis (Spector, Shochet et al. 1983; Martin and Leder 2001). Jasplakinolide, from the marine sponge Jaspis Johnston also, stabilizes microfilaments in vitro and is also cytotoxic (Bubb, Senderowicz et al. 1994; Odaka, Sanders et al. 2000).

In vitro microfilaments undergo polarized growth, the addition of actin monomers onto the plus or barbed end is favored over addition to the minus or pointed end, concomitant with polymerization is the hydrolysis of ATP and the slow release of Pi and ADP. Polymerization can be induced in vitro with the addition of hypertonic buffer and ATP, however, the rate of polymerization is particularly sensitive to the presence of divalent cations, particularly $\mathrm{Mg}^{2+}$ and $\mathrm{Ca}^{2+}$ (Gordon, Boyer et al. 1977; Estes, Selden et al. 1992).

Pateamine seems to decrease the initial rate of polymerization in a dose dependant manner that is dependent on the composition of the buffer in which the assay is performed (Figure 2.8). Although reducing the concentration of the polymerization buffer seems to exacerbate the inhibitory effect of pateamine (Figure 2.8c) this can be most likely be attributed to the combined effect of reducing the tonicity of the buffer and the mild effect of pateamine, 
rather than a synergistic interaction between the way in which the two affect polymerization. The apparent amelioration by EGTA may suggest $\mathrm{Ca}^{2+}$ bound actin is more sensitive to pateamine inhibition, but given $\mathrm{Ca}^{2+}$ is tightly regulated within the cytoplasm $\mathrm{Mg}^{2+}$ bound actin is likely to be the predominant species present.

While the effect on microfilament polymerization of pateamine occurs at a concentration lower than the effects on microtubule polymerization this still occurs at a concentration that is 50,000 fold higher than those required for apoptosis induction. Generally actin targeting compounds are effective at sub-micromolar concentrations in in vitro polymerization assays and cytotoxic in the low nanomolar range (Spector, Shochet et al. 1983; Coue, Brenner et al. 1987; Bubb, Senderowicz et al. 1994; Martin and Leder 2001).

This discrepancy in effective concentration between in vitro and in vivo drug activities is not an uncommon phenomenon and can be rationalized by taking the following into account: 1 . The difference in the nature of each of the assays: the actin polymerization assay directly measures an effect on microfilaments, that is the drug target itself, whereas a cellular viability assay measures the cells response, in viability terms, on exposure to a drug, this is a biological phenomenon that involves multiple pathways or processes and hence takes longer to manifest but is also subject to amplification. 2. Intracellular accumulation of the drug: Due to an overall negative plasma membrane potential (Okada, Ogawa et al. 1973) most cells accumulate cationic drug, such as pateamine, this has been shown to influence the intracellular concentrations of charged dyes (Farkas, Wei et al. 1989), doxorubicin (Robinson and Roepe 1996) and 2- $N$-methyl-ellipticinium (Charcosset, Jacquemin-Sablon et al. 1984). 
However, it can be presumed that regardless of cellular potential drug will accumulate due to the sequestering effect of being bound by the their targets, this would be particularly true for compounds that form a covalent bond with their target. The net results is that the intracellular concentrations, and hence the concentration around the target, of most drugs will exceed that of the surrounding media. Although the concentration required for in vitro effects on microfilament polymerization are 50,000-fold higher than those required for cytotoxicity over $24 \mathrm{~h}$, only 1,000 - 10,000-fold of this difference can be attributed to the expected difference between in vivo and in vitro activities. Therefore the effect on actin can be estimated to be occurring at a concentration of pateamine around 50- to 500-fold above that required for apoptosis, a proposition that could be assessed by visualization by fluorescence of the actin cytoskeletal following a treatment of a high concentration of pateamine, and the kinetics of any affect observed related to the kinetics of the induction of caspase activity and therefore the induction of apoptosis to ensure that the effect observed preceded this.

\subsubsection{Irreversibility of pateamine-induced cytotoxicity}

The irreversible nature of pateamine-induced protein synthesis inhibition (Bordeleau, Matthews et al. 2005) can be explained in two ways: 1. Pateamine binds covalently or with exceptionally high affinity to eIF4AI/II; 2. Pateamine rapidly induces apoptosis. This work has shown that a short time exposure to pateamine is also able to irreversibly induce cytotoxicity, presumably via the induction of apoptosis, it has also shown that pateamine treatment activated caspase 3 and that inhibition of caspase activation by the treatment with z-VAD-FMK somewhat prevents pateamine induced cell death. It has previously been shown that activated caspase 3 is able to cleave the translation initiation factors eIF4GII and eIF $2 \alpha$ and this, at least in part contributes to the inhibition of translation initiation after the induction of apoptosis (Marissen and Lloyd 1998; Marissen, Gradi et al. 2000; 
Marissen, Guo et al. 2000), therefore it is possible protein synthesis is irreversibly inhibited by pateamine through the induction of caspase 3, which then cleaves other initiation factors, preventing recovery of translation. However, only 15-30 min is required for the irreversible induction of cell death, and significant caspase 3 activity is only observed after $1 \mathrm{~h}$ of exposure to pateamine which suggests it is not responsible for the observed effect on protein synthesis, although this does not exclude the possibility of a mechanism that precedes caspase 3 activation acting on translation initiation, which also causes a commitment to apoptosis.

The alternative hypothesis regarding a high affinity or covalent interaction between pateamine and eIF4AI/II is supported by the observation that it was difficult to elute eIF4A from the affinity resin by means other than the application of completely denaturing and reducing conditions. The requirements for reducing conditions combined with the presence of a possible point of Michael addition in pateamine, and the presence of a conserved cysteine in pateamine-sensitive eIF4As that is not present in the pateamine-insensitive Ded1p, and is in close in proximity to an area of significant movement in eIF4AIII upon RNA binding and the fact that RNA is required for the binding of pateamine to eIF4A (Low, Dang et al. 2007) all circumstantially suggests that eIF4A may form a covalent complex with pateamine. While this is speculation, the characterization of the eIF4A-pateamine adduct should be easily amenable to identification by mass spectrometry.

\subsubsection{Mammalian pateamine targets}

Other than eIF4AIII, all of the putative protein targets identified by pateamine affinity chromatography are known targets of cytotoxic compound or involved in pathways targeted by toxic compound, however, the most likely relevant target for pateamine in 
mammalian cells is the eIF4A family of proteins. Although it has been shown here that $\beta$-tubulin and $\beta$-actin are able to interact with the pateamine affinity resin, and seem to be affected in their ability to polymerize in the presence of soluble pateamine in vitro, it is unlikely they are targeted at concentrations comparable to the $24 \mathrm{~h} \mathrm{IC}_{50}$ value for a number of reasons. First, the concentration required to affect microtubule or microfilament polymerization in vitro are 10,000-10,000 fold greater than those that are cytotoxic, a discrepancy not seen with compounds that have been verified to affect these structures such as taxol and latrunculin. Second, a cellular phenotype, such as cell cycle blockage, specific for targeting of either actin or tubulin was not observed in the presence of pateamine. Third, the interaction between eIF4AI/II/III and the pateamine affinity resin was less prone than that of $\beta$-tubulin and $\beta$-actin to disruption by a high concentration of salt, though it must be noted that if the interaction between eIF4A and pateamine is due to hydrophobic interactions the high salt wash would increase the observed stability of interaction.

Even though eIF4A function has been perturbed in vitro at low micromolar concentrations of pateamine, approximately 1,000 fold greater than the cytotoxic concentration, total protein synthesis and the translation of a cap-dependent reporter gene are significantly inhibited at a concentration directly comparable to the $24 \mathrm{~h} \mathrm{IC}_{50}$ value for cytotoxicity (Bordeleau, Matthews et al. 2005; Low, Dang et al. 2005), at this concentration (5 - 10 $\mathrm{nM}$ ) microfilament and microtubule function are unlikely to be affected appreciably. What is less clear is whether the inhibition of both cap-dependent protein synthesis and nonsense mediated decay is required for the induction of apoptosis by pateamine, given the latter is only inhibited at higher concentrations. 


\subsection{Conclusions}

Putative cellular targets of pateamine belonging to the eIF4A family of proteins, and the cytoskeletal components $\beta$-tubulin and actin were isolated by affinity chromatography and identified with peptide mass-fingerprinting. The results of the in vitro microfilament and microtubule polymerization assays suggest these structures are not targeted at concentrations of pateamine that induce apoptosis over a two to four hour time period, though actin polymerization might be affected at concentrations much higher than this. In comparison the evidence, both in vitro and in vivo, regarding the specific action of pateamine on translation initiation through perturbation of eIF4A strongly implicates it as the primary target responsible for the induction of apoptosis. This proposition is further assessed in future chapters using the model organism Saccharomyces cerevisiae. 


\section{The generation and characterization of pateamine resistant yeast}

\subsection{Introduction}

The generation and characterization of drug resistant mutants has been used in a number of cases to determine the target and mode-of-action of bioactive compounds in numerous organisms. The first drug resistant $S$. cerevisiae mutant reported in the literature was raised against the protein synthesis inhibitor cycloheximide, to which resistance was determined by a single dominant mutation (Middlekauff, Hino et al. 1957). Following this, a further five resistance conferring mutations were reported, where these ranged from completely recessive, semi-dominant and completely dominant mutations (Wilkie and Lee 1965). The motivation behind these studies was not to determine the target of the compound but rather the mode of resistance conferred by the mutations. Technology at the time allowed a relatively crude mapping procedure based on linkage disequilibrium with a small number of genetic markers. It was later found that the ribosomes isolated from the recessive cycloheximide resistant mutant were able to confer resistance to cycloheximide in an in vitro protein synthesis assay, whereas the extracts made from the semi-dominant mutants showed the same in vitro sensitivity to cycloheximide (Cooper, Banthorp et al. 1967).

In the case of cycloheximide it was well established that the ribosome was the target for a number of years before the exact nature of the drug resistance conferring mutations within the ribosome was determined. As would be expected for a compound that targets a large multi-subunit protein complex, such as the ribosome, mutations in a number of these subunits conferred cycloheximide resistance that have been shown to be recessive or semi-dominant in nature (Sutton, Ares et al. 1978; Stocklein and Piepersberg 1980; Stocklein, Piepersberg et al. 1981; Fried and Warner 1982; Kaaufer, Fried et al. 1983). 
Following studies with cycloheximide in S. cerevisiae the same approach was used to generate mutants resistant to a number of small molecule inhibitors including: caffeine and nicotine (Lindegren, Lindegren et al. 1959); nystatin (Ahmed and Woods 1967); oligomycin (Wakabaya.K and Gunge 1970); aminopyrazolo-(3,4-d)-pyrimidine (Pickerin and Woods 1973); cryptopteurine (Grant, Sanchez et al. 1974); anisomycin (Jimenez, Sanchez et al. 1975); trichodermin (Grant, Schindler et al. 1976); axenomycin (Sora, Ciferri et al. 1980); edeine (Herrera, Franceschi et al. 1986). In a number of cases these resistant mutants were integral in the determination of the targets of these compounds.

While it is easy to generate a drug-resistant mutant, the challenge remained to identify the exact gene in which it occurred and the nature of the mutation, with respect to whether it occurs in the target encoding gene or a one that alters the response of the cell to the drug. In the case of cycloheximide, the first molecular identification of a protein potentially containing a resistance conferring mutation was achieved by comparison of ribosomes purified from a resistant mutant and from a wild-type strain by two-dimensional SDS-PAGE (Stocklein and Piepersberg 1980). The resulting amino acid substitution was identified by tryptic digest and peptide sequencing fragments differing from the wild-type protein (Stocklein, Piepersberg et al. 1981), the gene encoding this protein was subsequently cloned with the use of a cosmid clone bank (Fried and Warner 1982).

With the advent of modern molecular biological techniques including gene cloning, DNA sequencing and PCR, the ability to map and characterize drug resistance conferring mutations has increased markedly. In the case of cycloheximide, the best part of 25 years was required to identify the genetic basis of mutations conferring resistance to it, in the last decade this has been reduced, in some cases, to a matter of months. A common procedure 
used to identify the gene bearing the resistance mutation involves producing a plasmid-borne genomic library from the resistant mutant (Fried and Warner 1981). This is transformed into the parental strain the resistant mutant was derived from, and the selection of the fragment containing the resistance conferring mutation is carried out using a high concentration of the drug. This fragment can then be sequenced to determine the position of the mutation.

In this way, it was shown trichodermin and curvularol inhibit protein synthesis by targeting the large ribosome subunit, Rpl3p specifically (Fried and Warner 1981; Kobayashi, Mizunuma et al. 2006), whereas reveromycin does so by inhibiting isoleucyl-tRNA transferase (Miyamoto, Machida et al. 2002), and GM193663 by targeting eukaryotic elongation factor 2 (Capa, Mendoza et al. 1998); also NKH-7 was shown to affect cell cycle progression by targeting $\alpha$-tubulin (Chanklan, Mizunuma et al. 2008). However, in order to recover the mutation bearing vector from the genomic library the mutation must be dominant or at least semi-dominant. Ho et al. have developed a method to identify recessive drug-resistance conferring mutations using a molecular barcoded yeast ORF library and a microarray based growth assay. In this assay, a drug resistant mutant is transformed with a library of plasmids containing the native ORFs, each ORF bearing plasmid is marker with unique DNA barcodes. In the case of a recessive drug resistant mutant the transformant that has received the wild-type copy of the drug resistance genes will not grow in the presence of the drug, and once identified using the barcode and an oligo-nucleotide microarray, the mutant gene is cloned and sequenced (Ho, Magtanong et al. 2009). 
While it is relatively easy these days to identify drug resistance conferring mutations, it is more challenging to identify a drug-target gene purely on this basis, in most cases there are many ways to become resistant to a bioactive compound. While it makes intuitive sense that a mutation that prevents the drug binding to its target will be dominant, this is not always the case. The dominant or recessive nature of the mutant allele is likely dependent on a number of factors, including the mechanism by which the compound affects its target function, the nature of the target function, and the consequence of the mutation with respect to drug binding and functional perturbation of the target.

Drug resistant mutants can be categorized broadly into three groups, those that occur in: drug target genes; drug efflux pumps or the transcription factors that control them; or genes related to the response of the cell to the inhibition of the target. For instance cycloheximide resistance conferring mutations have been found in ribosomal genes mentioned above, genes that control drug efflux pump expression (Keeven, Ko et al. 2002) and numerous protease components (McCusker and Haber 1988; McCusker and Haber 1988; Gerlinger, Guckel et al. 1997). While the proteasome is not directly targeted by cycloheximide, the short half-life of ubiquitin means protein synthesis inhibition significantly decreases the pool of ubiquitin available for ligation (Hanna, Leggett et al. 2003). As such, the proteasome component mutations were resistant to the compound because they increased the ubiquitin pool by preventing its degradation by the proteasome.

Another example is rapamycin, an immunosuppressant cyclic peptide which first binds to FK506 binding protein 12 (FKBP12), this complex then binds to and inhibits Tor1p and Tor2p as a part of the TOR1C complex. Rapamycin mimics amino acid deprivation, which also inhibits the TOR1C, and prevents exit from $\mathrm{G}_{1}$ phase of the cell cycle (Crespo and 
Hall 2002). Resistance conferring mutations in the FPR1 gene, which encodes FKBP12, are often recessive, whereas numerous mutation have been found in TOR 1 and TOR 2 that are recessive, dominant or temperature-sensitive semi-dominant (Heitman, Movva et al. 1991; Lorenz and Heitman 1995). On the other hand, only recessive resistant conferring mutations have been reported for the topoisomerase II inhibitor etoposide (Liu, Hsiung et al. 1994). This can be rationalized by the observation that etoposide requires the enzymatic activity of topoisomerase II to be toxic (Nitiss and Beck 1996), any wild-type protein present will be able to cause toxicity. In the cases of drug resistance conferring mutants in the literature there is no correlation between the dominance or recessiveness of the mutant and the nature of the gene with respect to being the drug target. The determination of the dominant-recessive nature of the drug resistant allele can provide vital information necessary for the mapping of the mutation, and as seen in the above examples, can often be rationalized when more details of the drug mechanism of action are known, unfortunately this knowledge alone does not allow the distinction between target and non-target conferring mutations when multiple loci are found to confer resistance.

To avoid the generation of a resistant clone because of increased drug efflux, a number of the previously mentioned studies used yeast strains that have, at times multiple, genes deleted that result in hypersensitivity to most drugs. For example, the pleiotropic drug resistance (PDR) genes which include a number of transmembrane pumps that are responsible for the removal of xenobiotics from the cytosol (Balzi and Goffeau 1995; Cui, Hirata et al. 1996). Without taking such steps, mutations can be found that cause existing pumps to export the drug more efficiently (Tutulan-Cunita, Mikoshi et al. 2005), or in transcription factors that control the expression of the pumps, Pdr1p for instance (McCusker and Haber 1988; Wendler, Bergler et al. 1997). These mutations are the least informative with respect to the target of the drug or its mechanism. The deletion of genes 
associated with ergosterol synthesis, which decreases the sterol content of the plasma membrane whilst increasing membrane fluidity and permeability, also sensitizes yeast to a number of bioactive compounds (Mukhopadhyay, Kohli et al. 2002; Abe and Hiraki 2009).

In addition to inducing apoptosis in mammalian cell lines, pateamine has also been shown to affect the growth of the fungi Trichophyton mentagrophytes, Cladosporium resinae and the yeast Candida albicans (Northcote, Blunt et al. 1991). Yet there is no reported inhibitory effects on any prokaryotic organism and no effect observed in an in vitro translation extract derived from E. coli cells (Bordeleau, Matthews et al. 2005). S. cerevisiae has orthologues of all of the genes that encode all of the proteins identified as being putative pateamine target in mammalian cells: Actin ( $\mathrm{Ng}$ and Abelson 1980), $\beta$-tubulin (Water and Kleinsmith 1976), and the eIF4A family proteins. Yeast eIF4A is encoded by two genes, TIF1 and TIF2, which, in contrast to human eIF4AI and II, differ only at six nucleotide positions but encode an identical polypeptide sequence (Linder and Slonimski 1988; Linder and Slonimski 1989). The closest yeast orthologue of eIF4AIII is Fallp, an essential gene integral for $40 \mathrm{~S}$ ribosomal subunit maturation (Kressler, de la Cruz et al. 1997). 


\subsection{Aims and objectives}

The aim of this study is to generate a pateamine resistant mutant and establish the genetic basis for this resistance. In order to generate a strongly resistant mutant, a sensitized starting strain from a collection of deletion mutants was chosen, mutagenized, and exposed to a high concentration of pateamine. As the most likely target for pateamine is eIF4A, the starting strain was one with a sensitizing deletion and the deletion of $T I F 2$, this was done to simplify the isolation of the eIF4A sequence at the TIF1 locus. Resistant clones were genotyped at the TIF1 locus and this sequence was cloned and re-introduced into the starting strain on a $2 \mu$ plasmid to verify pateamine resistance. 


\subsection{Materials and methods}

\subsubsection{Yeast strains}

All strains of $S$. cerevisiae used in this study were of the MATa mating type of the BY4741 background and have a genotype of his $3 \Delta 1$, leu $2 \Delta 0$, met $15 \Delta 0$ and ura3 $\Delta 0$. For this study the strain his $3 \Delta:: K a n R$ was used as a surrogate wild-type strain, replacement of the HIS3 gene with the kanamycin resistance cassette is presumed to be inconsequential since BY4741 is a histidine auxotroph. All deletion strains were purchased from Thermo Scientific-Open Biosystems (Huntsville, AL, USA) as a part of the YKO MATa Strain Collection (Winzeler, Shoemaker et al. 1999). The tif2 $\Delta:: N a t R$ pdr5 $\Delta:: K a n R$, tif $2 \Delta:: N a t R$ $\operatorname{erg} 2 \Delta:: K a n R$, tif $2 \Delta:: N a t R$ erg $3 \Delta:: K a n R$, tif $2 \Delta:: N a t R$ erg $5 \Delta:: K a n R$ and tif $2 \Delta:: N a t R$ $\operatorname{erg} 6 \Delta:: K a n R$, tif2 $\Delta:: N a t R$ his $3 \Delta:: K a n R$ double deletion strains were kindly supplied by Veronica Venturi (Chemical-genetics Laboratory, School of Biological Sciences, Victoria University of Wellington) and were constructed via the synthetic genetic array mass mating method (Tong and Boone 2006) using a MAT $\alpha$ query strain containing tif2 $\Delta:: N a t R$.

\subsubsection{Growth media}

All cultures were performed in the media below supplemented with G418 (Invitrogen, Carlsbad, CA) or G418 and clonNAT (Werner BioAgents, Jena, Germany). All yeast strains were cultured according to standard yeast methods (Amberg, Burke et al. 2005) in one of the following media:

YPD (1\% (w/v) yeast extract, $2 \%(\mathrm{w} / \mathrm{v})$ bacto-peptone, $2 \%(\mathrm{w} / \mathrm{v})$ glucose);

YPGal (1\% (w/v) yeast extract, 2\% (w/v) bacto-peptone, 2\% (w/v) galactose);

SC (synthetic complete media: $0.17 \%$ (w/v) Bacto-yeast nitrogen base (without amino acids or ammonium sulphate), $0.1 \%(\mathrm{w} / \mathrm{v})$ monosodium glutamate, $0.2 \%(\mathrm{w} / \mathrm{v})$ "amino 
acid mix" (3 g adenine, $2 \mathrm{~g}$ uracil, $2 \mathrm{~g}$ inositol, $0.2 \mathrm{~g}$ para-aminobenzoic acid, $2 \mathrm{~g}$ alanine, $2 \mathrm{~g}$ arginine, $2 \mathrm{~g}$ asparagine, $2 \mathrm{~g}$ aspartic acid, $2 \mathrm{~g}$ cycteine, $2 \mathrm{~g}$ glutamic acid, $2 \mathrm{~g}$ glutamine, $2 \mathrm{~g}$ glycine, $2 \mathrm{~g}$ histidine, $2 \mathrm{~g}$ isoleucine, $10 \mathrm{~g}$ leucine, $2 \mathrm{~g}$ lysine, $2 \mathrm{~g}$ methionine, $2 \mathrm{~g}$ phenyalanine, $2 \mathrm{~g}$ proline, $2 \mathrm{~g}$ serine, $2 \mathrm{~g}$ threonine, $2 \mathrm{~g}$ tyrosine, $2 \mathrm{~g}$ tryptophan, $2 \mathrm{~g}$ valine);

SD -Ura (synthetic dropout minus uracil; as with SC but without uracil in the "amino acid mix");

SD -Leu (as with SC but without leucine in the "amino acid mix").

\subsubsection{Plasmids used in this study}

The DH5 $\alpha$ E. coli clone bearing a 2 micron plasmid containing the TIF1 open reading frame fused to a tandem affinity tag (Protein A and 6xHis domains) was purchased from Thermo Scientific-Open Biosystems. This plasmid was derived from pRSAB1234 by modification of the C-terminal fusion tag to create BG1805 (Gelperin, White et al. 2005), herein the plasmid containing the wild type TIF1 ORF are referred to as pBG1805-TIF1, while plasmids containing potential pateamine resistant alleles of TIF1 are referred to as pBG1805-PAR1 - 5. Gene expression is driven by the S. cerevisiae GAL1 promoter. This plasmid contains the URA3 gene for selection in S. cerevisiae and an ampicillin resistance gene for selection in E. coli.

\subsubsection{Liquid growth assay}

The sensitivity of haploid MATa, his3山::KanR, S .cerevisiae to pateamine was determined by measuring turbidity in 96-well plates. Briefly, pateamine was serially diluted 2-fold, in triplicate, in $50 \mu 1$ of YPD containing $0.2 \%$ DMSO, to give a range final concentration of 
$40-0.625 \mu \mathrm{M}$, after which $50 \mu \mathrm{l}$ of YPD containing $1 \times 10^{5}$ cells was added to each well. The carrier solvent control was YPD containing 0.1\% DMSO. The plate was incubated for $30 \mathrm{~h}$ at $30{ }^{\circ} \mathrm{C}$, and the absorbance at $590 \mathrm{~nm}$ measured using the Wallac EnVision 2102 plate-reader (Perkin-Elmer, Waltham, MA, USA).

\subsubsection{Pateamine recovery assay}

The ability of haploid MATa, his3 $3:: K a n R, S$.cerevisiae to recover from pateamine induced growth inhibition was assessed. A single colony was inoculated into $2 \mathrm{ml}$ of YPD and incubated overnight at $30{ }^{\circ} \mathrm{C}$ on a rotator. The overnight culture was diluted to an OD600 of 0.2 in $2 \mathrm{ml}$ of YPD containing either $0.1 \%$ DMSO, $250 \mathrm{mM}$ acetic acid, $1 \mu \mathrm{M}$ cycloheximide, $10 \mu \mathrm{M}$ or $50 \mu \mathrm{M}$ pateamine, and returned to the incubator. After $24 \mathrm{~h}$, cells were recovered by centrifugation, washed three times with $\mathrm{ddH}_{2} \mathrm{O}$, and resuspended in $10 \mathrm{ml}$ of YPD media to an OD600 of 0.01 . Cultures were incubated at $30{ }^{\circ} \mathrm{C}$ with agitation and the OD600 measured at 6, 12, 24, 30 and $48 \mathrm{~h}$ using the Genova spectrophotometer (Jenway Ltd., Dunmow, Essex, UK).

\subsubsection{Colony forming unit assay}

A single MATa, his $3 \Delta:: K a n R$, colony was inoculated into $2 \mathrm{ml}$ of YPD and incubated overnight at $30{ }^{\circ} \mathrm{C}$ on a rotator. The overnight culture was diluted to an OD600 of 0.2 in $2 \mathrm{ml}$ of YPD containing either $250 \mathrm{mM}$ acetic acid or $50 \mu \mathrm{M}$ pateamine, and incubated at $30{ }^{\circ} \mathrm{C}$ with agitation. After $24 \mathrm{~h}$, cells were recovered by centrifugation, washed three times with $\mathrm{ddH}_{2} \mathrm{O}$, resuspended in $2 \mathrm{ml}$ of $\mathrm{ddH}_{2} \mathrm{O}, 100 \mu \mathrm{l}$ was spread onto YPD agar plates and incubated $30{ }^{\circ} \mathrm{C}$ for 3 days. 


\subsubsection{Phenol-chloroform-IAA DNA extraction}

Phenol-chloroform-isoamyl alcohol DNA extraction was performed according to standard molecular biology methods (Ausubel 1988). Briefly, an equal volume of 25:24:1 Tris buffered (10 mM, pH 8) saturated aqueous phenol:chloroform:isoamyl alcohol was added to the sample and vortexed for $30 \mathrm{~s}$. Following micro-centrifugation (13.2k rpm, Centrifuge 5415R, Eppendorf, Hamburg, Germany) for $5 \mathrm{~min}$, the aqueous layer was removed and added to an equal volume of 24:1 chloroform:isoamyl alcohol, vortexed for $30 \mathrm{~s}$ and returned to the micro-centrifuge for $5 \mathrm{~min}$. The aqueous layer was removed and retained.

\subsubsection{Ethanol precipitation}

When described in methods below, ethanol precipitation was performed according to standard molecular biology methods (Ausubel 1988). Briefly, sodium acetate was added, giving a final acetate concentration of $0.3 \mathrm{M}$ followed by 3 volumes of $95 \%$ ethanol (v/v). After vortexing this was placed at $-20{ }^{\circ} \mathrm{C}$ for $15 \mathrm{~min}$. Precipitated DNA was collected by micro-centrifugation for $15 \mathrm{~min}$ at $2{ }^{\circ} \mathrm{C}$, the resulting pellet was air dried at room temperature for 15 min and re-dissolved in $\mathrm{ddH}_{2} \mathrm{O}$ or TE buffer ( $1 \mathrm{mM}$ EDTA, $10 \mathrm{mM}$ Tris- $\mathrm{HCl} \mathrm{pH}$ 7.5).

\subsubsection{Isopropanol precipitation}

When described in methods below, isopropanol precipitation of DNA was performed according standard molecular biology methods (Ausubel 1988). Briefly, ammonium acetate was added giving a final acetate concentration of $2 \mathrm{M}$, followed by 0.7 volumes of isopropanol. After $15 \mathrm{~min}$ incubation at room temperature precipitated DNA was recovered 
by micro-centrifugation and the pellet air-dried at room temperature for $15 \mathrm{~min}$ and re-dissolved in $\mathrm{ddH}_{2} \mathrm{O}$ or TE buffer (1 mM EDTA, $10 \mathrm{mM}$ Tris-HCl pH 7.5).

\subsubsection{E. coli plasmid preparation}

Isolation and purification of plasmid DNA from DH5a E. coli was performed with the Zyppy $^{\mathrm{TM}}$ Mini-prep kit (Zymo Research, Orange, CA, USA) according to the manufacturers' instructions. DNA was quantified using the Nano-Drop ND-1000 spectrophotometer (Thermo Scientific, Wilmington, DE) according to the standard protocol (Ausubel 1988), and purity and size assessed with agarose gel electrophoresis (Method 3.3.11).

\subsubsection{DNA electrophoresis}

All DNA electrophoresis was performed according to standard molecular biology methods (Ausubel 1988). Briefly, all electrophoresis was performed in $1 \%$ agarose gels, run in TBE buffer ( $89 \mathrm{mM}$ Boric Acid, $2 \mathrm{mM}$ EDTA disodium dihydrate, $89 \mathrm{mM}$ Tris Base $\mathrm{pH}$ 8.3) with $0.5 \mu \mathrm{g} / \mathrm{ml}$ ethidium bromide. All samples were dissolved in either ddH2O or TE buffer and mixed 5:1 with 6x sample loading buffer (30\% glycerol (v/v), 0.25\% (w/v) bromophenol blue, $0.25 \%(\mathrm{w} / \mathrm{v})$ cyanol xylene) prior to loading onto the gel. Electrophoresis was performed at a constant $100 \mathrm{~V}$ and visualized on a transilluminator at 365 nm (UVItec, Cambridge, UK). 


\subsubsection{EMS mutagenesis}

The double deletion tifl $1 \Delta:: N a t R$, $\operatorname{erg} 6 \Delta:: K a n R$ strain was inoculated into YPD medium with $200 \mu \mathrm{g} / \mathrm{ml} \mathrm{G} 418$ and $100 \mu \mathrm{g} / \mathrm{ml}$ clonNAT and grown overnight in a shaking incubator at $30{ }^{\circ} \mathrm{C}$. The overnight culture was diluted to an OD600 of 0.05 , returned to the shaking incubator and grown to an OD600 of 0.7. Cell concentration was determined using a haemocytometer (Amberg, Burke et al. 2005), aliquots containing 2 × $10^{8}$ cells were collected by centrifugation, washed three times with $0.1 \mathrm{M}$ sodium phosphate buffer $\mathrm{pH}$ 7.0, resuspended in $1 \mathrm{ml}$ of the same buffer containing 4\% EMS (v/v) (ethyl methane sulfonate) and returned to the incubator for $1 \mathrm{~h}$. Cells were recovered by micro-centrifugation, washed three times with $0.2 \mathrm{ml}$ of $20 \%(\mathrm{v} / \mathrm{v})$ sodium thiosulfate, re-suspended in $5 \mathrm{ml}$ of YPD and incubated at $30{ }^{\circ} \mathrm{C}$ overnight without shaking. Cells were recovered by centrifugation and resuspended in $20 \mathrm{ml}$ of YPD with $200 \mu \mathrm{g} / \mathrm{ml} \mathrm{G} 418$ and $100 \mu \mathrm{g} / \mathrm{ml}$ clonNAT and $50 \mu \mathrm{M}$ pateamine and incubated for at $30^{\circ} \mathrm{C}$ with shaking. After $48 \mathrm{~h}, 0.5 \mathrm{ml}$ of the culture was spread on YPD agar with $200 \mu \mathrm{g} / \mathrm{ml} \mathrm{G} 418$ and $100 \mu \mathrm{g} / \mathrm{ml}$ clonNAT and $50 \mu \mathrm{M}$ pateamine and incubated for three days at $30{ }^{\circ} \mathrm{C}$. Five resulting colonies, referred herein as PAR1-5, were picked and pateamine resistance confirmed by streaking onto YPD agar with $\mu \mathrm{g} / \mathrm{ml} \mathrm{G} 418$ and $100 \mu \mathrm{g} / \mathrm{ml}$ clonNAT and $10 \mu \mathrm{M}$ pateamine and incubation at $30{ }^{\circ} \mathrm{C}$ for three days.

\subsubsection{S. cerevisiae plasmid preparation}

Plasmids were recovered from $S$. cerevisiae according to standard yeast molecular genetics methods (Amberg, Burke et al. 2005). Briefly, a single colony of the plasmid bearing strain was inoculated into SD -Ura with $200 \mu \mathrm{g} / \mathrm{ml} \mathrm{G} 418$, or $200 \mu \mathrm{g} / \mathrm{ml} \mathrm{G} 418$ and $100 \mu \mathrm{g} / \mathrm{ml}$ clonNAT depending on the strain, and incubated at $30{ }^{\circ} \mathrm{C}$ overnight with shaking. The cells were recovered by centrifugation, washed three times with sterile $\mathrm{ddH}_{2} \mathrm{O}$, and resuspended in $0.2 \mathrm{ml}$ of a solution containing $2 \%(\mathrm{v} / \mathrm{v})$ Triton X-100, $1 \%$ SDS (w/v) 
(sodium dodecyl sulphate), $0.1 \mathrm{M} \mathrm{NaCl}, 1 \mathrm{mM}$ disodium EDTA, $10 \mathrm{mM}$ Tris-HCl pH 8.0. An equal volume of Zirconia beads (Applied Biosystems/Ambion, Austin, TX, USA) was added, followed by the $0.2 \mathrm{ml}$ of $25: 24: 1$ tris buffered saturated aqueous phenol:chloroform:isoamyl alcohol (Method 3.3.7) and vortexed for 2 min, followed by micro-centrifugation for $5 \mathrm{~min}$. Nucleic acids were recovered from the aqueous layer by ethanol precipitation (Method 3.3.8), the resulting pellet was then dissolved in TE buffer containing $10 \mu \mathrm{g} / \mathrm{ml}$ RNase A (Sigma-Aldrich, St Louis, MO, USA) and incubated at $30{ }^{\circ} \mathrm{C}$ for 15 min. Plasmid DNA was recovered by phenol-chloroform-IAA (Method 3.3.7) extraction followed by ethanol precipitation (Method 3.3.8). The resulting pellet was dissolved in TE buffer and purity and size assessed by agarose gel electrophoresis in $1 \%$ agarose gels (Method 3.3.11).

\subsubsection{Transformation of $S$. cerevisiae}

Transformation of S. cerevisiae was performed using the lithium acetate/single stranded carrier DNA/PEG method (Gietz and Schiestl 2007) with minor modifications. Prior to transformation a single colony of each strain to be transformed was inoculated into YPD media and incubated overnight at $30^{\circ} \mathrm{C}$ with shaking. The next day the culture was diluted to an OD600 of 0.05 in YPD media and returned to the incubator until the OD600 had reached $0.7-1$. Cell density was measured using a haemocytometer, the volume of culture corresponding to $1 \times 10^{8}$ cells was removed; the cells recovered by centrifugation (4000 rpm, Centrifuge 5810, Eppendorf), washed three times with $\mathrm{ddH}_{2} \mathrm{O}$ and resuspended in transformation mix (33.33\% PEG $3350(\mathrm{w} / \mathrm{v}), 0.27 \mathrm{mg} / \mathrm{ml}$ single stranded salmon sperm DNA, $0.1 \mathrm{M}$ lithium acetate) containing approximately $1 \mu \mathrm{g}$ of plasmid DNA. This was incubated at $42{ }^{\circ} \mathrm{C}$ for $40 \mathrm{~min}$, followed by micro-centrifugation for $1 \mathrm{~min}$, after which the transformation mix was removed; the cells were washed with $1 \mathrm{ml}$ of $30{ }^{\circ} \mathrm{C}$ YPD and 


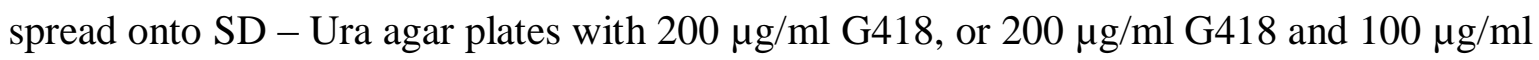
clonNAT depending on the strain, to select for successful transformants.

\subsubsection{TIF1-TAP plasmid digestion and purification}

Purified pBG1805-TIF1 plasmid was digested with AceII, HindIII and EcoRI restriction enzymes and the resulting large fragment was purified using gel permeation chromatography. Briefly, $0.5 \mathrm{mg}$ of plasmid was digested with 1000 units of HindIII and EcoRI in $0.5 \mathrm{ml} \mathrm{NEbuffer} 2\left(50 \mathrm{mM} \mathrm{NaCl}, 10 \mathrm{mM} \mathrm{MgCl}_{2}, 1 \mathrm{mM}\right.$ DTT, $10 \mathrm{mM}$ Tris-HCl pH 7.9, New England Biolabs, Ipswich, MA, USA) overnight at $37^{\circ} \mathrm{C}$. Complete digestion was confirmed by electrophoresis in a $1 \%$ agarose gel in $0.5 x$ TBE buffer (Method 3.3.11). Digested plasmid was isolated and purified by phenol-chloroform-IAA extraction (Method 3.3.7) and ethanol precipitation (Method 3.3.8). The purified digest mixture was resuspended in NEbuffer $4(50 \mathrm{mM}$ potassium acetate, $20 \mathrm{mM}$ Tris acetate, $10 \mathrm{mM}$ magnesium acetate, $1 \mathrm{mM}$ DTT, $\mathrm{pH}$ 7.9, New England Biolab) and further digested with AatII overnight at $37{ }^{\circ} \mathrm{C}$, and the resulting digested plasmid was purified by phenol-chloroform-IAA extraction (Method 3.3.7) and ethanol precipitation (Method 3.3.8). To ensure isolation of only the large digest fragment for transformation, after ethanol precipitation of the AatII digest, DNA was dissolved in $\mathrm{ddH}_{2} \mathrm{O}$, gel electrophoresis loading buffer was added to $1 \mathrm{x}$, and the mixture was then applied to a 2 x $120 \mathrm{~cm}$ glass Econo-Column (Bio-Rad, Hercules, CA, USA) packed with Bio-Gel A-15m (Bio-Rad) and allowed to enter the resin by gravity after which TE buffer was applied. Fractions were collected and DNA content assayed using the Nano-Drop spectrophotometer following standard procedures (Ausubel 1988). DNA containing fractions were analyzed by electrophoresis on $1 \%$ agarose and only those fractions containing the large digest product were combined, and precipitated with isopropanol (Method 3.3.9). The precipitate was 
recovered by centrifugation, dissolved in TE buffer and purity was assessed electrophoretically in 1\% agarose gels (Method 3.3.11).

\subsubsection{Gap-repair allelic recovery}

The pateamine resistant clones PAR1-5 were transformed with the large tif1 plasmid fragment prepared using Method 3.3.15 using the lithium acetate/single stranded carrier DNA/PEG method (Method 3.3.14), with $100 \mu \mathrm{g}$ of the large digest product. Selection was performed on SD - Ura agar plates with $200 \mu \mathrm{g} / \mathrm{ml}$ G418 and $100 \mu \mathrm{g} / \mathrm{ml}$ clonNAT. Re-circularized plasmids were recovered according to method 3.3.13.

\subsubsection{Serial spot dilution assay}

Strains generated using Method 3.3.16 were inoculated into YPD or YPGal media with the appropriate antibiotic (200 $\mu \mathrm{g} / \mathrm{ml} \mathrm{G} 418$ or $100 \mu \mathrm{g} / \mathrm{ml}$ clonNAT) and grown overnight in a shaking incubator at $30{ }^{\circ} \mathrm{C}$. The overnight culture was diluted to an OD600 of approximately 0.05 , returned to the shaking incubator and grown to an OD600 of 1 , this culture was added to a sterile 96 -well plate and serially diluted ten-fold at least 5 times. A multi-channel pipette was used to apply $2.5-5 \mu$ l of each dilution of the above culture onto YPD or YPGal agar plates containing $50 \mu \mathrm{M}$ pateamine or $0.1 \%$ (v/v) DMSO as a carrier control, after absorption by the agar the plate was incubated at $30{ }^{\circ} \mathrm{C}$ for 3 days (Parsons, Brost et al. 2004). 


\subsubsection{TIF1 sequencing}

The plasmids pBG1805-PAR1 - 5, originating from the PARt1-5 clones, produced using Method 3.3.16 were sent to the Allan Wilson Centre Genome Service for DNA sequencing of the TIF1 coding region (Allan Wilson Centre, Massey University, Palmerston North).

\subsubsection{De novo protein and RNA synthesis assay}

The strain his3 $\Delta:: K a n R$ was inoculated into YPD medium with $200 \mu \mathrm{g} / \mathrm{ml} \mathrm{G} 418$ and grown overnight in a shaking incubator at $30{ }^{\circ} \mathrm{C}$. The overnight culture was diluted to an OD600 of approximately 0.05 in SC medium, returned to the shaking incubator and grown to an OD600 of 0.7. Cells were diluted to an OD600 of 0.5 in either SD - Ura or SD - Leu containing pateamine (two-fold serial dilution from $40 \mu \mathrm{M}$ to $0.31 \mu \mathrm{M}$ of pateamine or a $0.1 \%$ (v/v) DMSO carrier control), and incubated for 30 min at $30{ }^{\circ} \mathrm{C}$ with shaking, after which the OD600 was measured and $1 \mu \mathrm{Ci}$ of $\left[5-{ }^{3} \mathrm{H}\right]$ uridine or $\mathrm{L}-\left[4,5-{ }^{3} \mathrm{H}\right]$ leucine $(\mathrm{GE}$ Healthcare, Amersham Biosciences, Uppsala, Sweden), was added and incubated at $30{ }^{\circ} \mathrm{C}$ for $15 \mathrm{~min}$. Cells were recovered by centrifugation, the supernatant removed, protein and RNA were precipitated with the addition of ice-cold aqueous $10 \%$ TCA (w/v) (trichloroacetic acid, Sigma-Aldrich) and recovered by filtration on GF/B glass fibre filters (Whatman Ltd., Kent, England), which were washed three times with ice-cold $10 \%$ TCA (w/v), followed by ice cold $95 \%$ ethanol (v/v). Filters were dried at $60{ }^{\circ} \mathrm{C}$ for $1 \mathrm{~h}$, incubated at room temperature overnight in the dark to reduce background chemoluminescence, and radioactivity measured in Biodegradable Scintillation Cocktail (GE Health Sciences) on a liquid scintillation counter (Wallac 1409, Pharmacia-LKB, Piscataway, NJ, USA). An $\mathrm{IC}_{50}$ was determined using SigmaPlot Ver 10.0 (Systat Software Inc., Richmond, CA, USA) for each individual assay, the results from three independent assays were then averaged, standard errors determined and error values propagated to final derived data through standard methods. 


\subsection{Results}

\subsubsection{Pateamine reversibly inhibits the growth of $S$. cerevisiae}

A liquid growth assay was used to establish an inhibitory concentration of pateamine against wild-type haploid MATa S. cerevisiae a liquid growth assay was performed. Figure 3.1 shows pateamine inhibits the growth of yeast over a $24 \mathrm{~h}$ period with an $\mathrm{IC}_{50}$ of approximately $3 \mu \mathrm{M}$. In contrast to the inhibitory effect of pateamine on protein synthesis (Bordeleau, Matthews et al. 2005), and cytotoxicity in mammalian cells (Figure 2.1) the effect in yeast is reversible. Figure 3.2 shows that in contrast to acetic acid, a known inducer of yeast apoptosis (Madeo, Herker et al. 2004), cells treated with pateamine are able to recover after the drug has been removed. However, in contrast to cycloheximide treated cells, which recover at the same rate as untreated cells, the recovery from pateamine induced growth inhibition is delayed by 6 and $24 \mathrm{~h}$ for 10 and $50 \mu \mathrm{M}$ pateamine respectively. A colony forming unit assay was performed to determine whether the observed delay in recovery was due to a small population of cells that remain viable, or the slow recovery of the entire treated population. Figure $3.3 \mathrm{~b}$ confirms the latter option, with all pateamine treated cells remaining viable but are stalled in their ability to recover from pateamine rather than non-viable as occurs after acetic acid treatment (Figure 3.3a). 
A

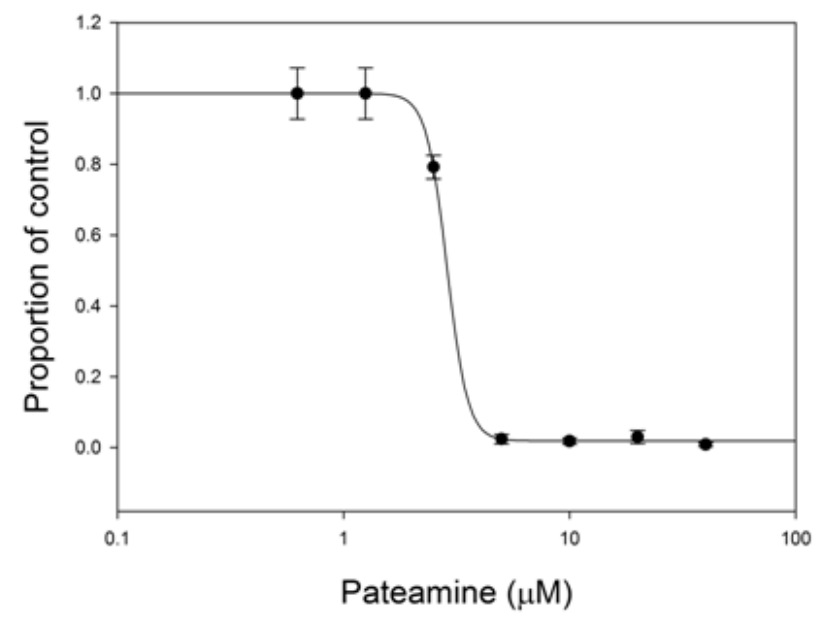

B 50 25

12.5

6.25

3.13 0

Figure 3.1 Yeast dose-response experiments. The sensitivity of the $\Delta$ his3 strain to pateamine, in liquid and solid media containing $200 \mu \mathrm{g} / \mathrm{ml} \mathrm{G} 418$. For liquid assays, the $\mathrm{IC}_{50}$ calculated from three independent experiments performed in triplicate with an average of $2.85 \pm 0.13$, this was calculated by fitting to a sigmoidal curve, presented is a representative dose-response curve. The solid media assay was performed in a 24-well plate with a $1 \mathrm{ml}$ volume of agar containing the concentration of pateamine in $\mu \mathrm{M}$ indicated above each well. Presented is a representative dose-response experiment, the average MIC after 2 days incubation at $30^{\circ} \mathrm{C}$ from three assays was $12.5 \mu \mathrm{M}$. 


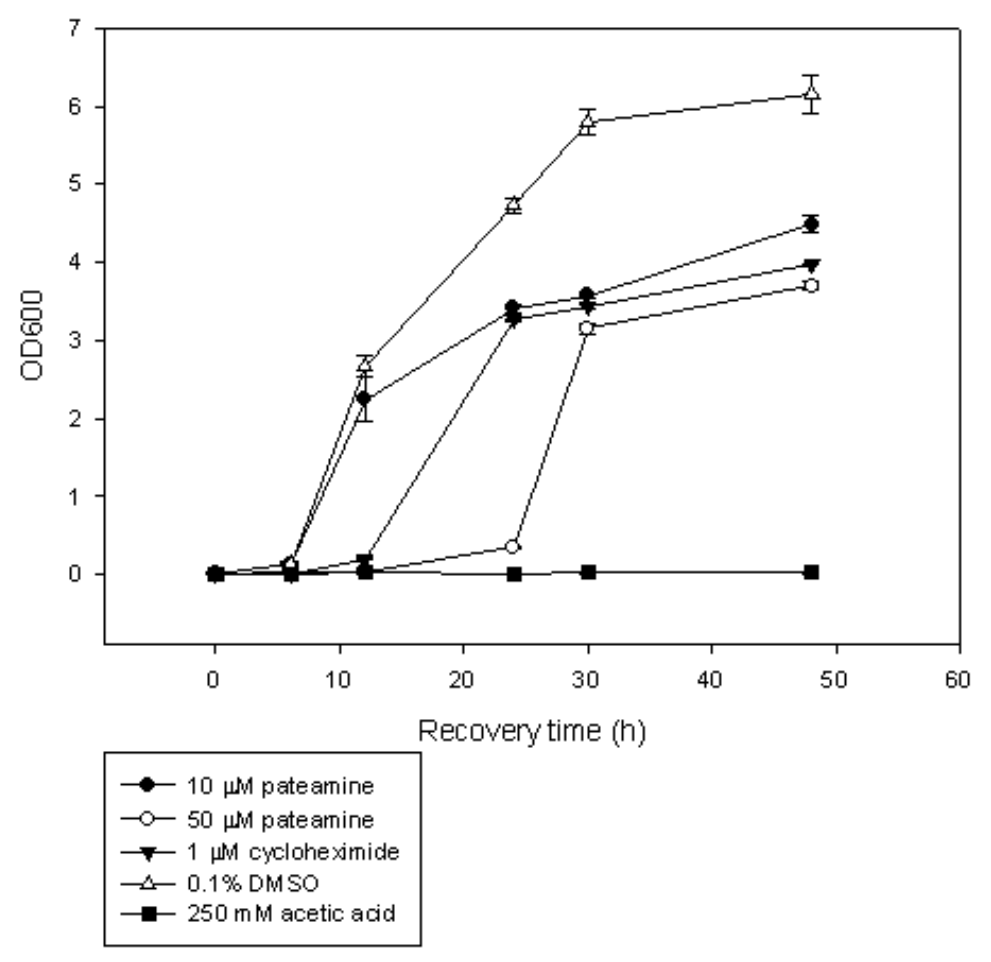

Figure 3.2 Growth inhibition recovery assay. Recovery of the $\Delta$ his3 strain after $24 \mathrm{~h}$ exposure to pateamine, cycloheximide or acetic acid induced growth inhibition was assessed by inoculating washed cells into YPD medium containing $200 \mu \mathrm{g} / \mathrm{ml}$ G418. Growth was measured spectrophotometrically at $600 \mathrm{~nm}$, each data point is an average of three independent experiments.

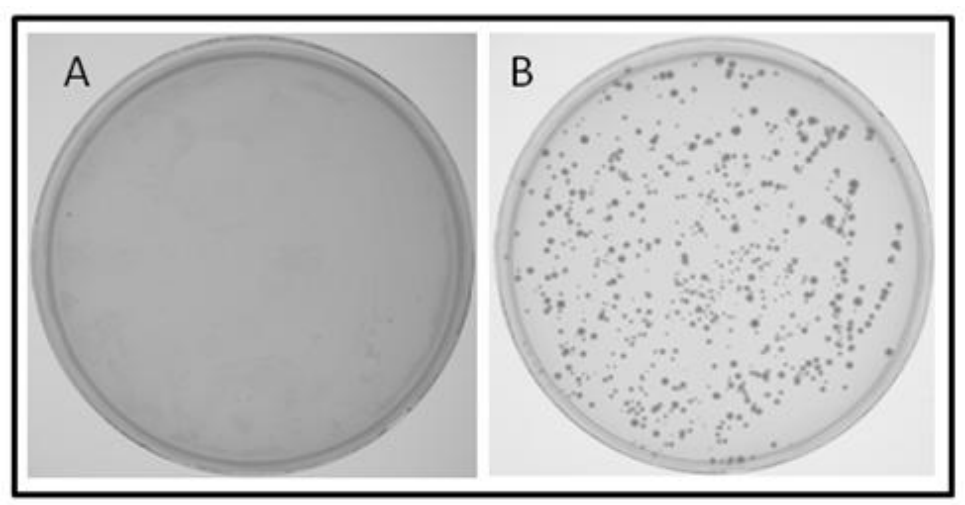

Figure 3.3 Colony forming unit assay. Subsequent to incubation at $30{ }^{\circ} \mathrm{C}$ for $24 \mathrm{~h}$ in YPD medium containing $200 \mu \mathrm{g} / \mathrm{ml} \mathrm{G} 418$ and A. $250 \mathrm{mM}$ acetic acid or B. $50 \mu \mathrm{M}$ pateamine. $\Delta$ his 3 cells were washed with water and an equal volume of each spread onto YPD agar containing $200 \mu \mathrm{g} / \mathrm{ml} \mathrm{G} 418$. Plates were incubated at $30^{\circ} \mathrm{C}$ for 3 days. 


\subsubsection{Multi-drug resistance pump and ergosterol pathway deletions sensitize to pateamine}

A number of haploid yeast deletion strains were tested by serial spot dilution assay (Method 3.3.17) for enhanced sensitivity to pateamine in order to minimize the amount of pateamine used for the resistant mutant generation, and also to impart a strong selection pressure for the most resistant mutant. The strains tested were deficient in either ergosterol synthesis pathway components or the major drug efflux pump Pdr5p, that have been previously found to enhance sensitivity to a number of bioactive compounds (Mukhopadhyay, Kohli et al. 2002; Parsons, Brost et al. 2004). Figure 3.4 shows that the deletions of all of these genes results in enhanced sensitivity to $10 \mu \mathrm{M}$ pateamine in YPD medium, however, the deletion of ERG2, ERG3 or ERG6 conferred the most sensitivity. Due to this enhanced sensitivity compared to the $\Delta p d r 5$ strain, the $\Delta e r g 6$ strain was chosen as the starting strain, it is also presumed that in this strain any mutation that up-regulates the expression of an efflux pump will not confer resistance as the increase in efflux will be negated by the increased permeability of the cell wall. For reasons outlined later, all of the strains tested were also deficient in TIF2 (tif2 $\triangle:: N a t R$ ) the gene that contributes the majority of eIF4A to the intercellular pool (Prat, Schmid et al. 1990). This deletion does not significantly increase the sensitivity to the concentration of pateamine used in this assay, beyond that of the surrogate wild-type $\Delta$ his3 strain (Figure 3.4). 


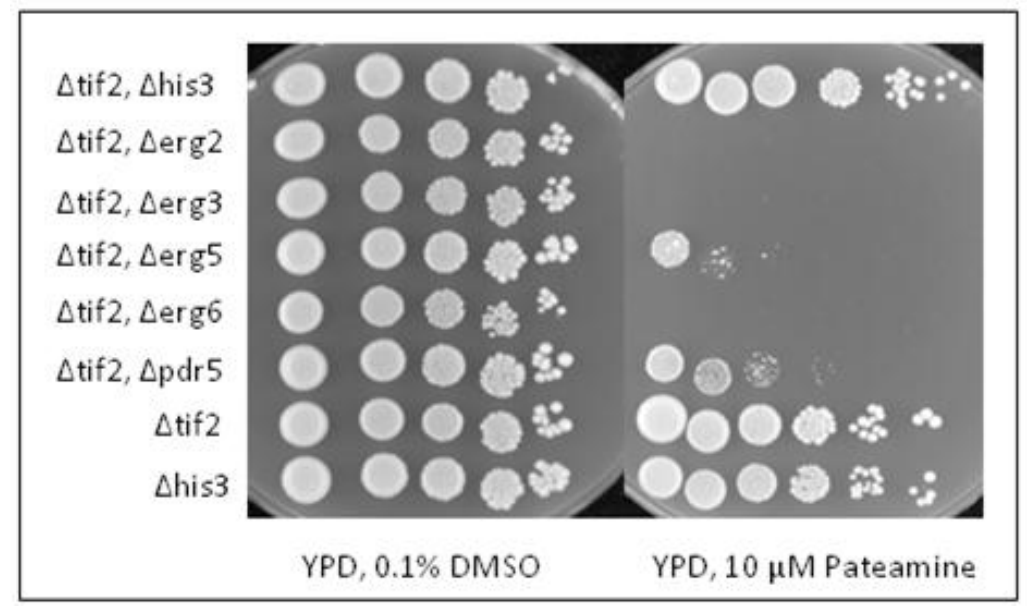

Figure 3.4 Serial spot dilution assay of strains deficient in ergosterol pathway components and the Pdr5p drug efflux pump. Overnight cultures were diluted to OD600 $=1$, which was serially diluted 10 fold, 4 times, and an equal volume of each strain and dilution was spotted onto YPD agar plates containing $200 \mu \mathrm{g} / \mathrm{ml} \mathrm{G} 418$ and either $0.1 \%$ DMSO or $10 \mu \mathrm{M}$ pateamine, and incubated at $30^{\circ} \mathrm{C}$ for 3 days.

\subsubsection{Pateamine resistance}

The $\Delta$ tif2, $\Delta$ erg6 strain was mutagenized using EMS and, in order to isolate the most resistant mutant, clones were enriched first by exposure in liquid culture to $50 \mu \mathrm{M}$ pateamine (a concentration that completely inhibits the growth of yeast over $24 \mathrm{~h}$, the resulting culture was plated onto YPD agar plates containing $50 \mu \mathrm{M}$ pateamine. Five resistant clones (PAR1-5) were isolated and confirmed by serial spot dilution assay. Figure 3.5 shows these clones are able to grow on YPD agar containing $10 \mu \mathrm{M}$ pateamine whereas the strain they were derived from was not. 


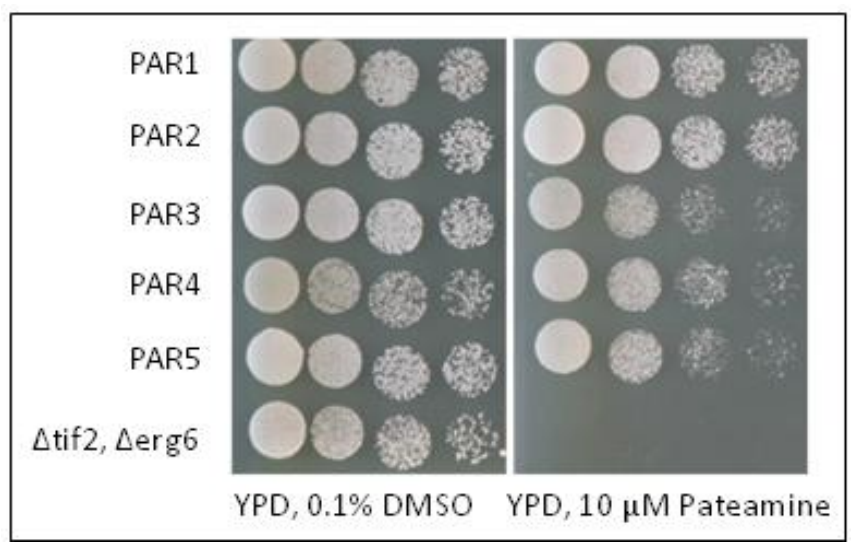

Figure 3.5 PAR clone resistance to pateamine confirmation by serial spot dilution. Pateamine resistant clones PAR1-5 and the strain they were derived from ( $\Delta$ tif2, $\Delta$ erg6) were grown overnight in YPD medium containing $100 \mu \mathrm{g} / \mathrm{ml}$ clonNAT and $200 \mu \mathrm{g} / \mathrm{ml} \mathrm{G418.} \mathrm{Each} \mathrm{culture}$ was diluted to $\mathrm{OD} 600=1$, then diluted serially 10 fold, 3 times, and an equal volume of each strain and dilution was spotted onto YPD agar plates containing $100 \mu \mathrm{g} / \mathrm{ml}$ clonNAT and $200 \mu \mathrm{g} / \mathrm{ml} \mathrm{G418}$ and $0.1 \% \mathrm{DMSO}$ or $10 \mu \mathrm{M}$ pateamine. Plates were incubated at $30^{\circ} \mathrm{C}$ for three days.

\subsubsection{Gap repair-mediated recovery of tif1 allele}

It was proposed the strongest resistance conferring mutation would occur in one of the genes encoding the yeast orthologues of mammalian eIF4AI/II, designated TIF1 and TIF2. Gap-repair mediated allelic recovery was used to recover the sequence at the TIF1 locus in order to establish whether mutation at that site conferred pateamine resistance. To allow the unambiguous recovery of the sequence from the TIF1 locus, the parental strain also carried a deletion of TIF2 (tif2 $\Delta:: N a t R)$. There are only six nucleotide differences between TIF1 and TIF2 all of which occur outside of the restriction sites used in the plasmid digestion, the choice of the deletion of TIF2 was for due to the fact that it contribute the greater proportion of eIF4A to the intracellular pool (Prat, Schmid et al. 1990), though this did not appear to affect pateamine sensitivity at the concentrations presented here. The plasmid BG1805-TIF1 was digested first with HindIII and EcoRI (Figure 3.6, Lane D) to remove a fragment 639 base pairs in size. To ensure that this fragment was not repaired back into the plasmid on transformation into yeast; the small fragment was further digested 
with AatII and separated from the large fragment by size exclusion chromatography (Method 3.3.15) (Figure 3.6, Lanes E - L).

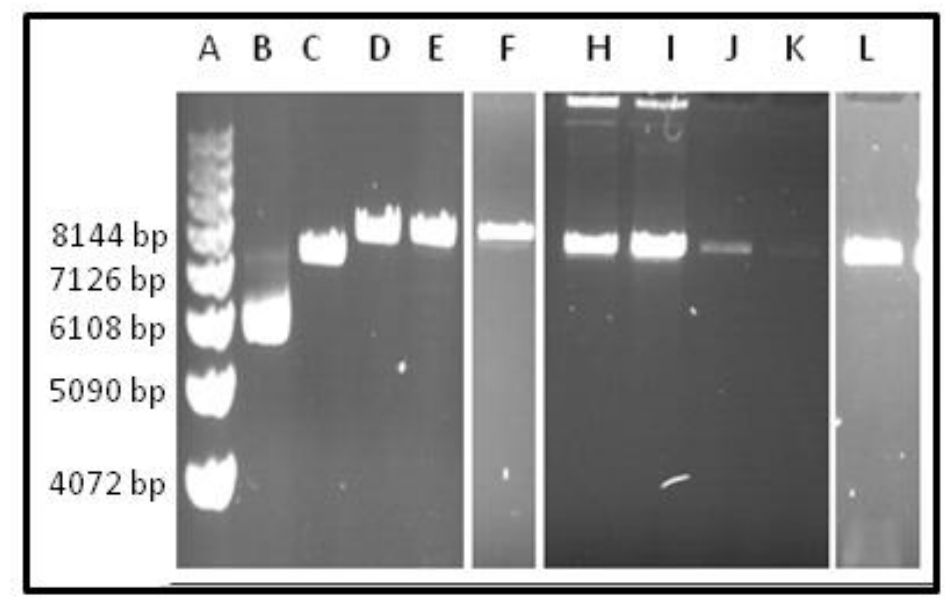

Figure 3.6 Large BG1805 plasmid fragment production by restriction digestion. Electrophoresis was performed on 1\% agarose gels and run in TBE buffer. Lane: A. 1kb Ladder; B. Undigested BG1805-TIF1 plasmid; C. HindIII digestion; D. EcoRI and HindllI digestion; E. HindIII, EcoRI and Aatll digestion; F. Purified digestion reaction; H - K. Size exclusion chromatography elution fractions; L. Purified and concentrated, pooled size exclusion eluate.

The clones, PAR1-5, were transformed with the large digest fragment generated by restriction enzyme digestion of the pBG1805-TIF1 plasmid (Methods 3.3.16). Repaired plasmids were isolated and transformed into the parental pateamine--sensitive $\Delta$ tif $2, \Delta \operatorname{erg} 6$ strain. A serial spot dilution assay confirmed that plasmids bearing the tifl alleles recovered from PAR1-5 confer pateamine resistance (Figure 3.7), while plasmids containing wild type $T I F 1$, the yeast eIF4AIII orthologue $F A L 1$, or an empty vector carrying the URA3 selectable marker were unable to do so (Figure 3.8). 


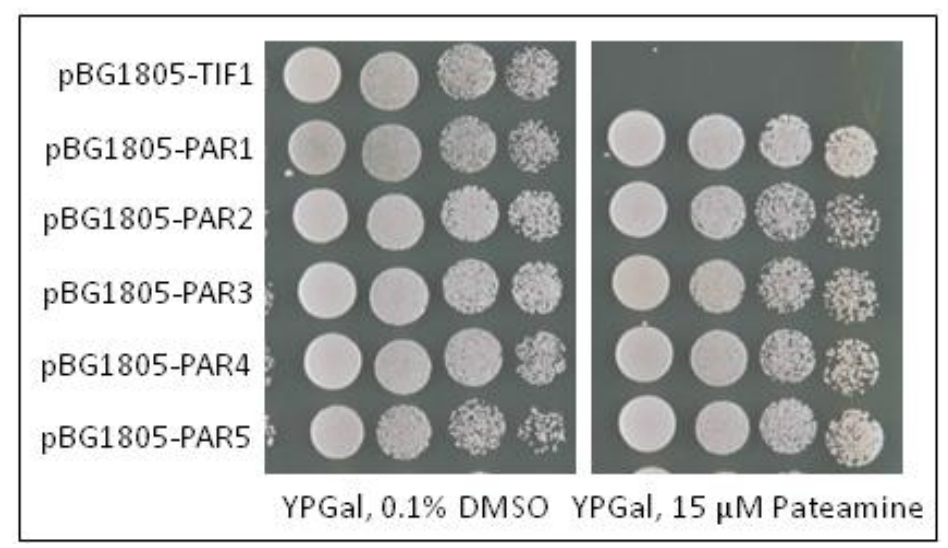

Figure 3.7 Clones bearing gap-repaired TIF1 plasmids recovered from PAR1-5 clones confer pateamine resistance to the $\Delta$ tif2, $\Delta$ erg6 strain. Transformants containing the indicated plasmids were grown overnight, diluted to $\mathrm{OD} 600=1$, then serially diluted $10 \mathrm{fold}, 3$ times. Equal volumes of each strain and dilution was spotted onto YPGal agar plates containing either $0.1 \%$ DMSO or $15 \mu \mathrm{M}$ pateamine, and incubated at $30^{\circ} \mathrm{C}$ for 3 days.

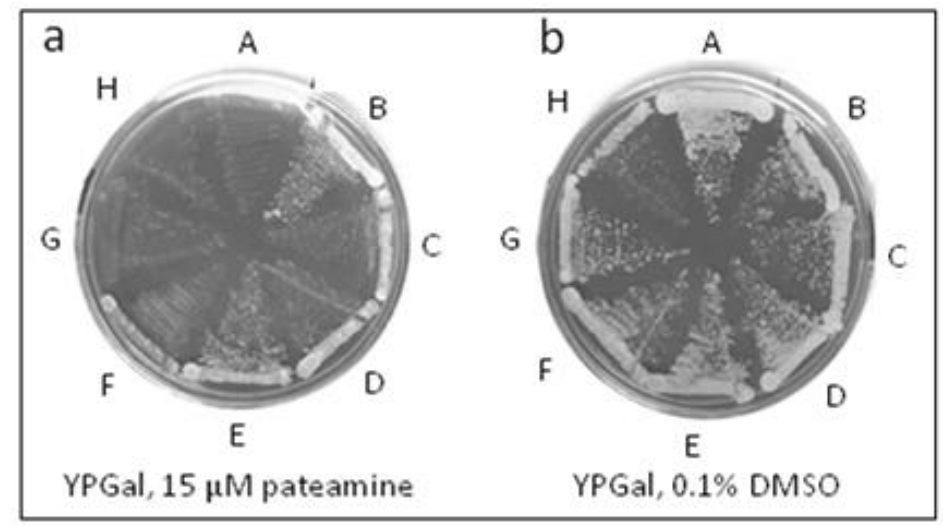

Figure 3.8 Pateamine resistance is not due to the URA3 selection marker presence. Overnight cultures were streaked onto YPGal medium containing $15 \mu \mathrm{M}$ pateamine or $0.1 \%$ DMSO. Clones contain the following plasmids: A. pBG1805-TIF1; B - F. pBG1805-PAR1 - PAR5; G. pBG1805-FAL1; H. pRS316 empty vector. Plates were incubated for 3 days at $30^{\circ} \mathrm{C}$. 


\subsubsection{Sequencing of tif 1 allele reveals a single point mutation}

Inspection of the sequence recovered by gap-repair shows the presence of a single point mutation in the plasmids recovered from PAR1-5 - a thymidine to cytosine transition at nucleotide 440 which, in turn leads to a proline to leucine substitution at position 147 of the resulting protein (Figure 3.9).

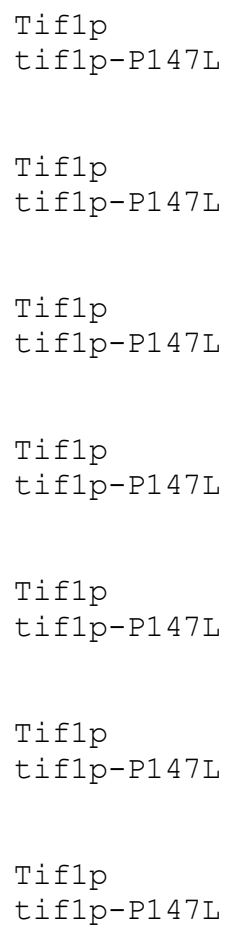

Figure 3.9 Recovered pBG1805-PAR1 - 5 amino acid sequence alignment with wild-type TIF1. The plasmids recovered from tPAR1 -5 all contained the single nucleotide transversion at nucleotide position 440 (colored red), which results in proline to leucine substitution at position 147.

\subsubsection{Pateamine inhibits protein and RNA synthesis in yeast}

While an exhaustive genome-wide mapping of the pateamine resistance mutant was not performed, the isolation of a tifl mutant that confers pateamine resistance strongly suggests that eIF4A is a target of pateamine in yeast. Consistent with the role of eIF4A in mammalian cells, yeast eIF4A has been shown to be an ATP dependent RNA helicase 
involved in translation initiation. In order to assess the impact of pateamine treatment on protein and RNA synthesis an in vivo metabolic labeling experiment was performed. Figure 3.10 shows representative dose-response curves for the incorporation of radio-labeled leucine (A) and uridine (B), which indicate pateamine is able to inhibit both protein and RNA synthesis with $\mathrm{IC}_{50}$ values of $4.4 \pm 0.4$ and $8.7 \pm 0.5$ respectively.

A Tritiated Leucine Incorporation Assay

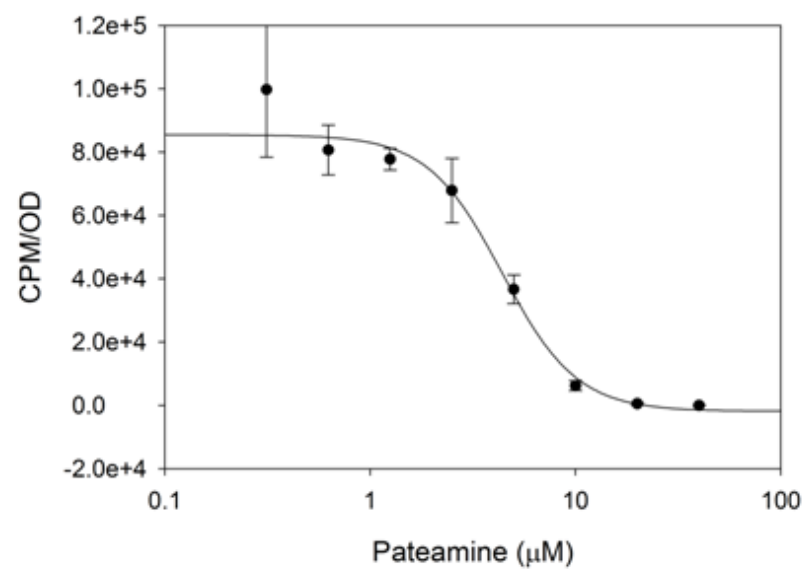

B

Tritiated Uridine Incorporation Assay

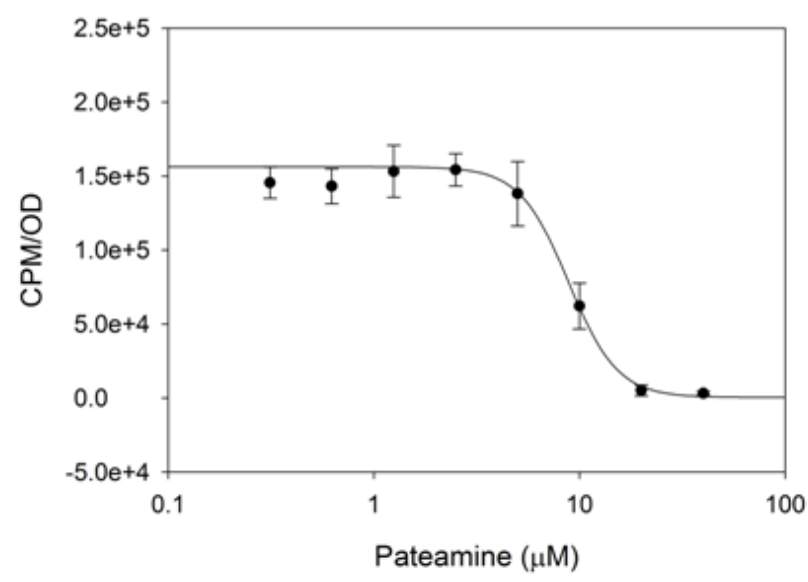

Figure 3.10 Pateamine inhibits in vivo macromolecule synthesis in yeast. The $\Delta$ his3 strain was grown to mid-log growth phase in SC medium, diluted to $O D=0.5$ in either SD - Leu or SD - Ura medium, and exposed to a twofold serial dilution of pateamine for $30 \mathrm{~min}$ at $30{ }^{\circ} \mathrm{C}$. Radiolabeled leucine or uridine was added and incubated at $30{ }^{\circ} \mathrm{C}$ for $15 \mathrm{~min}$, after ice-cold TCA precipitation, incorporated radioactivity was measured using liquid scintillation counting. Each experiment was repeated three times in triplicate, presented is representative curves for; A. leucine incorporation and $\mathrm{B}$. uridine incorporation. $\mathrm{IC}_{50}$ values were calculated after fitting to a sigmoidal curve to be $4.4 \pm 0.4 \mu \mathrm{M}$ and $8.7 \pm 0.5 \mu \mathrm{M}$ for radiolabeled leucine and uridine incorporation respectively. 


\subsubsection{Predicting a putative pateamine binding site}

To postulate a potential binding site for pateamine on eIF4A it was reasoned that such a site would be conserved on the known pateamine targets (human eIF4AI, eIF4AII, eIF4AIII and yeast Tif1p) but absent in Ded1p, which has been shown to be insensitive to pateamine in vitro. Also, that this site would not be a part of the RNA, ATP or eIF4G binding sites, as others have shown that pateamine enhances RNA binding, ATP binding and hydrolysis (Bordeleau, Matthews et al. 2005) and the interaction with eIF4G of human eIF4AI (Bordeleau, Cencic et al. 2006), and enhances ATP hydrolysis in human eIF4AIII and yeast Tif1p (Low, Dang et al. 2007). Given that eIF4AI is only able to hydrolyse ATP when bound to RNA (Lorsch and Herschlag 1998) the ATP and RNA binding surfaces as well as the of eIF4A can also be excluded as a possible binding site. Furthermore it could be suggested that this site should also be in close proximity to the resistance conferring mutation in yeast Tiflp identified in this work and occurs at least predominantly on the $\mathrm{N}$-terminal lobe, which has been shown to bind, albeit weakly to pateamine (Low, Dang et al. 2005).

In order to identify possible positions for this binding site the amino acid sequences of the known targets of pateamine (human eIF4AI, eIF4AII, eIF4AIII and yeast Tif1p) were aligned with each other and the sequences of Ded1p and Fal1p, which was included due to its high degree of homology to all the verified pateamine targets (Figure 3.11). An immediate observation is that the sequence surrounding and including the resistance mutation (P147L in Tif1p which corresponds to P164 in eIF4AIII, underlined in red) is highly conserved in all of the sequences aligned here regardless of whether the protein is a pateamine target: this suggests it is not the exact site. Closer inspection of residues within $15 \AA$ of P147/164 (numbering referring to Tif1p/eIF4AIII) that are retained in the pateamine sensitive eIF4A homologues but not in Ded1p reveals a conserved cysteine 
residue (C124 and C140 in Tif1p and eIF4AIII respectively) that is replaced by a valine in the equivalent position in Ded1p. This cysteine is embedded in a sequence (HACI) that is followed by a sequence of four amino acids whose position changes significantly upon the binding of eIF4AIII to RNA. This was established by fitting the crystal structure of the N-terminal lobe of eIF4AIII bound to RNA (Nielsen, Chamieh et al. 2009) to the N-terminal lobe structure of apo-eIF4AIII and coloring the former by RMS (Figure 3.12). 


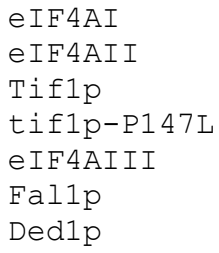

MSASQDSRSR 10

MSGGSADYNRE 11

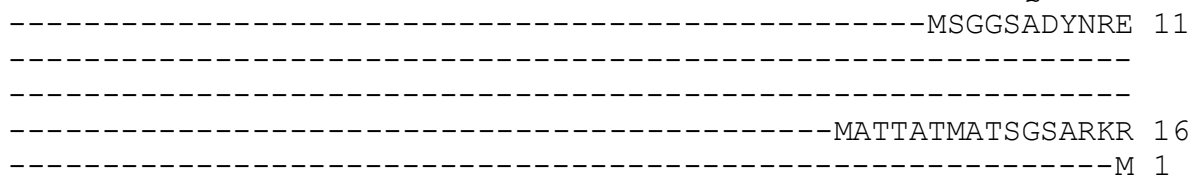

RRGGYGNGGFFGGNNGGSRSNGRSGGRWIDGKHVPAPRNEKAEIAIFGVPEDPNFQSSGI 120

DNGPDGMEPEGVIESNWNEIVDSFDDMNLSESLLRGIYAYGFEKPSAIQQRA ILPCIKGY 70 HGGPEGMDPDGVIESNWNEIVDNFDDMNLKESLLRGIYAYGFEKPSAIQQRAIIPCIKGY 71 MSEGITDIEESQIQTNYDKVVYKFDDMELDENLLRGVFGYGFEEPSA IQQRAIMPIIEGH 60 MSEGITDIEESQIQTNYDKVVYKFDDMELDENLLRGVFGYGFEEPSAIQQRAIMP I IEGH 60 LLKEEDMTKVEFETSEEVDVTPTFDTMGLREDLLRGIYAYGFEKPSAIQQRAIKQIIKGR 76 SFDREEDOKLKFKTSKKLKVSSTFESMNLKDDLLRGIYSYGFEAPSS IOSRA ITOI ISGK 61 NFDNYDDIPVDASGKDVPEPITEFTSPPLDGLLLENIKLARFTKPTPVQKYSVPIVANGR 180

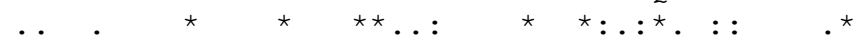

DVIAQAQSGTGKTATFAISILQQ------------IELDLKATQALVLAPTRELAQQ 115 DVIAQAQSGTGKTATFAIS ILQQ--------------LEIEFKETQALVLAPTRELAQQ 116 DVLAQAQSGTGKTGTFSIAALQR-------------IDTSVKAPQALMLAPTRELALQ 105 DVLAQAQSGTGKTGTFS IAALQR--------------IDTSVKAPQALMLAPTRELALQ 105 DVIAQSQSGTGKTATFS ISVLQC-------------LDIQVRETQALILAPTRELAVQ 121 DVIAQAQSGTGKTATFTIGLLQA-------------IDLRKKDLQALILSPTRELASQ 106 DLMACAQTGSGKTGGFLFPVLSESFKTGPS PQPESQGSFYQRKAYPTAVIMAPTRELATQ 240

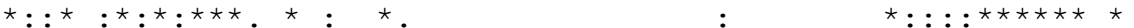

IQKVVMALGDYMGASCHAC IGGTNVRAEVQKLQMEAPHI IVGTPGRVFDMLNRRYLSPKY 175 IQKVILALGDYMGATCHACIGGTNVRNEMQKLQAEAPHIVVGTPGRVFDMLNRRYLSPKW 176 IQKVVMALAFHMDIKVHACIGGTSFVEDAEGLRDAQ--IVVGTPGRVFDNIQRRRFRTDK 163 IQKVVMALAFHMDIKVHAC IGGTSFVEDAEGLRDAQ--IVVGTLGRVFDNIQRRRFRTDK 163 IQKGLLALGDYMNVQCHACIGGTNVGEDIRKLDYGQ-HVVAGTPGRVFDMIRRRSLRTRA 180 IGQVVKNLGDYMNVNAFAITGGKTLKDDLKKMQKHGCQAVSGTPGRVLDMIKKQMLQTRN 166 IFDEAKKFTYRSWVKACVVYGGSPIGNQLREIERGC-DLLVATPGRLNDLLERGKISLAN 299

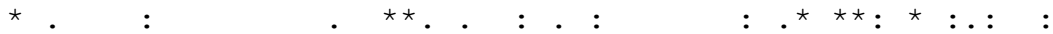

IKMFVLDEADEMLSR--GFKDQIYDIFQKLNSN----TQVVLLSATMPSDVLEVTKKFMR 229 IKMFVLDEADEMLSR--GFKDQIYEIFQKLNTS----IQVVLLSATMPTDVLEVTKKFMR 230 IKMFILDEADEMLSS--GFKEQIYQIFTLLPPT----TQVVLLSATMPNDVLEVTTKFMR 217 IKMFILDEADEMLSS--GFKEQIYQIFTLLPPT----TQVVLLSATMPNDVLEVTTKFMR 217 IKMLVLDEADEMLNK--GFKEQIYDVYRYLPPA----TQVVLISATLPHEILEMTNKFMT 234 VQMLVLDEADELLSETLGFKQQIYDIFAKLPKN----CQVVVVSATMNKDILEVTRKFMN 222 VKYLVLDEADRMLDMG--FEPQIRHIVEDCDMTPVGERQTLMFSATFPADIQHLARDFLS 357

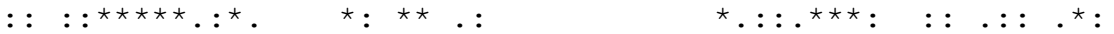

DPIRILVKKEELTLEGIROFY INVEREEWKLDTLCDLYETLTITOAVIFINTRRKVDWLT 289 DPIRILVKKEELTLEGIKQFY INVEREEWKLDTLCDLYETLTITQAVIFLNTRRKVDWLT 290 NPVRILVKKDELTLEGIKQFYVNVEEEEYKYECLTDLYDS ISVTQAVIFCNTRRKVEELT 277 NPVRILVKKDELTLEGIKQFYVNVEEEEYKYECLTDLYDS ISVTQAVIFCNTRRKVEELT 277 DPIRILVKRDELTLEGIKQFFVAVEREEWKFDTLCDLYDTLTITQAVIFCNTKRKVDWLT 294 DPVKILVKRDEISLEGIKQYVVNVDKEEWKFDTLCDIYDSLTITQCVIFCNTKKKVDWLS 282 DYIFLSVGRVGSTSENITQKVLYVENQ-DKKSALLDLLSASTDGLTLIFVETKRMADQLT 416

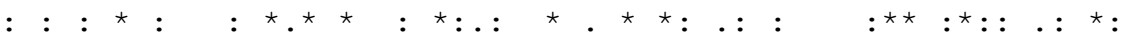

EKMHARDFTVSAMHGDMDQKERDVIMREFRSGSSRVLITTDLLARGIDVQQVSLVINYDL 349 EKMHARDFTVSALHGDMDQKERDVIMREFRSGSSRVLITTDLLARGIDVQQVSLVINYDL 350 TKLRNDKFTVSAIYSDLPQQERDTIMKEFRSGSSRILISTDLLARGIDVQQVSLVINYDL 337 TKLRNDKFTVSAIYSDLPQQERDTIMKEFRSGSSRILISTDLLARGIDVQQVSLVINYDL 337 EKMREANFTVSSMHGDMPQKERESIMKEFRSGASRVLISTDVWARGLDVPQVSLIINYDL 354 QRLIQSNFAVVSMHGDMKQEERDKVMNDFRTGHSRVLISTDVWARGIDVQQVSLVINYDL 342 DFLIMQNFRATAIHGDRTQSERERALAAFRSGAATLLVATAVAARGLDI PNVTHVINYDL 476

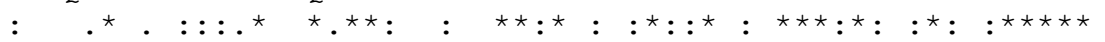

PTNRENYIHRIGRGGRFGRKGVA INMVTEEDKRTLRDIETFYNTSIEEMPLNVADLI--- 406 PTNRENYIHRIGRGGRFGRKGVAINFVTEEDKRILRDIETFYNTTVEEMPMNVADLI--- 407 PANKENYIHRIGRGGRFGRKGVA INFVTNEDVGAMRELEKFYSTQIEELPSDIATLLN -- 395 PANKENYIHRIGRGGRFGRKGVAINFVTNEDVGAMRELEKFYSTQIEELPSDIATLLN-- 395 PNNRELYIHRIGRSGRYGRKGVAINFVKNDDIRILRDIEQYYSTQI DEMPMNVADLI--- 411 PEI IENYIHRIGRSGRFGRKGVAINFITKADLAKLREIEKFYSIKINPMPANFAELS--- 399 PSDVDDYVHRIGRTGRAGNTGLATAFFNSENSNIVKGLHEILTEANQEVPSFLKDAMMSA 536

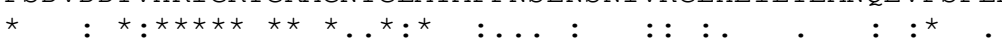


Figure 3.11 Potential pateamine binding site proposition by sequence alignment. Amino acid sequences of verified pateamine sensitive elF4A proteins (human elF4AI, elF4All, elF4Alll, yeast elF4A (Tif1p), pateamine resistant Tif1p (Tif1p-P147L), pateamine insensitive Ded1p and a potential yeast pateamine target Fal1p were aligned using the Clustal-W algorithm. Presented is the sequence alignment corresponding to the region of human elF4Al from amino acid 52 to 246 and constitutes the majority of the $\mathrm{N}$-terminal lobe of all sequences pictured. The position of the pateamine resistance conferring mutation in Tif1p (P147L) is in red, and part of the potential pateamine binding site (surrounding $\mathrm{C124}$ ) is in green. 

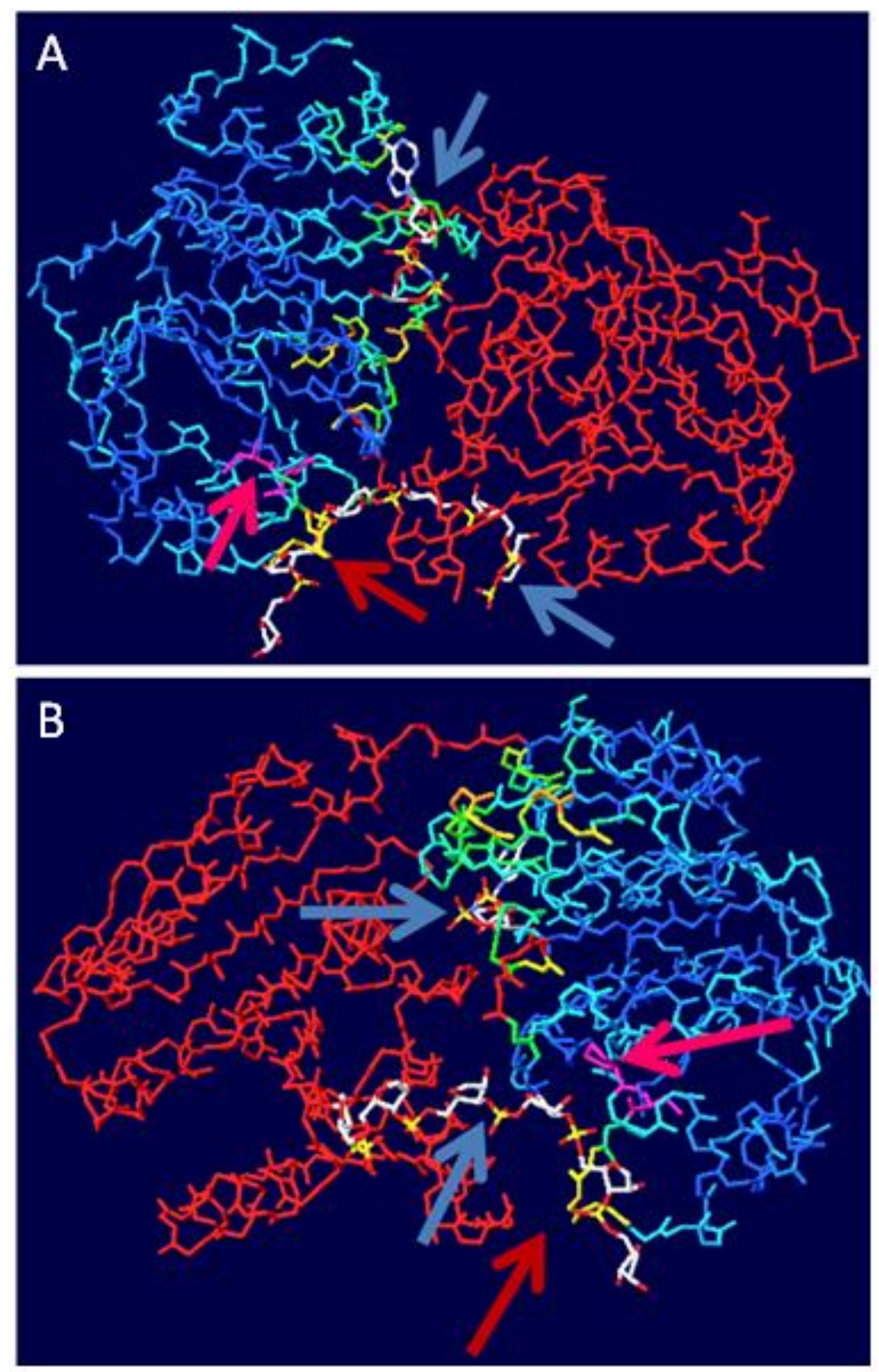

Figure 3.12 elF4All bound to RNA abstracted from the crystal structure of the EJC (3ex7.pdb). N-terminal is on the left and colored by RMS calculated relative to the apo-elF4AIII crystal structure, poly-U and ATP are indicated by blue arrows, the side-chain of $\mathrm{C} 124$ is colored magenta and indicated by the magenta arrow and the red arrow indicates the sequence immediately $\mathrm{C}$-terminal to the $\mathrm{HACl}$ motif which changes position upon RNA binding. Shown are two views from the $(A)$ front and $(B)$ back. 


\subsection{Discussion}

\subsubsection{Pateamine inhibits the growth of yeast in a but does not kill them}

Consistent with previously published results regarding the sensitivity of yeast and fungal species sensitivity to pateamine (Northcote, Blunt et al. 1991) the growth of S. cerevisiae was inhibited in both liquid and agar media, with an $\mathrm{IC}_{50}$ of approximately $3 \mu \mathrm{M}$ in liquid media and a MIC of $12.5 \mu \mathrm{M}$ in solid. Compounds that affect the growth of yeast generally inhibit their growth rather than kill them, a relatively small number of compounds that show inhibitory activity towards yeast induce a cell death process analogous to mammalian apoptosis (Almeida, Silva et al. 2008).

While pateamine irreversibly induces apoptosis in human cell lines (Hood, West et al. 2001; Miller, Rouwe et al. 2004; Low, Dang et al. 2005), it reversibly inhibits cell division in yeast. Yeast treated with pateamine in liquid culture require more time to recover than those treated with cycloheximide, the reason for this may be that the interaction between pateamine and its target in yeast is of high affinity, the inability of mammalian eIF4A to be eluted from the pateamine affinity resin, by any means other than completely denaturing and reducing conditions, may be indicative of a high affinity or covalent interaction. An alternative explanation that the compound accumulates intracellularly, due to low levels of efflux though the hypersensitivity of $\Delta p d r 5$ deletion strain suggests this is not the case.

If the interaction between pateamine and eIF4A is covalent this may explain the slow recovery from pateamine exposure, in this case the adduct would have to be cleared by proteolytic degradation. Yeast eIF4A has been identified as a protein that is degraded via the proteasome after ubiquitination (Tagwerker, Flick et al. 2006). Given the large number 
of ubiquitinated proteins, and the fact that inactivation of eIF4A (in this case by pateamine) prevents protein synthesis, the resolution of the adduct and the production of new eIF4A and ubiquitination would be slow, which could account for the considerably increased recovery time.

\subsubsection{Multi-drug resistance pump and ergosterol pathway deletions sensitize to pateamine}

The major drug efflux pump expressed in S. cerevisiae is Pdr5p; the deletion of the gene that encodes this pump confers sensitivity to pateamine, indicating this pump recognizes it as a substrate and removes it from the cell. The recognition of pateamine by Pdr5p raises the possibility that resistance to pateamine may be generated by up regulation of this or other efflux pumps, such as Snq2p or Yor1p (Balzi and Goffeau 1995). Alternatively a mutation may occur in the substrate recognition domain of a pump that pateamine is not a substrate for, making it now a substrate (Tutulan-Cunita, Mikoshi et al. 2005). Deletion of a number of genes in the ergosterol pathway also sensitize to pateamine, most likely due to increased permeability and fluidity of the plasma membrane, because of decreased ergosterol levels, that allows greater diffusion of the compound into the cell (Mukhopadhyay, Kohli et al. 2002; Abe and Hiraki 2009). Pateamine resistance of these strains is less likely to occur because of efflux pump up-regulation since this would not lower the concentration of the drug in the cytosol, the increased permeability of the cell negates increasing efflux. For this reason the deletion of ERG6 was used to generate pateamine resistant clones. 


\subsubsection{Pateamine resistance}

Given that pateamine treatment causes growth arrest, if it is presumed the target in yeast is a protein, it is possible to speculate as to the nature of its target in limited terms: pateamine may target an essential gene product; or the functionally redundant product of two non-essential duplicated genes; alternatively a lethal function of a non-essential gene product in a essential pathway may be agonized. Given the high degree of homology between human eIF4AI, the target in human cells, and yeast Tif1/2p (Linder 2003), it is not unreasonable to suggest this is the target in yeast. Consistent with the above speculations regarding the nature of the pateamine target, yeast Tif $1 / 2 \mathrm{p}$ is the product of two duplicated non-essential genes, TIF1 and TIF2, which are functionally redundant and display a synthetic lethal genetic interaction (Linder and Slonimski 1989). In order to simplify the recovery of a mutation in one of these genes conferring pateamine resistance, the parental strain used to generate the resistant clones was deficient in both $E R G 6$, for reasons stated above, and TIF2. The deletion of TIF2 was chosen since it contributes the majority of eIF4A present in yeast (Prat, Schmid et al. 1990), removal of one of the genes encoding eIF4A simplifies the recovery of the sequence at the other locus by gap-repair.

In order to isolate the most pateamine resistant mutant following the incubation of the mutagenized $\Delta$ tif2, $\Delta$ erg6 strain in YPD, to allow the expression of any mutant genes, the cells were exposed to a high $(50 \mu \mathrm{M})$ concentration of pateamine in liquid media, and allowed to grow to OD corresponding to mid-log growth phase. This allowed the relative increase of the strongest mutant, and may explain why all of the TIF1 sequences recovered from the pateamine resistance mutants all contained the same point mutation (see below). Of note is that all mutants retained pateamine-resistance after growth in non-selective media (YPD) (Figure 3.5), which suggests the observed resistance is not due to the 
temporary up-regulation of drug efflux pumps, for instance Pdr5p for which the deletion of was shown to confer pateamine sensitivity (Figure 3.4).

\subsubsection{Gap repair mediated recovery of tif1 allele}

Typically once a clone resistant to the drug of interest is generated classical yeast molecular genetics approaches are used to determine broad characteristics of the mutation. For instance, the dominant or recessive nature of this mutation with respect to the wild-type gene is determined by mating the resistant clone with the opposite mating type of the parental from which it was derived and quantifying the drug sensitivity of the resulting diploid clones. Whether the resistance observed is due to a single genetic locus is determined after sporulation of the above diploid and quantifying the drug sensitivity of the resulting haploid progeny. Whether all of the clones generated belong to the same complementation group, that is whether they map to the same position, is determined by quantifying the drug sensitivity of the haploid progeny resulting from mating the drug resistant haploid clones (Miyamoto, Machida et al. 2002). However, given the identification of the eIF4A family of proteins as putative mammalian targets of pateamine and the high degree of homology between eIF4AI and Tif1/2p (Linder 2003), the ability of the TIF1 locus from the clones PAR1-5 was to confer resistance to the parental $\Delta$ tif2, $\Delta$ erg6 strain was assessed directly.

The sequence recovered from the TIF1 locus of all of the PAR clones by gap-repair mediated allelic recovery was able to confer resistance to the parental strain when over-expressed from a 2-micron plasmid driven by a galactose inducible promoter, whereas the wild-type TIF1 gene when over-expressed failed to confer resistance upon the parental strain, as did the over-expression of Fal1p. This suggests a sequence difference in 
the TIF1 allele recovered from the PAR1-5 clones compared to wild-type TIF1 and that this confers pateamine resistance, and represents the major target in yeast.

\subsubsection{Sequencing of tif1 allele reveals a single point mutation}

Primers designed outside of the HindIII and EcoRI restriction sites were used to determine the sequence of the DNA recovered from the TIF1 locus of the PAR clones. This revealed the presence of a single point mutation within the coding region of $T I F 1$ that results in a proline to leucine substitution at position 147. In the wild type protein P147, as is commonly seen in other proteins, causes a sharp kink in the peptide back-bone at the end of an alpha helix which facilitates the tight turn required to place the next helix in the correct position (Caruthers, Johnson et al. 2000), and is close in proximity to the RNA binding portion of the N-terminal of eIF4A. Given this scenario it is possible that substitution of a leucine may prevent this tight kink and therefore have dramatic and far reaching consequences on the overall structure of the domain. However, there are a number of crystal structures reported in the literature that contain a leucine in an equivalent sequence to the P147 in wild-type yeast eIF4A motif $\mathrm{Ib}$, whilst still retaining the kink characteristic of the eIF4A proline-containing motif (Figure 7.4, Appendix B) (Stec, Rao et al. 1995; Matias, Soares et al. 2001), which indicates that leucine is capable of maintaining the kink in the peptide back-bone that the proline does. Also, since the only source of Tif1/2p in the original PAR clones, which evidenced no growth defect, was the pateamine resistant form bearing this mutation, it is obviously functional, arguing against a large-scale change to protein structure due to this mutation. It is currently unclear whether this mutation confers resistance to pateamine by abrogating the binging event or by uncoupling the binding event from the structural change that pateamine induces upon binding. 
It is of interest to note that the position at which this point mutation occurs is highly conserved across almost all DEAD-box helicase enzymes, known as motif Ib (Linder 2006), yet pateamine seems to be a specific eIF4A inhibitor, since it does not affect Ded1p function in vitro, or any of the helicases involved in the mammalian splicing reaction in vitro (Bordeleau, Matthews et al. 2005). The ubiquitous presence of motif Ib in DEADbox helicase enzymes suggest that this position does not constitute the exact pateamine binding site, however, given the stimulatory activity of pateamine on mammalian eIF4AI helicase and RNA binding activity, this might suggest the P147L mutation uncouples the pateamine binding event from the stimulation of RNA binding, possibly by decreasing the affinity the $\mathrm{N}$-terminal lobe has for RNA, or perhaps prevents the formation of a pateamine-eIF4A covalent adduct.

\subsubsection{Pateamine inhibits protein and RNA synthesis in yeast}

Consistent with the role of Tif1/2p in translation initiation in yeast, pateamine inhibits the incorporation of tritiated leucine at concentrations comparable to those that inhibit growth in liquid culture. The incorporation of tritiated uridine was also inhibited at slightly higher concentrations suggesting an effect of pateamine treatment on RNA synthesis. Temperature sensitive mutants that are defective in translation display lowered rates of uridine incorporation when grown at the non-permissive temperature (Gross and Pogo 1976), as do cells treated with high concentrations of the protein synthesis inhibitors edeine and cycloheximide (Gross and Pogo 1974; Gross and Pogo 1976), which suggests a control mechanism that relates the rate of RNA synthesis to the protein synthetic ability of the cell. It has been proposed that some protein factor, presumably of short half-life, is essential for RNA transcription and is not synthesized in the presence of cycloheximide (Gross and Pogo 1974). The concentration of cycloheximide seen to decrease RNA synthesis far exceeds that required to inhibit protein synthesis. Given that the majority of the RNA 
synthesized by yeast cells at any one time is rRNA (Michels and Hernandez 2006), and the high degree of homology shared between Tif1/2p and Fallp (Kressler, de la Cruz et al. 1997), the two-fold difference between the $\mathrm{EC}_{50}$ values for leucine and uridine incorporation may suggest a functional effect of pateamine on Fallp and hence ribosome biogenesis, or that rRNA synthesis in yeast is more susceptible to inhibition of protein synthesis by targeting the initiation phase than it is by targeting elongation.

While the effect on RNA synthesis is more marked in the case of pateamine treatment, compared to cycloheximide, and that it is possible that this is due to an effect on Fallp function, it must be noted that the P147L point mutation in Tif1p is sufficient in conferring pateamine resistance in the presence of, presumably, wild-type Fal1p. This indicates that any direct effect on Fallp by pateamine may only occur at exceedingly high concentrations, or that Fallp is not strictly essential, meaning that even though there may be a functional effect by pateamine, the contribution of this to the decreased fitness in the presence of pateamine is minor. This is supported by the observations that the heterozygous deletion is not haploinsufficient in rich media (Deutschbauer, Jaramillo et al. 2005) and clones containing FAL1 driven by either a tetracycline repressible promoter or the GAL1 promoter displays negligible fitness defect in the presence of doxycycline (Mnaimneh, Davierwala et al. 2004), or glucose respectively, despite the isolation of temperature sensitive mutants of FAL1 that display reduced fitness at the non-permissive temperature (Kressler, de la Cruz et al. 1997).

\subsubsection{Putative pateamine binding site on eIF4A}

It could be presumed the pateamine resistance conferring mutation identified in this work would not cause a large change in the surface properties of eIF4A, despite the increase in 
amino acid side chain size from proline to leucine, the flexibility of the leucine side chain would not necessarily abrogate the binding of pateamine, although a thorough in silico assessment of this proposition is probably required to say for sure. Given this mutation occurs in a region that is highly conserved amongst both pateamine sensitive eIF4A homologues and other DEAD-box helicases it could be presumed it does not represent the exact binding site. The presence of the cysteine that is conserved amongst the verified eIF4A pateamine targets and not in the pateamine insensitive Ded1p, and resides within $15 \AA$ of the resistance conferring mutation in combination with the presence of the conjugated diene in pateamine at $\mathrm{C} 19-\mathrm{C} 22$ which is directly connected to one of the carbonyl carbon $(\mathrm{C} 18)$ of one of the lactone groups, raises the possibility that the thiol group of the cysteine, may be involved in creating a covalent adduct of pateamine and eIF4A as have been found to be formed by andrographolide and NF- $\kappa \mathrm{B}$ (Xia, Ye et al. 2004).

This may explain the considerable lag period in the recovery of yeast treated with pateamine and also requirement for reducing conditions in the recovery of eIF4A and not $\beta$-tubulin or actin in the affinity isolation experiments. While this is highly speculative, and requires verification, it may be that the $\mathrm{P} 147 \mathrm{~L}$ mutation causes a slight change in orientation of the cysteine side-chain preventing such an addition reaction to occur, alternatively the mutation may cause subtle changes in the surface of eIF4A that may alter the relative position of the diene with respect to the cysteine thiol. As mentioned in the previous chapter the potential eIF4A-pateamine covalent can be investigated with mass spectrometry. 


\subsection{Conclusions}

Pateamine has been shown to inhibit the growth of yeast in a reversible manner and deletion of the major drug efflux pump, Pdr5p, or ergosterol synthesis pathway components increases its potency, despite a recent publication stating the pateamine is not a substrate for the human PgP drug efflux pump which share significant homology with Pdr5p (Kuznetsov, Xu et al. 2009). A pateamine resistant mutant was isolated and the basis of this resistance was shown to be a single point mutation, $\mathrm{P} 147 \mathrm{~L}$, in the TIF1 gene which encodes the yeast orthologue of the mammalian pateamine target eIF4AI. The P147L mutation might be expected to cause significant structural changes, however since the mutant protein was the only source of eIF4A in the original pateamine resistant clones this appears to not be the case. Consistent with the role of eIF4A in yeast translation, pateamine inhibits protein synthesis. While it was not assessed whether the genes encoding actin or $\beta$ tubulin were altered in the drug resistant mutant, the likelihood of a second mutation outside of the TIF1 gene that confers additional resistance is low, furthermore, reintroducing only the TIF1 mutation into a yeast background without mutation elsewhere, albeit at high copy number, was sufficient to provide resistance on its own.

The position of the resistance conferring mutation in a motif highly conserved amongst DEAD-box helicase suggests this might not be the precise binding site of pateamine, but may uncouple the drug binding event from the structural changes normally induced upon drug-binding, or possibly prevent the formation of a covalent adduct. The relatively potent effect of pateamine, compared to other protein synthesis inhibitors, on RNA synthesis, might suggest a role for the inhibition of the eIF4A like protein, Fallp, albeit in a noncovalent manner given the presence of an isoleucine at the equivalent position to the cysteine in the HACI motif, in the growth inhibitory effects of this compound in 
S. cerevisiae, or the effect on uridine incorporation may be as a result of the effect of pateamine on translation initiation. 


\section{Chemogenomic profiling with pateamine}

\subsection{Introduction}

The use of yeast in drug target identification or mode-of-action studies has markedly increased with the advent of chemogenomic screening methods. These methods aim to identify yeast deletion mutants, from a genome-wide collection, that display altered sensitivity to the compound of interest, and infer the mode-of-action or mechanism of that compound based on the function of those genes (Luesch 2006; Boone, Bussey et al. 2007). The completion of the Saccharomyces cerevisiae genome sequencing program (Goffeau, Barrell et al. 1996), and the subsequent designation of putative open reading frames (ORFs), coupled with robotic nucleic acid synthesis technology and the ease at which homologous recombination occurs in this yeast (Baudin, Ozierkalogeropoulos et al. 1993), facilitated the Saccharomyces Gene Deletion Project, the aim of which was to create a deletion strain for each putative ORF found in S. cerevisiae (Winzeler, Shoemaker et al. 1999). The immediate output of this program was the designation of each putative ORF as essential or non-essential in rich media conditions, as well as the production of four yeast deletion libraries: the hemizygous MATa and MAT $\alpha$, deletion sets, in which each strain has a non-essential gene replaced with an antibiotic resistance cassette; the homozygous deletion set which is a result of mating the two hemizygous sets to produce a diploid library of deletion strains; and the heterozygous deletion set where the one copy of each gene in the diploid organism has been replaced with the antibiotic resistance cassette.

Each of these libraries has been used in the literature in an attempt to identify drug targets, or ascribe a mode-of-action to a biologically active compound. Various screen formats have been published including the discrete screening of each deletion mutants in liquid media in 96 or 384 well plates (Butcher and Schreiber 2004), or arrayed to high density on 
agar media (Chan, Carvalho et al. 2000; Xie, Jin et al. 2005), both of which often require considerable amounts of the drugs of interest. In contrast, the parallel or competitive growth assay allows an entire deletion library to be screened in a culture volume of 5-10 ml, this method takes advantage of a unique DNA barcode included in each deletion cassette which allows the relative abundance of each strain in the pooled culture to be quantified by microarray analysis (Shoemaker, Lashkari et al. 1996; Giaever, Chu et al. 2002). While the screening procedure for the homozygous and heterozygous deletion sets is essentially identical, the theoretical basis of their use and the interpretation of the results differ somewhat.

\subsubsection{The heterozygous deletion library}

The use of this library in drug target identification relies on the notion that reducing the copy number of the drug-target encoding gene will cause hypersensitivity to an inhibitory compound. It was reported that increasing the copy number of a drug-target encoding gene decreases the sensitivity of that yeast to the corresponding drug (Rine, Hansen et al. 1983; Launhardt, Hinnen et al. 1998), and the converse, reducing the copy number of the gene by half, by generating a heterozygote deletion strain, leads to hypersensitivity to a drug that targets that gene product (Giaever, Shoemaker et al. 1999). Therefore, it was reasoned that screening a library of heterozygous genes deletion strains of every essential gene with an inhibitory compound, should identify the gene product targeted by that compound, by virtue of the hypersensitivity of the target deletion strain to that compound. In this way, the heterozygous deletion strain of $D F R l$, the gene that encodes dihydrofolate reductase, the target of methotrexate, was found to be the most sensitive strain to that compound, and the heterozygous deletion strains of both $H M G 1$ and $H M G 2$, which encode the target of atorvastatin, HMG-CoA reductase, were the most sensitive in its presence (Giaever, Flaherty et al. 2004). While it is not always the most sensitive heterozygous deletion 
strains that encodes the drug target, for instance the YFLO32W deletion strain is more sensitive to tunicamycin than the deletion strain of its target, ALG7 (Kuo and Lampen 1974), it appears the target gene is often within the top ten sensitive strains and other hypersensitive strains are often within the same pathway. For instance terbinafine targets the ergosterol synthesis pathway by inhibiting Erg1p, the heterozygous deletion of ERG1 displays hypersensitivity along with the deletion of $N C P 1$ which acts as a NADH cofactor binding subunit for ERG11, also within the ergosterol synthesis pathways (Lum, Armour et al. 2004). Hence it has been proposed that heterozygous deletion set screens may provide information regarding all of the functionally relevant target interactions for a drug, including potential secondary targets (Giaever, Flaherty et al. 2004).

The use of the heterozygous yeast deletion library has allowed characterization of a number of novel bioactive compounds. For instance: dihydromotuporamine was shown to affect sphingolipid biosynthesis (Baetz, McHardy et al. 2004) and was later used as a tool to identify the cellular effects of inhibiting sphingolipid biosynthesis; cincreasin was shown to inhibit the Mps1p protein kinase (Dorer, Zhong et al. 2005); and tenovin-6, indentified as an activator of p53 was shown to target the histone deacetylase Sir2p (Lain, Hollick et al. 2008). Given the potential to identify every functionally relevant drug-target interaction, this library has also been used to further elucidate the mechanism of nitrogencontaining bisphosphonates, which are used clinically to treat diseases which involved excess bone resorption and are suspected to act through a variety of mechanisms (Bivi, Romanello et al. 2009). However, by far the most powerful use of the heterozygous deletion set in determining drug mode-of-action has been its use in concert with the homozygous deletion set. 


\subsubsection{The homozygous deletion library}

The use of the homozygous deletion library in determining the mode-of-action of a compound is based on the observation that recessive mutants that display hyper-sensitivity to a drug can identify genes involved in that drug target's function (Umesono, Toda et al. 1983). Stearns and co-workers used EMS to increase genetic variation of a population of yeast then individually screened 20,000 clones for sensitivity to the microtubule depolymerizing agent benomyl (Stearns, Hoyt et al. 1990). Subsequent characterization of these genes showed mutations in the tubulin encoding genes, TUB1, TUB2 and TUB3 as well as three other unlinked genetic loci, named CIN1, CIN2 and CIN4 which were also identified in an independent screen for decreased chromosome stability (Hoyt, Stearns et al. 1990). The authors showed that of the CIN genes genetically interact with TUB1 in a synthetic lethal manner, and that mutation in the TUB2 gene can suppress the hypersensitivity of the $\Delta \operatorname{cin} 1$ and $\Delta \operatorname{cin} 4$ strains to benomyl, indicating a functional relationship between microtubules and the CIN genes. Since their discovery the CIN genes have been shown to be essential for the folding of $\beta$-tubulin (Lopez-Fanarraga, Avila et al. 2001). Importantly the authors noted that deletion of CIN1 and CIN2 gave rise to the same level of benomyl sensitivity as the spontaneous mutations isolated in the original screen, and while the deletion of CIN4 was not as sensitive to benomyl as the spontaneous mutant, it was still more sensitive than wild-type.

Hitherto a common approach to drug target identification in yeast was to isolate drug resistant yeast mutants, the isolation of hypersensitive mutants is considerably more laborious since their identification is based on negative rather than positive selection, which means potential hypersensitive mutants must be screened individually against the compound of interest. One advantage of the hyper-sensitivity screen is that the resulting mutation can be mapped by complementation with the wild-type gene in a plasmid library. 
However both resistance and hyper-sensitivity mutation screens both suffer from the considerable draw-back that mapping of the mutations is often laborious. Given the observation that hypersensitivity conferring mutations in non-essential genes are mimicked by the complete deletion of those genes (Stearns, Hoyt et al. 1990), the homozygous deletion set can be screened for the gene deletions that confer hypersensitivity, which will be functionally related to the target and are already mapped. This approach was used to identify components of the TOR signaling pathway by screening 2,216 haploid deletion strains for hypersensitivity or resistance to rapamycin. In this way a number of known TOR pathway components were identified as well as genes involved in other pathways and processes such as vacuolar function and protein synthesis (Chan, Carvalho et al. 2000).

In the same way, the yeast DNA damage response pathway has been extensively studied in screens for hypersensitivity to UV radiation (Birrell, Giaever et al. 2001), $\gamma$-rays (Bennett, Lewis et al. 2001; Game, Birrell et al. 2003), methyl methanesulfonate (Begley, Rosenbach et al. 2002; Chang, Bellaoui et al. 2002; Hanway, Chin et al. 2002) and numerous clinically relevant DNA damaging agents (Birrell, Brown et al. 2002; Wu, Brown et al. 2004). In a truly chemical-genetic fashion, the inhibitor PS-341 was used to study the cellular effects of proteasome inhibition (Fleming, Lightcap et al. 2002), wortmannin was used to propose novel functions of the phosphatidylinositol pathway (Zewail, Xie et al. 2003), the role of the Rho-PKC-MAPK in cell wall biosynthesis was revealed by virtue of caspofungin hypersensitivity (Markovich, Yekutiel et al. 2004) and the cellular functions of the chaperone Hsp90p was demonstrated with geldanamycin, in combination with an assessment Hsp90p's genome-wide synthetic lethal interactions and physical interactions (Zhao, Davey et al. 2005). Although all of these studies used well characterized compounds they show the power in this approach not only to identify genes directly involved in the same process affected by a drug, but also other cellular processes that may 
be required for resistance to that drug or response to its presence, and that the function of these hypersensitive mutants could aid in the elucidation of the mode-of-action of an uncharacterized drug.

In support of this supposition it was shown that the profile of deletion mutants that display hypersensitivity to compounds with a similar mode-of-action are significantly correlated, as in the cases of the immunosuppressants cyclosporine A and FK506 and the DNA damaging agents hydroxyurea and camptothecin. Furthermore it was shown the drugspecific hypersensitivity profiles for cyclosporine and FK506 were highly correlated with negative-genetic interactions of their target gene, $C N B 1$, likewise the profile of benomyl was very similar to the synthetic lethal genetic interaction profile of a temperature sensitive TUB2 allele, and they form a cluster in hierarchical cluster analysis (Parsons, Brost et al. 2004). The authors propose linking drugs to their targets by this chemical-genetic synthetic-lethal genetic interaction correlation, a proposition that relies on the notion that an active compound mimics a loss-of-function mutation in its target encoding gene. Most of the compounds that were shown to cluster with the genetic interaction profile of their targets (fluconazole, cyclosporine A, FK506 and benomyl) inhibit their targets (Erg11p, Cnb1p and Tub1/2p), camptothecin on the other hand requires the enzymatic activity of topoisomerase I in order to be toxic, so the lack of correlation with the TOP1 genetic interaction profile in understandable, nevertheless its chemical-genetic profile clustered with that of hydroxyurea and genes known to be involved in DNA replication and repair. It must be noted that the wide-spread application of this approach hinges on the existence of a database of genome-wide synthetic lethal interactions which will presumably be available in the next few years with the development of high throughput synthetic-genetic array analysis (Tong, Evangelista et al. 2001; Tong and Boone 2006; Costanzo, Baryshnikova et al. 2010). 
The development of parallel or competitive growth assays (Shoemaker, Lashkari et al. 1996; Giaever, Chu et al. 2002) has lead to a large number of chemical genetic profiles for drugs of diverse structure and activity (Parsons, Lopez et al. 2006; Hillenmeyer, Fung et al. 2008). These datasets have reaffirmed the concept that similar drugs generate similar profiles, albeit in an arguably mode-of-action dependant manner (Hillenmeyer, Ericson et al. 2010), as well as further defining genes whose deletions cause hypersensitivity to numerous active compounds, known as multi-drug sensitizing (MDS) gene deletions. This has highlighted the importance of vesicular trafficking in drug efflux function as well explaining these genes' presence in a number of profiles (Hillenmeyer, Fung et al. 2008). While homozygous deletion set profiling can be informative in terms of identifying the cellular processes required for resistance to the compound of interest, it rarely identifies drug targets directly, since essential drug targets are not present in this library, and the majority of drugs that are inhibitory in yeast target essential genes. This creates difficulties in interpreting the results of a screen with a compound that is truly novel. A more powerful approach is to screen both deletion libraries with the compound of interest (Hillenmeyer, Fung et al. 2008; Yu, Lopez et al. 2008; Kemmer, McHardy et al. 2009) and in combination with a multi-copy plasmid borne random genomic library to incorporate increased and decreased gene dosage effect (Hoon, Smith et al. 2008).

In chapter 3 it was shown that a single point mutation in the eIF4A encoding TIF1 gene, when over-expressed conferred resistance to a relatively high concentration of pateamine whereas over-expression of the wild-type TIF1 failed to. More than 25 genes encoding DEAD-box helicases are present in S. cerevisiae they are involved at almost every step of RNA metabolism and translation (Linder 2006), while the entire super-family is highly conserved structurally, Fal1p has high sequence homology to eIF4A (Kressler, de la Cruz et al. 1997), and therefore represents a distinctly possible secondary target for pateamine. 
Indeed its gene name arises from the fact that it produces a Four A-Like $(F A L)$ protein product. We sought to identify possible effects of pateamine, independent of its effects on eIF4A via a chemogenomic approach. 


\subsection{Aims and Objectives}

The aim of this work is to establish the breadth of target specificity of pateamine, that is to identify every functionally relevant interaction that pateamine takes part in. To this end multiple genome-wide yeast deletion libraries screens were performed to identify both essential genes that exhibit haploinsufficiency and non-essential genes that exhibit hypersensitivity when deleted, in the presence of pateamine, which is indicative of the biological processes affected by pateamine and hence it's targets. The profiles of gene deletions strains hypersensitive to pateamine will be assessed for functional enrichment and their similarity to previously published profiles attained for biologically and chemically diverse compounds. 


\subsection{Materials and Methods}

Yeast strains were maintained according to standard practices previously described. The MATa haploid homozygous yeast deletion library (Thermo Scientific-Open Biosystems) was incubated for 3 days at $30{ }^{\circ} \mathrm{C}$ in 96 well plates in YPD containing $200 \mu \mathrm{g} / \mathrm{ml} \mathrm{G} 418$, shaken every $12 \mathrm{~h}$, and stored at $4{ }^{\circ} \mathrm{C}$ prior to use.

\subsubsection{Serial spot dilution assay}

Deletion strains were grown to saturation in YPD overnight and diluted to an OD600 of 1 prior to use. One hundred $\mu 1$ of OD adjusted cultures were added to 96 well plates and serially diluted ten-fold, after which they were transferred in quadruplicate to rectangular petri dishes containing YPD agar with either $17 \mu \mathrm{M}$ pateamine, $50 \mu \mathrm{M}$ anisomycin, $3.5 \mu \mathrm{M}$ cycloheximide or $0.1 \%$ DMSO using the 96-pin hand pinning tool ( $\mathrm{V} \& \mathrm{P}$ Scientific Inc., San Diego, CA, USA). Plates were incubated for three days at $30^{\circ} \mathrm{C}$, before pictures were taken.

\subsubsection{Pateamine haploid hyper-sensitivity screen}

The screen for MATa haploid deletion strains that display hyper-sensitivity to pateamine was performed in 384 well plates, using YPD containing $16 \mu \mathrm{M}$ pateamine, this concentration was determined to correspond approximately to the $\mathrm{EC}_{20}$ of the $\Delta$ his 3 control strain. The BioTek Precision XS liquid handler (BioTek Instruments, Winooski, VT, USA) was used to dilute the starting culture plates approximately 1000 -fold before being inoculated in quadruplicate into 384 well plates. The plates were returned to the incubator for $30 \mathrm{~h}$ and optical density at $590 \mathrm{~nm}$ measured using the Wallac EnVision 2102 plate-reader (Perkin-Elmer). A deletion strain was deemed hypersensitive if it showed 
greater than $25 \%$ increase in sensitivity with respect to the control $\Delta$ his 3 strain in all three screen repeats. Candidate pateamine hypersensitive deletion strains were confirmed using a $24 \mathrm{~h}$, end-point assay turbidity in triplicate performed in 96 well plates at $16 \mu \mathrm{M}$ pateamine in YPD.

\subsubsection{Confirmation of altered pateamine sensitivity}

Deletion strains hypersensitive to pateamine in the pateamine hyper-sensitivity screen (Method 4.3.2) were further confirmed with the use of an end point liquid growth assay. Strains were picked from the MATa haploid yeast deletion library (Thermo ScientificOpen Biosystems), inoculated into 96-well plates containing YPD containing $200 \mu \mathrm{g} / \mathrm{ml}$ G418 and incubated for 3 days at $30^{\circ} \mathrm{C}$. The 96-pin hand pinning tool (V \& P Scientific Inc., San Diego, CA, USA) was used to inoculate in duplicate from the stationary phase culture into fresh YPD containing $200 \mu \mathrm{g} / \mathrm{ml} \mathrm{G} 418$ containing $4 \mu \mathrm{M}$ pateamine or $0.1 \%$ DMSO and returned to the incubator for $18 \mathrm{~h}$, after which the plates were shaken and their absorbance read at $600 \mathrm{~nm}$ on the Wallac EnVision 2102 plate-reader. Values analogous to the $\varepsilon$-scores used to establish genetic interactions (Schuldiner, Collins et al. 2005) were calculated, this was done by calculating the drug induced growth inhibition of the control $\Delta h i s 3$ strain, and expressing the growth of each strain relative to the $\Delta$ his 3 control, the multiplication of these values gives the predicted growth inhibition if the deletion strain displays no drug hyper or hypo-sensitivity. The growth of each strain in the drug was expressed as a proportion of the growth in the untreated sample, this value was subtracted from the expected score calculated above, if this number is negative the strain is hyposensitive to the drug, a positive values indicates hyper-sensitivity. 


\subsubsection{Pateamine HIPHOP assay}

The homozygous diploid non-essential gene deletion library and the heterozygous diploid essential gene deletion library were used to perform a haploinsufficiency profiling/homozygous profiling (HIPHOP) screen using the pooled microarray method (Pierce, Fung et al. 2006) by members of the Giaever and Nislow group at the University of Toronto Terrence Donnelly Centre for Cellular and Biomolecular Research. The screen was performed four times, twice at $28 \mathrm{nM}$ pateamine and twice a $38.5 \mathrm{nM}$ in YPD for 20 generations, concentrations that were established as being minimally inhibitory in the HIPHOP screen format. Herein the homozygous aspect of these screens are referred to as: HOP screen 1 (38.5 nM pateamine), HOP screen 2 (28 nM pateamine), HOP screen 3 (28 $\mathrm{nM}$ pateamine) and HOP screen 4 (38.5 $\mathrm{nM}$ pateamine); and the heterozygous aspect as: HIP screen 1 (38.5 $\mathrm{nM}$ pateamine), HIP screen 2 (28 nM pateamine), HIP screen 3 (28 $\mathrm{nM}$ pateamine) and HIP screen 4 (38.5 nM pateamine).

\subsubsection{Functional enrichment analysis}

Enrichment of function in the chemogenomic datasets was assessed by gene ontology term analysis performed with the BiNGO 2.41 plug-in (Maere, Heymans et al. 2005) for Cytoscape (version 2.7.0) (Shannon, Markiel et al. 2003) using the current S. cerevisiae gene annotation file (released 07/2010) and gene ontology file (downloaded 19/07/2010) from the GO Consortium website (www.geneontology.org). Over-representation of genes corresponding to GO terms was assessed using a hypergeometric test with a Benjamini and Hochberg false discovery rate correction (Benjamini and Hochberg 1995), significance was assigned to P-values less than 0.05 . 


\subsubsection{Hierarchical cluster analysis}

Two-dimensional agglomerative hierarchical cluster analysis was performed using the clustergram function in Matlab Version 7.8.0.347 (R2009a) (Mathworks Inc.) with two large scale chemical-genetic profiling datasets previously published (Parsons, Lopez et al. 2006; Hillenmeyer, Fung et al. 2008). Prior to clustering, previously identified MDS genes were removed, as well as those genes that do not display hyper- or hypo-sensitivity in the presence of any of the conditions in the datasets. Four datasets were used in the cluster analysis with the supplementary literature data from Hillenmeyer et al:

Dataset 1: $\log _{2}$ ratio data;

Dataset 2: $\log _{2}$ ratio data for hypersensitive and resistant (hyposensitive) strains after the application of a threshold (resistant $=\log _{2}<-1.5$, sensitive $=\log _{2}>0.5$ );

Dataset 3: $\log _{2}$ data of just the hypersensitive strains after the application of the threshold described for dataset 2;

Dataset 4: Dataset 3 converted to a binary form, where a 1 indicates hypersensitivity.

Clustering with the Parsons et al. supplementary data was performed only with the sensitive strain data but the same threshold as described for dataset 2 above was applied. The $\log _{2}$ ratio data was clustered using both the centered and uncentered Pearson distance metric and the binary data set was clustered using the Jaccard distance metric, in all cases the average linkage method was used to form clusters. 


\subsubsection{Protein synthesis inhibitor sensitive strain overlap}

The overlap of protein synthesis inhibitor chemogenomic datasets was visualized in Cytoscape (version 2.7.0) with the binary profiles of: hygromycin, verrucarin, streptovitacin, cycloheximide, neomycin sulfate, anisomycin (Hillenmeyer, Fung et al. 2008), emetine, anisomycin (Parsons, Brost et al. 2004), anisomycin, verrucarin, neomycin, emetine (Parsons, Lopez et al. 2006) supplemented with focused screen data on: sordarin (Botet, Rodriguez-Mateos et al. 2008), hygromycin B (Banuelos, Moreno et al. 2010), and paromomycin (Alamgir, Eroukova et al. 2008).

\subsubsection{Network analysis}

Physical and genetics interaction present in the SGD database for hits from all pateamine screens performed (the haploid screen, HOP screen $1-4$ and HIP screen $1-4$ ), were downloaded and merged, in Cytoscape, with a network consisting of individual nodes for each screen with edges connecting these nodes to nodes representing each hit in each of the screens. The pateamine screen nodes were selected, each node directly connected by these nodes (the screen hits) were selected and all other nodes were deleted. This left a network consisting of pateamine screen nodes, connected to their respective gene hits and the inter-hit interactions. This network was then searched with the MCODE algorithm for sub-networks of increased edge density; the resulting sub-networks were then assessed for enriched function using the BiNGO plug-in as described in Method 4.3.5. 


\subsection{Results}

\subsection{1 eIF4F component sensitivity to pateamine}

The sensitivity of various eIF4F complex members to pateamine was assessed in YPD using a serial spot dilution assay. The MATa strains bearing deletion of the eIF4F complex members elF4A ( $\Delta t i f 1$ and $\Delta t i f 2)$ and one of the isoforms of elF4G ( $\Delta t i f 4632)$, as well as the yeast homologues of human eIF4E-BP $(\Delta c a f 20)$ and eIF4B ( $\Delta$ tif3) were tested for hypersensitivity to pateamine and the ribosome targeting protein synthesis inhibitors cycloheximide and anisomycin (Figure 4.1). Each strain was serially diluted ten-fold twice and pinned in quadruplicate onto YPD agar media containing the drugs at a concentration that slightly inhibited the growth of the surrogate wild-type deletion strain ( $\Delta h i s 3)$ at the greatest cell dilution. Deletion of either TIF1 or TIF2 conferred a slight increase in pateamine sensitivity, whereas the $\Delta t i f 3$ strain was extremely sensitive to pateamine. While the deletion of TIF3 also caused hypersensitivity to both anisomycin and cycloheximide it was not to the same extent as to pateamine, it is also interesting to note that the $\Delta$ tif2 and not $\Delta$ tifl strain was hypersensitive to anisomycin, more so than it was to pateamine. The deletion of TIF4632 and CAF2O had a negligible effect on pateamine and cycloheximide sensitivity but conferred slight hypersensitivity to anisomycin. 


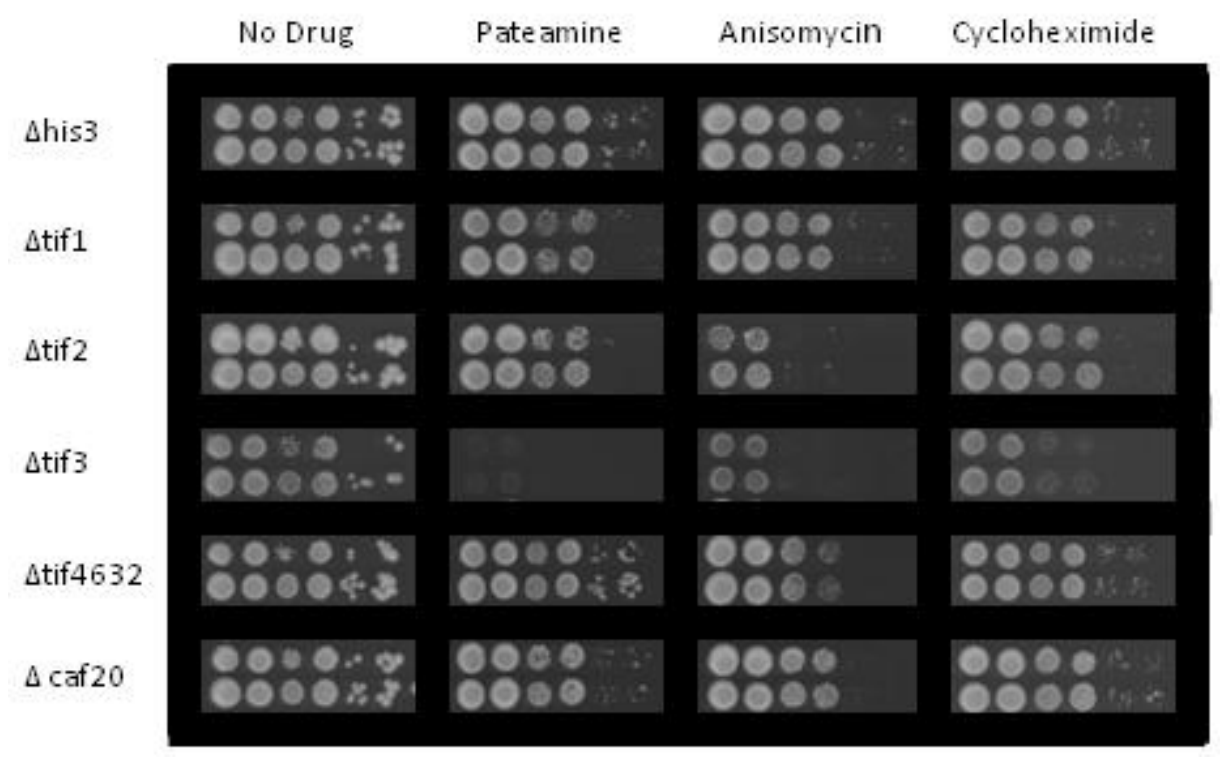

Figure 4.1 Serial spot dilution assay of elF4F component deletion strains. Overnight cultures of the deletion strains of elF4F components ( $\Delta$ tif1, $\Delta$ tif2 and $\Delta$ tif4632) as well as the yeast homologues of human elF4B ( $\Delta$ tif3) and 4E-BP ( $\Delta$ caf20) and the surrogate wild-type strain ( $\Delta$ his3) were diluted to an OD of 1 , and serially diluted 10 -fold twice in 96 well plates. A hand pinning tool was used to spot each dilution in quadruplicate onto YPD agar containing either: $17 \mu \mathrm{M}$ pateamine; $50 \mu \mathrm{M}$ anisomycin; $3.5 \mu \mathrm{M}$ cycloheximide; or $0.1 \%$ DMSO as a carrier solvent control.

The growth of the $\Delta$ tifl and $\Delta$ tif 2 strains in the presence of pateamine was quantified in liquid YPD, hypersensitivity must be defined as a growth inhibition that is greater than is to be expected when taking into account the growth defect conferred by the gene deletion in combination with that caused by the drug treatment, to this end $\varepsilon$-scores were calculate according to method 4.3.3. In the presence of $15 \mu \mathrm{M}$ pateamine the average $\varepsilon$-score of three independent experiments performed in triplicate was 0.087 and -0.096 for the both $\Delta$ tifl and $\Delta$ tif2 strains respectively, a score of 0 indicates that the growth rate of the deletion strain when treated with the drug is equal to what would be expected if the deletion does not confer hypersensitivity, that is the growth inhibition of both TIF1 and TIF2 deletion and pateamine treatment combine in an additive fashion. The same analysis was performed on the heterozygous deletion strain of $F A L 1$, here the average $\varepsilon$-score from three independent experiments performed in triplicate was -0.013 , indicating FAL1 is not 
haploinsufficient in the presence of pateamine, this is also illustrated in Figure 4.2 which shows the growth over time of the wild-type BY4743 and the FAL1 heterozygous deletion. While it appears the FAL1 heterozygous deletion strain grows slightly slower in the presence of $5 \mu \mathrm{M}$ pateamine, it is still within the error of the untreated curve. It would appear that the homozygous deletion TIF1 and TIF2 strains and the heterozygous FAL1 deletion strain are not hypersensitive to pateamine treatment and therefore would not be expected as hits in the HOP and HIP screens respectively.

BY4743

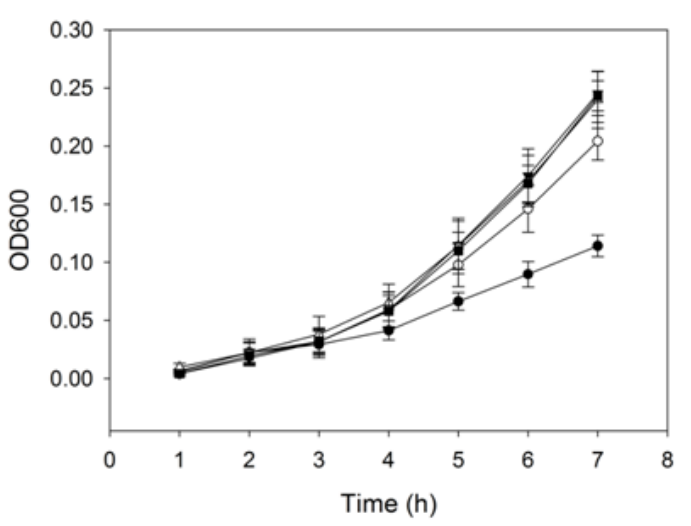

FAL1::fal1

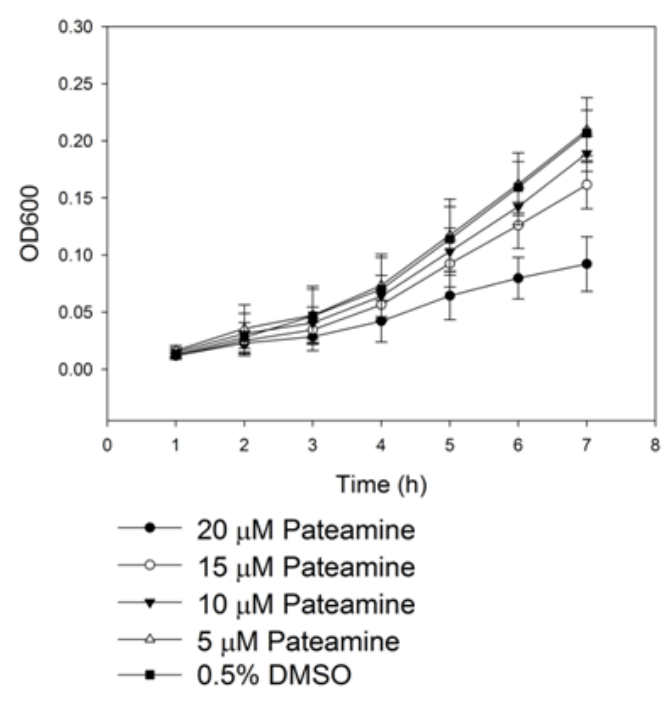

Figure 4.2 Pateamine sensitivity of the heterozygous $\Delta$ fal1 deletion strain. Wild-type diploid BY4743 and the heterozygous $\Delta$ fal1 strains were harvested from exponential growth phase cultures in YPD and diluted to an OD of 0.1 in YPD. Pateamine was added at the indicated concentrations in triplicate and $0.5 \%$ DMSO served as a carrier. OD $590 \mathrm{~nm}$ was measured using the Wallac EnVision 2102 plate-reader at the indicated time points, data points correspond to the average of the triplicates and errors bars correspond to the standard deviation. 


\subsubsection{Pateamine haploid hyper-sensitivity screen}

The MATa haploid deletion library was screened in 384 well plates for strains displaying hypersensitivity to $16 \mu \mathrm{M}$ pateamine in YPD. This screen was performed three times and strains that displayed hypersensitivity in all three screens were reassessed in 96 well plates at the same concentration of pateamine. A total of 247 haploid strains were found to be greater than $20 \%$ more sensitive to pateamine in these conditions (Sheet 1, Supplementary File 2), of which 17 carried deletions of uncharacterized genes and 63 have been previously shown to be multi-drug sensitizing (MDS) deletions in at least one of three large scale chemogenomic screening papers published (Parsons, Brost et al. 2004; Parsons, Lopez et al. 2006; Hillenmeyer, Fung et al. 2008) indicating not only that pateamine is a substrate of the membrane bound drug efflux pump, Pdr5p as observed previously (Section 3.4.2), but also that vacuolar acidification may play a role in resistance to it or its detoxification.

Assessment of functional enrichment by GO term analysis of those deletion strains that have not been identified as multi-drug sensitizing shows statistically significant enrichment of gene deletions involved in the ribosome $\left(\mathrm{P}=2.4 \times 10^{-3}\right)$, the eIF4F translation initiation complex $\left(\mathrm{P}=3.4 \times 10^{-4}\right)$ and stress granules $\left(\mathrm{P}=3.0 \times 10^{-2}\right)$, as well as genes involved in protein poly-ubiquitination $\left(\mathrm{P}=4.6 \times 10^{-2}\right)$, the Golgi apparatus function $\left(\mathrm{P}<9.0 \times 10^{-3}\right)$, RNA processing $\left(\mathrm{P}<1.5 \times 10^{-3}\right)$ and RNA polymerase II dependant transcription $\left(\mathrm{P}<2.7 \times 10^{-2}\right)$ (Sheet1, Supplementary File 3), processes that could be expected to be sensitive to, or whose disruption could sensitize to, a perturbation of eIF4A activity or protein synthesis. 
During the re-screen it was apparent that the effective concentration of pateamine in this format was significantly lower than that observed in the primary screen format. Given this, the deletion strains hypersensitive to $16 \mu \mathrm{M}$ pateamine were retested for hypersensitivity to $4 \mu \mathrm{M}$ pateamine, a concentration that inhibited the $\Delta$ his 3 surrogate wild-type strain by $10 \%$. Hyper-sensitivity to $4 \mu \mathrm{M}$ pateamine was established with a $\varepsilon$-score of less than -0.15 . A total of 27 deletion strains were deemed hypersensitive to $4 \mu \mathrm{M}$ pateamine, seven of which bear MDS deletions, and one which is uncharacterized (Sheet 1, Supplementary File 2). Those strains not bearing MDS deletions were analyzed for functional enrichment; however no statistically significant GO term enrichment was found. It is of note that consistent with the previously performed serial spot dilution assay (Figure 4.1) the $\Delta$ tif3 deletion strain retained pateamine hypersensitivity at the lower pateamine concentration yet the other eIF4F component encoding gene deletions do not. While no statistically significant enrichment of translation or RNA metabolism GO terms was found it is also of note that nine of the 21 non-MDS deletion strains that retain hypersensitivity to $4 \mu \mathrm{M}$ pateamine are all described as being involved in these processes (Sheet 1, Supplementary File 2).

The haploid deletion strains hypersensitive to pateamine were analyzed for overlap with previously published strains sensitive to the known protein synthesis inhibitors: cycloheximide (Cooper, Banthorp et al. 1967); paromomycin (Jacoby and Gorinl 1968); neomycin sulfate (Shimma and Uno 1990); anisomycin (Grollman 1967); emetine (Gupta and Siminovitch 1977); sordarin (Capa, Mendoza et al. 1998); hygromycin B (Cabanas, Vazquez et al. 1978); verrucarin (Fried and Warner 1981); and streptovitacin (Felicett, Colombo et al. 1966). A total of 133 from the 247 pateamine sensitive haploid strains where also sensitive to at least one previously screened protein synthesis inhibitor (Sheet 2, Supplementary File 2), however a significant proportion of these (46/133) were also 
previously identified as MDS deletion strains. Functional enrichment analysis of this overlap, minus the MDS deletion strains, gave statistically significant enrichment of genes involved in: RNA metabolism $\left(\mathrm{P}<3.2 \times 10^{-2}\right)$; regulation of transcription $\left(\mathrm{P}<1.8 \times 10^{-3}\right)$; the ribosome $\left(\mathrm{P}<1.9 \times 10^{-2}\right)$; regulation of translation $\left(\mathrm{P}=1.1 \times 10^{-3}\right)$; the Golgi apparatus $\left(\mathrm{P}<1.9 \times 10^{-2}\right)$; and the eIF4F complex $\left(\mathrm{P}=1.2 \times 10^{-3}\right)$ (Sheet 2, Supplementary File 3), this is consistent with the notion that these process could be sensitive to disruption of protein synthesis or translation initiation.

\subsubsection{Heterozygous essential gene deletion library results}

The library of heterozygous deletion strains of essential genes was screened for those that are haploinsufficient in the presence of pateamine, the screen was performed four times, with a range of correlation scores of the dataset both before and after the application of a $\log _{2}$ ratio threshold of 0.5 (Table 8.1, Appendix C). The application of the $\log _{2}$ ratio threshold serves to highlight the false increase in correlation observed when nonsignificant $\log _{2}$ ratio values are included in these calculations, it should be noted that this level of correlation is common amoungst HIP screen replicates previously published (Hillenmeyer, Fung et al. 2008; Hillenmeyer, Ericson et al. 2010).

In total, 49 heterozygous deletion strains (Sheet 3, Supplementary File 2) were identified to be haploinsufficient in the presence of pateamine in three of the four screens performed, of these, two ( $\Delta m e d 7$ and $\Delta g l c 7$ ) have been previously identified as displaying haploinsufficiency in the presence of a number of compounds (Hillenmeyer, Fung et al. 2008). These strains were therefore omitted from further analysis, as were the three dubious open-reading-frame deletions that exhibited haploinsufficiency. Consistent with the results of the growth rate experiments with the $\Delta$ fall heterozygous deletion strain 
(Figure 4.2) it did not appear to be haploinsufficient in the presence of pateamine in any of the four heterozygous screen replicates.

It has been previously noted that often the heterozygous deletion strain of a drug target encoding genes appears within the top-ten most sensitive strains to that drug (Lum, Armour et al. 2004). Since TIF1 and TIF2 are non-essential genes the heterozygous deletions were not amongst those tested for haploinsufficiency in the presence of pateamine. The previous growth assays of the $F A L 1$ heterozygous deletion strains showed a lack of haploinsufficiency and as such it is not surprising that this strain is not in the top-ten list of hits in any of the screen replicates (Table 4.1 and Sheet 4, Supplementary File 2). Only two heterozygous deletion strains were consistently within the top-ten most pateamine-sensitive, these genes encode the mRNA splicing factor, Prp3p (Vijayraghavan, Company et al. 1989) and the MAP kinase scaffold protein Ste5p which is involved in the pheromone response and mating (Elion 2001), neither of which have been implicated as potential pateamine targets

\begin{tabular}{|l|l|l|r|l|r|l|l|}
\hline HOP 1 & $\begin{array}{l}\log _{2} \\
\text { ratio }\end{array}$ & HOP 2 & $\begin{array}{l}\log _{2} \\
\text { ratio }\end{array}$ & HOP 3 & $\begin{array}{l}\log _{2} \\
\text { ratio }\end{array}$ & HOP 4 & $\begin{array}{l}\log _{2} \\
\text { ratio }\end{array}$ \\
\hline PRP3 & 1.20563 & SHQ1 & 2.81491 & SHR3 & 1.31592 & PRP3 & 1.63675 \\
\hline STE5 & 1.18035 & CFT2 & 2.56481 & PRP3 & 1.29605 & RHO1 & 1.31886 \\
\hline SHR3 & 1.10247 & MED7 & 2.54759 & ERG1 & 1.19322 & STE5 & 1.29398 \\
\hline SHQ1 & 1.07347 & MGE1 & 2.2001 & STE5 & 1.09775 & TLG1 & 1.26767 \\
\hline YNL114C & 1.06204 & PRP3 & 1.9873 & NBP35 & 1.07074 & SHR3 & 1.22015 \\
\hline ERB1 & 0.902135 & CDC37 & 1.98417 & GCD11 & 0.952337 & INH1 & 1.01295 \\
\hline ERG1 & 0.885164 & KRE5 & 1.91341 & CWC2 & 0.921177 & NBP35 & 0.994744 \\
\hline YNL247W & 0.865951 & ERG8 & 1.89348 & PSE1 & 0.896843 & ERB1 & 0.977173 \\
\hline NBP35 & 0.841353 & STE5 & 1.76521 & YGR114C & 0.893818 & YNL114C & 0.937676 \\
\hline ERG8 & 0.819469 & GCR1 & 1.71899 & KRE5 & 0.88745 & ASA1 & 0.883253 \\
\hline
\end{tabular}

Table 4.1 Top-ten haploinsufficient strains from four pateamine HIP replicates and their $\log _{2}$ ratio scores. HOP screens $1-4$ were performed in the presence of $38.5,28,28$ and $38.5 \mathrm{nM}$ pateamine respectively, in YPD medium. Bold gene names indicate the only two strains to appear in the top-ten hits of all screen replicates. 
Functional enrichment of the top ten hits from each screen was assessed using the BiNGO plug-in available for Cytoscape (Maere, Heymans et al. 2005), Sheet 3, Supplementary File 3 shows the GO terms which are found to be significantly over-represented. In HIP screen 1 the top ten hits were enriched for ncRNA metabolic process and ergosterol biosynthetic process $\left(\mathrm{P}=4.59 \times 10^{-2}\right.$ and $\mathrm{P}=3.38 \times 10^{-2}$ respectively). The ten most sensitive heterozygotes in HIP screen 4 were enriched for signal transduction regulation $\left(\mathrm{P}=3.22 \times 10^{-2}\right)$ and MAPKKK cascade regulation $\left(\mathrm{P}=7.51 \times 10^{-3}\right)$, as was HIP screen 2 , there were no significant GO terms represented in HIP screen 3.

It is not too surprising that there is little GO term enrichment in the top ten hits of these screen replicates given there were a total of $53,80,74$, and 90 hits above a $\log _{2}$ ratio of 0.5 in HIP screens 1 - 4 respectively. While the Pearson correlation score of the four screen replicates with a $\log _{2}$ ratio threshold shows a reasonably high degree of correlation between the replicates (Table 8.2, Appendix C), if the overlap of hits in each screen replicate is assessed using the Jaccard distance measure, the congruence of the four screens is lowered considerably (Table 8.2, Appendix C). Given the broad range of correlation scores for the screen replicates it may be more appropriate to look at the GO term enrichment of heterozygous deletion strains that display haploinsufficiency in each of the four screen replicates separately. Sheets $4-7$ of Supplementary File 3 show the significant GO term enrichment for each of the four screen replicates. While there is a reasonable degree of variation in the GO term enrichment results for each screen (Table 8.2, Appendix C), what is striking is the significant enrichment of almost every aspect of RNA metabolism including: mRNA transcription, splicing and polyadenylation; tRNA aminoacylation; and DNA polymerase II transcription and termination, and ribosome biogenesis; as well as the conspicuous absence of terms directly describing translation. Given the variation in replicate screen results, if only those heterozygotes that appear 
haploinsufficient in the presence of pateamine in three of the four screen replicates is assessed, only the terms RNA metabolic process and ncRNA (non-coding RNA) metabolic process appear significantly enriched $\left(\mathrm{P}=3.5 \times 10^{-3}\right.$ and $\mathrm{P}=3.52 \times 10^{-2}$ respectively); though it must be noted that ncRNA is a daughter term of RNA metabolic process and consequently includes all of the genes mapped to this term as well.

In order to establish the protein synthesis inhibitor specificity of the HIP results, the overlap between the pateamine sensitive heterozygous strains, and those known to be haploinsufficient in the presence of known protein synthesis inhibitors (Hillenmeyer, Fung et al. 2008), and that of resveratrol, which has recently been proposed to target eIF4A (Lomenick, Hao et al. 2009), was assessed (Sheet 5, Supplementary File 2). A total of 18 out of 49 heterozygote strains appear haploinsufficient in three of the four pateamine screen replicates. The presence of the $\Delta s t e 5$ and $\Delta c d c 37$ heterozygous strains in this overlapping set caused the statistically significant detection of the GO term regulation of MAPKKK cascade $\left(\mathrm{P}=1.1 \times 10^{-4}\right)($ Sheet 12 , Supplementary File 3$)$, however given there are only 18 genes ascribed to this term this significance may be misleading. The overlaps of the four individual HIP screens with known protein synthesis inhibitors was also assessed, in this case $19 / 53,42 / 88,24 / 74$ and $37 / 90$ of the pateamine haploinsufficient strains overlap with known protein synthesis inhibitors respectively (Sheet 5, Supplementary File 2). Functional enrichment of these overlaps shows statistically significant enrichment of RNA metabolism related process in all but screen replicate 3, as seen with the full individual screen results (Sheets $9-11$, Supplementary File 3), which suggests they may be indicative of a set of chemogenomic interactions that are specific to protein synthesis inhibitors. None of the overlaps identified included genes that have been identified as being multi-drug haploinsufficient heterozygous gene deletions, thus strengthening their attribution as protein synthesis inhibitor specific nature. 
In order to establish whether the profile of pateamine haploinsufficient strains was similar to any other drugs screened, hierarchical cluster analysis was performed with the four haploinsufficiency profiles of pateamine and the essential gene heterozygous deletion dataset from Hillenmeyer et al (2008). Prior to clustering, those heterozygous strains shown to be haploinsufficient in the presence of multiple compounds were removed, as were those strains that did not display haploinsufficiency to any of the conditions screened. Clustering was undertaken using a number of different approaches: $\operatorname{Raw} \log _{2}$ ratio dataset clustered using the centered correlation; Raw $\log _{2}$ ratio dataset clustered using the uncentered correlation distance metric; threshold dataset 2 (see method 4.3.6), sensitive strains are $\log _{2}$ ratio $>0.5$, resistant are $\log _{2}<-1.5$ clustered using the centered correlation distance metric; threshold dataset 2, clustered using the uncentered correlation distance metric; threshold dataset 3 , sensitive strains are $\log _{2}$ ratio $>0.5$ clustered using the centered correlation distance metric; threshold dataset 3 (see method 4.3.6), sensitive strains are $\log _{2}$ ratio $>0.5$ clustered using the uncentered correlation distance metric; binary representation of dataset 3, known as dataset 4, clustered with the Jaccard distance metric; binary representation of gene deletions that were sensitive in three of four screen replicates, clustered with dataset 4 using the Jaccard distance metric, all clustering was performed using the average linkage method to form clusters.

In each case, despite the overlap with the heterozygous deletion strain profiles of other protein synthesis inhibitors previously discussed, the haploinsufficiency profiles of pateamine failed to cluster with any other profiles of drugs or environmental conditions present in the dataset. Figure 4.3 provides an example clustergram, and complete clustergrams are presented in Figure 8.1 - 8.7, Appendix C. Of particular note is the lack of cluster with resveratrol despite it sharing the most overlaps with the pateamine haploinsufficient heterozygotes, also of note is the lack of coherent clusters formed by any 
of the protein synthesis inhibitors observed in previous analyses on this dataset (Hillenmeyer, Fung et al. 2008; Hillenmeyer, Ericson et al. 2010), this suggests that although there seems to be a set of protein synthesis inhibitor specific haploinsufficient genes, there is not enough similarity in the overall profiles to cause cluster formation with the methods used here.

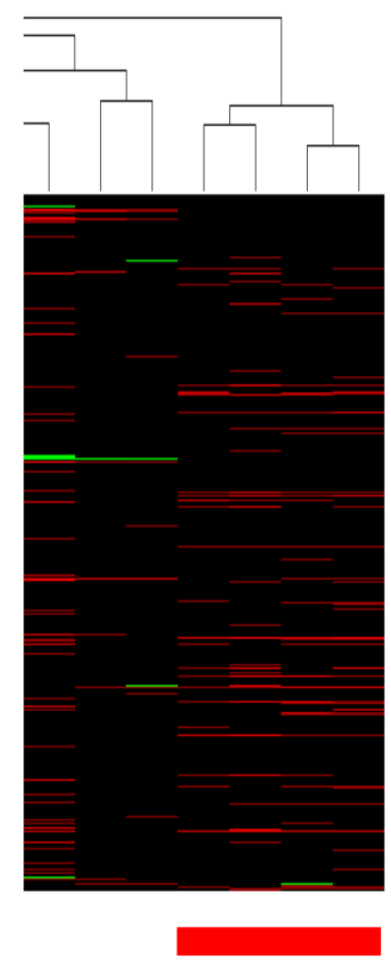

Figure 4.3 Heterozygous diploid (HIP) pateamine screen results hierarchically clustered with the essential heterozygous deletion screen dataset from Hillenmeyer et al with dataset 2 using the uncentered correlation distance metric. This was performed with a variety of distance metrics and dataset thresholds (see Figure 8.1 - Figure 8.7, Appedix $C$ for complete clustergrams). Pateamine screens are underlined with red where all four screen replicates were clustered.

\subsubsection{Homozygous deletion library screen results}

The library of homozygous diploid deletion strains was screened for those that conferred hypersensitivity to pateamine, the screen was performed four times with a broader range of 
correlation between screens, both before and after the application of a $\log _{2}$ ratio threshold of 0.5 , than was observed for the heterozygous screen (Table 8.3, Appendix C). The four HOP screens identified 231, 306, 386 and 407 pateamine hypersensitive deletions strains, of which: 30, 38, 41 and 51 were annotated as dubious open reading frames; 26, 47, 48 and 63 were annotated as uncharacterized open reading frames; and 16, 16, 23 and 20 were previously identified as MDS deletion strains respectively. A total of 198 strains displayed hypersensitivity to pateamine in three of the four screens performed, of which nine were previously identified as MDS deletion strains, 25 of which are annotated as dubious open reading frames, and 40 of which were annotated as uncharacterized. Nineteen pateamine hypersensitive haploid deletion strains were also identified in at least one HOP screen (Supplementary File 2, Sheet 9).

Functional enrichment analysis of each screen replicate and the hits from three of the four screens yielded no statistically significant results with the exception of the first screen replicate in which the GO terms: protein insertion into ER membrane $\left(\mathrm{P}=4 \times 10^{-3}\right)$; $\mathrm{M}$ phase $\left(\mathrm{P}=3.2 \times 10^{-2}\right)$; and cell cycle process $\left(\mathrm{P}=4 \times 10^{-2}\right)$ were found to be enriched (Sheet 13, Supplementary File 3). The application of a more stringent $\log _{2}$ ratio threshold also failed to reveal any significant GO term enrichment (data not shown).

The overlap of the strains hypersensitive to pateamine and other protein synthesis inhibitors was assessed for each screen replicate and for those that appeared hypersensitive to three of the four screen replicates. A significant proportion of the overlaps in each case were due to the presence of MDS deletion strains (Sheet 7, Supplementary File 2) as was seen in the previous haploid deletion set screen. Those overlapping hypersensitive strains that were not MDS strains were not significantly enriched for any functional category, with 
the exception of the overlap with screen one which showed enrichment for the GO term protein insertion into the ER membrane $\left(\mathrm{P}=3.7 \times 10^{-3}\right)$ (Sheet 14 , Supplementary File 3), as was noted in the same analysis on the complete hit list (Sheet 13, Supplementary File 3). This suggests that gene deletions that sensitize to multiple protein synthesis inhibitors do not fall into a discreet biological process.

Following removal of MDS-related hits, the homozygous diploid chemogenomic profiles obtained for the four pateamine screens were clustered with two previously published datasets, referred to as the Hillenmeyer (Hillenmeyer, Fung et al. 2008) and Parsons (Parsons, Lopez et al. 2006) datasets respectively (Figure 8.8 - Figure 8.14, Appendix C). The Hillenmeyer homozygous dataset variations used in this clustering experiment were the same as those for the heterozygous datasets from the same publication mentioned in the above section (Section 4.4.3), and included data pertaining to both sensitive and resistant strains in the various conditions screened, the Parsons dataset on the other hand contained only strains that were deemed as being hypersensitive to the compounds screened.

Once again, despite the overlaps between the pateamine hypersensitive deletions and those hypersensitive to known protein synthesis inhibitors, in each variation of the cluster analysis pateamine failed to cluster with any of the previously published profiles in either the Hillenmeyer (Figure 4.4) or Parsons (Figure 4.5) datasets, regardless of the type of data included with respect to sensitive and resistant strains or the application of the described thresholds on the data. The clustering methods, with respect to the choice of distances metric and threshold, have been previously applied to successfully identify clusters of compounds of similar modes of action (Parsons, Brost et al. 2004; Parsons, Lopez et al. 2006; Hillenmeyer, Fung et al. 2008; Hillenmeyer, Ericson et al. 2010), furthermore the 
clustering performed here has successfully recapitulated clusters of drugs previously published, specifically DNA damaging agents and oxidative stress inducing agents clusters, reaffirming the robustness and applicability of the methods performed. As was noted in the clustering of the heterozygous datasets, the few protein synthesis inhibitors that are present in the datasets fail to form a distinct cluster with any of the variations in dataset or clustering method employed here, as has been noted in previous analyses (Hillenmeyer, Fung et al. 2008; Hillenmeyer, Ericson et al. 2010).

Figure 4.4 Homozygous diploid (HOP) pateamine screen results hierarchically clustered with the essential heterozygous deletion screen dataset from Hillenmeyer et al with dataset 2 using the uncentered correlation distance metric. This was performed with a variety of distance metrics and dataset thresholds (see Figure 8.8 - 8.14, Appendix C for complete clustergrams). Pateamine screens are underlined with red where all four screen replicates were clustered. 


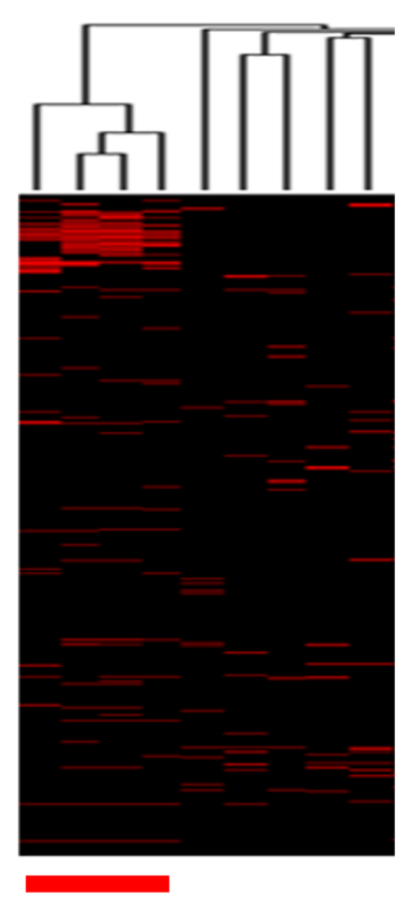

Figure 4.5 Homozygous diploid (HOP) pateamine screen results hierarchically clustered with the homozygous deletion screen dataset from Parsons et al using the uncentered correlation distance metric. This was performed with a variety of distance metrics and dataset thresholds (see Figure 8.15 - Figure 8.17, Appendix C for complete clustergrams). Pateamine screens are underlined with red where all four screen replicates were clustered.

\subsubsection{Network analysis}

Given the lack of significant functional enrichment in the pateamine HOP results and the failure to find other conditions or drugs that the pateamine profiles would cluster with, an alternative analysis was performed taking into account the known genetic and physical interactions of the genes whose deletions conferred hypersensitivity to pateamine. This allows gene deletions to be grouped according to empirically defined interactions rather than shared functional annotation. In this analysis the genetic and physical interactions of all of the pateamine hits from each of the screens described above were downloaded from SGD, a bipartite network was constructed where nodes correspond to each of the pateamine screens which are connected by an edge to nodes that correspond to their hits (Figure 8.18, Appendix C), this network was merged with the networks corresponding to 
genetic and physical interactions, this network consists of 5,390 nodes and 80,209 interactions (Figure 8.18, Appendix C), so was simplified by removing all nodes that correspond to genes which did not appear in any of the pateamine screens. The resulting network consists exclusively of pateamine hypersensitive or haploinsufficient gene deletions and the interactions they share with each other, and contains of 1,063 nodes and 19,179 interactions (Figure 8.18, Appendix C). The size of the network makes manual visual analysis challenging, therefore the Cytoscape plug-in MCODE was used to identify significant sub-networks characterized by localized areas of interaction density, which should be indicative of related function or shared pathway membership. While MCODE has been primarily used (Bader and Hogue 2003) to identify protein complexes from largescale protein-protein interaction datasets it treats all forms of interactions as equivalent and therefore can be applied to this scenario.

It must be noted that the physical and genetic interaction data present in the SGD database in a mixture of those derived from large-scale studies (for instance genome-wide affinity mass spectrometry defined protein-protein interactions (Collins, Kemmeren et al. 2007) and genetic interactions defined by genome-wide epistatisis analysis (Costanzo, Baryshnikova et al. 2010) a large number of which are not verified, and interactions that have been studied and verified individually. The interactions used in this analysis were not filtered for reliability on the premise that novel unverified interactions may be informative and those verified interactions exist as multiple interactions between nodes which will be recognized and scored more highly by the MCODE algorithm. Previously identified MDS genes were retained in this analysis, it is presumed that those related to detoxification or drug efflux will be identified as sub-networks and therefore do not compromise the interpretation of the results. A total of 13 sub-networks with more than five nodes were identified using MCODE, seven of which were significantly functionally enriched, those 
that were not were generally scored lower by the algorithm (Sheet 8, Supplementary File 2).

Each sub-network consists of nodes corresponding to genes from at least one of the five screens performed (HIP and HOP screens 1 - 4 and the homozygous haploid screen; Table 8.4, Appendix C) and was functionally enriched in a manner that appears more specific to the known mode-of-action of pateamine, translation inhibition, than the compiled list of all hits from all screens (compare Sheet 22 to Sheets 15 - 21, Supplementary File 3). Sub-network one (Figure 4.6) was enriched for processes related to RNA polymerase II related transcription $\left(\mathrm{P}<2.2 \times 10^{-6}\right)$, translation $\left(\mathrm{P}<2.1 \times 10^{-3}\right)$, tRNA metabolism $\left(\mathrm{P}<1.4 \times 10^{-2}\right)$ and protein ubiquitination $\left(\mathrm{P}<2.4 \times 10^{-2}\right)$ and includes most of the eIF4F complex $\left(\mathrm{P}<1.3 \times 10^{-7}\right)$. Sub-network two (Figure 4.7) was enriched for processes related to RNA transport $\left(\mathrm{P}<1.9 \times 10^{-2}\right)$, mitosis $\left(\mathrm{P}<4.5 \times 10^{-2}\right)$, transcription $\left(\mathrm{P}<1.3 \times 10^{-2}\right)$, DNA repair $\left(\mathrm{P}=3.4 \times 10^{-4}\right)$ and vacuolar acidification $\left(\mathrm{P}<2.9 \times 10^{-2}\right)$. Sub-network three (Figure 4.8) was enriched for various terms surrounding translation including the large and small ribosome subunits $\left(\mathrm{P}<2 \times 10^{-5}\right)$, ribosome biogenesis $\left(4.2 \times 10^{-2}\right)$, regulation of transcription $\left(1.4 \times 10^{-2}\right)$, particularly the mediator complex $\left(\mathrm{P}=2.9 \times 10^{-6}\right)$, and translation initiation $\left(2.6 \times 10^{-6}\right)$. Four other sub-networks were enriched in similar process to those mentioned above (Figure 8.21 - Figure 8.24, Appendix C) further highlighting the role of RNA centered biological processes in the sensitivity to pateamine. 


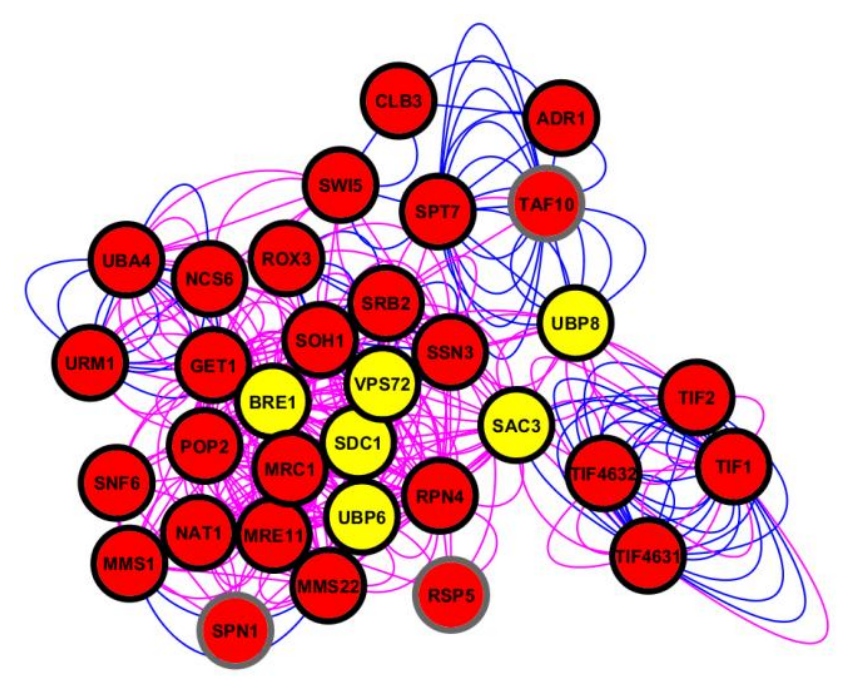

Figure 4.6 Sub-network one is enriched for processes related to RNA polymerase II related transcription, translation, tRNA metabolism and protein ubiquitination. Blue interactions are physical, magenta are genetic. Yellow nodes are MDS gene deletions; black node borders are homozygous strains sensitive to pateamine in at least one of the screens performed; grey node borders are heterozygous strains that display haploinsufficiency in the presence of pateamine.

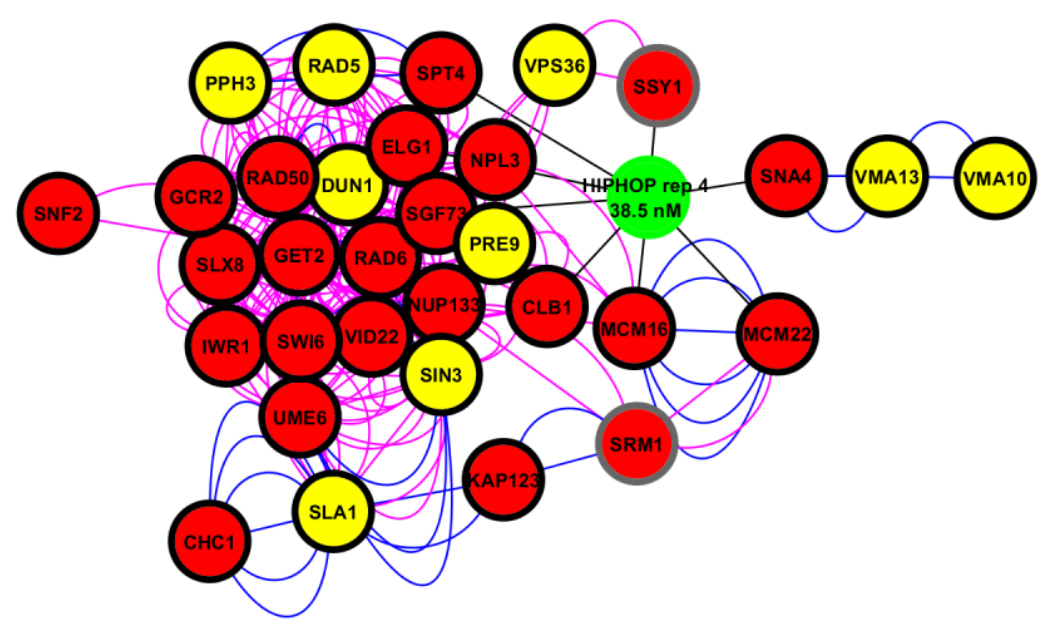

Figure 4.7 Sub-network two is enriched for processes related to RNA transport, mitosis, transcription, DNA repair and vacuolar acidification. Blue edges are physical interactions, magenta are genetic interactions and black are pateamine hypersensitive. Green node is the HIPHOP pateamine screen 4; Yellow nodes are MDS gene deletions; black node borders are homozygous strains sensitive to pateamine in at least one of the screens performed; grey node borders are heterozygous strains that display haploinsufficiency in the presence of pateamine. 


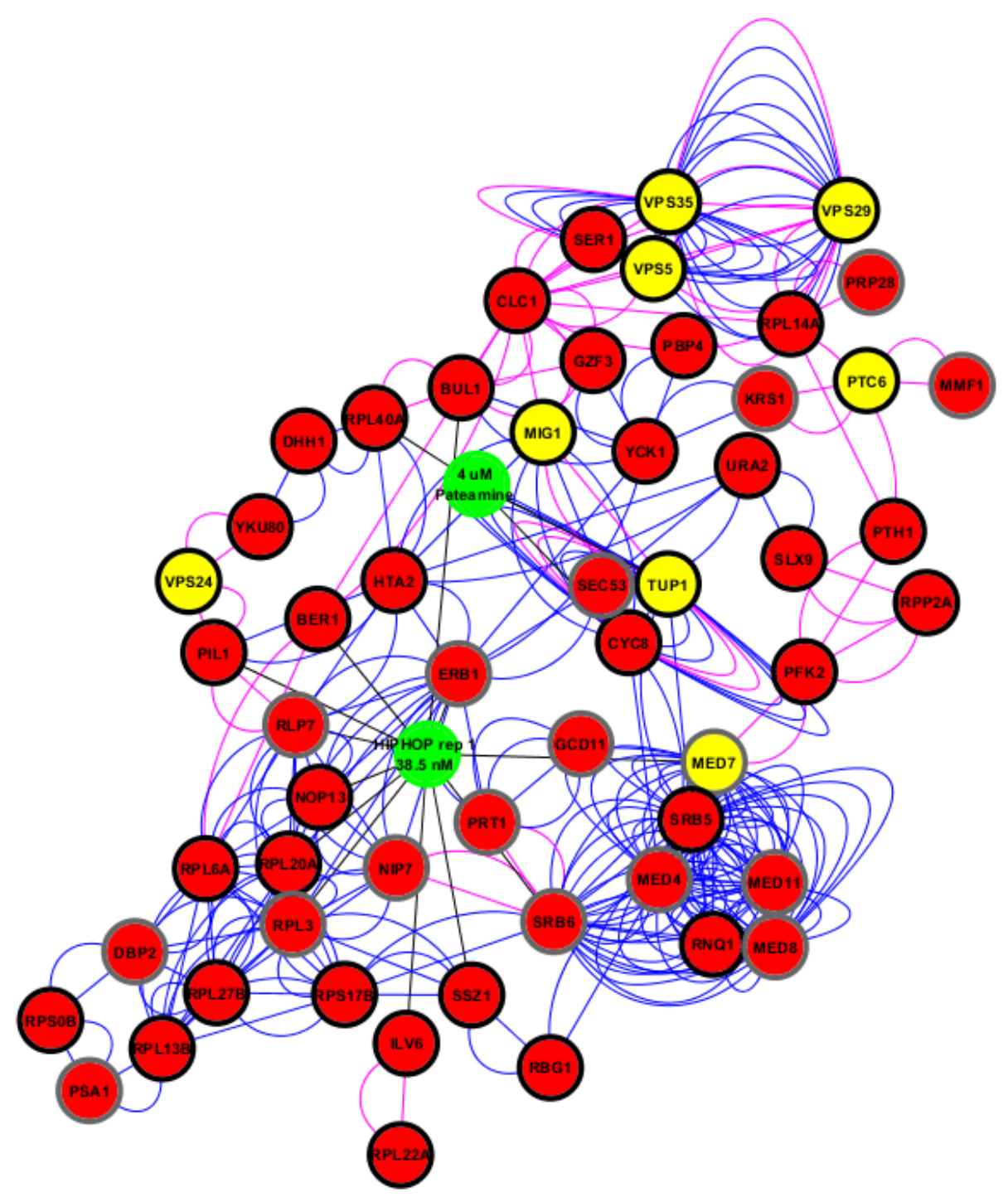

Figure 4.8 Sub-network three is enriched for large and small ribosome subunits, ribosome biogenesis, regulation of transcription and translation initiation. Blue edges are physical interactions, magenta are genetic interactions and black are pateamine hypersensitive. Green nodes are the pateamine screens as labeled; Yellow nodes are MDS gene deletions; black node borders are homozygous strains sensitive to pateamine in at least one of the screens performed; grey node borders are heterozygous strains that display haploinsufficiency in the presence of pateamine.

The results of this network based analysis of the pateamine screen data have shown that, in contrast to looking simply at GO term enrichment, incorporation of empirically defined genetic and physical interactions with chemogenomic datasets allows a greater statistical significance to be ascribed to the presence of certain functional groups of hits. The most 
striking outcome of this analysis was the occurrence of genes related to RNA polymerase II mediated transcription, which was also seen in the functional analysis of the haploid screen and HIP assays. By analyzing all of the screen results as a single set it has been possible to ascribe significant functional enrichment to genes that appeared in the HOP assay, where previous analysis of the HOP screens discretely failed to do so. 


\subsection{Discussion}

The motivation behind this work was to discover the breadth of functional specificity of pateamine. Given the clear evidence that both yeast eIF4A and human eIF4AI/II and eIF4AIII are targeted by pateamine in vivo and the strong degree of homology between yeast eIF4A and Fallp (Kressler, de la Cruz et al. 1997) there exists the distinct possibility that it too is targeted by pateamine. To this end the newly developed approach of chemogenomic profiling was employed with the hope it would reveal whether Fallp was in fact targeted by pateamine. Additionally the eIF4A family of proteins is a part of the much larger DEAD-box helicase super-family, all of which share significant sequence and structural homology (Linder 2006) and hence are also potential pateamine targets.

\subsection{1 eIF4F component deletion fitness in the presence of pateamine}

Initially the sensitivity of homozygous deletions of the various eIF4F complex members, namely TIF1 and TIF2 which encode yeast eIF4A (Linder and Slonimski 1989), TIF4632 which encodes a yeast eIF4G homologue (Goyer, Altmann et al. 1993), and TIF3 and CAF20, the yeast homologues of eIF4B (Coppolecchia, Buser et al. 1993) and eIF4E-BP (Altmann, Krieger et al. 1989) respectively, were assessed individually. Given the verified effect of pateamine on the function of the eIF4F complex, through perturbation of eIF4A function, this was performed in order to establish whether these gene deletions strains were likely to appear in the large-scale genome-wide deletion set screen to be performed later. The deletions of TIF1 and TIF2 had only very slight effects on pateamine sensitivity, with TIF2 deletion strain being slightly more sensitive than TIF1. This is not surprising given the duplicate nature of these genes, which encode identical protein products and display a synthetic lethal genetic interaction, indicating an essential gene product; the slight additional sensitivity of TIF2 may be explained by the observation that it contributes the slight majority of eIF4A (Prat, Schmid et al. 1990). This slight increase in sensitivity was 
only observed when the assay was performed on YPD agar, suggesting the potential of differential requirements or expression of TIF1 and TIF2 on solid media, and in high concentrations of pateamine in liquid YPD since lower concentrations failed to cause hypersensitivity. It is interesting to note that the deletion of TIF2 caused a greater hypersensitivity to anisomycin and not cycloheximide, two well characterized ribosome targeting, translation elongation inhibitors. The difference in sensitivity may be due to slight differences in the mechanism by which anisomycin and cycloheximide inhibit the ribosome, where anisomycin inhibits the ribosome A-site and cycloheximide binds to a position near the E-site and arrests and stabilizes the translocating ribosome on the mRNA being translated (as reviewed in Section 1.4).

While the deletions of TIF1 and TIF2 caused slight, and arguably negligible, hypersensitivity to pateamine, the deletion of TIF3 caused a significant decrease in fitness in the presence of pateamine, and while it also increased sensitivity to anisomycin and cycloheximide it was not nearly to the same extent. This hypersensitivity was retained in liquid media and both high and low concentrations of pateamine, and falls in line with the literature which shows that over-expression of TIF3 suppresses the growth defect of a temperature sensitive TIF1 allele (Coppolecchia, Buser et al. 1993). Tif3p shares a moderate but significant degree of homology with human eIF4B and eIF4H which have been shown to support the function of eIF4AI/II both in vitro and in vivo (Altmann, Muller et al. 1993), allowing it act as a processive helicase when present (Lorsch and Herschlag 1998), it has been suggested that this occurs due to its RNA binding properties (Altmann, Wittmer et al. 1995). Therefore the absence of Tif3p would be expected to sensitize particularly to conditions that perturb eF4A function, such as pateamine treatment. 
While the literature shows there exists numerous genetic interactions between TIF4632 and TIF1 and TIF2 (Neff and Sachs 1999; He, von der Haar et al. 2003; Watanabe, Murai et al. 2010), it may not be surprising that it does not cause pateamine hypersensitivity given the presence of TIF4631 which also encodes an isoform of eIF4G, also in contrast to Tif3p, recruitment by eIF4G to the eIF4F complex is required before eIF4A can exert is role in translation initiation. The deletion of $C A F 2 O$ did not cause a fitness defect in the presence of pateamine, which is also not surprising given that it's physiological role is to attenuate translation initiation by binding to eIF4E subsequent to being phosphorylated, and represents one of the many proteins involved in translation that is phosphorylated in response to various growth inhibiting stimuli or conditions (Zanchin and McCarthy 1995).

\subsubsection{FAL1 haploinsufficiency in the presence of pateamine}

Due to the significant homology of Fallp to yeast eIF4A it represents a most likely additional target for pateamine. Like the eIF4A protein, Fallp is an essential gene product, given that it exists a single copy in the yeast genome it is hence an essential gene, therefore the heterozygous deletion of FALl was assessed for haploinsufficiency in the presence of pateamine. Given previous observations that the heterozygous deletion of an inhibitortarget encoding gene is haploinsufficient in the presence of said inhibitor (Giaever, Shoemaker et al. 1999) if pateamine does inhibit Fallp then the heterozygous deletion should display haploinsufficiency in the presence of pateamine. This was not observed, the growth of the heterozygous $\Delta$ fall strain was not significantly different from the isogenic wild-type control. The success of haploinsufficiency profiling to identify drug targets relies on the premise that the heterozygous deletion of the target results in less gene product due to gene dosage effects, while it is possible that in this case the gene product is not significantly decreased in abundance by the heterozygous deletion of the gene this is argued against by the reporting of several conditions that do cause haploinsufficiency of in 
the $\Delta$ fall strain (for instance treatment with miconazole, lovastatin and camptothecin (Hillenmeyer, Fung et al. 2008)). This result explains the absence of the $\Delta$ fall heterozygous deletion strain in the pateamine haploinsufficiency profiling results and argues it is not targeted by pateamine, or that the affect of pateamine on eIF4A masks the haploinsufficiency of the $\Delta$ fall strain.

\subsubsection{Homozygous deletion library screens}

In order to further establish whether Fallp, or any other DEAD-box helicase, is a potential pateamine target two complementary homozygous deletion library screens were performed; one at VUW in an individual 384-well format with a relatively high concentration of pateamine on the MATa haploid deletion library; the other at the University of Toronto by members of the Giaever and Nislow group, at a much lower concentration with the homozygous diploid library which was multiplexed with the haploinsufficiency profiling screen, a system known as the HIPHOP assay (Pierce, Fung et al. 2006).

It is well established that homozygous deletion profiling with biologically active small molecules has the potential to reveal genes that are functionally related to the target protein or biological processes, and hence may be used to infer a drug target or a drug targeted process (Parsons, Brost et al. 2004; Parsons, Lopez et al. 2006). It is accepted that this screening procedure identifies "friends of the target" in contrast to haploinsufficiency profiling which was originally conceived to identify drug targets directly. These "friends of the target" often display hypersensitivity to the compound in question by virtue of synthetic lethal genetic interactions with the target, or by compromising the biological process in question, in the case of non-protein targeting compounds such as DNA 
damaging agents or lipid targeting drugs. As such, pateamine hypersensitive deletion strains may be directly related to the known target (i.e. eIF4A), as seems to be the case with the $\Delta$ tif3 strain, or may be related to one of the various biologically processes that members of the DEAD-box helicase super-family are known to be involved in (i.e. ribosome biogenesis in the case of Fal1p), or possibly related to the combined perturbation of all targets. However, a complicating factor in the interpretation of these screen results is the existence of so-called multi-drug sensitizing (MDS) deletions, while a significant proportion of the MDS deletions are the drug efflux pumps themselves (such as PDR5 and $S N Q 2$ ) or related to their regulation (such as the PDR1 and PDR3 transcription factors and genes involved vesicular transport and the recycling of the drug efflux pumps), also present in this list is genes involved in vacuolar function, in particular its acidification. However, a considerable proportion are genes that display a slow growth phenotype, which are often involved in the ribosome and its biogenesis (Parsons, Brost et al. 2004; Parsons, Lopez et al. 2006; Hillenmeyer, Fung et al. 2008), which may complicate the use of this approach in characterizing novel protein synthesis inhibitors.

The most simple analysis of homozygous deletion library screen results involves establishing whether any particular functional group of genes is over-represented (after the removal of MDS genes), the most common approach to this has been the utilization of the output of the Gene Ontology Project, hence it was applied here also.

It appears that pateamine is a substrate of the drug efflux pump Pdr5p and compromised vacuolar acidification also causes hypersensitivity. Subsequent to the removal of previously identified MDS gene deletions, it is apparent that genes involved in translation, particularly ribosomal proteins and the eIF4F complex, RNA processing, RNA polymerase 
II transcription and protein ubiquitination are significantly enriched amongst the pateamine hypersensitive strains in the high concentration screen. The presence of translation related genes can be explained by the effect of pateamine on eIF4A, also related to this may be the presence of ubiquitination genes given that ubiquitin has an extremely short half-life protein and it has been previously shown that deletions in ubiquitin related genes sensitize to cycloheximide (Hanna, Leggett et al. 2003). The presence of RNA processing and RNA polymerase II transcription related genes could also be explained by an effect of pateamine on translation initiation, however these enrichments may also be contributed to by an effect on ribosome biogenesis via Fallp, or indeed an effect on one of the many DEAD-box helicases that are involved in multiple facets of transcription, mRNA splicing, and RNA metabolism (Linder 2003; Linder 2006).

When yeast DEAD-box helicase sequences are aligned, it is notable that only one has an equivalently positioned cysteine residue to that proposed in section 3.4 .7 as being a possible pateamine binding site. This protein, Prp5p has been characterized as a DEAD-box helicase that is required for pre-spliceosome formation $(\mathrm{Xu}, \mathrm{Newnham}$ et al. 2004) and this raises the possibility that Prp5p, and not Fal1p, may be responsible for the RNA processing-related hits identified in these screens. In preliminary analysis, the $\Delta p r p 5$ heterozygous deletion strain showed increased sensitivity to pateamine compared to the effect found following either cycloheximide or anisomycin treatment (data not shown), which could indicate that it is a target for pateamine, however despite the existence of DDX46, the mammalian homologue of Prp5p (Will, Urlaub et al. 2002) pateamine does not inhibit mammalian in vitro cell splicing reactions (Bordeleau, Matthews et al. 2005). Therefore it is unlikely Prp5p is a pateamine target in yeast and the haploinsufficiency shown by the $\Delta p r p 5$ heterozygote is likely reflective of a functional link between mRNA splicing and translation initiation 
The likely intimate functional relationships between Fallp and eIF4A, and of course many other DEAD-box helicase makes a clear distinction difficult. This is not helped by the lack of any significant functional enrichment in the results from either the low concentration secondary screen performed on the haploid deletion hits, or the low concentration HOP screens performed at the University of Toronto.

An alternative to functional enrichment analysis, which depends on the deleted genes being characterized, cluster analysis has been used to assess chemogenomic profile similarity and hence group compounds of similar biological activity. Various clustering and partitioning methods have been employed to ascertain profile similarity, the most common, and arguably the most successful has been the application of hierarchical cluster analysis (Parsons, Brost et al. 2004; Parsons, Lopez et al. 2006; Hillenmeyer, Fung et al. 2008; Hillenmeyer, Ericson et al. 2010), which was popularized by its use in mRNA microarray data interpretation. Given the lack of significant functional enrichment in the low concentration HOP screen results, hierarchical clustering was employed to assess their similarity to other screened conditions.

Two large-scale genome-wide chemogenomic datasets have been previously published, which screened the homozygous diploid library for hypersensitivity to 178 and 82 unique, biologically and chemically diverse compounds and conditions respectively, and hence were used in clustering experiments with the pateamine HOP screen results (Parsons, Lopez et al. 2006; Hillenmeyer, Fung et al. 2008). However in each variation of the clustering method employed (as outlined in method 4.3.6) the pateamine HOP screen results failed to cluster with any drug or condition, despite the significant overlap between its hypersensitive deletion strains and those hypersensitive to other known protein 
synthesis inhibitors. There are two possible interpretations of this result: 1 . the pateamine HOP profile is truly novel, which may not be surprising since there are no translation initiation specific inhibitors, only translation elongation inhibitors, present in either of the datasets; 2. Protein synthesis inhibitor HOP profiles do not form coherent clusters, indicated by the lack of a "protein synthesis inhibitor cluster" in either this cluster analysis or the original analyses performed on these datasets. This result may suggest there is not a global response to protein synthesis inhibition in yeast but rather an inhibitor-mechanism dependant one, this is reflected by the observation that deletions in ubiquitin related genes sensitize to cycloheximide, and anisomycin but not to hygromycin B (Hanna, Leggett et al. 2003). Previous studies have shown that a compound's chemogenomic profile will cluster with the synthetic lethal interaction profile of its target (Parsons, Brost et al. 2004), there is small number overlap between the pateamine screens performed here and the negative genetic interactions of TIF1, TIF2 and FAL1 present in the literature (Figure 8.25, Appendix C), however this type of analysis suffers from the paucity of genetic interaction known for these three genes, due to their duplicate nature (in the case of TIF1 and TIF2) and the lack of large-scale geteic interaction data, as in the case of FAL1.

A subsequent analysis of the Hillenmeyer dataset published recently revealed that strains with gene deletions involved in translation, ribosome biogenesis and RNA metabolism also fail to form functionally enriched clusters across the many drugs and conditions screened (Hillenmeyer, Ericson et al. 2010), which may be reflective of an evolved genetic redundancy in these systems given their importance to fitness. Given a significant proportion of biologically active natural products target protein synthesis, this redundancy may have evolved in part to deal with numerous assaults on these systems by natural products produced by competing organisms. Ultimately the inability of the HOP approach 
to resolve the biological activities of pateamine likely reflects a broader problem of the application of this methodology to defining the activity of protein synthesis inhibitors.

\subsubsection{Haploinsufficiency profiling of pateamine}

Early analysis of haploinsufficiency profiling assays involved analyzing the top- ten most sensitive heterozygous deletions strains that showed haploinsufficiency in the presence of a compound, and that the drug target was often present (Lum, Armour et al. 2004). As already mentioned the $\Delta$ fall heterozygote is not haploinsufficient in the presence of pateamine and hence does not appear in the top-ten hits of any of the screen replicates, also absent from these lists are any DEAD-box helicases, however two gene deletions strains were consistently within the top-ten hits for each screen, the mRNA splicing factor PRP3 and STE5 a MAP kinase scaffold protein, neither of which have been implicated as potential pateamine targets. The haploinsufficiency caused by the heterozygous deletion of STE5 is not immediately explainable; however the growth defect of PRP3 once more is likely due to the relationship between translation and mRNA splicing. More recent studies have assessed functional enrichment as might be done for homozygous deletion set results (Baetz, McHardy et al. 2004; Kemmer, McHardy et al. 2009), this analysis performed on the top ten hits from each pateamine HIP screen revealed little evidence of an effect on either eIF4A or Fal1p, hence the analysis was performed on the entire haploinsufficient strain list for each screen. This revealed enrichment in numerous aspects of RNA metabolism, which, for reasons mentioned previously do not aid in determining whether any gene product other than eIF4A is affected by pateamine.

In more recent publications haploinsufficiency profiles have been clustered in the same manner as those for homozygous deletion sensitivity profiles (Hillenmeyer, Fung et al. 
2008). As was observed with the clustering of the pateamine homozygous profiles, the pateamine induced haploinsufficiency profiles failed to cluster with any other condition or drug present in the dataset, again despite overlap in the strains haploinsufficient in the presence of other protein synthesis inhibitors. Unlike the profile datasets used in the HOP cluster analysis, there was one compound that has been shown to potentially target translation initiation, specifically eIF4A. Resveratrol has recently been shown to physically interact with eIF4A in vitro, and also inhibit protein synthesis and the growth of yeast, albeit with a much lower potency that pateamine (Pan, Agarwal et al. 2008). However, despite sharing the greatest overlap out of any of the protein synthesis inhibitors with pateamine it too failed to cluster with pateamine.

According to prior literature, if eIF4A is a target of pateamine the heterozygous deletion of TIF1 and TIF2 should cause haploinsufficiency in its presence, since only essential genes were screened in this work the TIF1 and TIF2 heterozygous strains were absent from the pool, also the lack of $\Delta f a l l$ haploinsufficiency seen in both the large-scale screen (Table 4.1 and Sheet 3, Supplementary File 2) and when assessed individually (Figure 4.2) argues that Fallp is not a functionally relevant target for pateamine.

\subsubsection{Interactions of pateamine with other proposed targets}

The affinity chromatography and biochemical assays presented in chapter 2 raised the possibility that pateamine might interact functionally with actin and tubulin. Kuznetsov, $\mathrm{Xu}$ et al. (2009) also report the in vitro inhibition of DNA polymerases $\alpha$ and $\gamma$ by pateamine. None of these putative targets, all of which are proposed to require a higher concentration of pateamine than inhibition of the eIF4A proteins, have become apparent 
during the chemogenomic screens performed here. Inhibitors of tubulin (benomyl and nocodazole) and actin (latrunculin and cytochalasin) are present in each of the datasets the pateamine profiles were clustered with, and provide chemogenomic profiles that clearly identify their interactions with these targets, though the same cannot be said for inhibitors of DNA polymerase, since none appear in the either datasets. In contrast to protein synthesis inhibitors, actin and tubulin targeting compounds group together during hierarchical cluster analysis (Parsons, Brost et al. 2004; Parsons, Lopez et al. 2006; Hillenmeyer, Fung et al. 2008; Hillenmeyer, Ericson et al. 2010). Thus, although final clarification regarding DEAD-box helicase protein selectivity has not been fully established in the screens reported here, confirmation has been obtained that other putative targets are not involved in the mode of action of pateamine, at least in yeast.

\subsubsection{Pateamine-hit interaction network analysis}

The network analysis attempted here makes use of the large number of known physical and genetic interactions that have been enumerated for a significant proportion of the yeast genome. This provides an alternative to the more traditional approaches to analyzing chemogenomic screen data presented above. These traditional approaches rely on the functional annotation of genes whose deletion confers hypersensitivity to a drug or display haploinsufficiency in its presence, in the case of GO term enrichment, or on the existence of significantly similar deletion hypersensitivity profiles, as in the case of cluster analysis.

There are several disadvantages of functional enrichment analysis, first it relies on the genes of interest being annotated with GO terms, and while the vast majority of the genome has been functionally annotated there is considerable variation regarding the specificity of these annotations. The gene ontology system is hierarchically structured, 
with parent and daughter term relationships, this hierarchical structure can make the clear assessment of the results of a functional enrichment analysis difficult, with the significant enrichment of numerous GO terms occurring because of the same set of genes, the question is which term is the most informative or accurate? This can been seen in all of the GO term enrichment analysis results presented here (Supplementary File 3) where multiple GO terms are enriched due to presence of the same genes, a judgment must be made as to which to report, making what should be an objective analysis somewhat more subjective.

Another issue associated with GO term analysis is the effect of noisy datasets and the number of genes ascribed to certain terms. The methods that are used to assess statistical significance take into account the size of the dataset being analyzed, the proportion of that dataset that contains genes annotated to a certain term, the total number of genes in the genome annotated to that term relative to and the proportion of that total that is present in the dataset. Misleadingly low p-values can be found for the enrichment of a GO term if that term only has one or two genes annotated to it in the whole genome, and one of these is present in the dataset, as was seen with the enrichment of MAP kinase related terms in the HIP screen.

This problem is considerably exacerbated by the high level of noise present in chemogenomic data, where it is often not known what the p-value of specific hit is. Even when this is calculated, and found to be significant, the considerable variation in hits from different screen formats, i.e. pooled microarray methods vs. agar based screens, and from different labs using the same methods makes it difficult to assess the true validity of the hit. Therefore the same drug screened in different ways can give significantly different results; a good example of this is rapamycin, arguably the most screened compound. 
Comparing the list of hits from all of the screens performed just on agar based media shows considerable variation, the overlap between these datasets is even worse when liquid and pooled microarray assays are considered (Chan, Carvalho et al. 2000; Parsons, Brost et al. 2004; Xie, Jin et al. 2005; Parsons, Lopez et al. 2006). Even seemingly replicate screens often have significant variation in the hits that appear (Hillenmeyer, Fung et al. 2008), these variations affect not only functional enrichment but also cluster analysis results.

Cluster analysis suffers from separate but related issues, while it does not rely on the functional annotation of genes of interest its success is dependent on the presence of compounds of similar mode-of-action to the compound of interest being present in the dataset that is being clustered. Furthermore it relies on the notion that compounds with a similar mode-of-action will have a similar chemogenomic profile. As has been noted here, protein synthesis inhibitors as a class of drugs fail to form distinct clusters with each other, arguably this may be as a consequence of the fact that there are many ways to inhibit protein synthesis and therefore different gene deletions sensitize to different types of protein synthesis inhibitors depending on their exact mechanism and the consequence of their interaction with the ribosome. For instance emetine, anisomycin are both ribosomal A-site inhibitors have been shown to cluster together with the exclusion of hygromycin which also interacts with this site on the ribosome (Parsons, Lopez et al. 2006). This is, at least in part, due to the over-simplification in terms of ascribing a broad mode-of-action to a class of compounds such as protein synthesis inhibitors.

The removal of MDS deletions strains has become common-place prior to cluster analysis, this is due to the observation that the inclusion of these genes serves to make clusters "drug-hungry" (Parsons, Brost et al. 2004), meaning the formation of clusters is 
predominantly influenced by the presence of these genes. However, there may be information specific to a certain drug that is lost by excluding these results. For instance, vesicular mediated transport type genes are often excluded since they are presumed to act in a relatively non-specific manner with respect to their role in drug efflux pump recycling, however one wonders what would result from the exclusion of these genes if a drug was screened that affected this process directly. A more specific example to the case of protein synthesis inhibitors is that a number of these MDS genes are designated as such because they show a growth defect in rich media, and therefore often appear being sensitive to many compounds since the manner in which their fitness is defined in the presence of the drug does not take into account the additive effect of the drug and the gene deletion on fitness. For instance the $\Delta$ tif3 deletion strain grows particularly slowly in rich media, causing it to erroneously appear as a hit in many screens and is therefore in the MDS deletion list; however the extreme sensitivity of this strain to pateamine is informative with respect to the mode-of-action of pateamine, perturbing the function of eIF4A, and this extreme sensitivity is not seen with other protein synthesis inhibitors. For these reasons removal of MDS genes should be approached with caution and with knowledge of whether the drug in question is subject to pump mediated efflux.

In the interaction-based approach trialed in this study, rather than relying on grouping genes on the basis of shared functional annotation they are grouped on the basis of empirically defined physical or genetic interactions. A considerable advantage of using S. cerevisiae as a model organism in these experiments is the large amount of data available for this type of analysis. Aside from the full-genome sequence, there have been numerous genome-wide assays performed on it, for instance a number of large-scale protein-protein interaction studies. There also exists a wealth of genetic interaction data from both targeted studies and at least partially genome-wide epistatic or genetic 
interaction studies. Additionally numerous biochemical activity screens have been documented, for instance the enumeration of kinase and phosphatase substrates, RNA binding protein specificity for mRNAs, transcription factor binding (CHiP on Chip assays) etc... All of this information can be used to establish functional and physical relationships between the hits found in a chemogenomic screen, enabling them to be grouped in a way that is similar the grouping of genes by shared GO term annotation. The advantage over GO term analysis is that all of the data used has been experimentally defined, while this suffers from the level of noise present in each dataset, true interactions are more likely to be present in multiple datasets and therefore represented by multiple links in the resulting network. Therefore a method that identifies related gene clusters in a chemogenomic dataset on the basis localized density of interactions should score sub-networks consisting of the "real" interactions more highly, thereby negating the potentially high level of spurious interactions. One such method is implemented by the MCODE algorithm which was originally used to identify protein complexes for large-scale protein-protein interaction datasets by searching for localized areas of high interaction density (Bader and Hogue 2003).

In this work, a network was constructed that consisted of all of the hits from each pateamine screen performed, and their physical and genetic interactions with each other. Inter-hit interactions were obtained from the SGD database and represent genetic and physical interactions established through a variety of means (see Table 8.5 and Table 8.6 for a description of each), MCODE was used to find localized regions of interaction density, which were presumed to represent biological processes or systems that are functionally related to the target(s) of pateamine or, due to inclusion of MDS strains, detoxification mechanisms employed in its presence. It was hoped by the inclusion of these inter-hit interactions that noise in the datasets would be negated as only those hits that 
share interactions with other hits would be present in any resulting sub-networks, thereby allowing a more appropriate application of functional analysis assessments, or a less ambiguous interpretation of the results. It must be noted that some of the interactions present in the network analyzed by MCODE are directional, for instance positive epistatic and RNA binding interactions, however the directions were ignored, the presence of an interaction is all that matters in this analysis, MCODE ignores edge directionality.

Seven sub-networks were identified from the pateamine-hit interaction network that were significantly functionally enriched. Not only did this analysis highlight biological processes required for resistance to pateamine, it also drew relationships between those processes on the basis of literature interactions. For instance, sub-network one was enriched for components of the eIF4F complex, RNA polymerase II transcription, tRNA processing all of which can be directly associated with translation, and protein ubiquitination which is also related in that many proteins involved in translation are ubiquinated. Sub-networks two and five (Figure 8.22, Appendix C) on the other hand show significant enrichment for vacuolar function, which may be related to the detoxification of pateamine, or to recycling of drug efflux pumps. Sub-network three appears enriched for proteins involved in translation, especially ribosome components and initiation factors and members of the mediator complex which is directly related to the transcription of RNA polymerase II. The MAP kinase enrichment of sub-network four (Figure 8.21, Appendix C) might reflect signaling pathways employed in the presence of pateamine to modulate response to its presence, or they may be reflective of a general stress response.

By undertaking this analysis it was hoped to clearly delineate pateamine-sensitizing deletions related to the inhibition of translation initiation (and thus eIF4A) or ribosome 
biogenesis (related to Fallp inhibition), the significant enrichment of genes in sub-network six (Figure 8.23, Appendix C) related to rRNA processing may well be reflective of an inhibitory effect on Fallp, though this interpretation must be approached with caution given the intimate link between ribosome biogenesis and translation. Sub-network seven (Figure 8.23, Appendix C)was another network in which genes relating to the transcription by RNA polymerase II were significantly enriched, this has been seen in a number of other sub-networks and also in the functional analysis of the HIP screen results.

RNA polymerase II is responsible for the transcription of all ribosomal gene mRNA which represents $\sim 50 \%$ of all $\mathrm{mRNAs}$ that it is responsible for transcribing. Therefore deletions that affect its function will impact the production of ribosomes (Hampsey 1998), which could in turn aggravate inhibition of translation initiation or ribosome biogenesis. However, ribosome biogenesis is also impacted by the synthesis of rRNA, which are transcribed by RNA polymerase III, it might be expected if a direct effect on rRNA synthesis by pateamine occurs there would also be a number of genes related to the function of RNA polymerase III, and other genes directly related to the processing of rRNA. There is a lack of a clear enrichment of these genes in any of the screens lists or sub-networks within the pateamine-hit interaction network. Therefore, it could be suggested that pateamine does not affect Fallp function and that all of the RNA metabolism enrichment seen above is as a result of a direct effect on yeast eIF4A.

Interpretation of these results must be done with caution, since they are dependent on interactions present in the literature there will be a bias as to which processes are most represented in the data, predominantly due to the presence of a small set of highly focused epistatic interaction datasets. The so-called EMAP (epistatic mini-array profiling) studies 
performed in the Weissman laboratory at the University of California, San Francisco, involve pre-selecting genes on the basis of previously known annotations and localizations and establishing positive and negative epistatic interaction within this restricted list of genes (Schuldiner, Collins et al. 2005). For instance the relative fitness of double mutants of all genes that have been annotated to the early secretory pathway as well as those that have been localized to structures associated with it, were measured and epistatic relationships established within this subset of the genome. The same analysis has been performed on: RNA processing genes (Wilmes, Bergkessel et al. 2008); chromatin function (Schuldiner, Collins et al. 2006); protein kinases and phosphatases (Fiedler, Braberg et al. 2009); and the early secretory pathway (Schuldiner, Collins et al. 2005) therefore the literature has an over-representation of the interactions in which these genes partake. While there is a program underway to delineate these interactions on a genomewide basis (Costanzo, Baryshnikova et al. 2010), it is yet to be completed, therefore a significant proportion of the genome is under-represented in the genetic interaction databases.

The network analysis presented here is of a pilot nature, further refinements would include a way of correcting for the over/under representation of genetic interactions analysis of the identified sub-networks due to literature biases. Also, this analysis only takes into account interaction data in the literature, the deletion set has been used in conjunction with numerous phenotypic assays, to identify genes contributing to these phenotypes. For instance gene deletion impact on: glycogen levels (Wilson, Wang et al. 2002), ncRNA abundance, basal unfolded protein levels (Jonikas, Collins et al. 2009); cell size and shape (Giaever, Chu et al. 2002; Jorgensen, Nishikawa et al. 2002; Zhang, Schneider et al. 2002); lipid droplet number and size (Fei, Alfaro et al. 2008); CPY export (Bonangelino, Chavez et al. 2003); and type II intron splicing (Luban, Beutel et al. 2005) has been assessed for 
most of the non-essential yeast deletion library. The inclusion of these gene deletion attributes may allow another level of grouping of chemogenomic data based on shared phenotype. Additionally there are numerous datasets identifying proteins that are post-translationally modified by phosphorylation, isoprenylation, ubiquitination, SUMOylation, glycosylation and methylation that could also been included in this analysis that might reveal further relationships between the hits in a chemogenomic screen. Other information that may be incorporated would be data pertaining to protein and mRNA abundance, half-life or stability, as well as mRNA 5 and 3`UTR structure (which may be particularly illuminating in the case of pateamine with its verified effect on eIF4A activity). This type of analysis is most likely beyond a simple network density analysis presented here, but would take into account the deletion phenotypes, post-translation modifications and protein and mRNA characteristics listed, as node attributes which could be analyzed in a similar way as GO term annotation, or in combination with it. 


\subsection{Conclusions}

The motivation behind this work was to identify possible targets of pateamine in yeast other than eIF4A. The yeast genome encodes 25 DEAD-box helicase enzymes that share a significant degree of homology with eIF4A, therefore the distinct possibility that one or more of these may represent potential non-eIF4A targets for pateamine. The use of the homozygous and heterozygous deletion libraries has failed to clearly discern whether any of these, or in fact any other gene products are targeted by pateamine. This could be explained in a number of ways: 1 . The close relationship between the pathways and processes in which the DEAD-box helicase enzymes function makes it difficult to disentangle the effect on one system or process from another; 2 . The poor performance of these assays in discerning similarities in the response of yeast to protein synthesis inhibition by chemical agents; 3 . The paucity of data derived from the use of chemical or genetic perturbation of each process in which a DEAD-box helicase plays a role.

The ambiguity in the data caused by the intimate link between ribosome biogenesis and translation can be cleared experimentally in a number of ways, the most obvious of which would be an assay of the ATPase activity of Fallp in the presence of pateamine, which would establish whether it is able to interact with pateamine in vitro, also the pateamine resistance conferring mutation identified in eIF4A in the previous chapter could be incorporated into FAL1 and this strain tested for resistance to pateamine. The same mutation in eIF4A could be incorporated into the deletion set and the haploid screen performed again, any gene deletions related to eIF4A functions would not be sensitive in this screen and any resulting hits should be directly related to Fallp, or any other secondary target. In conclusion, it cannot be definitively stated whether pateamine only targets eIF4A in yeast, however it is clear its effects are centered on one or more aspects of translation, ribosome biogenesis or RNA metabolism and are distinct from other putative 
targets, including actin, tubulin. Similarly there is little obvious evidence from the screen performed for the role of the inhibition of DNA polymerases, despite the lack of a chemogenomic profile corresponding to this condition it would expected that a considerable number of non-essential genes involved in DNA replication would sensitize to pateamine if DNA polymerase was targeted. 


\section{Discussion}

\subsection{Pateamine targets the eIF4A helicase family in mammalian cell lines}

Pateamine is a potent inducer of mammalian apoptosis in a variety of mammalian cell lines (Hood, West et al. 2001), the initial affinity chromatographic approach to identifying the targets of pateamine in these cell line was undertaken, by and large, for reasons of ease. The existence of the reactive primary amine group afforded a simple means by which to conjugate pateamine to a solid phase support, additionally there was ample evidence to suggest that derivatisation at this position was tolerated in terms of biological activity (Romo, Rzasa et al. 1998; Romo, Choi et al. 2004). This lead to the identification of three, high abundance proteins that specifically interact with the pateamine affinity resin, two of which ( $\beta$-tubulin and actin) are well characterized targets of numerous natural products and synthetic agents that are also known to induce apoptosis in mammalian cell lines and hence were possible targets (Jordan and Wilson 2004; Rao and Li 2004). The third protein, eIF4A, was at the time, an unknown target for any drug studied at that time, however, evidence from the Pelletier group at McGill University suggested that pateamine was able to specifically inhibit cap-dependent translation initiation in vitro so therefore may be the target process of pateamine.

Subsequently two classes of compounds have been shown to target the eIF4A family of proteins. One series, known as the hippuristanols, isolated from the gorgonian Isis hippuris (Higa, Tanaka et al. 1981), have been shown to inhibit eIF4AI, II and III ATP hydrolysis activity in vitro, by preventing them from binding RNA, at least in the case of murine eIF4AI (Lindqvist, Oberer et al. 2008). The other class is the cyclopenta[b]benzofuran flavaglines, of which silvestrol is a representative member, was also shown to inhibit cap- 
dependent translation in vitro, and increase the RNA binding activity of eIF4A in both its free form, and as a part of the eIF4F complex (Bordeleau, Robert et al. 2008; Cencic, Carrier et al. 2009).

The results of the affinity chromatography experiments suggested that the interaction between eIF4A and the pateamine affinity resin was either covalent or at least of higher affinity than that of $\beta$-tubulin and actin, as its binding was largely insensitive to a high salt wash and only able to be disrupted under strong denaturing, basic and reducing conditions, which would be harsh enough to reverse a possible conjugate addition reaction. Additionally, the in vitro polymerization assays with bovine microtubules and rabbit muscle microfilaments showed that the concentration of pateamine required to affect polymerization far exceeded those of other agents known to target these structures (Jordan, Toso et al. 1993; Bollag, McQueney et al. 1995; Hood, West et al. 2002; Usui, Kazami et al. 2004). The retention of eIF4AIII, which is of considerably lower cellular abundance that the eIF4AI or II isoforms, by the pateamine resin also suggests that this is a high affinity, specific interaction.

It has been shown that pateamine is able to inhibit mammalian protein synthesis in vivo at concentrations directly comparable to those that induce apoptosis, and that this occurs by specifically targeting the initiation step, shown by an absence of polysome formation upon pateamine treatment (Bordeleau, Matthews et al. 2005; Low, Dang et al. 2005). These studies also showed that, unlike the hippuristanols, pateamine stimulates the helicase activity of murine eIF4AI, increases RNA binding, abrogates the requirement of ATP binding for RNA binding, increases ATP binding and hydrolysis of murine eIF4AI in a RNA-dependent manner. The increase in RNA binding effect of pateamine only manifests 
in free eIF4AI, that is not when it is a part of the eIF4F complex, in contrast to silvestrol that is able to increase RNA binding by eIF4A when it is also a part of the eIF4F complex (Cencic, Carrier et al. 2009). Confirmation of the eIF4AI1-specific nature of these effects was shown by the lack of inhibition of an in vitro splicing reaction, which involves numerous, non-eIF4AI, DEAD-box RNA helicases. The absence of an effect on the related yeast DEAD-box helicase, Ded1p, in an in vitro helicase activity and a lack of an effect on prokaryotic translation in a cell free bacterial translation system also provides strong evidence for the specificity of pateamine for eIF4A (Bordeleau, Matthews et al. 2005).

Confirmation of the physical interaction between eIF4AI and pateamine was shown by an independent group with biotinylated-pateamine, derivatized at the same position we presume coupling to the epoxy-Sepharose resin occurs at (Figure 2.2), whereas an inactive analogue failed to recover eIF4AI from a cell lysate (Low, Dang et al. 2005). The same group showed that over-expression of eIF4AI afforded modest resistance to the growth inhibitory effect of pateamine in vivo, however they also suggested that pateamine stabilized the interaction between eIF4AI and eIF4B, a proposition that has since been disputed as it was shown that this observed increase in binding is dependent on the presence of RNA and is therefore probably a consequence of pateamine's ability to increase the eIF4AI-RNA interaction (Bordeleau, Cencic et al. 2006). This work has lead to the development of a model whereby pateamine causes unscheduled loading of eIF4AI onto mRNA in a manner independent of the eIF4G scaffolding protein which is normally responsible for eIF4AI being recruited to mRNA. While some reviewers suggest pateamine disrupts eIF4F complex function by weakening the interaction between eIF4A and eIF4G (Schneider-Poetsch, Usui et al. 2010), this is potentially a misleading statement given there is evidence that this interaction is not inhibited directly by pateamine (Bordeleau, Cencic et 
al. 2006), thus this so-called weakening is most probably a result of the stabilization of eIF4A on mRNA sequestering it from taking part in the eIF4F complex.

Pateamine has also been shown to induce the formation of stress granules in mammalian cells. The use of biotinylated-pateamine, a derivative that retains biological activity, allowed visualization of a punctate cellular distribution that prompted the authors to investigate whether eIF4A was localized to stress granules formed by arsenite (Low, Dang et al. 2005). Arsenite treatment leads to phosphorylation of eIF2 $\alpha$, which attenuates translation initiation and causes a ribonuleoprotein complex known as a stress granule to form. These stress granules contain numerous translation initiation factors, RNA binding proteins and mRNA and are thought to act as a triage complex, allowing the storage of mRNA that is made available for translation after alleviation of the encountered stress (Anderson and Kedersha 2006). Unlike previous conditions in which the phosphorylation of eIF $2 \alpha$ is required for the formation of the stress granules, pateamine treatment did not cause the phosphorylation and cells expressing mutant eIF2 $\alpha$ that is unable to be phosphorylated still formed stress granules upon treatment. In light of pateamine's ability to enhance the interaction between eIF4A and RNA it has been proposed these stress granules form as a direct consequence of this enhancement rather than because of its ability to inhibit protein synthesis, thus circumventing the requirement for eIF2 $\alpha$ phosphorylation (Dang, Kedersha et al. 2006).

Co-treatment of cells with pateamine and cycloheximide prevents stress granule formation, a phenomena seen with stress granules formed due to arsenite treatment. Cycloheximide inhibits stress granule formation by sequestering components essential for their formation in polysomes by virtue of its ability to stabilize translating ribosomes on mRNA (Anderson 
and Kedersha 2008). One interesting characteristic of pateamine-induced stress granules is that they are not resolved upon withdrawal of pateamine, however they do dissipate after treatment with cycloheximide, suggesting a continuation of dynamic exchange of components of the stress granule between itself and polysomes. Though it is not immediately obvious why they would resolve only upon cycloheximide treatment following pateamine treatment and not simply upon the withdrawal of pateamine, it must be noted the authors monitored the TIA-1 component of the stress granules in these experiments and not eIF4A, therefore it is possible that it remains bound to mRNA even upon cycloheximide treatment and it is the dynamic nature of the other stress granule components that cause their dissipation.

The initial affinity chromatographic recovery of eIF4AIII (Bordeleau, Matthews et al. 2005) was confirmed by an independent group, who also showed that pateamine is able to inhibit non-sense mediated mRNA decay in vivo independent of its affect on eIF4AI and translation initiation (Dang, Low et al. 2009). In contrast to the stabilization of eIF4AI on mRNA previously characterized, which occurs exclusively with the free form of the protein when it is not part of the eIF4F complex, in vitro at least, pateamine was shown to stabilize the entire EJC complex on premature termination codon (PTC) containing transcripts, in a manner independent of the phosphorylation of Upf1, the factor normally responsible for the stabilization of this complex on mRNA transcripts that contain a PTC (Page, Carr et al. 1999; Ohnishi, Yamashita et al. 2003; Kashima, Yamashita et al. 2006).

In contrast to the compelling evidence for the targeting of the eIF4A family of proteins in mammalian cells, little evidence exists to suggest that it may also target actin or tubulin in cells at concentrations required to induce apoptosis. While both of these proteins were 
isolated from all three cell lines during the affinity chromatography experiments the effect of pateamine on their function in vitro was weak, additionally these protein were not isolated by biotinylated-pateamine (Low, Dang et al. 2005). While the polymerization of each was perturbed by pateamine, the concentrations required to observe an effect far exceeded those of known inhibitors, such as taxol, cytochalasin and latrunculin especially taking into account the potency of pateamine in inducing apoptosis in these cell lines (Hood, West et al. 2001; Hood 2002). In short it is unlikely that if there is an effect on either of these targets by pateamine in vivo or that it contributes significantly to the cell death process, though it is possible their function may be perturbed at very high concentrations of pateamine, a possible risk for high concentration, short-term bioactivity assays. Another group has suggested that pateamine is able to inhibit DNA synthesis in vivo, more specifically they found inhibitory effects of pateamine against DNA polymerases $\alpha$ and $\gamma$ but not $\beta$ in an in vitro cell free assay (Kuznetsov, Xu et al. 2009). There was no evidence from the affinity chromatography experiments presented here that pateamine was able to recover any DNA helicase enzymes from any of the cell lines used.

\subsection{Pateamine targets yeast eIF4A}

The generation and characterization of drug resistant mutants in $S$. cerevisiae has proven hugely successful in the past in identifying drug targets. In this respect the characterization of a pateamine resistance-conferring mutation that occurs in the yeast eIF4A encoding gene TIF1, adds further weight to the argument that pateamine targets the eIF4A family of proteins in both yeast and mammalian cell lines, as does the stimulatory effect of pateamine on Tiflp ATP hydrolysis observed in vitro (Low, Dang et al. 2007). Consistent with this is the inhibitory effect of pateamine on radiolabeled amino acid incorporation at concentrations that were directly comparable to those that inhibit growth. However, pateamine also appears to inhibit radiolabeled uridine incorporation in yeast at 
concentrations much closer to those that are growth inhibitory compared to mammalian cell lines where, in one study, a significant effect on uridine incorporation was not observed at concentrations $\sim 1000$-fold higher than those that induce apoptosis (Bordeleau, Matthews et al. 2005), and in another study an effect was seen at 50-fold higher concentrations (Low, Dang et al. 2005).

While it is well established that inhibition of protein synthesis in yeast, via chemical or genetic means, results in a decrease in uridine incorporation (Foury and Goffeau 1973; Gross and Pogo 1974; Gross and Pogo 1976; Gross and Pogo 1976), the concentration at which the latter effect manifests with pateamine is much closer to that which inhibits leucine incorporation, compared to the respective effective cycloheximide concentrations. It is possible that this indicates an effect of pateamine on Fallp, and that there exists a mechanism by which defects in rRNA processing feedback to inhibit transcription, especially of RNA polymerase I which is responsible for the production of the $35 \mathrm{~S}$ prerRNA (Michels and Hernandez 2006). However, without a direct assessment of the effect of pateamine on Fallp in vitro, and the in vivo effect on pre-rRNA processing this cannot be resolved. The use of the pateamine resistant eIF4A allele described above would allow an assessment of the in vivo effects on rRNA processing in the absence of an effect on protein synthesis.

The P147L point mutation in TIF1 that confers pateamine resistance strongly suggests that eIF4A is the primary pateamine target in yeast, however it may also indicate the position of its binding site. The sequence surrounding this point mutation is highly conserved in both pateamine-sensitive and insensitive DEAD-Box helicase, such as Ded1p, and therefore probably does not constitute the exact binding site, however taking into consideration the 
requirements for eIF4A binding to pateamine, and the requirements for an effect on in vitro function of eIF4A, coupled with published crystal structures of eIF4AIII, speculation of the approximate position of this site is possible. It has been shown that the $\mathrm{N}$-terminal lobe of eIF4AI is able to weakly interact with biotinylated-pateamine (Low, Dang et al. 2005) and that RNA is required for the binding of full length eIF4AI to biotinylated-pateamine (Low, Dang et al. 2007). It has also been shown that the stimulation of ATP binding of eIF4AI by pateamine is dependent on the presence of RNA (Bordeleau, Matthews et al. 2005) and that pateamine is able to stabilize the EJC complex on PTC containing transcripts (Dang, Low et al. 2009).

All of these observations suggest that the full pateamine binding site may not exist on eIF4A when it is not bound to RNA, it is reasonable to propose that the binding site of pateamine exists on a surface of the protein that changes conformation upon binding to RNA. Given the publication of the crystal structure of the EJC, in which eIF4AIII is bound to RNA (Bono, Ebert et al. 2006), a comparison of the RNA bound and apo crystal structures may reveal this site, and that the amino acid sequence of this site should not be conserved in pateamine insensitive DEAD-Box helicases, furthermore it may be in close proximity to the amino acid analogous to P147 in Tif1p. The alignment of the sequences of the pateamine-sensitive eIF4As and the insensitive Ded1p reveals a motif of four amino acids in the N-terminal lobe of eIF4A that is not present in Ded1p, furthermore this HACI motif is within $15 \AA$ of P164, the Tif1p P147 analogous amino acid in eIF4AIII, and is exposed on the surface of the protein. Analysis of the amino acid sequences that differ in position between the apo and RNA bound eIF4AIII crystal structures shows that one of these areas immediately precedes the HACI motif. Furthermore, the site is positioned such that pateamine bound at this motif could interact with the RNA, for example through an ionic interaction between the protonated tertiary amino group at the end of the extended 
conjugated side arm of pateamine and the phosphate backbone of the RNA. Such an interaction would stabilize the binding considerably and, by making RNA part of the binding site, would be consistent with the observations of low affinity to eIF4A in the absence of RNA, especially the N-terminal lobe.

The presence of a cysteine residue in the HACI sequence, that is also within $15 \AA$ of the resistance-conferring point mutation, that is conserved in pateamine-sensitive but not insensitive DEAD-box helicases, coupled with the requirement of reducing conditions for the elution of human eIF4A from the pateamine affinity resin, and the presence of a conjugated diene in pateamine capable of acting as a site for Michael-type addition raises the possibility that a covalent adduct may be formed between pateamine and eIF4A. This might explain the significantly increased recovery time from pateamine treatment in yeast compared to cycloheximide, the irreversible inhibitory effect on protein synthesis and stress granule formation, and the irreversible induction of apoptosis in mammalian cell lines. Although it could be argued that this is simply the result of a particularly high affinity interaction between eIF4A and pateamine, the possibility for a formation of a covalent adduct exists and warrants further investigation.

\subsection{Functional specificity of pateamine}

Through chemogenomic screens performed it was hoped an appreciation of all of the cellular effects of pateamine in yeast would be revealed. What was clear from these results was that the effect of pateamine is influenced by the deletion of genes involved in multiple facets of RNA metabolism, with the exclusion of results that would suggest a direct effect on either actin or tubulin cytoskeletal components or DNA polymerase. 
While there is clear evidence for the targeting of human and murine eIF4AI/II and eIF4AIII and yeast eIF4A by pateamine both in vitro and in vivo, its effect, if any, on Fallp remains to be resolved. The level of homology between Fallp and the other eIF4A family members suggests that it too could be targeted, however the chemogenomic screens performed in order to address this failed to provide a clear result. The lack of haploinsufficiency of the $\Delta$ fall heterozygote in the presence of pateamine, and the lack of any significant functional enrichment of deletions involved in ribosome biogenesis in the homozygous deletion screens may suggest it is not a target, however in both the heterozygous and homozygous screens there was clearly significant enrichment of numerous processes surrounding RNA metabolism. It is possible to imagine an aggravating effect of simultaneously inhibiting Fallp with pateamine and compromised RNA metabolism; however it is equally easy to imagine this would also be aggravating with an inhibition of translation initiation.

Finally, if a covalent adduct is actually formed between eIF4A and pateamine it might be expected that Fallp is not a target given it has an isoleucine rather than the cysteine residue conserved in pateamine sensitive eIF4A isoforms and putatively proposed as a site for pateamine covalent modification of the eIF4As. The question of pateamine targeting Fallp may be resolved by investigating whether rRNA processing is perturbed in the strains bearing the pateamine resistant form of eIF4A, and whether the introduction of the pateamine resistance conferring mutation adds to the resistance seen with the resistant eIF4A mutant. Unfortunately attempts to develop an assay for rRNA processing undertaken during this work were unsuccessful (data not shown). 
Prp5p is another DEAD-Box helicase which could act as a target for pateamine given its homology to the eIF4A family and the presence of the conserved cysteine seen in pateamine sensitive eIF4As. Although the heterozygous deletion of this gene was not haploinsufficient in the presence of pateamine, the chemogenomic screen results, as in the case of an effect on Fal1p, fail to clearly implicate or absolve Prp5p in mediating the inhibitory effect of pateamine in yeast. Though given the overwhelming amount of evidence regarding the targeting of eIF4A, any effect on Prp5p, or indeed any other target, would likely be masked by the effect on eIF4A and translation initiation.

\subsection{Pateamine and apoptosis}

Pateamine was discovered by virtue of its cytotoxicity towards a murine leukemic cell line (Northcote, Blunt et al. 1991), further studies have shown that this cytotoxicity is due to the induction of apoptosis (Hood, West et al. 2001) that occurs via the intrinsic apoptotic pathway involving the induction of caspase 9 (Miller, Rouwe et al. 2004), and this work has shown it depends on caspase 3/7 induction. There are a number of potential scenarios for the induction of apoptosis by pateamine: 1. Inhibition of protein synthesis via the stabilization of eIF4AI/II on mRNA; 2. Inhibition of NMD by the stabilization of the EJC on mRNA; 3. A synergistic combination of both; 4. A response to the presence of these stabilized RNP complexes that is independent of or synergistic with the inhibitory effects on either pathway.

The role of protein synthesis in apoptosis remains controversial. While a number of protein synthesis inhibitors are known to induce apoptosis it has been shown that, depending on the manner in which apoptosis is induced, some of these inhibitors actually inhibit apoptosis. Also the protein synthesis inhibitor didemnin B, which targets eEF1 $1 \alpha$, rapidly 
induces apoptosis but the inhibition of protein synthesis is not required for this induction. It has been suggested that the inhibition of protein synthesis may induce apoptosis by decreasing the pool of ubiquitin available, as occurs in yeast treated with anisomycin or cycloheximide (Hanna, Leggett et al. 2003). Other unstable proteins have been implicated in the induction of apoptosis by protein synthesis inhibitors in mammalian cell lines, for instance Mcl-1 levels have been shown to rapidly decrease after treatment with the protein synthesis inhibitors silvestrol (Cencic, Carrier et al. 2010), lycorine (Liu, Jiang et al. 2009), homoharringtonine (Tang, Faussat et al. 2006) and cycloheximide (Adams and Cooper 2007). Mcl-1 is an anti-apoptotic member of the Bcl-2 family of proteins (Gross, McDonnell et al. 1999). When its intracellular levels decrease the pro-apoptotic Bcl-2 family members Bik and Bax are activated (Adams and Cooper 2007), which leads to mitochrondrial membrane permeabilisation, release of cytochrome $\mathrm{C}$ and activation of caspase 9 (Gross, McDonnell et al. 1999).

A complication to the mechanism proposed above in the case of pateamine is that a number of anti-apoptotic proteins arise from transcripts that contain an IRES, which according to previous studies would still be translated in the presence of pateamine (Bordeleau, Matthews et al. 2005; Low, Dang et al. 2005). Furthermore the simultaneous knockdown of eIF4AI and II with siRNA does not seem to induce cell death (Ferraiuolo, Lee et al. 2004), arguing that the simultaneous inhibition of eIF4AIII is also required for apoptosis induction. However silvestrol, which also targets eIF4A, has been shown to reduce Mcl-1 levels and therefore it is presumed that pateamine would as well (Cencic, Carrier et al. 2010). 
The role of NMD in apoptosis is not clear, it is presumed that NMD functions to prevent the production of truncated, partially functional protein products that could prove to be deleterious in a dominant-negative manner and hence possibly cause cell death. This falls in line with the observation that depleting eIF4AIII levels by siRNA causes cell death, therefore it is possible that pateamine induced inhibition of this process may cause cell death. However, while pateamine may stabilize mRNA containing PTCs these transcripts cannot be translated, since translation initiation would also be inhibited. Even in the case of IRES-controlled transcripts that contain a PTC it is unclear whether they will be translated since the ribosome would probably not be able to displace the pateamine-stabilized EJC that occurs at every exon-exon junction, although this is somewhat speculative, as the study that showed pateamine to inhibit NMD only measured transcript abundance and not their translation (Dang, Low et al. 2009). In that study, while they used IRES-controlled NMD reporter constructs they did not measure their translation, and while they validated the insensitivity of the IRES to pateamine it was done with a luciferase reporter that did not contain introns.

This argues that while simultaneous inhibition of translation initiation and NMD occurs in the presence of pateamine, the consequence to the cell may be independent of the result of the inhibition of NMD, which would be the production of potentially dominant-negative truncated protein products. So, unless a system exists within the cell to detect NMD inhibition independent of the production of truncated proteins, no synergy would occur due to the simultaneous inhibition of both processes. The question of whether IRES-containing transcripts that also contain introns are actually translated in the presence of pateamine cannot be answered as each assay that has shown insensitivity of IRES controlled transcript translation has used intron-less reporter genes (Bordeleau, Matthews et al. 2005; Low, Dang et al. 2005). The incorporation of the pateamine resistance-conferring mutation 
into eIF4AI and II in mammalian cells in combination with the same mutation in eIF4AIII would allow the relative contribution of the inhibition of each of translation inhibition and NMD to the induction of apoptosis by pateamine to be assessed.

\subsection{Models of pateamine action}

The in vitro stimulatory effect of pateamine on the RNA binding and ATP hydrolysis activities of eIF4A could be modeled in two ways:

1. Pateamine locks eIF4A in a confirmation that allows the binding of ATP, its hydrolysis and the subsequent release of ADP, but prevents the release of RNA. In this model either pateamine first interacts with eIF4A which then binds RNA, or, more likely, pateamine binds to eIF4A once it is bound to RNA, and locks both lobes onto RNA while still allowing the intra-molecular movement required to bind ATP, hydrolyze it and release ADP, allowing another ATP molecule to bind (Figure 5.1). The implication of this model is that pateamine is able to stabilize the RNA interaction of both lobes of eIF4A which would require direct contact between pateamine and both lobes directly, or indirectly via a strong interaction with the RNA substrate. 


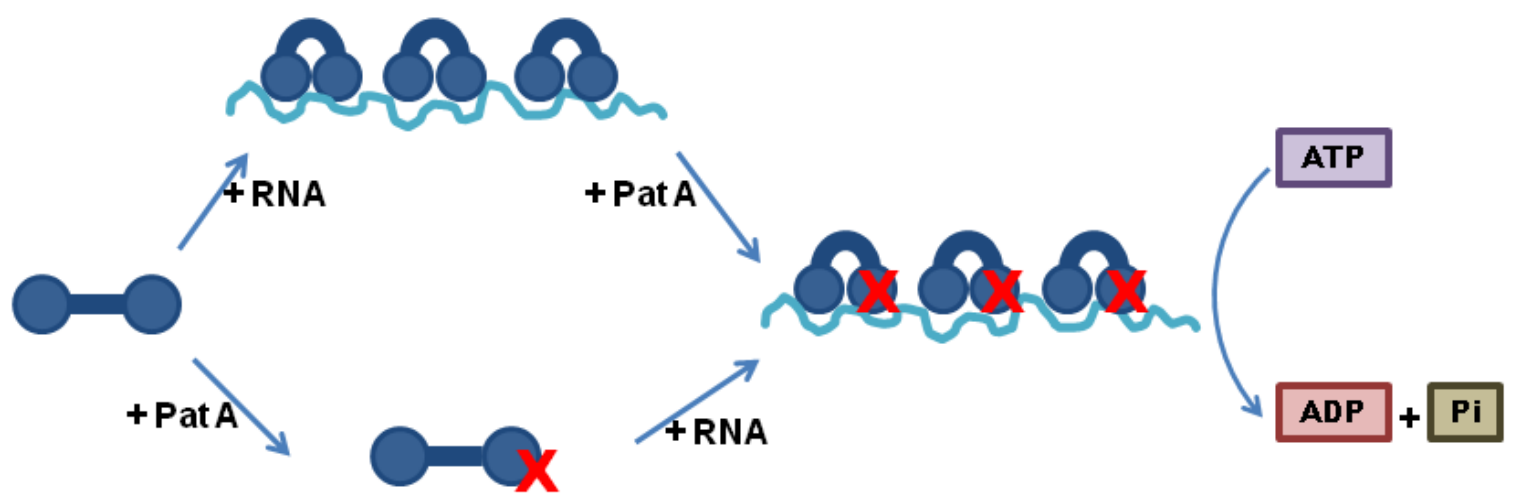

Figure 5.1 Pateamine mechanism model 1: Pateamine locks elF4A onto RNA in a way that allows ATP hydrolysis and ADP release. A red cross indicates pateamine binding.

2. Alternatively, pateamine may interact with the N-terminal lobe of eIF4A first, which raises its affinity for RNA, ATP binding would occur in concert with the C-terminal lobe making contact with the RNA. Once hydrolyzed the C-terminal lobe may lose contact with the RNA allowing another ATP molecule to bind, while the N-terminal lobe remains bound, possibly due to the direct interaction of pateamine and RNA for instance. The newly bound ATP would be hydrolyzed; the energy produced causing the C-terminal to lose contact again and the release of ADP (Figure 5.2). This model implies that the interaction between the N-terminal eIF4A and RNA is very stable, and does not change due to the energy released by ATP hydrolysis. Both models suggest that the increase in RNA helicase activity caused by pateamine is due to the increase in RNA binding and the uncoupling of RNA release from ATP hydrolysis, as of yet there no evidence that allow discrimination between these two models. 


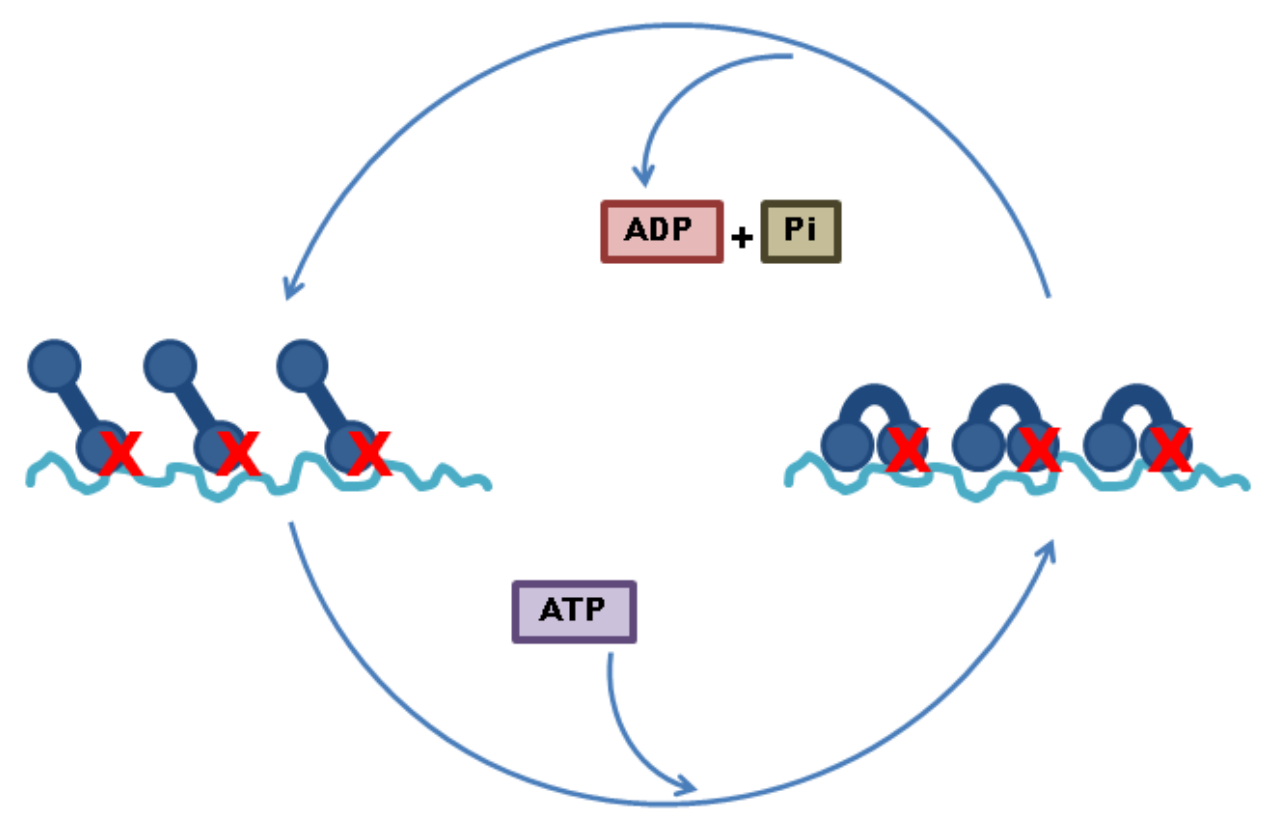

Figure 5.2 Pateamine mechanism 2: Pateamine stabilizes the interaction between the $\mathrm{N}$-terminal lobe of elF4A and RNA. A red cross indicates pateamine binding.

The order of binding of pateamine, RNA and ATP by eIF4A is currently unclear. Given the ATP binding site exists between both lobes (Pause and Sonenberg 1992) and that in vitro eIF4A has higher affinity for RNA than it does ATP (Lorsch and Herschlag 1998), it is likely that RNA is bound first. Given the weak binding of the N-terminal lobe to pateamine it is possible that pateamine binds after, or even co-operatively with RNA. The potential for an interaction between RNA and pateamine exists due to the proximity of the P147L pateamine resistance-conferring mutation in yeast Tif1p, to the RNA binding site of the $\mathrm{N}$-terminal lobe, this interaction may be mediated by the tertiary amine at $\mathrm{C} 17$ of the trienyl tail of pateamine, given the primary amine at $\mathrm{C} 3$ can be removed without a loss of activity (Romo, Choi et al. 2004; Low, Dang et al. 2005).

It has been proposed in vivo that pateamine circumvents the requirement of eIF4G for eIF4A recruitment to mRNA, in direct parallel to the suggested in vitro mechanisms, and 
the stabilization of the eIF4A-RNA interaction causes stress granule formation by simultaneously inhibiting translation initiation and providing a starting point for the rest of the granule to form. This was suggested due to the observation that RNA and ATP binding by eIF4A is not increased when it is a part of the eIF4F complex (Bordeleau, Cencic et al. 2006), though it is of note that this was done with purified eIF4F complex which contains at the most a two-fold increase in the amount of eIF4A relative to eIF4G and eIF4E, whereas in yeast, eIF4A exists in vivo at approximately 40-fold the level of eIF4GI (von der Haar and McCarthy 2002) and at least five-fold the level of eIF4G in HeLa cells (Duncan and Hershey 1983; Duncan, Milburn et al. 1987). Also of note is that there is much more RNA relative to the amount of eIF4A in the in vitro assays performed compared to in vivo, where the relative concentrations of mRNA will be significantly lower. In order for pateamine to cause eIF4A to be loaded onto mRNA independent of eIF4G, eIF4A must either interact with mRNA at some level, independent of eIF4G recruitment, or pateamine must bind to eIF4A first and drastically increase its affinity for mRNA. These mechanistic details are yet to be elucidated fully. 


\subsection{Conclusions}

The work presented here, in combination with studies by other groups, has shown that pateamine specifically targets the eIF4A family of proteins, resulting in the inhibition of protein synthesis in yeast and mammalian cells, and non-sense mediated decay in mammalian cells. While the targeting of other proteins has been implicated, it is clear that the primary target of pateamine is the eIF4A family of proteins, and hence it is the first compound known to specifically and directly inhibit translation initiation and non-sense mediated decay. While it is unclear whether inhibiting non-sense mediated decay by stabilizing the interaction of the exon-exon junction complex on mRNA would produce a cellular consequence, the mechanism by which pateamine induces apoptosis likely involves the decrease of the anti-apoptotic protein Mcl-1. The generation of a pateamine-resistant form of eIF4A through random mutagenesis has allowed the speculation of an approximate binding site for pateamine on the $\mathrm{N}$-terminal lobe of eIF4A, close to the RNA binding site. It also raises the possibilities of the formation of a covalent adduct between pateamine and eIF4A, and a direct interaction between RNA and pateamine. Regardless of the mechanistic details, pateamine has proven to be the first compound able to stabilize the interaction between a protein target and RNA. Further investigation is required to establish whether the related yeast protein, Fallp, is targeted by pateamine, if so it will also be the first compound able to directly impair rRNA processing. If Fallp is truly not a target it places pateamine in the position to become an invaluable reagent for studying eIF4A activity in yeast, allowing chemical access to a proteins' function that has been challenging to access genetically due to its redundant encoding by duplicate genes. The study presented here provides the groundwork for the further development of pateamine as a specific biological probe of eIF4A. 


\section{Appendix A}

HeLa MTT 1
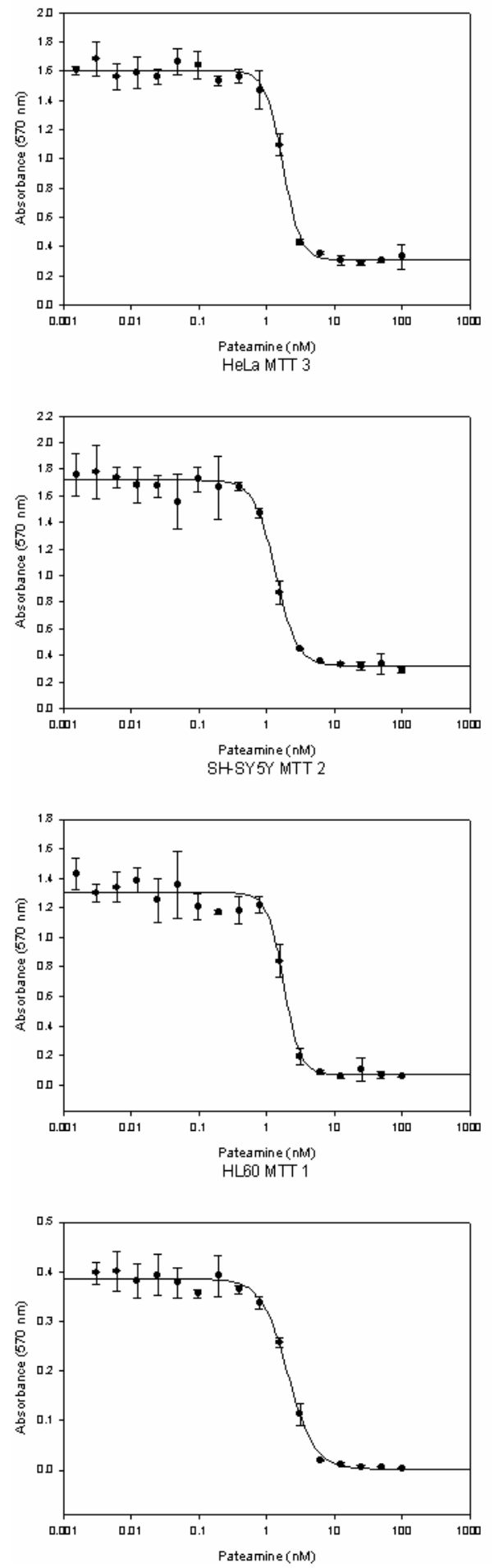

HeLa MTT 2
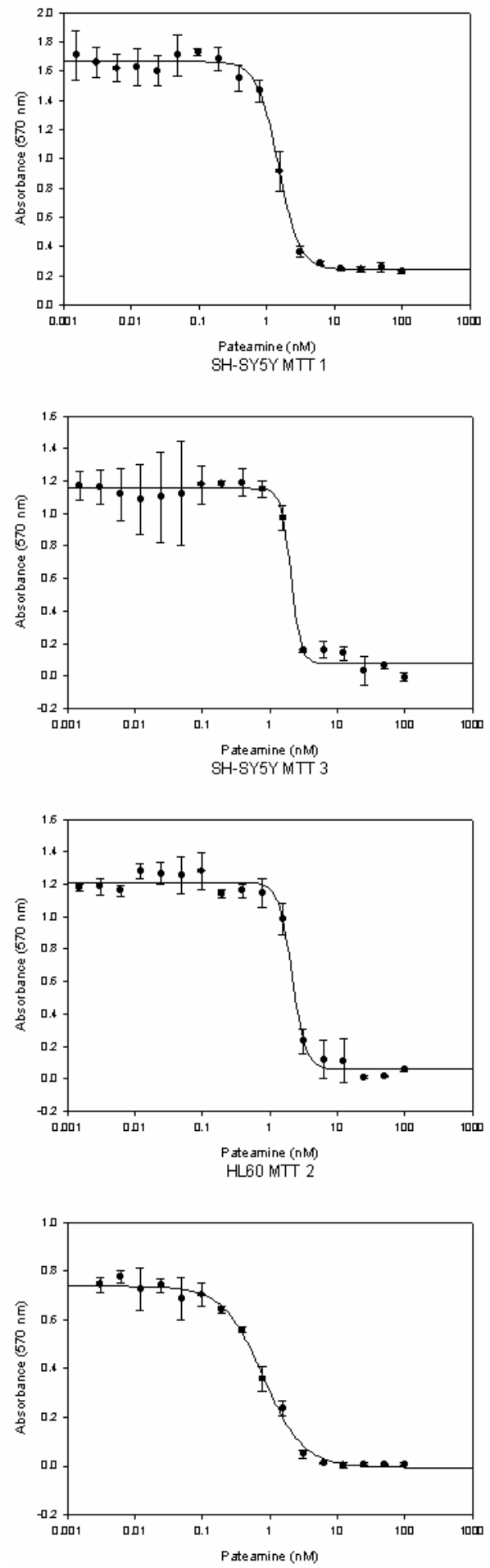

Figure 6.1 Replicate MTT assay dose response curves for HeLa, SH-SY5Y, and HL-60 cell lines. Each point is the average of triplicate samples, with error bars as standard deviation. 


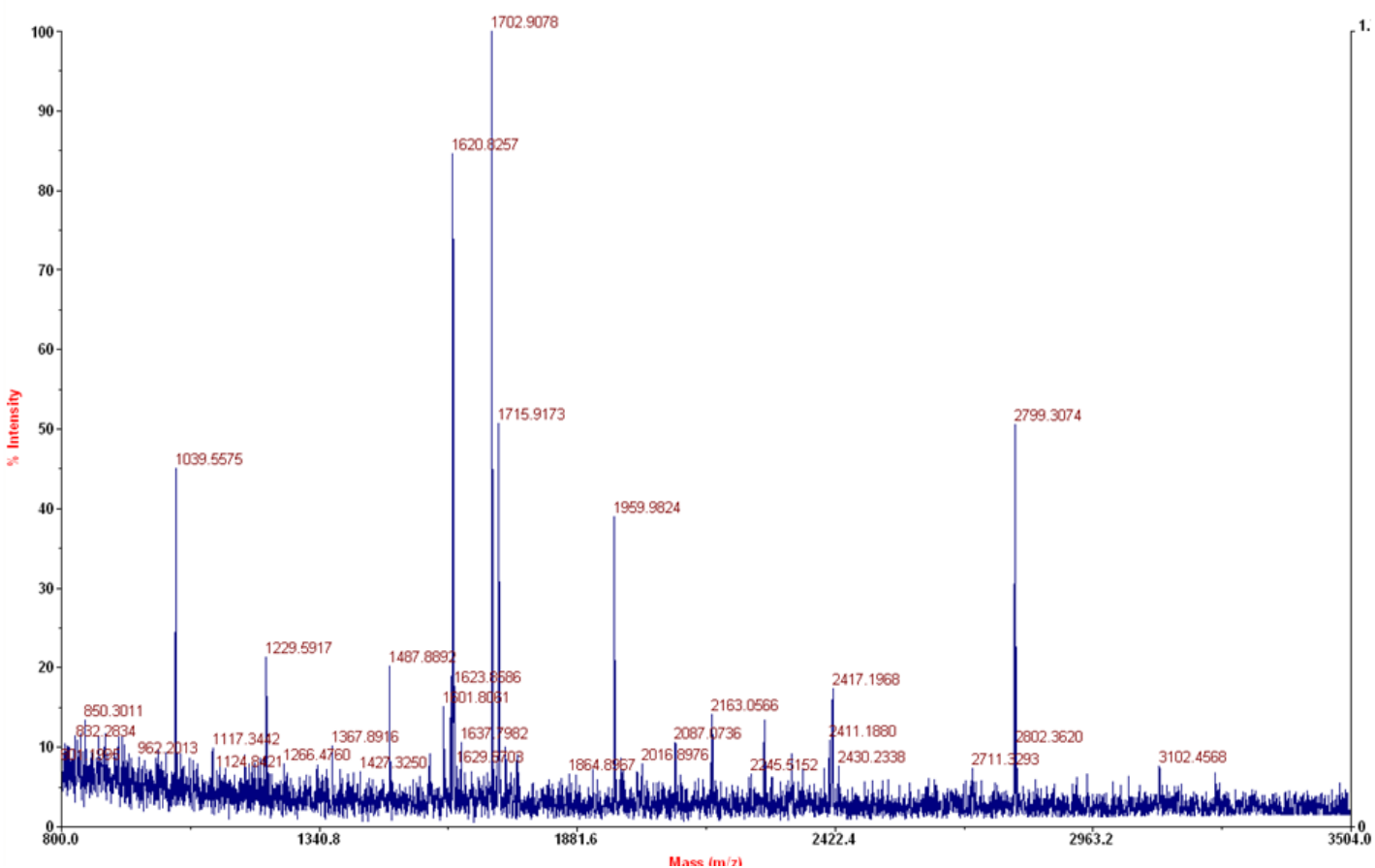

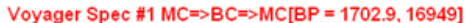

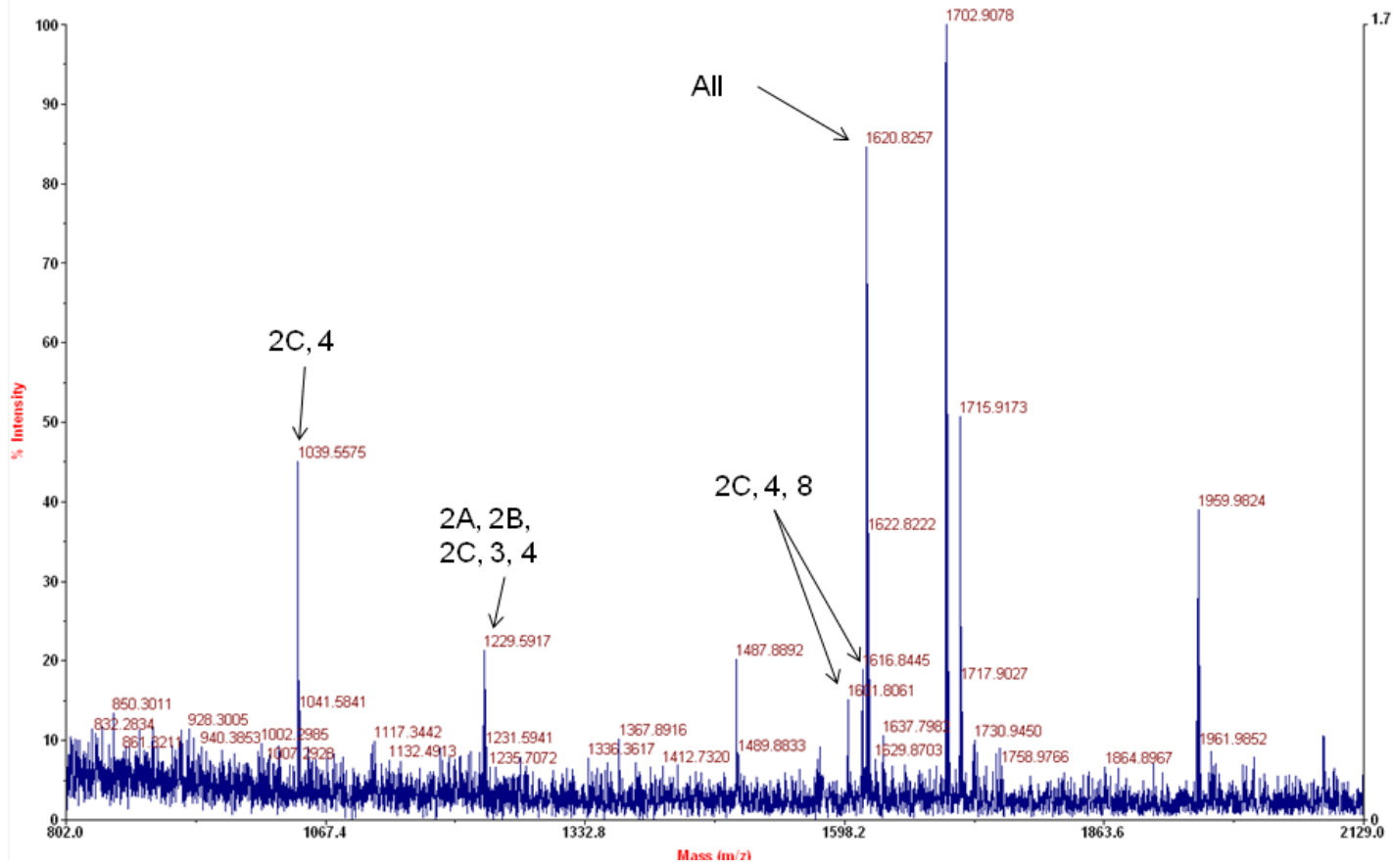

Figure 6.2 Mass spectra close-up images. A. Mass spectrum obtained for gel band one isolated from HeLa cell lysate; $B$. Close up indicating the presence of peptides specific to different isotypes of $\beta$-tubulin 

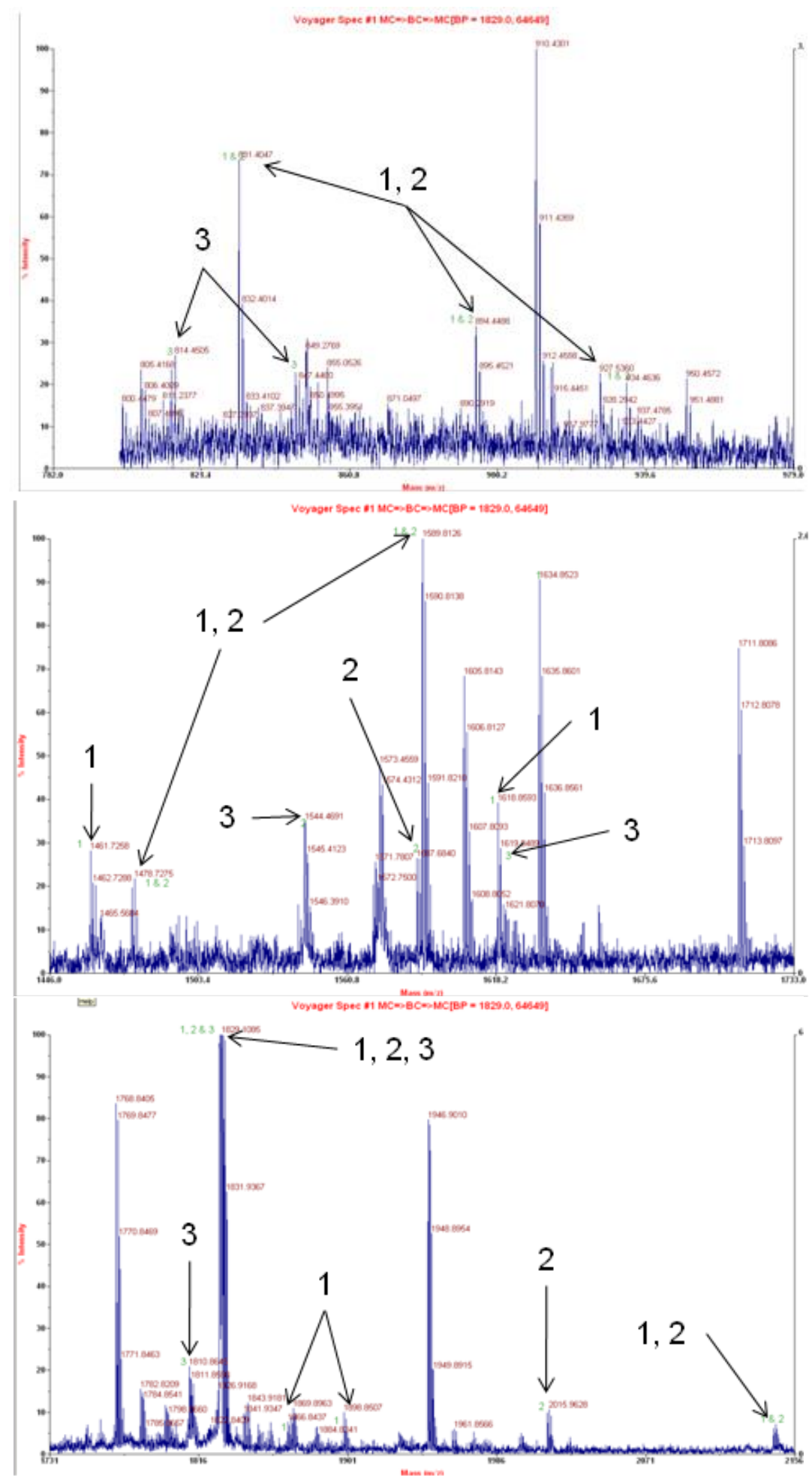

Figure 6.3 Close up of spectrum acquired from gel band two. Isolated from the HeLa cell lysate, indicated are peptides specific to elF4A1, 2 and 3. 


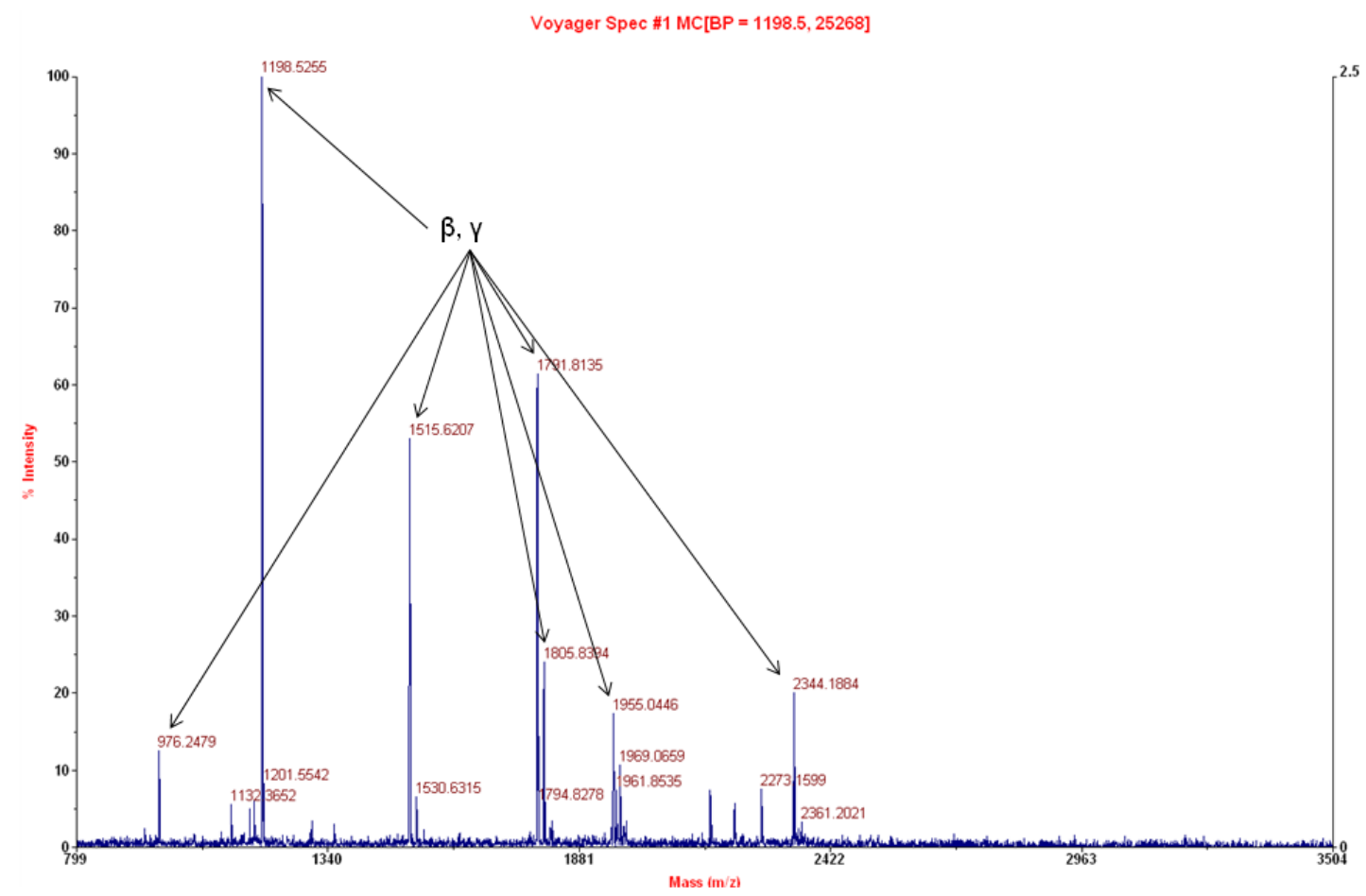

Figure 6.4 Mass spectrum acquired from gel band three. Isolated from the HeLa cell lysate, indicated peptides are common to both $\beta$ and $y$ actin.

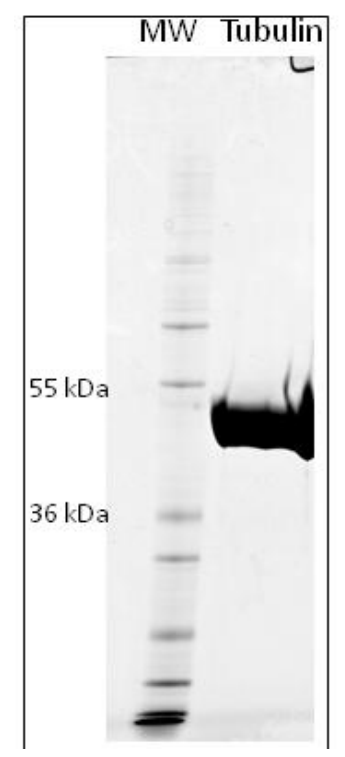

Figure 6.5 LDS-PAGE of purified bovine tubulin. 
Sp|P60709|ACTB_ M--DDDIAALVVDNGSGMCKAGFAGDDAPRAVFPSIVGRPRHQGVMVGMGQKDSYVGDEA 58 SP 1 P63261 ACTG_M--EEEIAALVIDNGSGMCKAGFAGDDAPRAVFPSIVGRPRHQGVMVGMGQKDSYVGDEA 58

SP 1 P68135 ACTS_ MCDEDETTAL VCDNGSGLVKAGFAGDDAPRAVFPSIVGRPRHQGVMVGMGQKDSYVGDEA 60

等, :

SP|P60709|ACTB_ QSKRGILTLKYPIEHGIVTNWDDMEKIWHHTFYNELRVAPEEHPVLLTEAPLNPKANREK 118

Sp P63261 ACTG QSKRGILTLKYPIEHGIVTNWDDMEKIWHHTFYNELRVAPEEHPVI TEAPLNPKANREK 118

sp |P68135

sp|P60709|ACTB_ MTQIMFETFNTPAMYVAIQAVLSLYASGRTTGIVMDSGDGVTHTVPIYEGYALPHAILRL 178

sp |P63261 ACTG_ MTQIMFETFNTPAMYVAIQAVLSLYASGRTTGIVMDSGDGVTHTVPIYEGYALPHAILRL 178

SP|P68135|ACTS_ MTQIMFETFNVPAMYVAIQAVLSLYASGRTTGIVLDSGDGVTHNVPIYEGYALPHAIMRL 180

sp|P60709|ACTB_ DLAGRDLTDYLMKILTERGYSFTTTAEREIVRDIKEKLCYVALDFEQEMATAASSSSLEK 238

Sp |P63261 |ACTG_ DLAGRDL TDYLMKILTERGYSFTTTAEREIVRDIKEKLCYVALDFEQEMATAASSSSLEK 238

sp | P68135|ACTS_ DLAGRDLTDYLMKILTERGYSFVTTAEREIVRDIKEKLCYVALDFENEMATAASSSSLEK 240

SP|P60709|ACTB _ SYELPDGQVITIGNERFRCPEALFQPSFLGMESCGIHETTFNSIMKCDVDIRKDLYANTV 298

SP P63261 ACTG_ SYELPDGQVITIGNERFRCPEALFQPSFLGMESCGIHETTFNSIMKCDVDIRKDLYANTV 298

sp|P68135|ACTS_ SYELPDGQVITIGNERFRCPETLFQPSFIGMESAGIHETTYNSIMKCDIDIRKDLYANNV 300

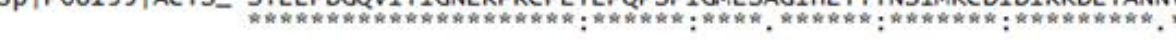

Sp|P60709|ACTB_ LSGGTTMYPGIADRMQKEITALAPSTMKIKIIAPPERKYSWWIGGSILASLSTFQQMWIS 358

sp|P63261 ACTG_ LSGGTTMYPGIADRMQKEITALAPSTMKIKIIAPPERKYSWWIGGSILASLSTFQQMWIS 358

sp|P68135 |ACTS_ MSGGTTMYPGIADRMQKEITALAPSTMKIKIIAPPERKYSWWIGGSILASLSTFQQMWIT 360

SP|P60709|ACTB_ KQEYDESGPSIVHRKCF 375

sp |P63261 ACTG_ KQEYDESGPSIVHRKCF 375

sp |P68135|ACTS_ KQEYDEAGPSIVHRKCF 377

की

Figure 6.6 Multiple amino acid sequence alignment of actin. Human $\beta$ actin (ACTB), $\gamma$ actin (ACTG) and rabbit $\alpha$ actin (ACTS). 


\section{Appendix B}

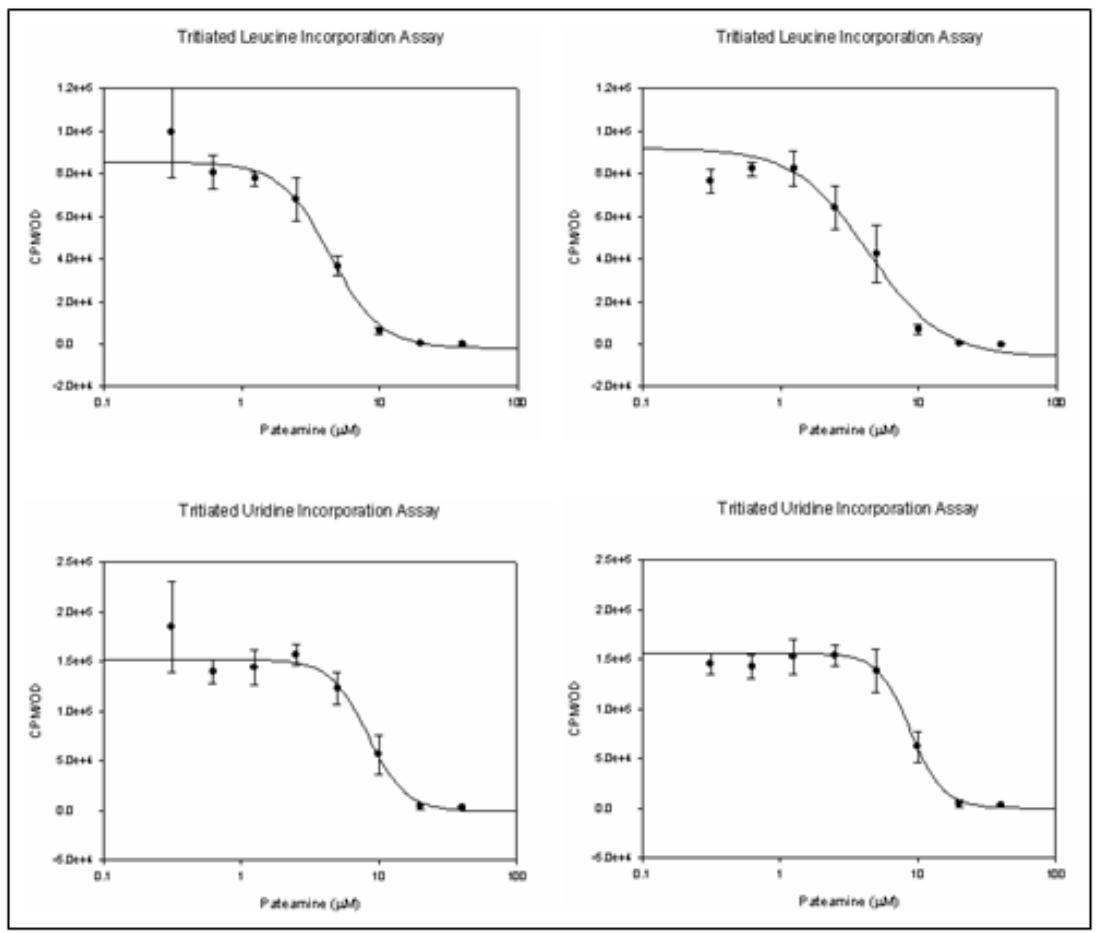

Figure 7.1 Replicate tritiated leucine and tritiated uridine incorporation dose-response curves. Each data point is the average of three replicates and standard deviation as error bars.

\begin{tabular}{|l|l|l|l|l|}
\hline $\begin{array}{l}\text { Leucine } \\
\text { incorporation }\end{array}$ & $\begin{array}{l}\text { Replicate } \\
1\end{array}$ & $\begin{array}{l}\text { Replicate } \\
2\end{array}$ & $\begin{array}{l}\text { Replicate } \\
3\end{array}$ & Mean \\
\hline $\mathrm{EC}_{50}(\mu \mathrm{M})$ & 4.55 & 4.39 & 4.36 & 4.43 \\
\hline Standard error & 0.37 & 0.50 & 0.91 & 0.59 \\
\hline $\begin{array}{l}\text { Uridine } \\
\text { incorporation }\end{array}$ & & & & \\
\hline $\mathrm{EC}_{50}(\mu \mathrm{M})$ & 8.90 & 8.32 & 8.85 & 8.69 \\
\hline Standard error & 0.62 & 1.06 & 0.96 & 0.88 \\
\hline
\end{tabular}

Table 7.1 Summary statistics for leucine and uridine incorporation assays. $E C_{50}$ values defined for the three independent leucine and uridine incorporation assays (Figure 3.10 and Figure 7.1) 


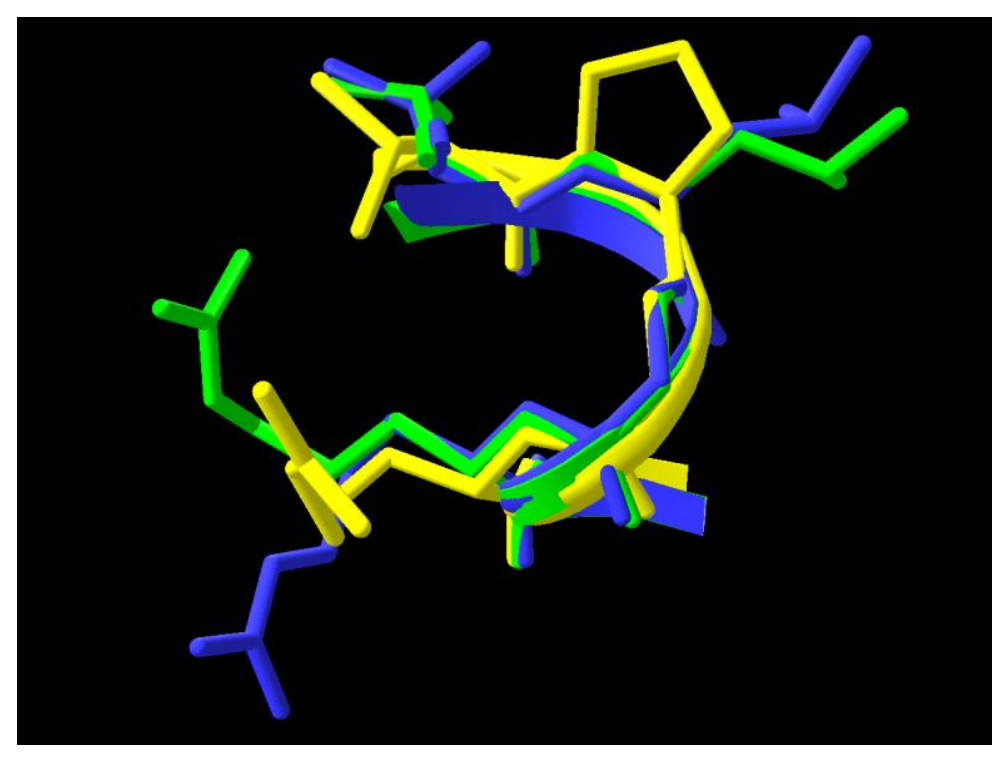

Figure 7.2 TPG and TLG sequences are able to assume the same conformation. Yeast elF4A (yellow, pdb: 1FUU) TPG motif was aligned with TLG sequences from beta-purothionin (Blue, pdb: $1 \mathrm{BHP})$ and [NiFe] hydrogenase from Desulfovibrio desulfuricans (Green, pdb: 1E3D).
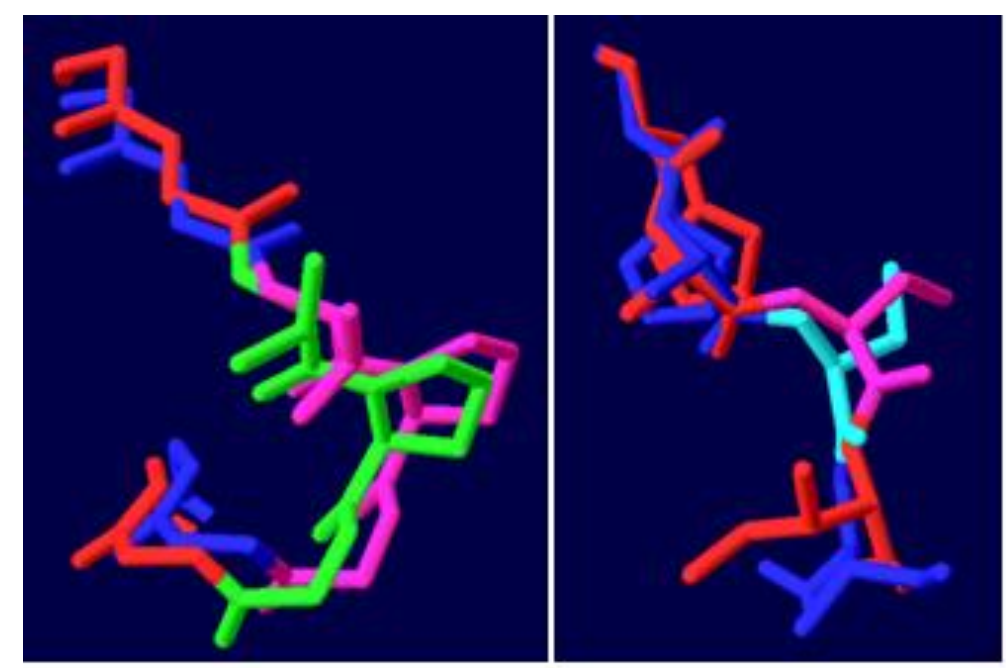

Figure 7.3 Conformational differences in RNA bound and apo structures. TPG (left) and HACI (right) motif conformational differences in the RNA bound (magenta) and apo crystal structures of elF4Alll (green and cyan). Only the side chains for P164 and C124 are shown. 


\section{Appendix C}

\begin{tabular}{|l|r|r|r|r|}
\hline & $\begin{array}{l}\text { HIP } \\
\text { Screen 1 }\end{array}$ & $\begin{array}{l}\text { HIP } \\
\text { Screen 2 }\end{array}$ & $\begin{array}{l}\text { HIP } \\
\text { Screen 3 }\end{array}$ & $\begin{array}{l}\text { HIP } \\
\text { Screen 4 }\end{array}$ \\
\hline $\begin{array}{l}\text { HIP } \\
\text { Screen 1 }\end{array}$ & 1 & 0.74996 & 0.8505 & 0.82568 \\
\hline $\begin{array}{l}\text { HIP } \\
\text { Screen 2 }\end{array}$ & 0.63349 & 1 & 0.66916 & 0.7096 \\
\hline $\begin{array}{l}\text { HIP } \\
\text { Screen 3 }\end{array}$ & 0.6762 & 0.4773 & 1 & 0.89838 \\
\hline $\begin{array}{l}\text { HIP } \\
\text { Screen 4 }\end{array}$ & 0.60713 & 0.50861 & 0.76653 & \\
\hline
\end{tabular}

Table 8.1 Pearson correlation of heterozygous deletion set HIP screen results. Upper right: correlation scores of the entire datasets for each screen. Lower left: correlation scores after applying the $\log _{2}$ ratio threshold of 0.5 used to identify sensitive strains.

\begin{tabular}{|l|r|r|r|r|}
\hline & \multicolumn{1}{|l|}{$\begin{array}{l}\text { HIP } \\
\text { Screen 1 }\end{array}$} & $\begin{array}{l}\text { HIP } \\
\text { Screen 2 }\end{array}$ & $\begin{array}{l}\text { HIP } \\
\text { Screen 3 }\end{array}$ & $\begin{array}{l}\text { HIP } \\
\text { Screen 4 }\end{array}$ \\
\hline $\begin{array}{l}\text { HIP } \\
\text { Screen 1 }\end{array}$ & & 0.39 & 0.43 & 0.37 \\
\hline $\begin{array}{l}\text { HIP } \\
\text { Screen 2 }\end{array}$ & 0.34 & & 0.29 & 0.31 \\
\hline $\begin{array}{l}\text { HIP } \\
\text { Screen 3 }\end{array}$ & 0.22 & 0.2 & & 0.56 \\
\hline $\begin{array}{l}\text { HIP } \\
\text { Screen 4 }\end{array}$ & 0.33 & 0.46 & 0.27 & \\
\hline
\end{tabular}

Table 8.2 HIP screen overlaps in hit and GO term enrichment. Upper right: Screen replicate hit heterozygous gene deletion overlap measured by Jaccard distance. Lower left: Screen replicate GO term overlap measured by Jaccard distance. 


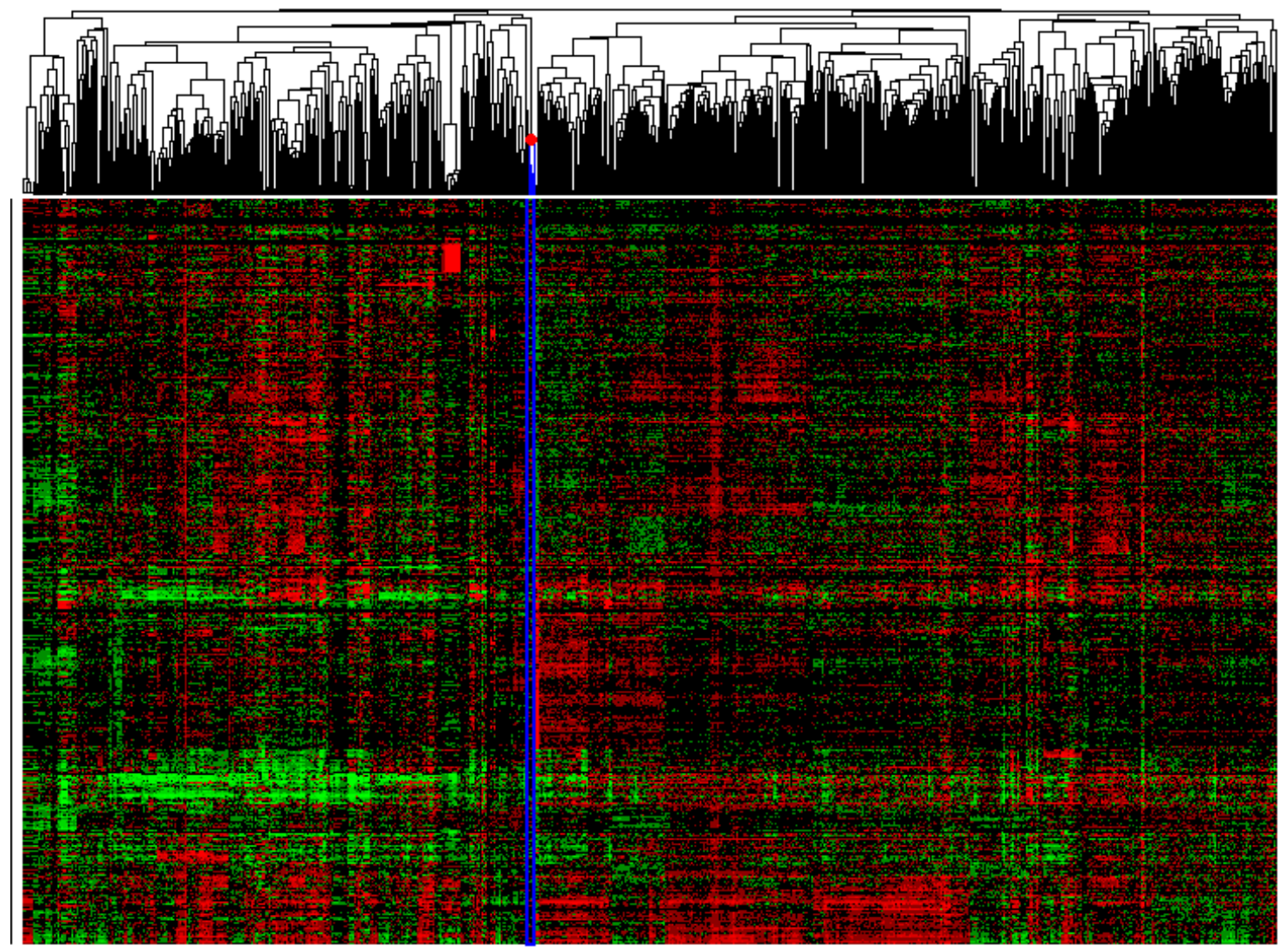

Figure 8.1 Complete clustergram resulting from the hierarchical clustering of pateamine HIP screens with the essential heterozygous screen data from Hillenmeyer et al 2008. Dataset 1 (Method 4.3.6) was clustered using the centered Pearsons distance metric and average linkage method. Pateamine HIP screens are indicated in blue. 


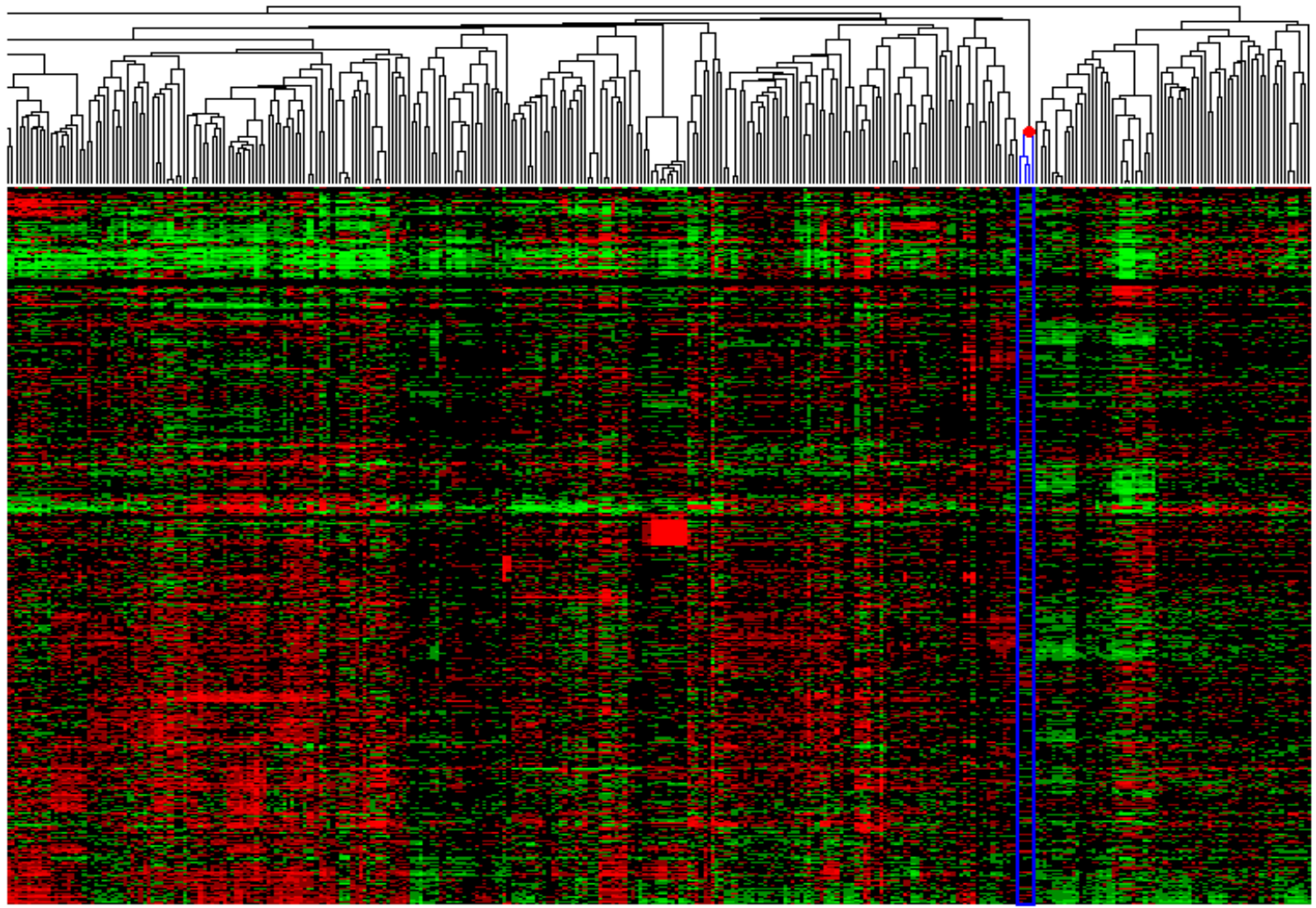

Figure 8.2 Complete clustergram resulting from the hierarchical clustering of pateamine HIP screens with the essential heterozygous screen data from Hillenmeyer et al 2008. Dataset 1 (Method 4.3.6) was clustered using the uncentered Pearsons distance metric and average linkage method. Pateamine HIP screens are indicated in blue. 


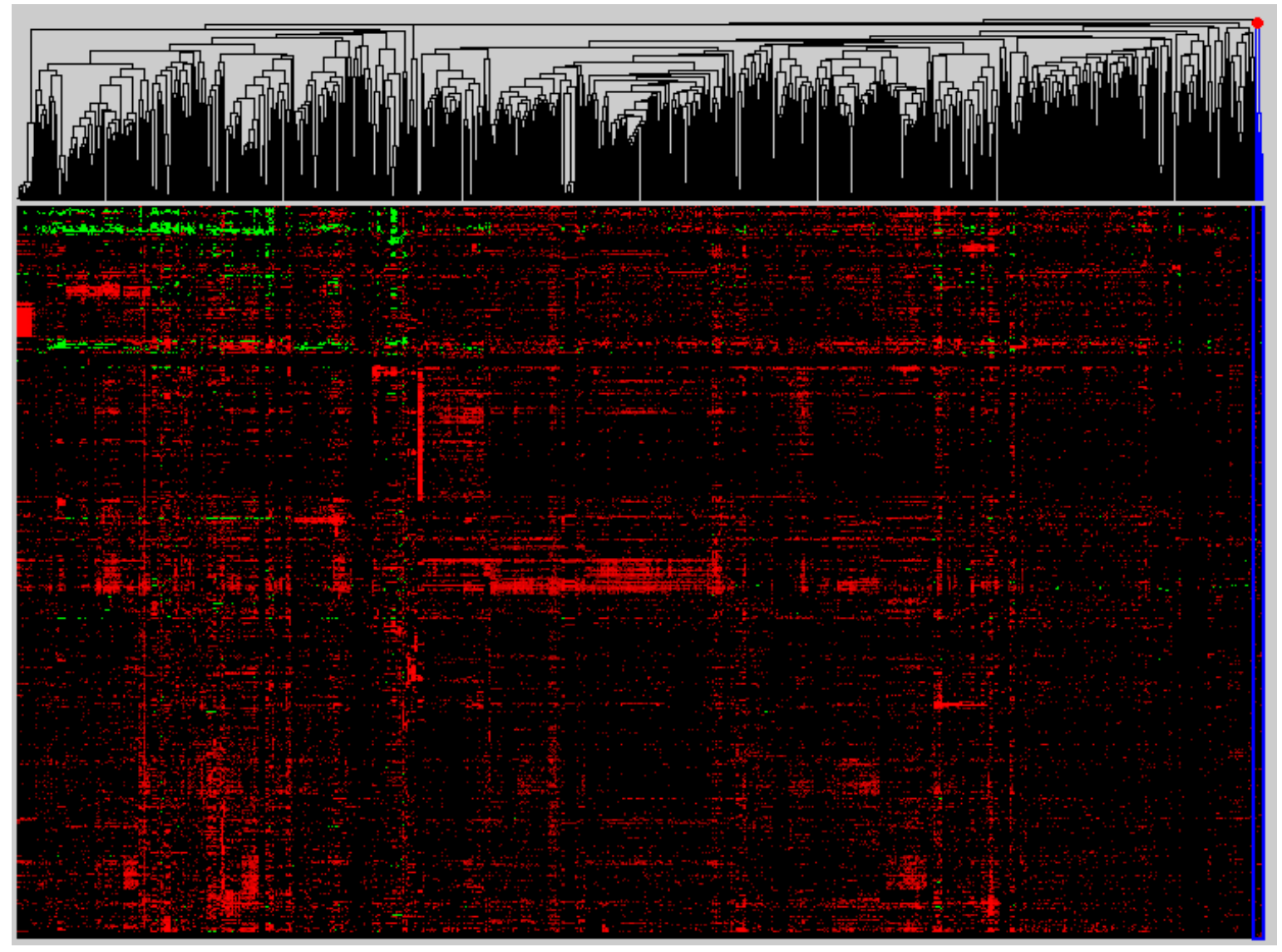

Figure 8.3 Complete clustergram resulting from the hierarchical clustering of pateamine HIP screens with the essential heterozygous screen data from Hillenmeyer et al 2008. Dataset 2 (Method 4.3.6) was clustered using the centered Pearsons distance metric and average linkage method. Pateamine HIP screens are indicated in blue. 


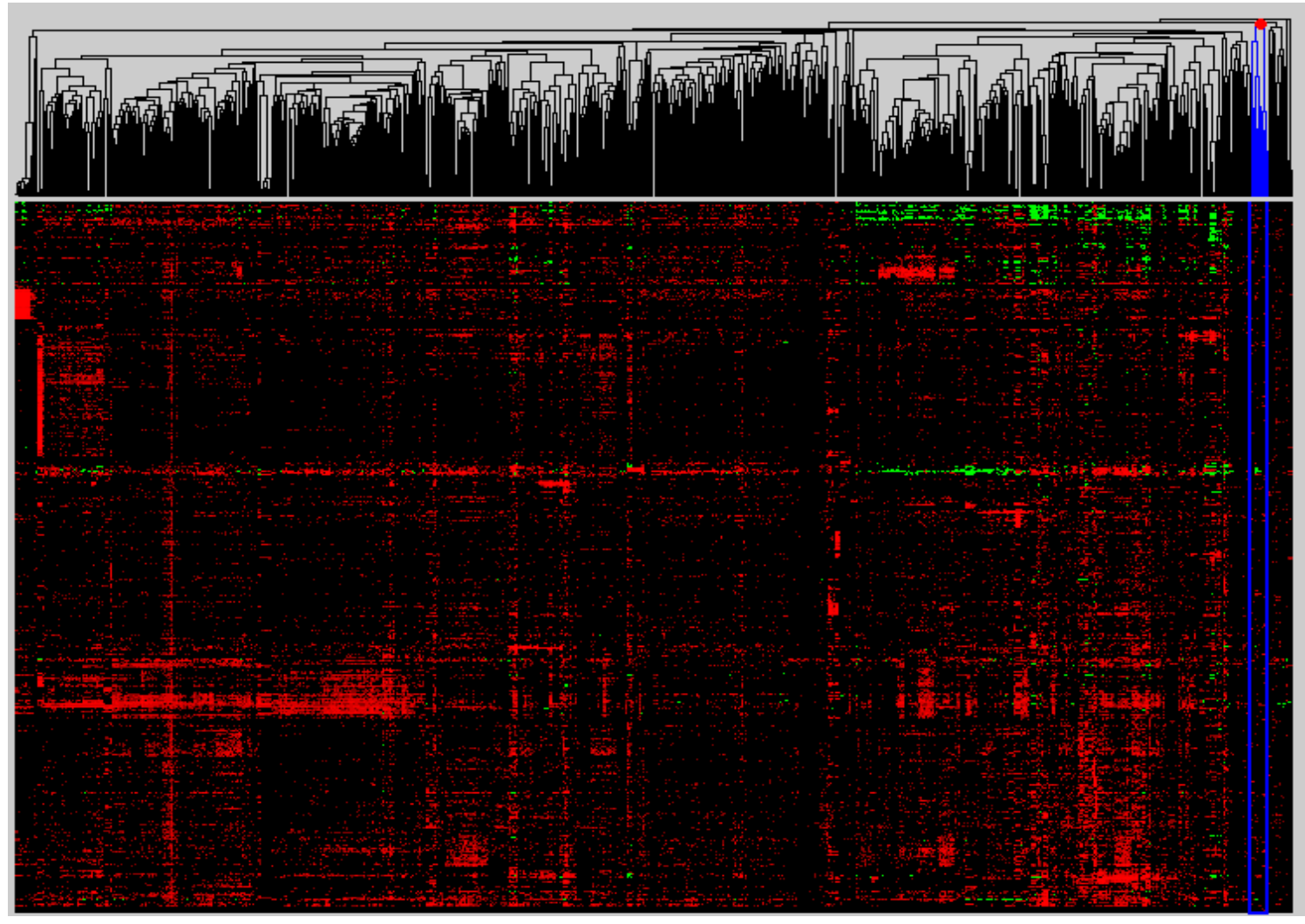

Figure 8.4 Complete clustergram resulting from the hierarchical clustering of pateamine HIP screens with the essential heterozygous screen data from Hillenmeyer et al 2008. Dataset 2 (Method 4.3.6) was clustered using the uncentered Pearsons distance metric and average linkage method. Pateamine HIP screens are indicated in blue. 


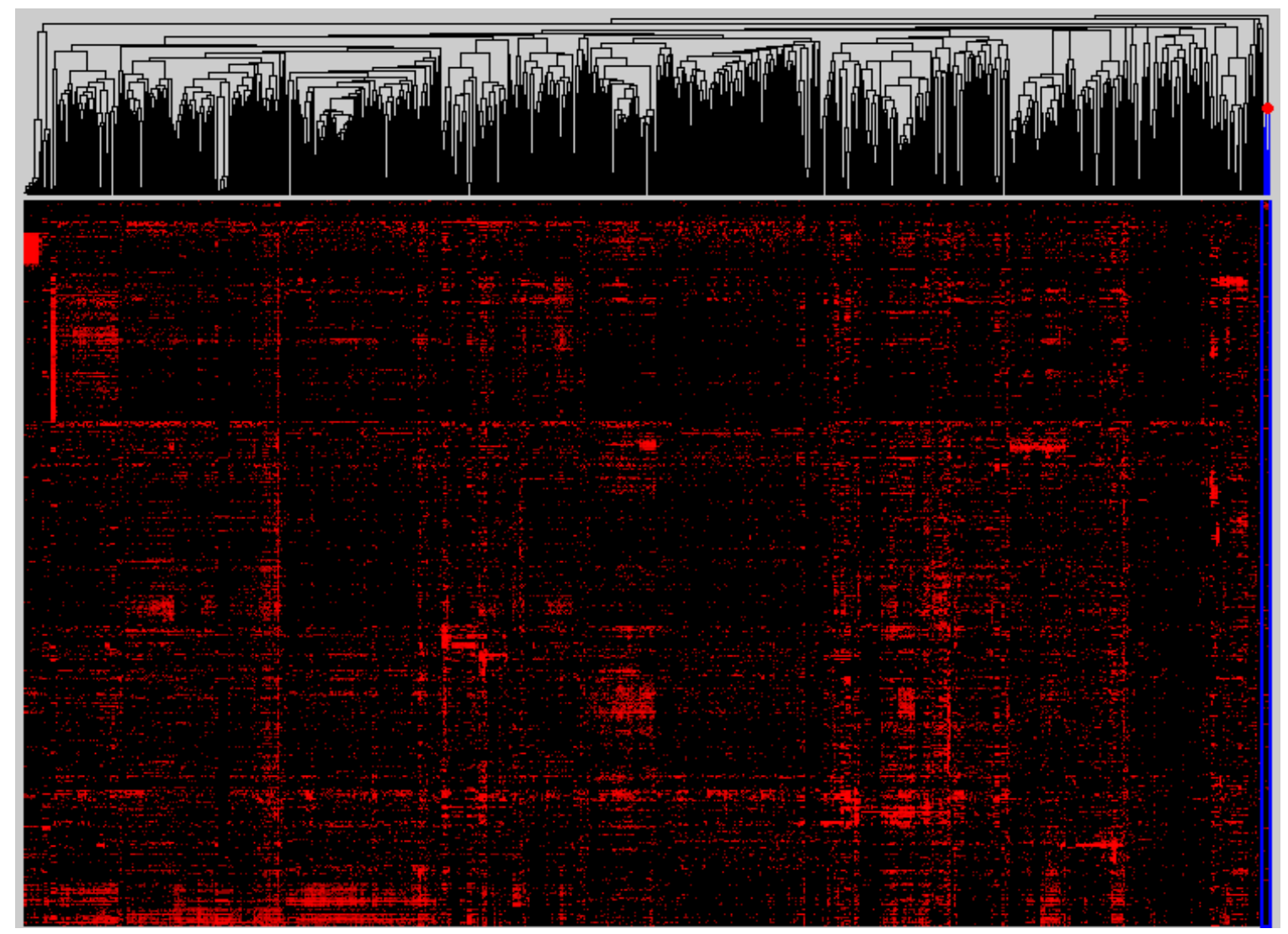

Figure 8.5 Complete clustergram resulting from the hierarchical clustering of pateamine HIP screens with the essential heterozygous screen data from Hillenmeyer et al 2008. Dataset 3 (Method 4.3.6) was clustered using the centered Pearsons distance metric and average linkage method. Pateamine HIP screens are indicated in blue. 


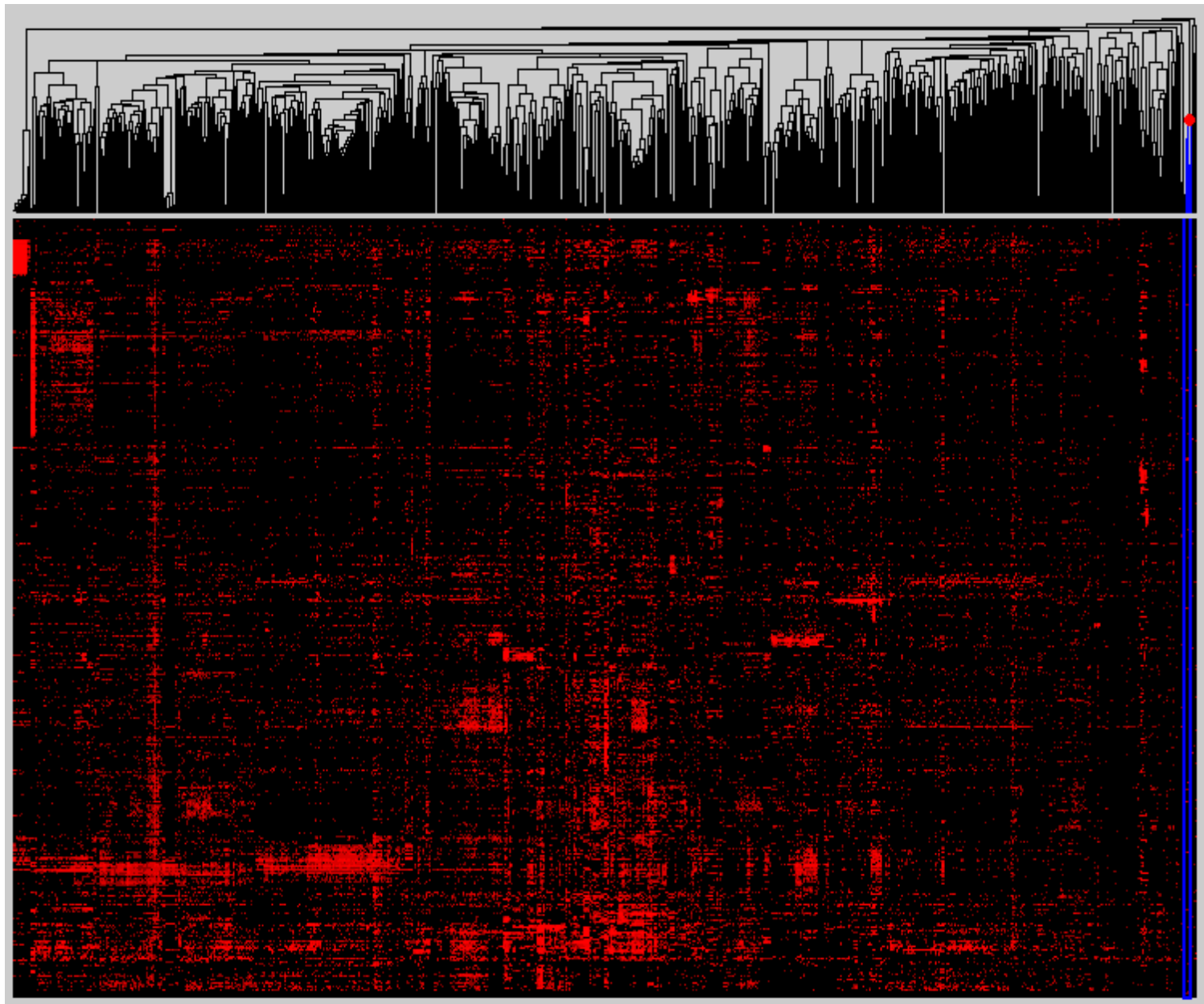

Figure 8.6 Complete clustergram resulting from the hierarchical clustering of pateamine HIP screens with the essential heterozygous screen data from Hillenmeyer et al 2008. Dataset 3 (Method 4.3.6) was clustered using the centered Pearsons distance metric and average linkage method. Pateamine HIP screens are indicated in blue. 


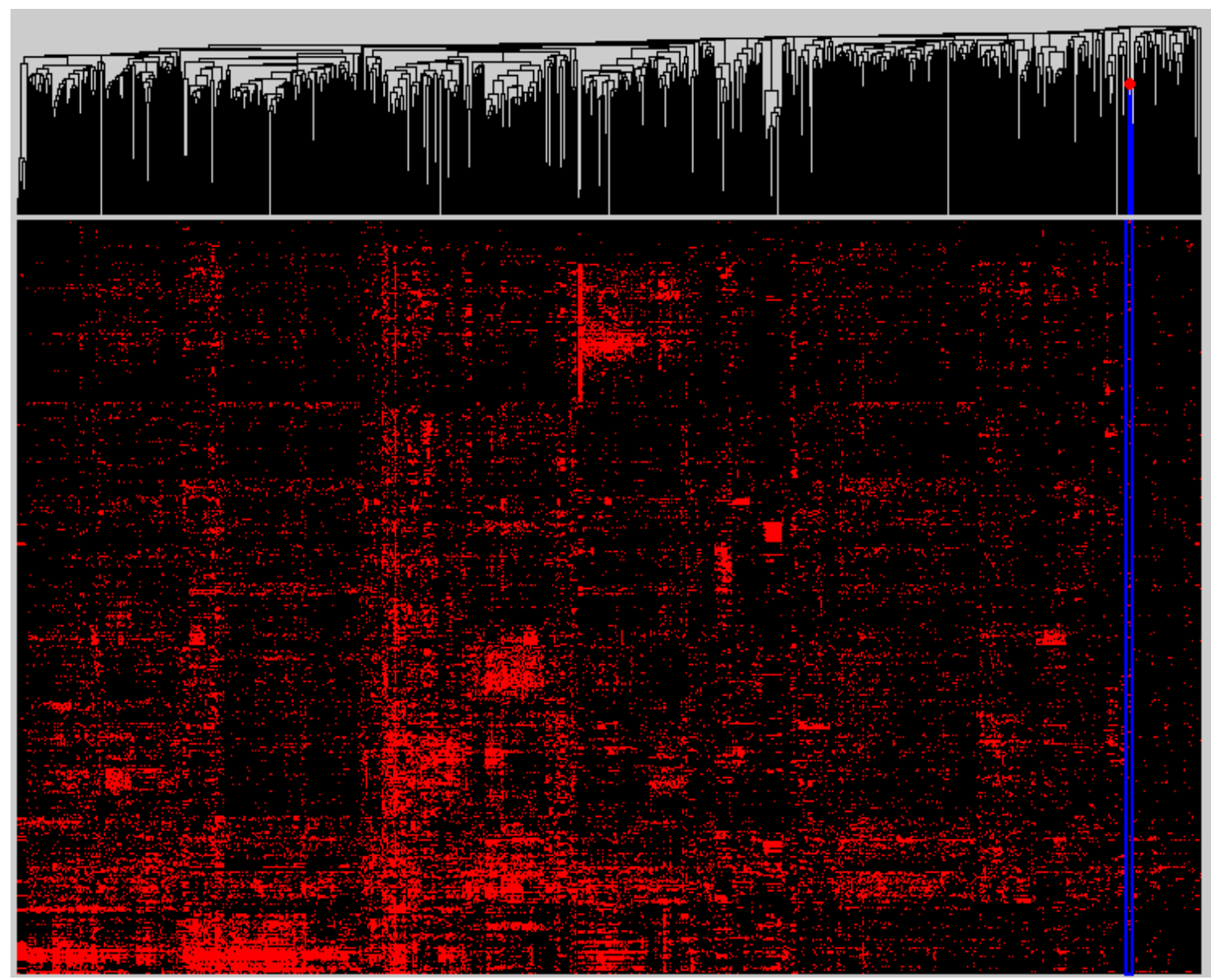

Figure 8.7 Complete clustergram resulting from the hierarchical clustering of pateamine HIP screens with the essential heterozygous screen data from Hillenmeyer et al 2008. Dataset 4 (Method 4.3.6) was clustered using the Jaccard distance metric and average linkage method. Pateamine HIP screens are indicated in blue.

\begin{tabular}{|l|l|l|l|l|}
\hline & $\begin{array}{l}\text { HOP } \\
\text { Screen 1 }\end{array}$ & $\begin{array}{l}\text { HOP } \\
\text { Screen 2 }\end{array}$ & $\begin{array}{l}\text { HOP } \\
\text { Screen 3 }\end{array}$ & $\begin{array}{l}\text { HOP } \\
\text { Screen 4 }\end{array}$ \\
\hline $\begin{array}{l}\text { HOP } \\
\text { Screen 1 }\end{array}$ & 1 & 0.34 & 0.59 & 0.47 \\
\hline $\begin{array}{l}\text { HOP } \\
\text { Screen 2 }\end{array}$ & 0.17 & 1 & 0.07 & 0.27 \\
\hline $\begin{array}{l}\text { HOP } \\
\text { Screen 3 }\end{array}$ & 0.38 & -0.05 & 1 & 0.67 \\
\hline $\begin{array}{l}\text { HOP } \\
\text { Screen 4 }\end{array}$ & 0.34 & 0.17 & 0.55 & 1 \\
\hline
\end{tabular}

Table 8.3 Pearson correlation of homozygous deletion set HOP screen results. Upper right: correlation scores of the entire datasets for each screen. Lower left: correlation after applying the $\log 2$ ratio threshold of 0.5 used to identify sensitive strains. 


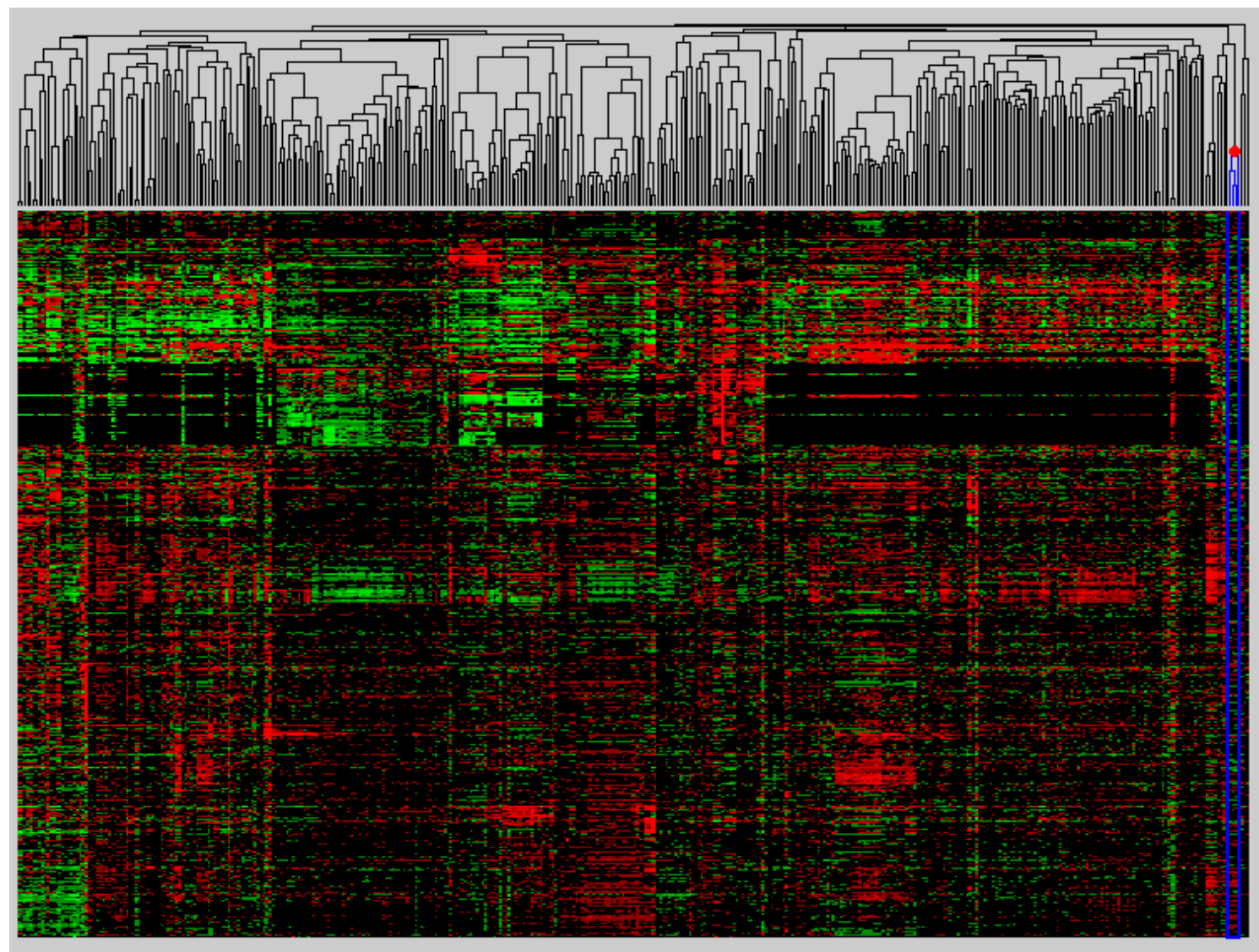

Figure 8.8 Complete clustergram resulting from the hierarchical clustering of pateamine HOP screens with the homozygous diploid screen data from Hillenmeyer et al 2008. Dataset 1 (Method 4.3.6) was clustered using the centered Pearsons distance metric and average linkage method. Pateamine HOP screens are indicated in blue. 


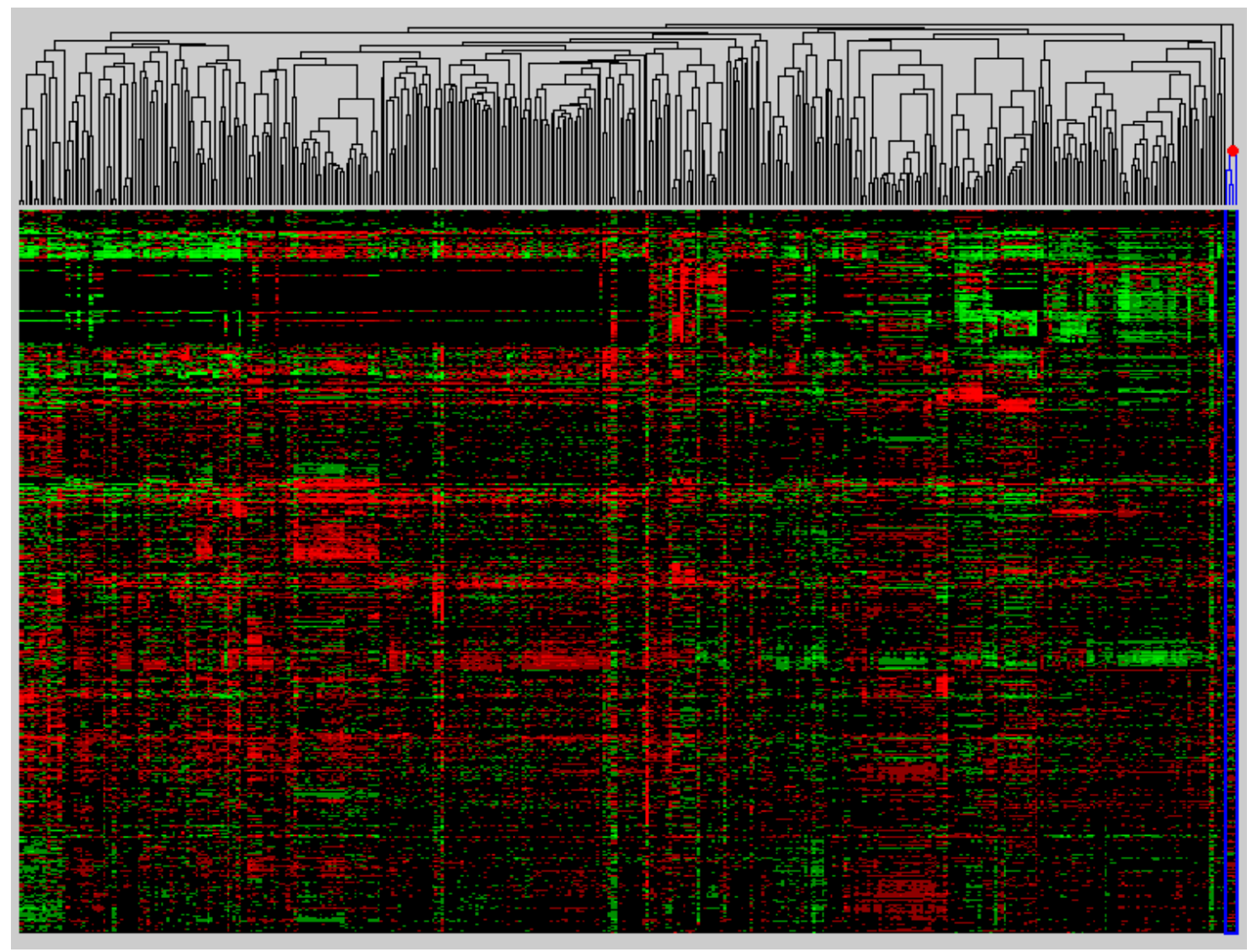

Figure 8.9 Complete clustergram resulting from the hierarchical clustering of pateamine HOP screens with the homozygous diploid screen data from Hillenmeyer et al 2008. Dataset 1 (Method 4.3.6) was clustered using the uncentered Pearsons distance metric and average linkage method. Pateamine HOP screens are indicated in blue. 


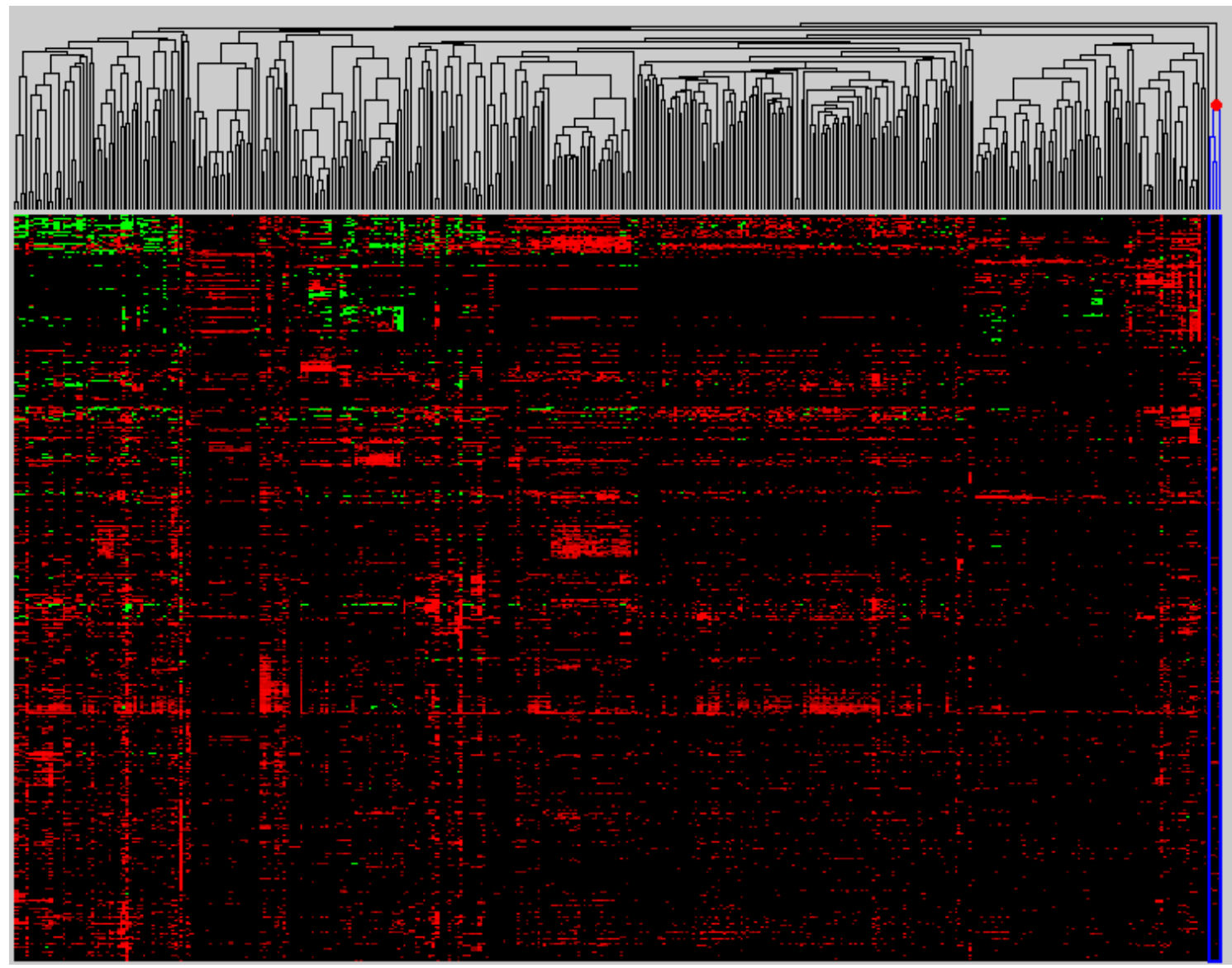

Figure 8.10 Complete clustergram resulting from the hierarchical clustering of pateamine HOP screens with the homozygous diploid screen data from Hillenmeyer et al 2008. Dataset 2 (Method 4.3.6) was clustered using the centered Pearsons distance metric and average linkage method. Pateamine HOP screens are indicated in blue. 


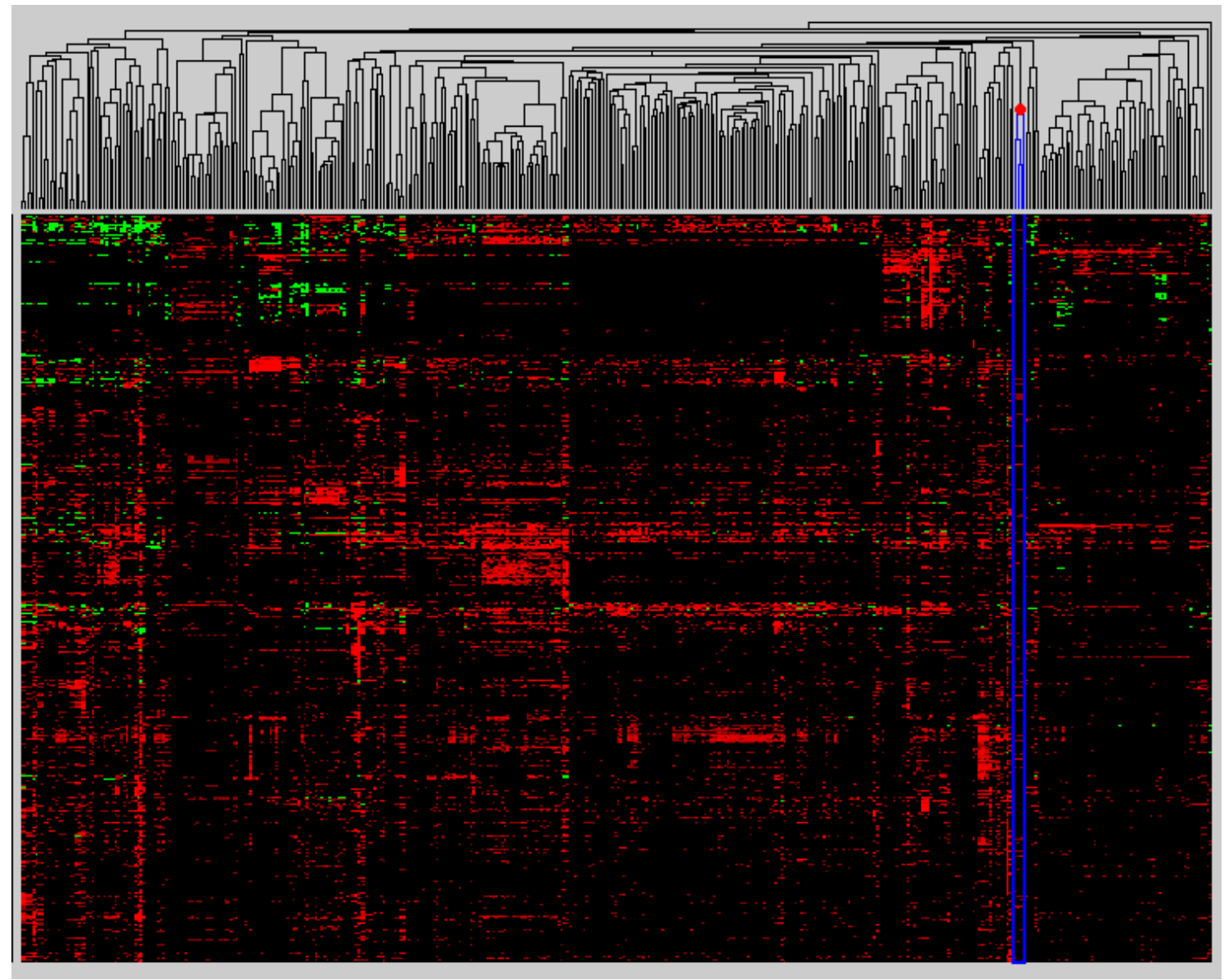

Figure 8.11 Complete clustergram resulting from the hierarchical clustering of pateamine HOP screens with the homozygous diploid screen data from Hillenmeyer et al 2008. Dataset 2 (Method 4.3.6) was clustered using the uncentered Pearsons distance metric and average linkage method. Pateamine HOP screens are indicated in blue. 


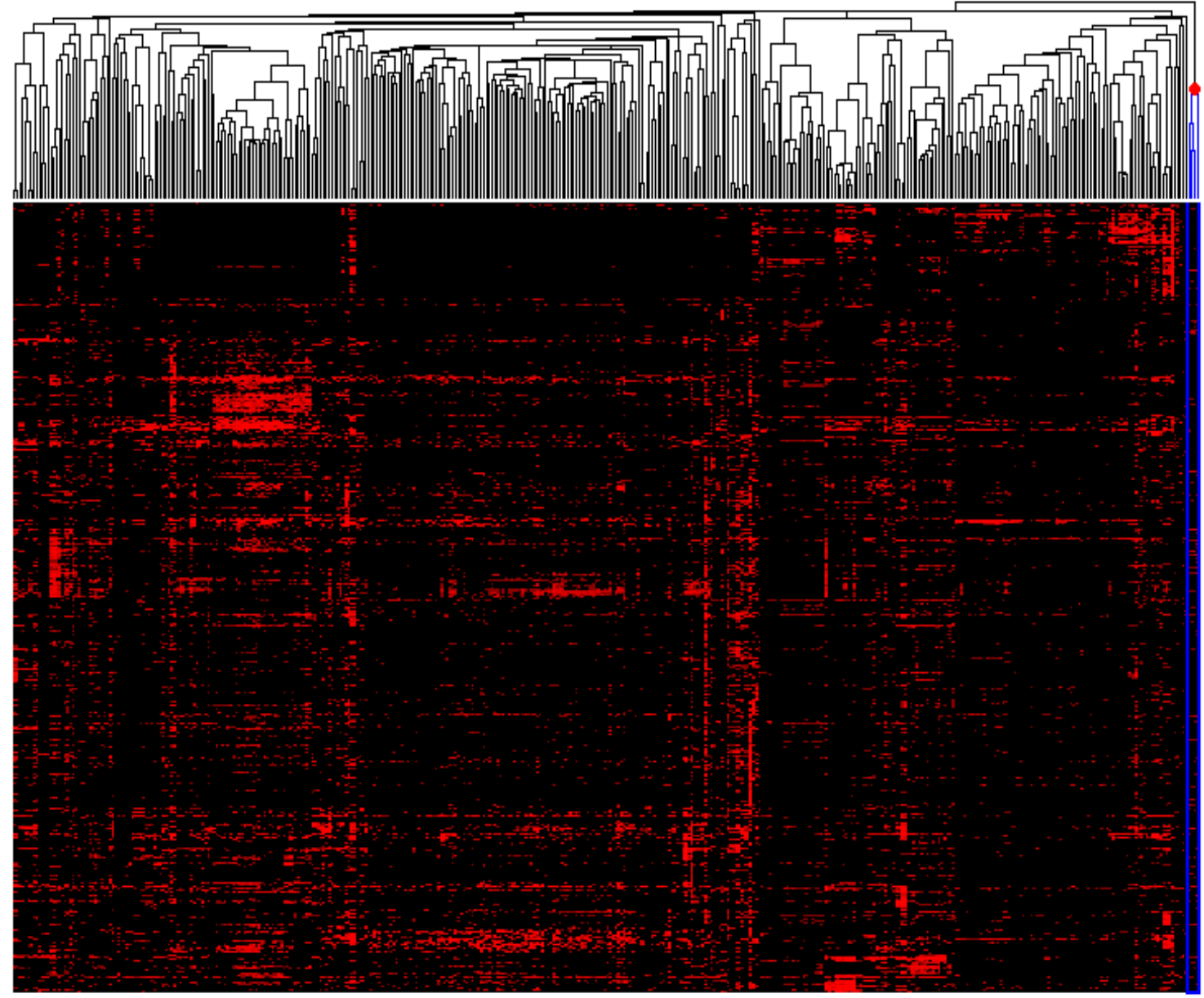

Figure 8.12 Complete clustergram resulting from the hierarchical clustering of pateamine HOP screens with the homozygous diploid screen data from Hillenmeyer et al 2008. Dataset 3 (Method 4.3.6) was clustered using the centered Pearsons distance metric and average linkage method. Pateamine HOP screens are indicated in blue. 


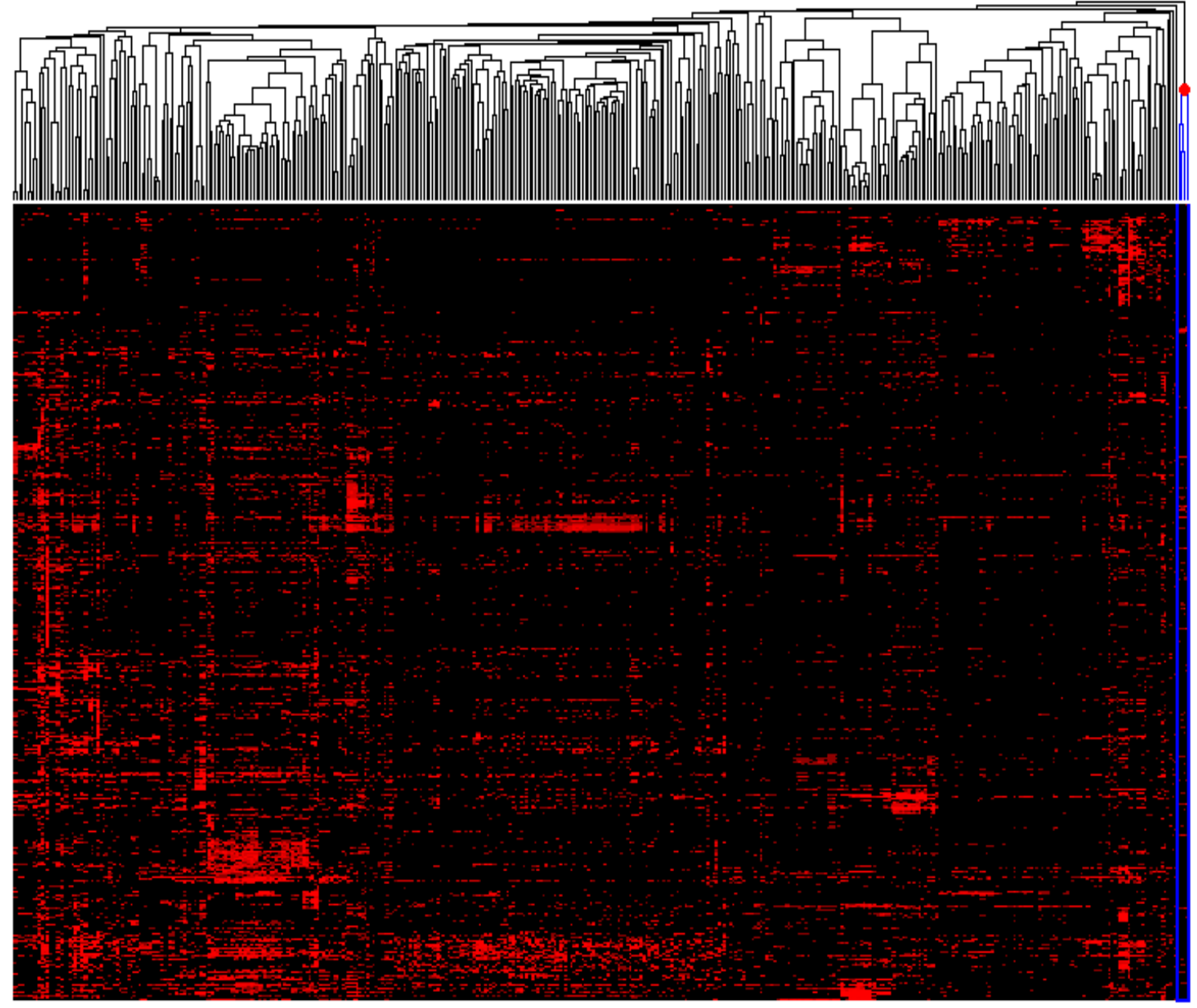

Figure 8.13 Complete clustergram resulting from the hierarchical clustering of pateamine HOP screens with the homozygous diploid screen data from Hillenmeyer et al 2008. Dataset 3 (Method 4.3.6) was clustered using the uncentered Pearsons distance metric and average linkage method. Pateamine HOP screens are indicated in blue. 


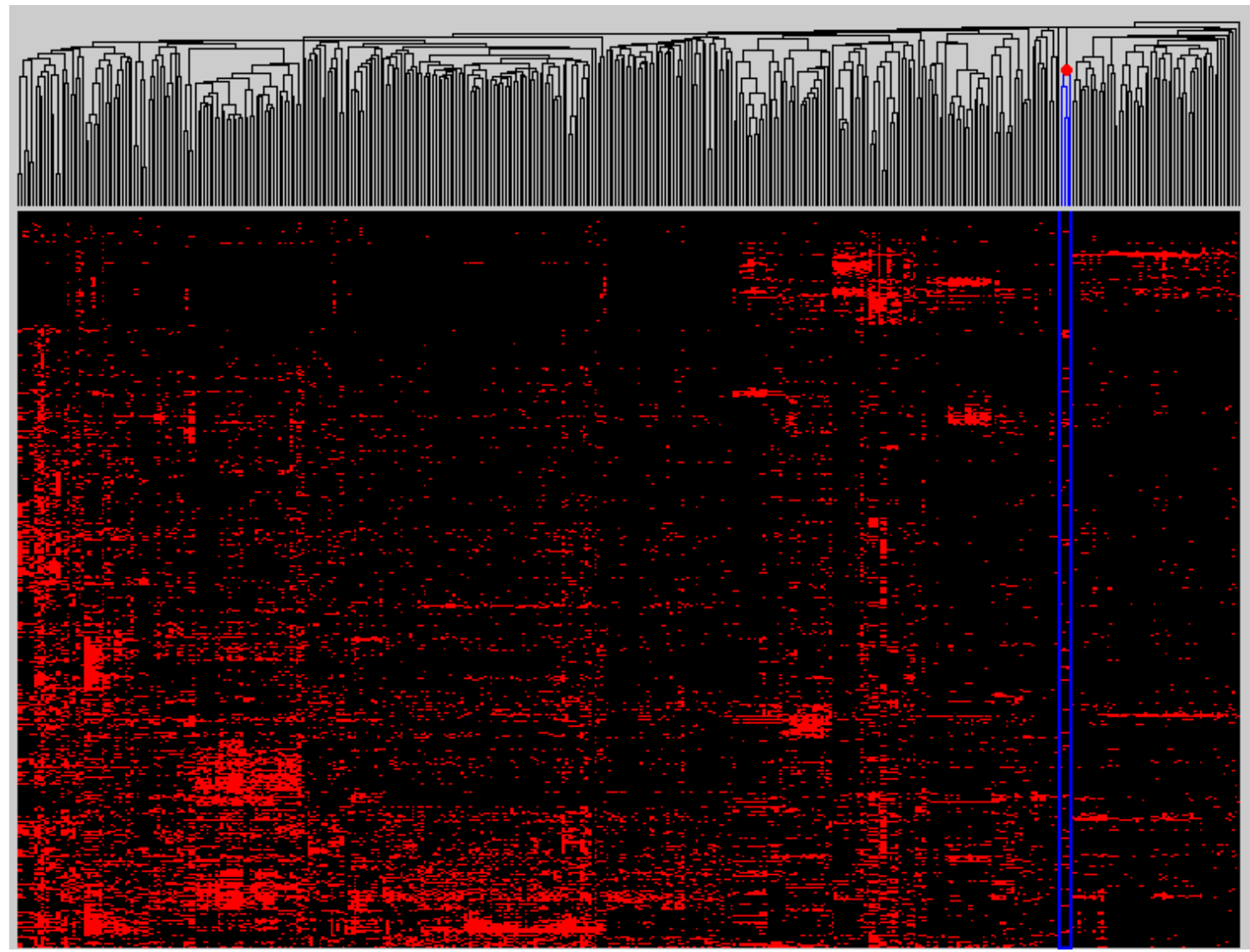

Figure 8.14 Complete clustergram resulting from the hierarchical clustering of pateamine HOP screens with the homozygous diploid screen data from Hillenmeyer et al 2008. Dataset 4 (Method 4.3.6) was clustered using the Jaccard distance metric and average linkage method. Pateamine HOP screens are indicated in blue. 


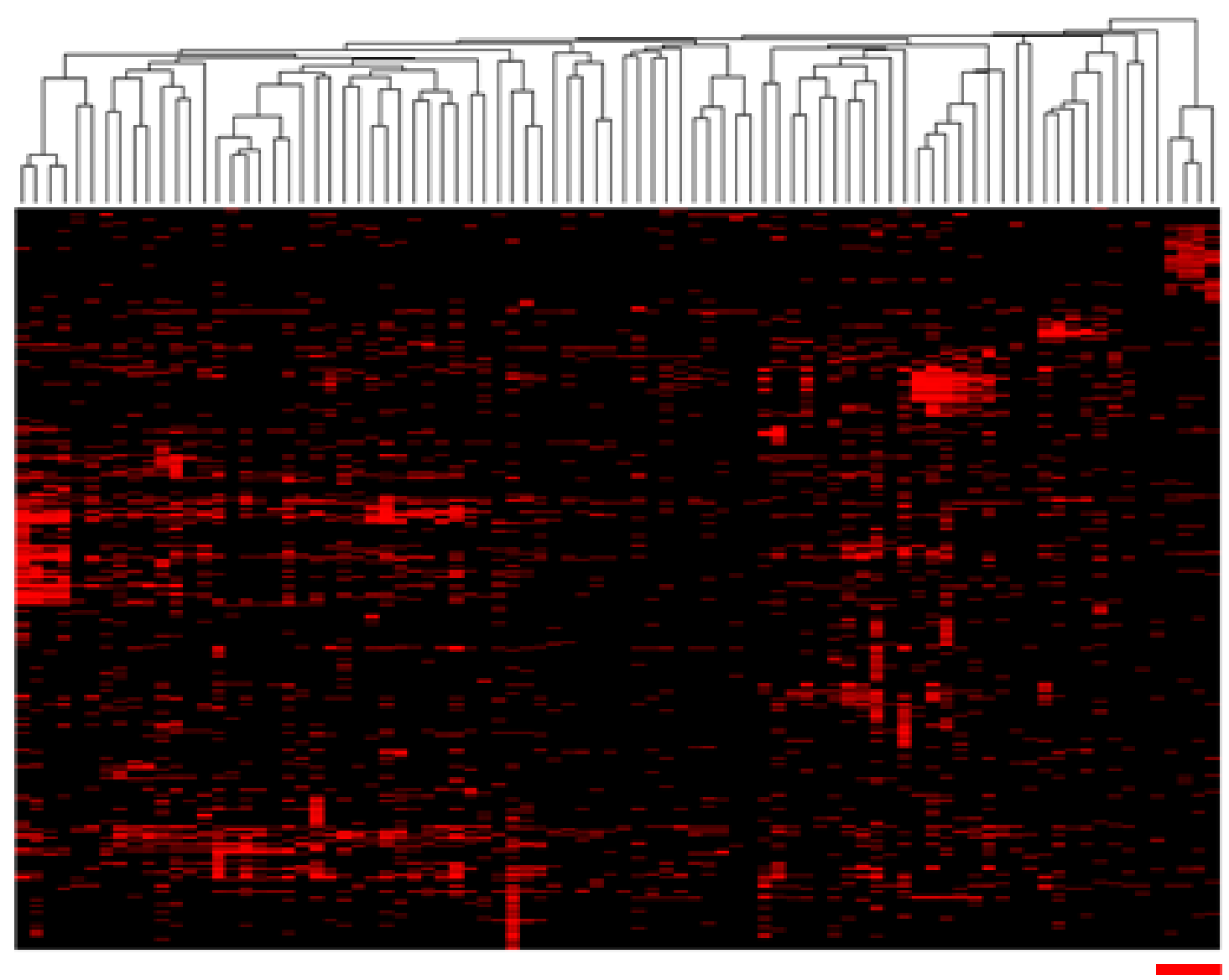

Figure 8.15 Complete clustergram resulting from the hierarchical clustering of pateamine HOP screens with the homozygous diploid screen data from Parsons et al 2006 . $\log _{2}$ ratio data after the application of the described threshold (Method 4.3.6) was clustered using the centered Pearsons distance metric and average linkage method. Pateamine HOP screens are indicated by the red bar. 


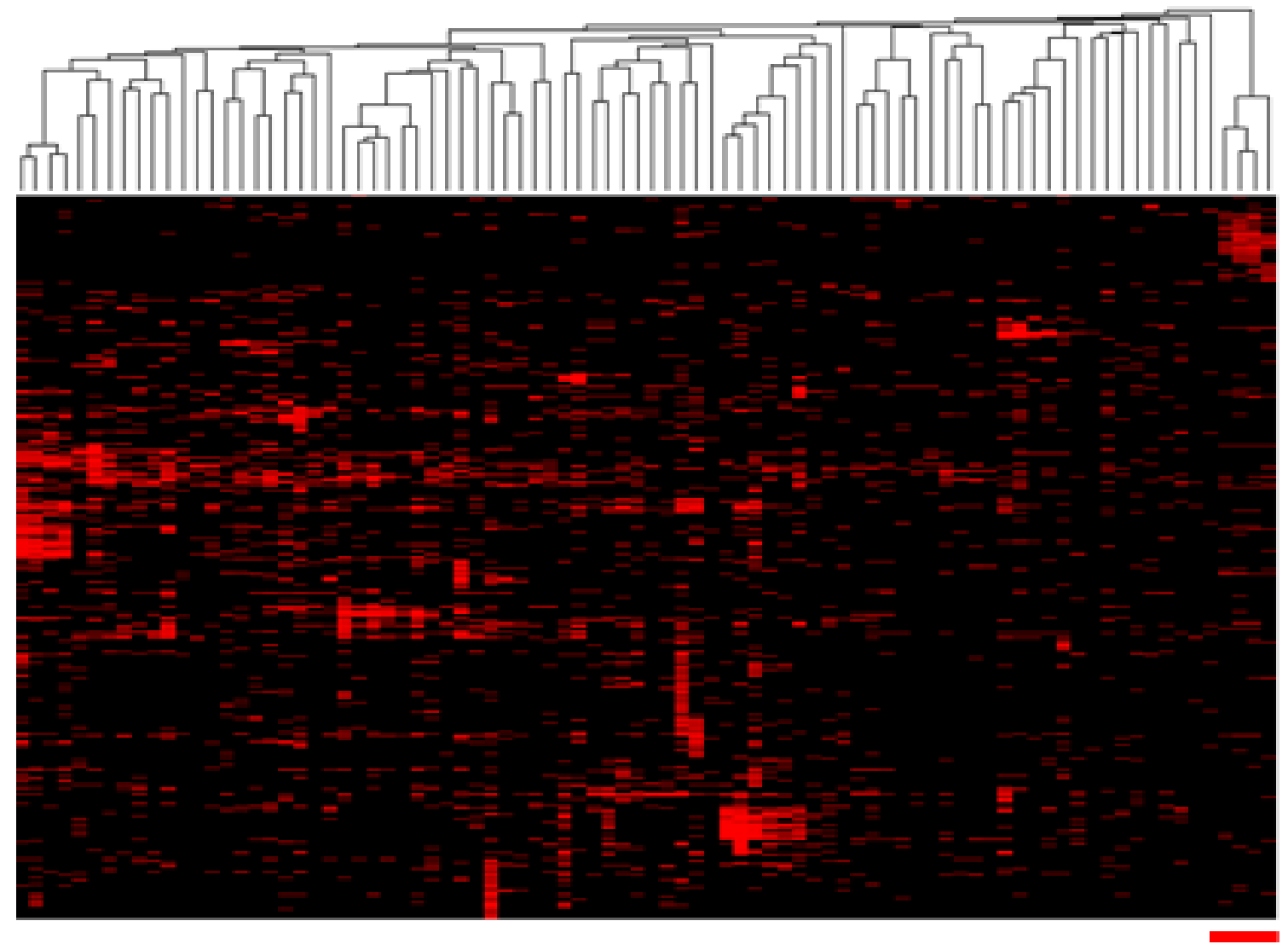

Figure 8.16 Complete clustergram resulting from the hierarchical clustering of pateamine HOP screens with the homozygous diploid screen data from Parsons et al 2006. Log $_{2}$ ratio data after the application of the described threshold (Method 4.3.6) was clustered using the uncentered Pearsons distance metric and average linkage method. Pateamine HOP screens are indicated by the red bar. 


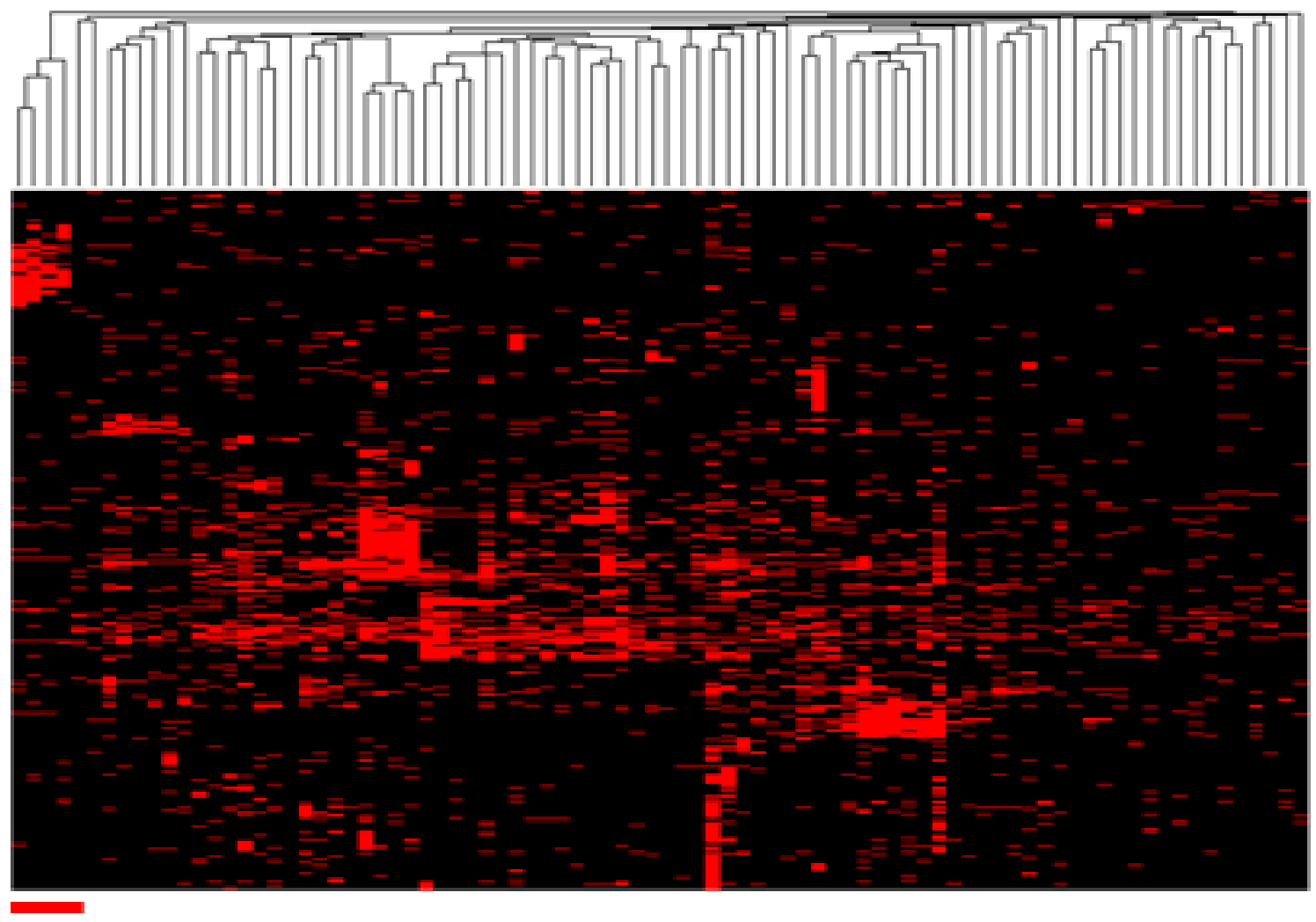

Figure 8.17 Complete clustergram resulting from the hierarchical clustering of pateamine HOP screens with the homozygous diploid screen data from Parsons et al 2006. $\log _{2}$ ratio data after the application of the described threshold (Method 4.3.6) was clustered using the uncentered Pearsons distance metric and average linkage method. Pateamine HOP screens are indicated by the red bar. 


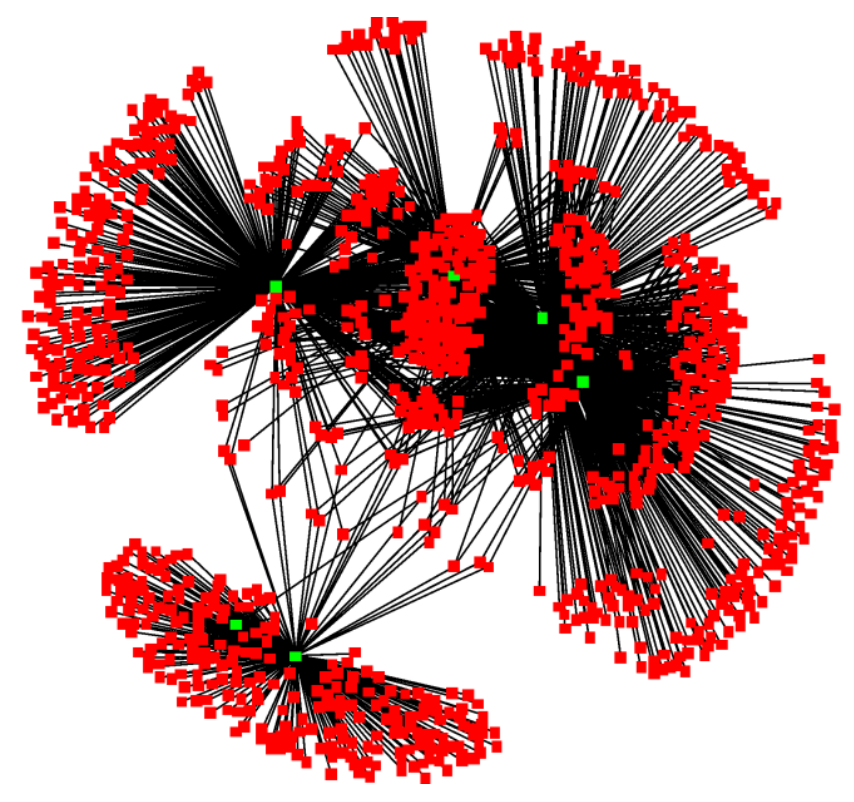

Figure 8.18 Pateamine hypersensitive and haploinsufficient gene deletion network. Green nodes correspond to pateamine screens, red nodes correspond to gene deletions that confer hypersensitivity or haploinsufficiency from all screen performed.

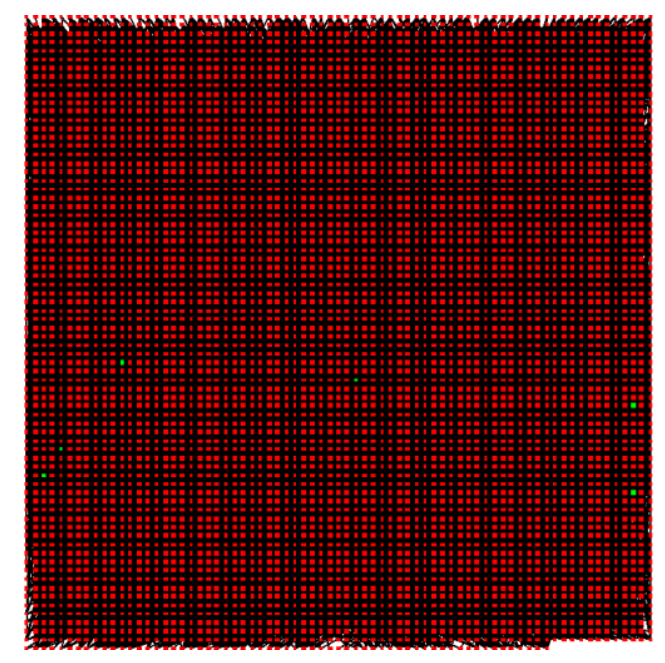

Figure 8.19 Pateamine screen hit interaction network. This network consists of nodes corresponding to individual pateamine screens (green), connected to their hits, which are further connected to genes in the SGD database with which they interact physically or genetically. 


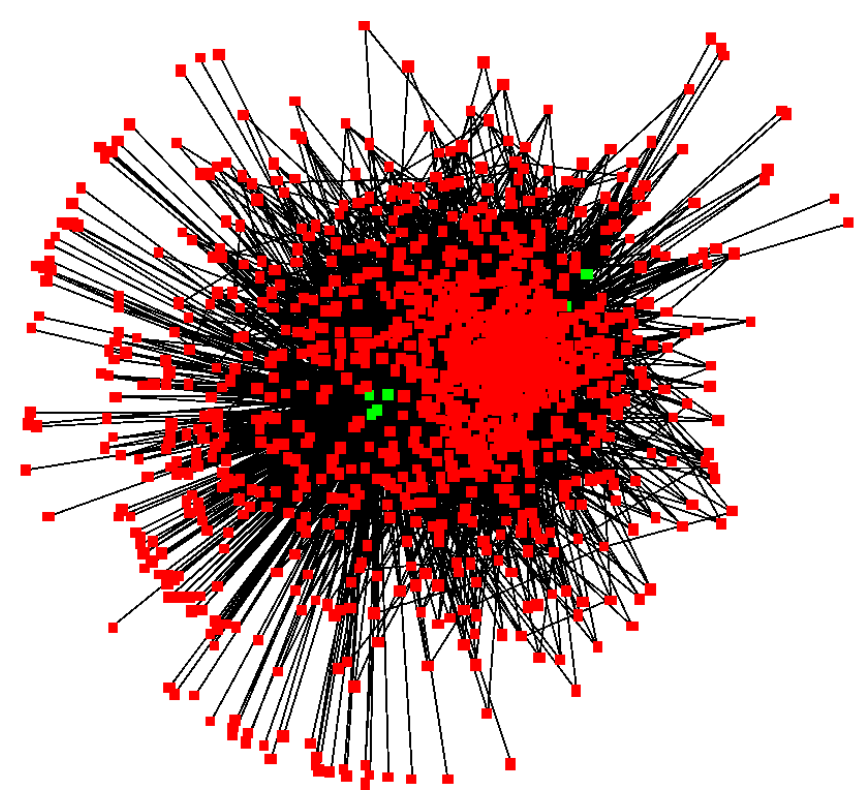

Figure 8.20 Pateamine screen hit interactions with other hits. This network is the same as Figure 8.19 but the genes that interact with the hits, according to SGD, have been removed. The remaining physical and genetic interactions occur only between genes that are haploinsufficient or hypersensitive to pateamine in one or more of the screens performed.

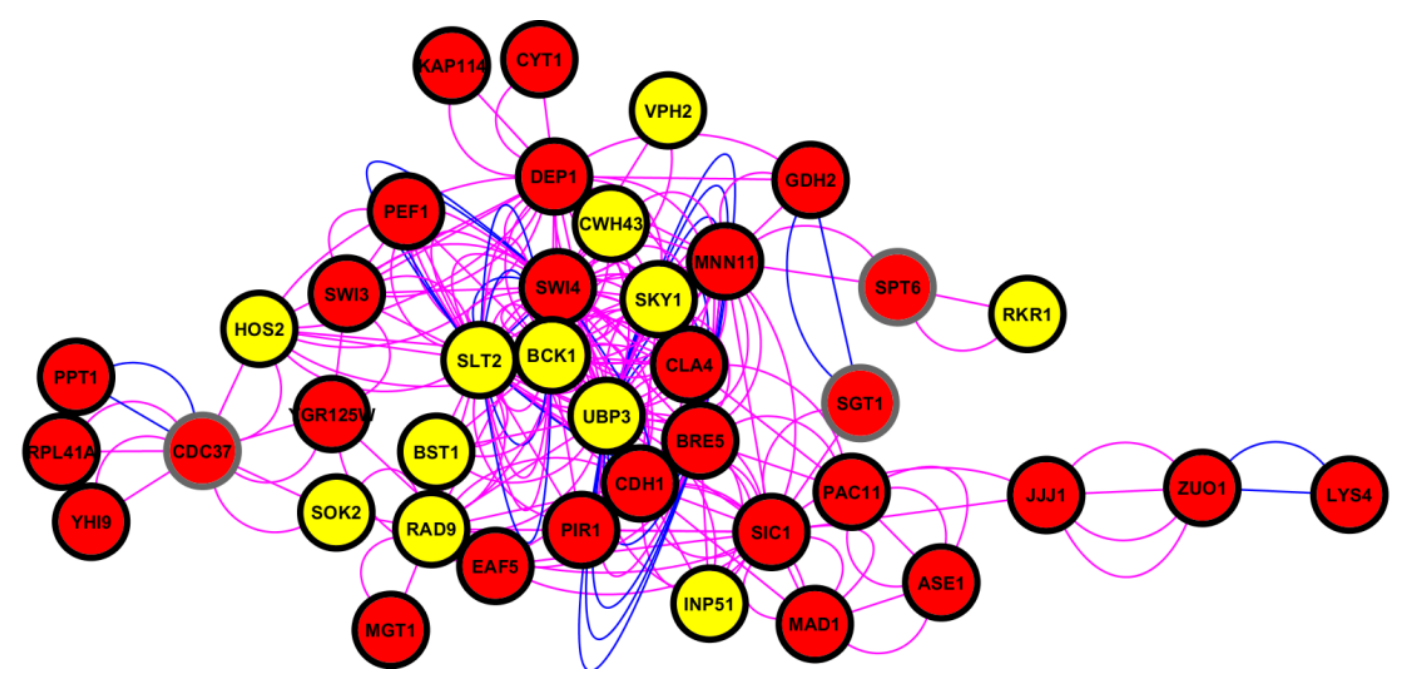

Figure 8.21 Sub-network four. Blue interactions are physical, magenta are genetic. Yellow nodes are MDS gene deletions; black node borders are homozygous strains sensitive to pateamine in at least one of the screens performed; grey node borders are heterozygous strains that display haploinsufficiency in the presence of pateamine. Sub-network four is enriched for numerous MAP kinase related terms $\left(\mathrm{P}<1.1 \times 10^{-2}\right)$ and terms related to the unfolded protein response $(\mathrm{P}<1.9 \mathrm{x}$ $\left.10^{-2}\right)$. 


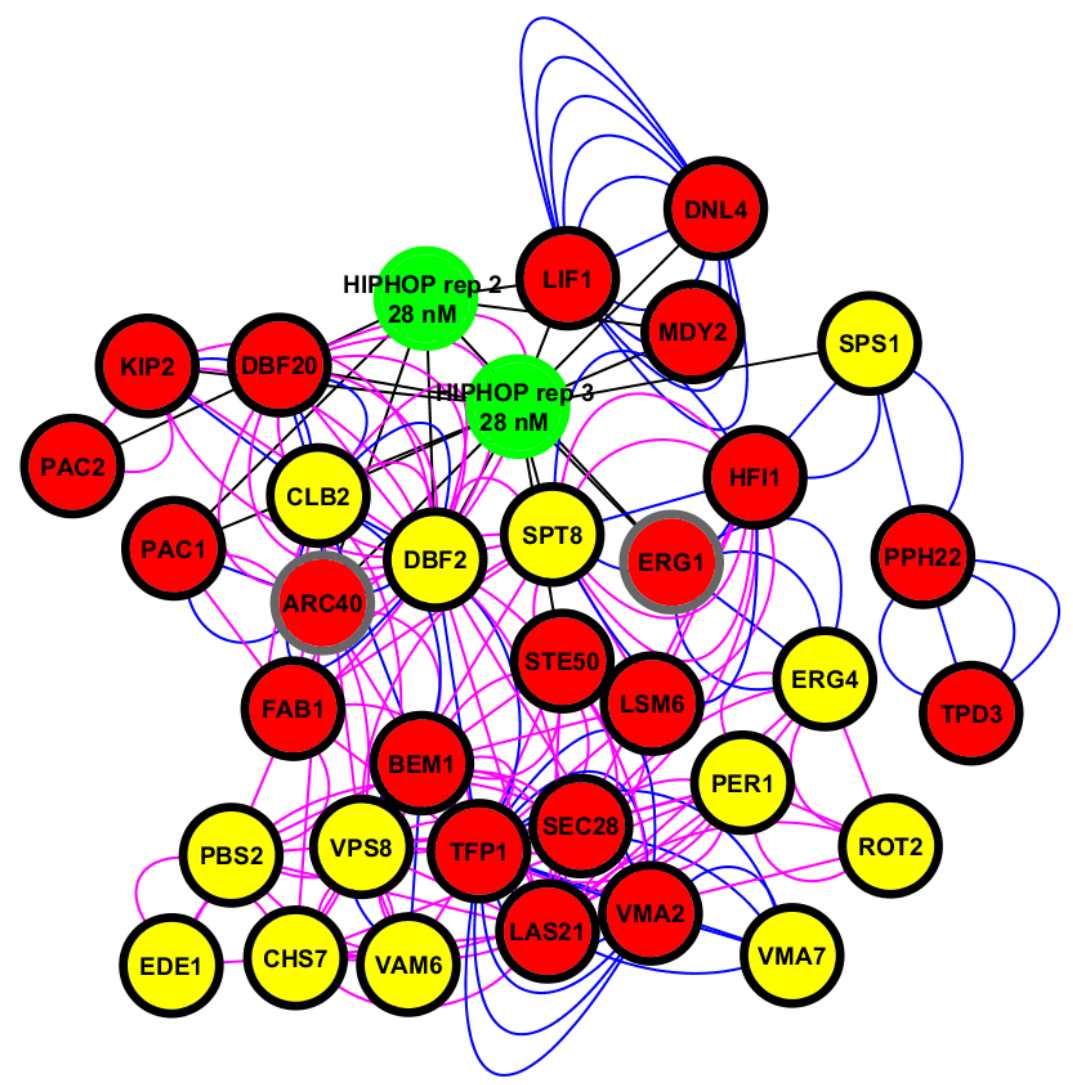

Figure 8.22 Sub-network five. Blue edges are physical interactions, magenta are genetic interactions and black are pateamine hypersensitive. Green nodes are the pateamine screens as labeled; Yellow nodes are MDS gene deletions; black node borders are homozygous strains sensitive to pateamine in at least one of the screens performed; grey node borders are heterozygous strains that display haploinsufficiency in the presence of pateamine. Sub-network five is enriched for similar terms but also vacuolar function, particularly its acidification $\left(P<1.8 \times 10^{-3}\right)$ and the ergosterol biosynthesis pathway $\left(P=3.8 \times 10^{-2}\right)$. 


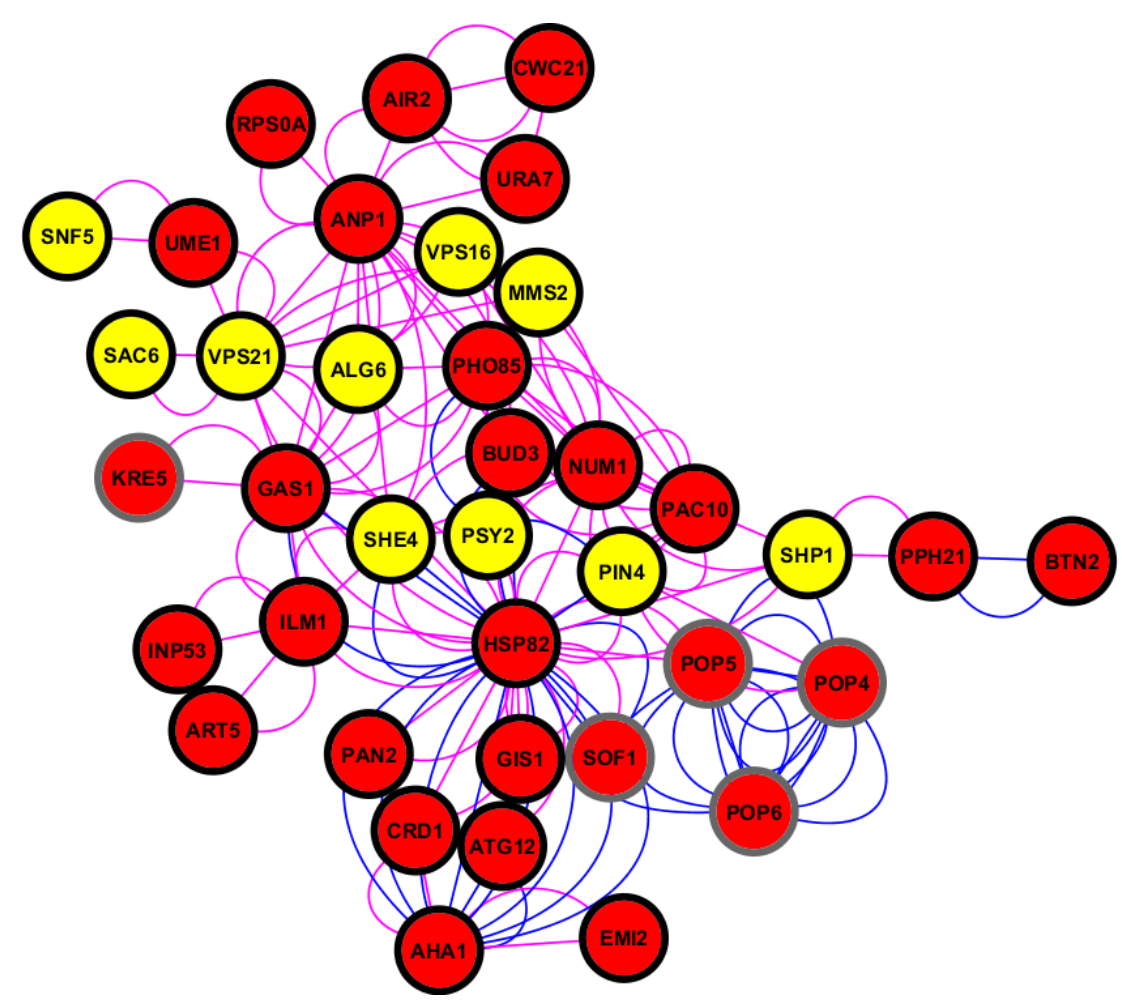

Figure 8.23 Sub-network six. Blue interactions are physical, magenta are genetic. Yellow nodes are MDS gene deletions; black node borders are homozygous strains sensitive to pateamine in at least one of the screens performed; grey node borders are heterozygous strains that display haploinsufficiency in the presence of pateamine. Sub-network six was significantly enriched for genes involved in RNA metabolism in part by the inclusion of three POP (Processing Of Precursor RNAs) genes, which, as a part of the RNase MRP and RNase P complexes, cleave pre-rRNA and tRNA precursors (Houser-Scott, Xiao et al. 2002). 


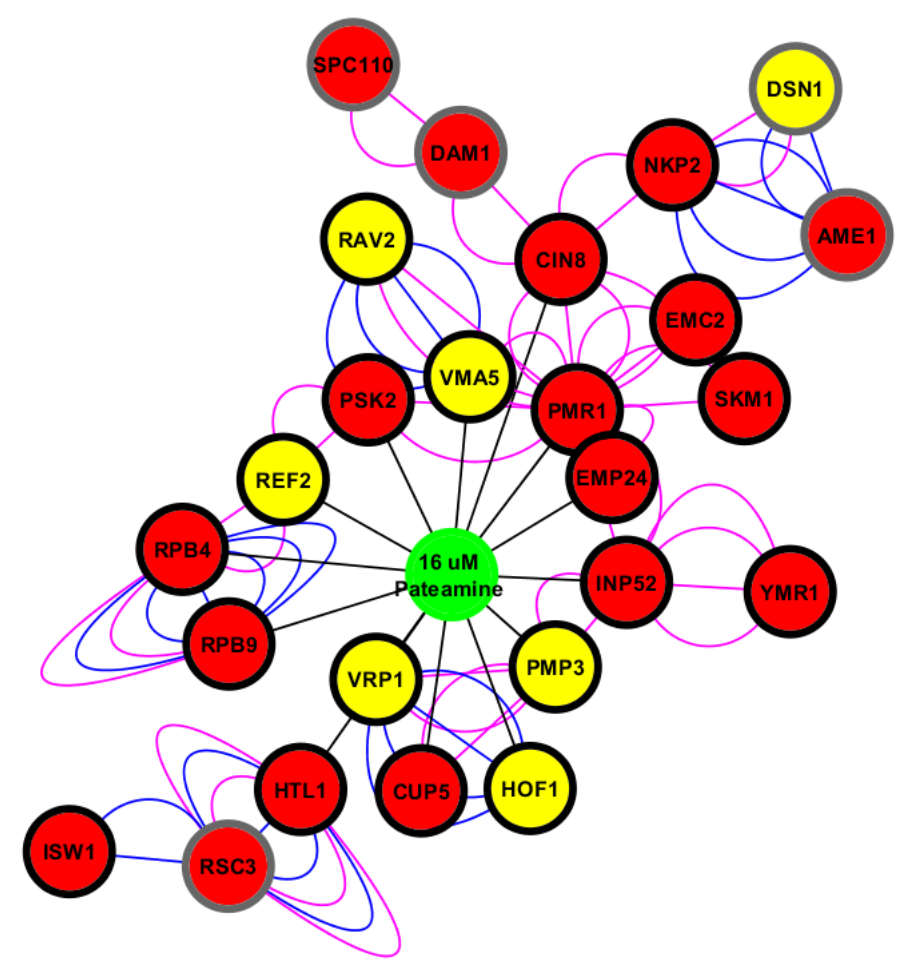

Figure 8.24 Sub-network seven. Blue edges are physical interactions, magenta are genetic interactions and black are pateamine hypersensitive. The green node is the $16 \mu \mathrm{M}$ pateamine haploid screen; Yellow nodes are MDS gene deletions; black node borders are homozygous strains sensitive to pateamine in at least one of the screens performed; grey node borders are heterozygous strains that display haploinsufficiency in the presence of pateamine. Sub-network seven was enriched in genes involved in transcription $\left(P<4.1 \times 10^{-3}\right)$ specifically from RNA polymerase II promoters $\left(\mathrm{P}<4.4 \times 10^{-4}\right)$ and various aspects of chromosome biology, including the spindle $\left(P<2.9 \times 10^{-2}\right)$, the kinetochore $\left(P=1.5 \times 10^{-7}\right)$ and chromatin remodeling $\left(P=2.9 \times 10^{-3}\right)$. 


\begin{tabular}{|r|r|r|r|r|r|r|}
\hline $\begin{array}{l}\text { Sub- } \\
\text { network }\end{array}$ & $\begin{array}{l}\text { Haploid } \\
\text { Screen }\end{array}$ & $\begin{array}{l}\text { HIPHOP } \\
\text { Screen 1 }\end{array}$ & $\begin{array}{l}\text { HIPHOP } \\
\text { Screen 2 }\end{array}$ & $\begin{array}{l}\text { HIPHOP } \\
\text { Screen 3 }\end{array}$ & $\begin{array}{l}\text { HIPHOP } \\
\text { Screen4 }\end{array}$ & \multicolumn{1}{l|}{ Total } \\
\hline 1 & 14 & 9 & 9 & 8 & 12 & 33 \\
\hline 2 & 15 & 5 & 1 & 5 & 4 & 33 \\
\hline 3 & 22 & 10 & 18 & 14 & 16 & 58 \\
\hline 4 & 16 & 6 & 11 & 14 & 14 & 40 \\
\hline 5 & 15 & 6 & 5 & 10 & 8 & 35 \\
\hline 6 & 15 & 9 & 8 & 11 & 8 & 38 \\
\hline 7 & 14 & 5 & 6 & 2 & 4 & 26 \\
\hline 8 & 3 & 3 & 3 & 7 & 10 & 21 \\
\hline
\end{tabular}

Table 8.4 Contribution of pateamine screen data to MCODE clusters.

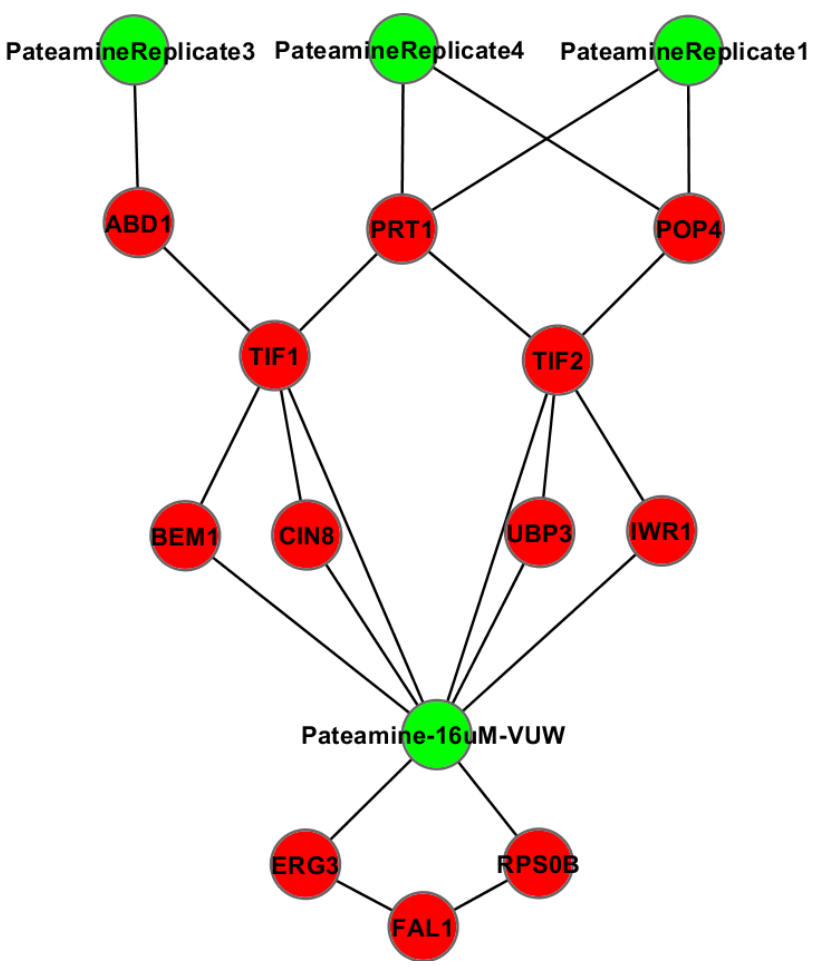

Figure 8.25 Synthetic lethal and negative genetic interactions present in the SGD database for yeast elF4A encoding genes TIF1 and TIF2 and the closely related FAL1. Edges between red nodes correspond to synthetic lethal or negative genetic interactions; edges between green and red nodes correspond to pateamine hypersensitive homozygous diploid gene deletions in HOP screens 1,3 and 4 and haploid gene deletions strains hypersensitive to $16 \mu \mathrm{M}$ pateamine. 


\begin{tabular}{|c|c|}
\hline Genetic interaction type & Description \\
\hline Synthetic Rescue & $\begin{array}{l}\text { A genetic interaction is inferred when mutations or } \\
\text { deletions of one gene rescues the lethality or growth defect } \\
\text { of a strain mutated or deleted for another gene. }\end{array}$ \\
\hline Positive Genetic & $\begin{array}{l}\text { Positive epistatic interaction, defined by genome-wide } \\
\text { SGA. }\end{array}$ \\
\hline $\begin{array}{l}\text { Synthetic } \\
\text { Haploinsufficiency }\end{array}$ & $\begin{array}{l}\text { A genetic interaction is inferred when mutations or } \\
\text { deletions in separate genes, at least one of which is } \\
\text { hemizygous, cause a minimal phenotype alone but result in } \\
\text { lethality when combined in the same cell under a given } \\
\text { condition. }\end{array}$ \\
\hline Negative Genetic & $\begin{array}{l}\text { Synthetic-sick or lethal interactions, defined by genome- } \\
\text { wide SGA. }\end{array}$ \\
\hline Dosage Lethality & $\begin{array}{l}\text { A genetic interaction is inferred when over expression or } \\
\text { increased dosage of one gene causes lethality in a strain that } \\
\text { is mutated or deleted for another gene. }\end{array}$ \\
\hline Synthetic Lethality & $\begin{array}{l}\text { A genetic interaction is inferred when mutations or } \\
\text { deletions in separate genes, each of which alone causes a } \\
\text { minimal phenotype, result in lethality when combined in } \\
\text { the same cell under a given condition. }\end{array}$ \\
\hline $\begin{array}{l}\text { Phenotypic } \\
\text { Enhancement }\end{array}$ & $\begin{array}{l}\text { A genetic interaction is inferred when mutation or over- } \\
\text { expression of one gene results in enhancement of any } \\
\text { phenotype (other than lethality/growth defect) associated } \\
\text { with mutation or over expression of another gene. }\end{array}$ \\
\hline Synthetic Growth Defect & $\begin{array}{l}\text { A genetic interaction is inferred when mutations in separate } \\
\text { genes, each of which alone causes a minimal phenotype, } \\
\text { result in a significant growth defect under a given condition } \\
\text { when combined in the same cell. }\end{array}$ \\
\hline Dosage Rescue & $\begin{array}{l}\text { A genetic interaction is inferred when over-expression or } \\
\text { increased dosage of one gene rescues the lethality or growth } \\
\text { defect of a strain that is mutated or deleted for another gene. }\end{array}$ \\
\hline Phenotypic Suppression & $\begin{array}{l}\text { A genetic interaction is inferred when mutation or over- } \\
\text { expression of one gene results in suppression of any } \\
\text { phenotype (other than lethality/growth defect) associated } \\
\text { with mutation or over expression of another gene. }\end{array}$ \\
\hline Dosage Growth Defect & $\begin{array}{l}\text { A genetic interaction is inferred when over expression or } \\
\text { increased dosage of one gene causes a growth defect in a } \\
\text { strain that is mutated or deleted for another gene. }\end{array}$ \\
\hline
\end{tabular}

Table 8.5 Descriptions of genetic interactions used in network analysis. Downloaded from The BioGRID database (http://grid.princeton.edu/help.php). 


\begin{tabular}{|c|c|}
\hline Physical interaction type & Description \\
\hline Two-hybrid & $\begin{array}{l}\text { Bait protein expressed as a DNA binding domain (DBD) } \\
\text { fusion and prey expressed as a transcriptional activation } \\
\text { domain (TAD) fusion and interaction measured by } \\
\text { reporter gene activation. }\end{array}$ \\
\hline Affinity Capture-RNA & $\begin{array}{l}\text { An interaction is inferred when a bait protein is affinity } \\
\text { captured from cell extracts by either polyclonal antibody } \\
\text { or epitope tag and associated RNA species identified by } \\
\text { Northern blot, RT-PCR, affinity labeling, sequencing, or } \\
\text { microarray analysis. }\end{array}$ \\
\hline PCA & $\begin{array}{l}\text { A protein-protein interaction assay in which a bait protein } \\
\text { is expressed as fusion to one of the either } \mathrm{N} \text { - or } \mathrm{C} \text { - } \\
\text { terminal peptide fragments of a reporter protein and prey } \\
\text { protein is expressed as fusion to the complementary } \mathrm{N} \text { - or } \\
\mathrm{C} \text { - terminal fragment of the same reporter protein. } \\
\text { Interaction of bait and prey proteins bring together } \\
\text { complementary fragments, which can then fold into an } \\
\text { active reporter. }\end{array}$ \\
\hline Reconstituted Complex & $\begin{array}{l}\text { An interaction is detected between purified proteins in } \\
\text { vitro. }\end{array}$ \\
\hline Affinity Capture-MS & $\begin{array}{l}\text { An interaction is inferred when a "bait" protein is affinity } \\
\text { captured from cell extracts by either polyclonal antibody } \\
\text { or epitope tag and the associated interaction partner is } \\
\text { identified by mass spectrometric methods. }\end{array}$ \\
\hline Affinity Capture-Western & $\begin{array}{l}\text { An interaction is inferred when a Bait protein affinity } \\
\text { captured from cell extracts by either polyclonal antibody } \\
\text { or epitope tag and the associated interaction partner } \\
\text { identified by Western blot with a specific polyclonal } \\
\text { antibody or second epitope tag. This category is also used } \\
\text { if an interacting protein is visualized directly by dye stain } \\
\text { or radioactivity. Note that this differs from any co- } \\
\text { purification experiment involving affinity capture in that } \\
\text { the co-purification experiment involves at least one extra } \\
\text { purification step to get rid of potential contaminating } \\
\text { proteins. }\end{array}$ \\
\hline Far Western & $\begin{array}{l}\text { An interaction is detected between a protein immobilized } \\
\text { on a membrane and a purified protein probe. }\end{array}$ \\
\hline Biochemical Activity & $\begin{array}{l}\text { An interaction is inferred from the biochemical effect of } \\
\text { one protein upon another, for example, GTP-GDP } \\
\text { exchange activity or phosphorylation of a substrate by a } \\
\text { kinase. The "bait" protein executes the activity on the } \\
\text { substrate "hit" protein. }\end{array}$ \\
\hline Protein-peptide & $\begin{array}{l}\text { An interaction is detected between a protein and a peptide } \\
\text { derived from an interaction partner. This includes phage } \\
\text { display experiments. }\end{array}$ \\
\hline FRET & $\begin{array}{l}\text { An interaction is inferred when close proximity of } \\
\text { interaction partners is detected by fluorescence resonance } \\
\text { energy transfer between pairs of fluorophore-labeled } \\
\text { molecules, such as occurs between CFP (donor) and YFP } \\
\text { (acceptor) fusion proteins. }\end{array}$ \\
\hline Co-fractionation & $\begin{array}{l}\text { Interaction inferred from the presence of two or more } \\
\text { protein subunits in a partially purified protein preparation. }\end{array}$ \\
\hline
\end{tabular}




\begin{tabular}{|c|c|}
\hline & $\begin{array}{l}\text { If co-fractionation is demonstrated between } 3 \text { or more } \\
\text { proteins, one is chosen as the bait and binary interactions } \\
\text { are recorded between that protein and the others. }\end{array}$ \\
\hline Protein-RNA & $\begin{array}{l}\text { An interaction is detected between and protein and an } \\
\text { RNA. }\end{array}$ \\
\hline Co-crystal Structure & $\begin{array}{l}\text { Interaction directly demonstrated at the atomic level by } \\
\text { X-ray crystallography. Also used for NMR or Electron } \\
\text { Microscopy (EM) structures. If a structure is } \\
\text { demonstrated between } 3 \text { or more proteins, one is chosen } \\
\text { as the bait and binary interactions are recorded between } \\
\text { that protein and the others. }\end{array}$ \\
\hline Co-localization & $\begin{array}{l}\text { An interaction is inferred from co-localization of two } \\
\text { proteins in the cell, including co-dependent association of } \\
\text { proteins with promoter DNA in chromatin } \\
\text { immunoprecipitation experiments. }\end{array}$ \\
\hline Co-purification & $\begin{array}{l}\text { An interaction is inferred from the identification of two or } \\
\text { more protein subunits in a purified protein complex, as } \\
\text { obtained by classical biochemical fractionation or affinity } \\
\text { purification and one or more additional fractionation } \\
\text { steps. }\end{array}$ \\
\hline $\begin{array}{l}\text { Affinity Capture- } \\
\text { Luminescence }\end{array}$ & $\begin{array}{l}\text { An interaction is inferred when a bait protein, tagged with } \\
\text { luciferase, is enzymatically detected in } \\
\text { immunoprecipitates of the prey protein as light emission. } \\
\text { The prey protein is affinity captured from cell extracts by } \\
\text { either polyclonal antibody or epitope tag. }\end{array}$ \\
\hline
\end{tabular}

Table 8.6 Descriptions of physical interactions used in network analysis. Downloaded from The BioGRID database (http://grid.princeton.edu/help.php) 


\section{References}

Abe, F. and T. Hiraki (2009). "Mechanistic role of ergosterol in membrane rigidity and cycloheximide resistance in Saccharomyces cerevisiae." Biochimica Et Biophysica Acta-Biomembranes 1788(3): 743-752.

Adams, K. and G. Cooper (2007). "Rapid turnover of Mcl-1 couples translation to cell survival and apoptosis." Journal of Biological Chemistry 282(9): 6192-6200.

Ahmed, K. A. and R. A. Woods (1967). "A genetic analysis of resistance to nystatin in Saccharomyces cerevisiae." Genetical Research 9(2): 179-\&.

Alamgir, M., V. Eroukova, et al. (2008). "Chemical-genetic profile analysis in yeast suggests that a previously uncharacterized open reading frame, YBR261C, affects protein synthesis." BMC Genomics 9: 583.

Alessenko, A., P. Boikov, et al. (1997). "Mechanisms of cycloheximide-induced apoptosis in liver cells." FEBS Letters 416(1): 113-116.

Almeida, B., A. Silva, et al. (2008). "Drug-induced apoptosis in yeast." Biochimica Et Biophysica Acta-Molecular Cell Research 1783(7): 1436-1448.

Altmann, M., M. Krieger, et al. (1989). "Nucleotide-sequence of the gene encoding a 20 $\mathrm{kDa}$ protein associated with the cap binding-protein eIF-4E from Saccharomyces cerevisiae." Nucleic Acids Research 17(18): 7520-7520.

Altmann, M., P. P. Muller, et al. (1993). "A Saccharomyces cerevisiae homolog of mammalian translation initiation factor 4A contributes to RNA helicase activity." EMBO Journal 12(10): 3997-4003.

Altmann, M., B. Wittmer, et al. (1995). "The Saccharomyces cerevisiae translation initiation factor TIF3 and its mammalian homolog, eIF4B, have RNA annealing activity." EMBO Journal 14(15): 3820-3827.

Amberg, D., D. Burke, et al. (2005). Methods in yeast genetics : a Cold Spring Harbor Laboratory course manual. Cold Spring Harbor, N.Y., Cold Spring Harbor Laboratory Press.

Anderson, P. and N. Kedersha (2006). "RNA granules." Journal of Cell Biology 172(6): 803-808.

Anderson, P. and N. Kedersha (2008). "Stress granules: the Tao of RNA triage." Trends in Biochemical Sciences 33(3): 141-150.

Arakawa, T., D. Ejima, et al. (2006). "Small molecule pharmacological chaperones: From thermodynamic stabilization to pharmaceutical drugs." Biochimica et Biophysica Acta (BBA) - Proteins \& Proteomics 1764(11): 1677-1687.

Ausubel, F. (1988). Current protocols in molecular biology. New York, Published by Greene Pub. Associates and Wiley-Interscience : J. Wiley.

Bach, S., M. Knockaert, et al. (2005). "Roscovitine targets, protein kinases and pyridoxal kinase." Journal of Biological Chemistry 280(35): 31208-31219.

Bader, G. and C. Hogue (2003). "An automated method for finding molecular complexes in large protein interaction networks." BMC Bioinformatics 4: 2.

Baetz, K., L. McHardy, et al. (2004). "Yeast genome-wide drug-induced haploinsufficiency screen to determine drug mode of action." Proceedings of the National Academy of Sciences of the United States of America 101(13): 45254530.

Baker, M., D. Grubb, et al. (2002). "Didemnin B induces apoptosis in proliferating but not resting peripheral blood mononuclear cells." Apoptosis 7(5): 407-412.

Balzi, E. and A. Goffeau (1995). "Yeast multidrug-resistance - the PDR network." Journal of Bioenergetics and Biomembranes 27(1): 71-76.

Bantscheff, M., D. Eberhard, et al. (2007). "Quantitative chemical proteomics reveals mechanisms of action of clinical ABL kinase inhibitors." Nature Biotechnology 25(9): 1035-1044. 
Bantscheff, M., A. Scholten, et al. (2009). "Revealing promiscuous drug-target interactions by chemical proteomics." Drug Discovery Today 14(21-22): 1021-1029.

Banuelos, M. G., D. E. Moreno, et al. (2010). "Genomic analysis of severe hypersensitivity to hygromycin B reveals linkage to vacuolar defects and new vacuolar gene functions in Saccharomyces cerevisiae." Current Genetics 56(2): 121-137.

Bastide, M., S. Jouvert, et al. (1982). "A comparison of the effects of several antifungal imidazole derivatives and polyenes on Candida-albicans - an ultrastructural-study by scanning electron-microscopy." Canadian Journal of Microbiology 28(10): 1119-1126.

Baudin, A., O. Ozierkalogeropoulos, et al. (1993). "A simple and efficient method for direct gene deletion in Saccharomyces cerevisiae." Nucleic Acids Research 21(14): 3329-3330.

Begley, T. J., A. S. Rosenbach, et al. (2002). "Damage recovery pathways in Saccharomyces cerevisiae revealed by genomic phenotyping and interactome mapping." Molecular Cancer Research 1(2): 103-112.

Benjamini, Y. and Y. Hochberg (1995). "Controlling the false discovery rate - a practical and powerful approach to multiple testing." Journal of the Royal Statistical Society Series B-Methodological 57(1): 289-300.

Bennett, C. B., L. K. Lewis, et al. (2001). "Genes required for ionizing radiation resistance in yeast." Nature Genetics 29(4): 426-434.

Bennett, L. L., V. L. Ward, et al. (1965). "Inhibition of protein synthesis in vitro by cycloheximide and related glutarimide antibiotics." Biochimica Et Biophysica Acta 103(3): 478-\&.

Biedler, J. L., S. Roffler-Tarlov, et al. (1978). "Multiple neurotransmitter synthesis by human neuroblastoma cell lines and clones." Cancer Research 38(11_Part_1): 3751-3757.

Birrell, G. W., J. A. Brown, et al. (2002). "Transcriptional response of Saccharomyces cerevisiae to DNA-damaging agents does not identify the genes that protect against these agents." Proceedings of the National Academy of Sciences of the United States of America 99(13): 8778-8783.

Birrell, G. W., G. Giaever, et al. (2001). "A genome-wide screen in Saccharomyces cerevisiae for genes affecting UV radiation sensitivity." Proceedings of the National Academy of Sciences of the United States of America 98(22): 1260812613.

Bivi, N., M. Romanello, et al. (2009). "Identification of secondary targets of N-containing bisphosphonates in mammalian cells via parallel competition analysis of the barcoded yeast deletion collection." Genome Biology 10(9): R93.

Bollag, D. M., P. A. McQueney, et al. (1995). "Epothilones, a new class of microtubulestabilizing agents with a taxol-like mechanism of action." Cancer Research 55(11): 2325-2333.

Bonangelino, C., E. Chavez, et al. (2003). "Genomic Screen for new vacuole protein sorting mutants in Saccharomyces cerevisiae." Yeast 20: S271-S271.

Bono, F., J. Ebert, et al. (2006). "The crystal structure of the exon junction complex reveals how it maintains a stable grip on mRNA." Cell 126(4): 713-725.

Boone, C., H. Bussey, et al. (2007). "Exploring genetic interactions and networks with yeast." Nature Reviews Genetics 8(6): 437-449.

Bordeleau, M. E., R. Cencic, et al. (2006). "RNA-mediated sequestration of the RNA helicase eIF4A by pateamine A inhibits translation initiation." Chemistry and Biology 13(12): 1287-1295.

Bordeleau, M. E., J. Matthews, et al. (2005). "Stimulation of mammalian translation initiation factor eIF4A activity by a small molecule inhibitor of eukaryotic translation." Proceedings of the National Academy of Sciences of the United States of America 102(30): 10460-10465. 
Bordeleau, M. E., A. Mori, et al. (2006). "Functional characterization of IRESes by an inhibitor of the RNA helicase eIF4A." Nature Chemical Biology 2(4): 213-220.

Bordeleau, M. E., F. Robert, et al. (2008). "Therapeutic suppression of translation initiation modulates chemosensitivity in a mouse lymphoma model." Journal of Clinical Investigation 118(7): 2651-2660.

Borisy, G. G. and E. W. Taylor (1967). "The mechanism of action of colchicine: Binding of colchincine- ${ }^{3} \mathrm{H}$ to cellular protein." Journal of Cell Biology 34(2): 525-533.

Botet, J., M. Rodriguez-Mateos, et al. (2008). "A chemical genomic screen in Saccharomyces cerevisiae reveals a role for diphthamidation of translation elongation factor 2 in inhibition of protein synthesis by sordarin." Antimicrobial Agents and Chemotherapy 52(5): 1623-1629.

Brazelton, T. and R. Morris (1996). "Molecular mechanisms of action of new xenobiotic immunosuppressive drugs: tacrolimus (FK506), sirolimus (rapamycin), mycophenolate mofetil and leflunomide." Current Opinions in Immunology 8(5): 710-720.

Brehmer, D., K. Godl, et al. (2004). "Proteome-wide identification of cellular targets affected by bisindolylmaleimide-type protein kinase C inhibitors." Molecular and Cellular Proteomics 3(5): 490-500.

Bubb, M. R., A. M. J. Senderowicz, et al. (1994). "Jasplakinolide, a cytotoxic natural product, induces actin polymerization and competitively inhibits the binding of phalloidin to F-actin." Journal of Biological Chemistry 269(21): 14869-14871.

Butcher, R. A. and S. L. Schreiber (2004). "Identification of Ald6p as the target of a class of small-molecule suppressors of FK506 and their use in network dissection." Proceedings of the National Academy of Sciences of the United States of America 101(21): 7868-7873.

Cabanas, M. J., D. Vazquez, et al. (1978). "Dual interference of hygromycin-B with ribosomal translocation and with aminoacyl-transfer-RNA recognition." European Journal of Biochemistry 87(1): 21-27.

Cannon, M., A. Jimenez, et al. (1976). "Competition between trichodermin and several other sesquiterpene antibiotics for binding to their receptor site(s) on eukaryotic ribosomes." Biochemical Journal 160(2): 137-145.

Capa, L., A. Mendoza, et al. (1998). "Translation elongation factor 2 is part of the target for a new family of antifungals." Antimicrobial Agents and Chemotherapy 42(10): 2694-2699.

Carrasco, L., M. Barbacid, et al. (1973). "Trichodermin group of antibiotics, inhibitors of peptide-bond formation by eukaryotic ribosomes." Biochimica Et Biophysica Acta 312(2): 368-376.

Carrasco, L., A. Jimenez, et al. (1976). "Specific inhibition of translocation by tubulosine in eukaryotic polysomes." European Journal of Biochemistry 64(1): 1-5.

Carter, M. S., J. Doskow, et al. (1995). "A regulatory mechanism that detects premature nonsense codons in T-cell receptor transcripts in vivo is reversed by protein synthesis inhibitors in vitro." Journal of Biological Chemistry 270(48): 2899529003.

Caruthers, J. M., E. R. Johnson, et al. (2000). "Crystal structure of yeast initiation factor 4A, a DEAD-box RNA helicase." Proceedings of the National Academy of Sciences of the United States of America 97(24): 13080-13085.

Cencic, R., M. Carrier, et al. (2009). "Antitumor Activity and Mechanism of Action of the Cyclopenta[b]benzofuran, Silvestrol." Plos One 4(4).

Cencic, R., M. Carrier, et al. (2010). "Synergistic effect of inhibiting translation initiation in combination with cytotoxic agents in acute myelogenous leukemia cells." Leukemia Research 34(4): 535-541.

Chan, C., J. Dostie, et al. (2004). "eIF4A3 is a novel component of the exon junction complex." RNA 10(2): 200-209. 
Chan, T. F., J. Carvalho, et al. (2000). "A chemical genomics approach toward understanding the global functions of the target of rapamycin protein (TOR)." Proceedings of the National Academy of Sciences of the United States of America 97(24): 13227-13232.

Chang, M., M. Bellaoui, et al. (2002). "A genome-wide screen for methyl methanesulfonate-sensitive mutants reveals genes required for $\mathrm{S}$ phase progression in the presence of DNA damage." Proceedings of the National Academy of Sciences of the United States of America 99(26): 16934-16939.

Chanklan, R., M. Mizunuma, et al. (2008). "Identification of Saccharomyces cerevisiae Tub1 alpha-tubulin as a potential target for NKH-7, a cytotoxic 1-naphthol derivative compound." Bioscience Biotechnology and Biochemistry 72(4): 10231031.

Charcosset, J.-Y., A. Jacquemin-Sablon, et al. (1984). "Effect of membrane potential on the cellular uptake of 2-N-methyl-ellipticinium by L1210 cells." Biochemical Pharmacology 33(14): 2271-2275.

Chen, J., W. Lane, et al. (1999). "The identification of myriocin-binding proteins." Chemistry and Biology 6(4): 221-235.

Cheng, K. W., C. C. Wong, et al. (2010). "Identification and characterization of molecular targets of natural products by mass spectrometry." Mass Spectrometry Reviews 29(1): 126-155.

Collins, S. R., P. Kemmeren, et al. (2007). "Toward a comprehensive atlas of the physical interactome of Saccharomyces cerevisiae." Molecular and Cellular Proteomics 6(3): 439-450.

Conti, E. and E. Izaurralde (2005). "Nonsense-mediated mRNA decay: molecular insights and mechanistic variations across species." Current Opinion in Cell Biology 17(3): 316-325.

Cooper, D., D. V. Banthorp, et al. (1967). "Modified ribosomes conferring resistance to cycloheximide in mutants of Saccharomyces cerevisiae." Journal of Molecular Biology 26(2): 347-\&.

Coppolecchia, R., P. Buser, et al. (1993). "A new yeast translation initiation factor suppresses a mutation in the eIF4A RNA helicase." EMBO Journal 12(10): 40054011.

Costanzo, M., A. Baryshnikova, et al. (2010). "The genetic landscape of a cell." Science 327(5964): 425-431.

Coue, M., S. L. Brenner, et al. (1987). "Inhibition of actin polymerization by latrunculinA." FEBS Letters 213(2): 316-318.

Crespo, J. L. and M. N. Hall (2002). "Elucidating TOR signaling and rapamycin action: lessons from Saccharomyces cerevisiae." Microbiology and Molecular Biology Reviews 66(4): 579-591.

Crews, C. M., J. L. Collins, et al. (1994). "GTP-dependent finding of the antiproliferative agent didemnin to elongation-factor 1-alpha." Journal of Biological Chemistry 269(22): 15411-15414.

Cui, Z. F., D. Hirata, et al. (1996). "The multidrug resistance-associated protein (MRP) subfamily (Yrs1/Yor1) of Saccharomyces cerevisiae is important for the tolerance to a broad range of organic anions." Journal of Biological Chemistry 271(25): $14712-14716$.

Dang, Y. J., N. Kedersha, et al. (2006). "Eukaryotic initiation factor 2 alpha-independent pathway of stress granule induction by the natural product pateamine A." Journal of Biological Chemistry 281(43): 32870-32878.

Dang, Y. J., W. K. Low, et al. (2009). "Inhibition of Nonsense-mediated mRNA Decay by the Natural Product Pateamine A through Eukaryotic Initiation Factor 4AIII." Journal of Biological Chemistry 284(35): 23613-23621. 
Deutschbauer, A. M., D. F. Jaramillo, et al. (2005). "Mechanisms of haploinsufficiency revealed by genome-wide profiling in yeast." Genetics 169(4): 1915-1925.

Dong, L. F., P. Low, et al. (2008). "alpha-tocopheryl succinate induces apoptosis by targeting ubiquinone-binding sites in mitochondrial respiratory complex II." Oncogene 27(31): 4324-4335.

Dorer, R., S. Zhong, et al. (2005). "A small-molecule inhibitor of Mps1 blocks the spindlecheckpoint response to a lack of tension on mitotic chromosomes." Current Biology 15(11): 1070-1076.

Dreisewerd, K. (2003). "The desorption process in MALDI." Chemical Reviews 103(2): 395-425.

Duncan, R. and J. W. B. Hershey (1983). "Identification and quantitation of levels of protein-synthesis initiation-factors in crude HeLa-cell lysates by two-dimensional polyacrylamide-gel electrophoresis." Journal of Biological Chemistry 258(11): 7228-7235.

Duncan, R., S. C. Milburn, et al. (1987). "Regulated phosphorylation and low abundance of HeLa-cell initiation-factor eIF4F suggest a role in translational control - heatshock effects on eIF4F." Journal of Biological Chemistry 262(1): 380-388.

Elion, E. A. (2001). "The Ste5p scaffold." Journal of Cell Science 114(22): 3967-3978.

Estes, J. E., L. A. Selden, et al. (1992). "Tightly-bound divalent cation of actin." Journal of Muscle Research and Cell Motility 13(3): 272-284.

Farkas, D. L., M. D. Wei, et al. (1989). "Simultaneous imaging of cell and mitochondrial membrane potentials." Biophysical Journal 56(6): 1053-1069.

Feher, M. and J. M. Schmidt (2003). "Property distributions: Differences between drugs, natural products, and molecules from combinatorial chemistry." Journal of Chemical Information and Computer Sciences 43(1): 218-227.

Fei, W. H., G. Alfaro, et al. (2008). "Genome-wide analysis of sterol-lipid storage and trafficking in Saccharomyces cerevisiae." Eukaryotic Cell 7(2): 401-414.

Felicett, L., B. Colombo, et al. (1966). "Inhibition of protein synthesis in reticulocytes by antibiotics .2. site of action of cycloheximide streptovitacin A and pactamycin." Biochimica Et Biophysica Acta 119(1): 120-\&.

Fenteany, G., R. F. Standaert, et al. (1995). "Inhibition of proteasome activities and subunit-specific amino-terminal threonine modification by lactacystin." Science 268(5211): 726-731.

Fenteany, G. and S. T. Zhu (2003). "Small-molecule inhibitors of actin dynamics and cell motility." Current Topics in Medicinal Chemistry 3(6): 593-616.

Ferraiuolo, M. A., C.-S. Lee, et al. (2004). "A nuclear translation-like factor eIF4AIII is recruited to the mRNA during splicing and functions in nonsense-mediated decay." Proceedings of the National Academy of Sciences of the United States of America 101(12): 4118-4123.

Fiedler, D., H. Braberg, et al. (2009). "Functional organization of the S. cerevisiae phosphorylation network." Cell 136(5): 952-963.

Fleming, J. A., E. S. Lightcap, et al. (2002). "Complementary whole-genome technologies reveal the cellular response to proteasome inhibition by PS-341." Proceedings of the National Academy of Sciences of the United States of America 99(3): 14611466.

Foury, F. and A. Goffeau (1973). "Stimulation of yeast RNA-synthesis by cycloheximide and 3',5'-cyclic AMP." Nature-New Biology 245(141): 44-47.

Freshney, R. I. (2005). Culture of animal cells : a manual of basic technique. New York, Wiley-Liss.

Fried, H. M. and J. R. Warner (1981). "Cloning of yeast gene for trichodermin resistance and ribosomal protein L3." Proceedings of the National Academy of Sciences of the United States of America 78(1): 238-242. 
Fried, H. M. and J. R. Warner (1982). "Molecular-cloning and analysis of yeast gene for cycloheximide resistance and ribosomal-protein L29." Nucleic Acids Research 10(10): 3133-3148.

Gallagher, R., S. Collins, et al. (1979). "Characterization of the continuous, differentiating myeloid cell line (HL-60) from a patient with acute promyelocytic leukemia." Blood 54(3): 713-733.

Game, J. C., G. W. Birrell, et al. (2003). "Use of a genome-wide approach to identify new genes that control resistance of Saccharomyces cerevisiae to ionizing radiation." Radiation Research 160(1): 14-24.

Gasteiger, E., A. Gattiker, et al. (2003). "ExPASy: the proteomics server for in-depth protein knowledge and analysis." Nucleic Acids Research 31(13): 3784-3788.

Gelperin, D. M., M. A. White, et al. (2005). "Biochemical and genetic analysis of the yeast proteome with a movable ORF collection." Genes \& Development 19(23): 28162826.

Gerlinger, U. M., R. Guckel, et al. (1997). "Yeast cycloheximide-resistant crl mutants are proteasome mutants defective in protein degradation." Molecular Biology of the Cell 8(12): 2487-2499.

Giaever, G., A. M. Chu, et al. (2002). "Functional profiling of the Saccharomyces cerevisiae genome." Nature 418(6896): 387-391.

Giaever, G., P. Flaherty, et al. (2004). "Chemogenomic profiling: Identifying the functional interactions of small molecules in yeast." Proceedings of the National Academy of Sciences of the United States of America 101(3): 793-798.

Giaever, G., D. D. Shoemaker, et al. (1999). "Genomic profiling of drug sensitivities via induced haploinsufficiency." Nature Genetics 21(3): 278-283.

Gietz, R. and R. Schiestl (2007). "High-efficiency yeast transformation using the LiAc/SS carrier DNA/PEG method." Nature Protocols 2(1): 31-34.

Gilbert, W. V., K. H. Zhou, et al. (2007). "Cap-independent translation is required for starvation-induced differentiation in yeast." Science 317(5842): 1224-1227.

Gingras, A., B. Raught, et al. (1999). "eIF4 initiation factors: effectors of mRNA recruitment to ribosomes and regulators of translation." Annual Review of Biochemistry 68: 913-963.

Goffeau, A., B. G. Barrell, et al. (1996). "Life with 6000 Genes." Science 274(5287): 546567.

Gonzalez, A., A. Jimenez, et al. (1978). "Studies on the mode of action of hygromycin B, an inhibitor of translocation in eukaryotes." Biochimica Et Biophysica Acta 521(2): 459-469.

Gordon, D. J., J. L. Boyer, et al. (1977). "COMPARATIVE BIOCHEMISTRY OF NONMUSCLE ACTINS." Journal of Biological Chemistry 252(22): 8300-8309.

Gottesman, M. M. (2002). "Mechanisms of cancer drug resistance." Annual Review of Medicine 53: 615-627.

Goyer, C., M. Altmann, et al. (1993). "TIF4631 and TIF4632 - two yeast genes encoding the high-molecular-weight subunits of the cap-binding protein complex (eukaryotic initiation factor-4F) contain an RNA recognition motif-like sequence and carry out an essential function." Molecular and Cellular Biology 13(8): 4860-4874.

Grant, P., L. Sanchez, et al. (1974). "Cryptopleurine resistance - genetic locus for a 40S ribosomal component in Saccharomyces cerevisiae." Journal of Bacteriology 120(3): 1308-1314.

Grant, P. G., D. Schindler, et al. (1976). "Mapping of trichodermin resistance in Saccharomyces cerevisiae - genetic locus for a component of $60 \mathrm{~S}$ ribsomal subunit." Genetics 83(4): 667-673.

Grifo, J., S. Tahara, et al. (1983). "New initiation factor activity required for globin mRNA translation." Journal of Biological Chemistry 258(9): 5804-5810. 
Grollman, A. P. (1967). "Inhibitors of protein biosynthesis II: Mode of action of anisomycin." Journal of Biological Chemistry 242(13): 3226-3233.

Gross, A., J. M. McDonnell, et al. (1999). "BCL-2 family members and the mitochondria in apoptosis." Genes \& Development 13(15): 1899-1911.

Gross, K. and A. Pogo (1976). "Control of ribonucleic acid synthesis in eukaryotes. 2. The effect of protein synthesis on the activities of nuclear and total DNA-dependent RNA polymerase in yeast." Biochemistry 15(10): 2070-2081.

Gross, K. and A. Pogo (1976). "Control of ribonucleic acid synthesis in eukaryotes. 3. The effect of cycloheximide and edeine on RNA synthesis in yeast." Biochemistry 15(10): 2082-2086.

Gross, K. J. and A. O. Pogo (1974). "Control mechanism of ribonucleic acid synthesis in eukaryotes: The effect of amino acid and glucose starvation and cycloheximide on yeast deoxyribonucleic acid-dependent ribonucleic acid polymerases." Journal of Biological Chemistry 249(2): 568-576.

Guimaraes, C. A. and R. Linden (2004). "Programmed cell deaths: Apoptosis and alternative deathstyles." European Journal of Biochemistry 271(9): 1638-1650.

Gupta, R. S. and L. Siminovitch (1977). "Molecular-basis of emetine resistance in chinesehamster ovary cells - alteration in 40S ribosomal-subunit." Cell 10(1): 61-66.

Hamel, E. and C. M. Lin (1981). "Glutamate-induced polymerization of tubulin: Characteristics of the reaction and application to the large-scale purification of tubulin." Archives of Biochemistry and Biophysics 209(1): 29-40.

Hampsey, M. (1998). "Molecular genetics of the RNA polymerase II general transcriptional machinery." Microbiology and Molecular Biology Reviews 62(2): 465-503.

Hanna, J., D. S. Leggett, et al. (2003). "Ubiquitin depletion as a key mediator of toxicity by translational inhibitors." Molecular and Cellular Biology 23(24): 9251-9261.

Hanway, D., J. K. Chin, et al. (2002). "Previously uncharacterized genes in the UV- and MMS-induced DNA damage response in yeast." Proceedings of the National Academy of Sciences of the United States of America 99(16): 10605-10610.

Harding, M. W., A. Galat, et al. (1989). "A receptor for the immunosuppressant FK506 is a cis-trans peptidyl-prolyl isomerase." Nature 341(6244): 758-760.

He, H., T. von der Haar, et al. (2003). "The yeast eukaryotic initiation factor 4G (eIF4G) HEAT domain interacts with eIF1 and eIF5 and is involved in stringent AUG selection." Molecular and Cellular Biology 23(15): 5431-5445.

Heitman, J., N. R. Movva, et al. (1991). "Targets for cell-cycle arrest by the immunosuppressant rapamycin in yeast." Science 253(5022): 905-909.

Hentze, M. W. and A. E. Kulozik (1999). "A perfect message: RNA surveillance and nonsense-mediated decay." Cell 96(3): 307-310.

Henzel, W. J., C. Watanabe, et al. (2003). "Protein identification: The origins of peptide mass fingerprinting." Journal of the American Society for Mass Spectrometry 14(9): 931-942.

Hernandez, G. and P. Vazquez-Pianzola (2005). "Functional diversity of the eukaryotic translation initiation factors belonging to eIF4 families." Mechanisms of Development 122(7-8): 865-876.

Herrera, F., F. Franceschi, et al. (1986). "An altered ribosomal-protein in an edeineresistant mutant of Saccharomyces cerevisiae." Molecular \& General Genetics 202(1): 120-124.

Higa, T., J. Tanaka, et al. (1981). "Hippuristanols cytotoxic polyoxygenated steroids from the gorgonian Isis hippuris." Chemistry Letters (11): 1647-1650.

Hillenmeyer, M. E., E. Ericson, et al. (2010). "Systematic analysis of genome-wide fitness data in yeast reveals novel gene function and drug action." Genome Biology 11(3): 17. 
Hillenmeyer, M. E., E. Fung, et al. (2008). "The chemical genomic portrait of yeast: Uncovering a phenotype for all genes." Science 320(5874): 362-365.

Ho, C. H., L. Magtanong, et al. (2009). "A molecular barcoded yeast ORF library enables mode-of-action analysis of bioactive compounds." Nature Biotechnology 27(4): 369-377.

Holcik, M. and R. G. Korneluk (2000). "Functional characterization of the X-linked inhibitor of apoptosis (XIAP) internal ribosome entry site element: role of la autoantigen in XIAP translation." Molecular and Cellular Biology 20(13): 46484657.

Holcik, M. and N. Sonenberg (2005). "Translational control in stress and apoptosis." Nature Reviews Molecular and Cellular Biology 6(4): 318-327.

Honore, S., E. Pasquier, et al. (2005). "Understanding microtubule dynamics for improved cancer therapy." Cellular and Molecular Life Sciences 62(24): 3039-3056.

Hood, K. A. (2002). "Biological activity of Mycale marine sponge secondary metabolites, including Peloruside A, a novel microtubule stabilising compound." A thesis submitted to the Victoria University of Wellington in fulfilment of the requirements for the degree of Doctor of Philosophy in Cell Biology.

Hood, K. A., L. M. West, et al. (2001). "Induction of apoptosis by the marine sponge (Mycale) metabolites, mycalamide A and pateamine." Apoptosis 6(3): 207-219.

Hood, K. A., L. M. West, et al. (2002). "Peloruside A, a novel antimitotic agent with paclitaxel-like microtubule- stabilizing activity." Cancer Research 62(12): 33563360.

Hoon, S., A. M. Smith, et al. (2008). "An integrated platform of genomic assays reveals small-molecule bioactivities." Nature Chemical Biology 4(8): 498-506.

Houser-Scott, F., S. Xiao, et al. (2002). "Interactions among the protein and RNA subunits of Saccharomyces cerevisiae nuclear RNase P." Proceedings of the National Academy of Sciences of the United States of America 99(5): 2684-2689.

Hoyt, M. A., T. Stearns, et al. (1990). "Chromosome instability mutants of Saccharomyces cerevisiae that are defective in microtubule-mediated processes." Molecular and Cellular Biology 10(1): 223-234.

Ishigaki, Y., X. Li, et al. (2001). "Evidence for a pioneer round of mRNA translation: mRNAs subject to nonsense-mediated decay in mammalian cells are bound by CBP80 and CBP20." Cell 106(5): 607-617.

Jackson, R. J., C. U. T. Hellen, et al. (2010). "The mechanism of eukaryotic translation initiation and principles of its regulation." Nature Reviews Molecular Cell Biology 11(2): 113-127.

Jacoby, G. A. and L. Gorinl (1968). The effect of streptomycin and other aminoglycoside antibiotics on protein synthesis, Mechanism of action. Springer-Verlag, Inc.

Jimenez, A., L. Sanchez, et al. (1975). "Simultaneous ribosomal resistance to trichodermin and anisomycin in Saccharomyces cerevisiae mutants." Biochimica Et Biophysica Acta 383(4): 427-434.

Johannes, G. and P. Sarnow (1998). "Cap-independent polysomal association of natural mRNAs encoding c-myc, BiP, and eIF4G conferred by internal ribosome entry sites." RNA 4(12): 1500-1513.

Jonikas, M. C., S. R. Collins, et al. (2009). "Comprehensive characterization of genes required for protein folding in the endoplasmic reticulum." Science 323(5922): 1693-1697.

Jordan, M. A., R. J. Toso, et al. (1993). "Mechanism of mitotic block and inhibition of cellproliferation by taxol at low concentrations." Proceedings of the National Academy of Sciences of the United States of America 90(20): 9552-9556.

Jordan, M. A. and L. Wilson (2004). "Microtubules as a target for anticancer drugs." Nature Reviews Cancer 4(4): 253-265. 
Jorgensen, P., J. L. Nishikawa, et al. (2002). "Systematic identification of pathways that couple cell growth and division in yeast." Science 297(5580): 395-400.

Kaaufer, N. F., H. M. Fried, et al. (1983). "Cycloheximide resistance in yeast: the gene and its protein." Nucleic Acids Research. 11(10): 3123-3135.

Kageyama, A., I. Kusano, et al. (2002). "Comparison of the apoptosis-inducing abilities of various protein synthesis inhibitors in U937 cells." Bioscience and Biotechnological Biochemistry 66(4): 835-839.

Kaida, D., H. Motoyoshi, et al. (2007). "Spliceostatin A targets SF3b and inhibits both splicing and nuclear retention of pre-mRNA." Nature Chemical Biology 3(9): 576583.

Kapp, L. and J. Lorsch (2004). "The molecular mechanics of eukaryotic translation." Annual Review of Biochemistry 73: 657-704.

Kashima, I., A. Yamashita, et al. (2006). "Binding of a novel SMG-1-Upf1-eRF1-eRF3 complex (SURF) to the exon junction complex triggers Upf1 phosphorylation and nonsense-mediated mRNA decay." Genes \& Development 20(3): 355-367.

Keeven, J., D. Ko, et al. (2002). "PDR2 gain-of-function mutations eliminate the need for Pdr1 and require the UBP6 product for resistance to translational inhibitors." Current Genetics 41(1): 11-19.

Kemmer, D., L. McHardy, et al. (2009). "Combining chemical genomics screens in yeast to reveal spectrum of effects of chemical inhibition of sphingolipid biosynthesis." BMC Microbiology 9: 9.

Kentsis, A., I. Topisirovic, et al. (2004). "Ribavirin suppresses eIF4E-mediated oncogenic transformation by physical mimicry of the 7-methyl guanosine mRNA cap." Proceedings of the National Academy of Sciences of the United States of America 101(52): 18105-18110.

Kobayashi, Y., M. Mizunuma, et al. (2006). "Identification of Saccharomyces cerevisiae ribosomal protein L3 as a target of curvularol, a G(1)-specific inhibitor of mammalian cells." Bioscience Biotechnology and Biochemistry 70(10): 2451-2459.

Korneeva, N. L., B. J. Lamphear, et al. (2001). "Characterization of the two eIF4A-binding sites on human eIF4G-1." Journal of Biological Chemistry 276(4): 2872-2879.

Koshland, D. E. (1994). "The key-lock theory and the induced fit theory." Angewandte Chemie-International Edition 33(23-24): 2375-2378.

Kotake, Y., K. Sagane, et al. (2007). "Splicing factor SF3b as a target of the antitumor natural product pladienolide." Nature Chemical Biology 3(9): 570-575.

Kouyama, T. and K. Mihashi (1981). "Fluorimetry study of N-(1-pyrenyl)iodoacetamidelabelled F-actin. Local structural change of actin protomer both on polymerization and on binding of heavy meromyosin." European Journal of Biochemistry 114(1): 33-38.

Kressler, D., J. de la Cruz, et al. (1997). "Fallp is an essential DEAD-box protein involved in 40S-ribosomal- subunit biogenesis in Saccharomyces cerevisiae." Molecular and Cellular Biology 17(12): 7283-7294.

Kuo, S. C. and J. O. Lampen (1974). "Tunicamycin - Inhibitor of yeast glycoprotein synthesis." Biochemical and Biophysical Research Communications 58(1): 287295.

Kuznetsov, G., Q. L. Xu, et al. (2009). "Potent in vitro and in vivo anticancer activities of des-methyl, des-amino pateamine A, a synthetic analogue of marine natural product pateamine A." Molecular Cancer Therapeutics 8(5): 1250-1260.

Lain, S., J. Hollick, et al. (2008). "Discovery, in vivo activity, and mechanism of action of a small-molecule p53 activator." Cancer Cell 13(5): 454-463.

Lanker, S., P. P. Muller, et al. (1992). "Interactions of the eIF-4F subunits in the yeast Saccharomyces cerevisiae." Journal of Biological Chemistry 267(29): 2116721171. 
Launhardt, H., A. Hinnen, et al. (1998). "Drug-induced phenotypes provide a tool for the functional analysis of yeast genes." Yeast 14(10): 935-942.

Le Hir, H., D. Gatfield, et al. (2001). "The exon-exon junction complex provides a binding platform for factors involved in mRNA export and nonsense-mediated mRNA decay." Embo Journal 20(17): 4987-4997.

Le Hir, H., E. Izaurralde, et al. (2000). "The spliceosome deposits multiple proteins 20-24 nucleotides upstream of mRNA exon-exon junctions." EMBO Journal 19(24): 6860-6869.

Lee, Y. J. and P. C. Keng (2005). "Studying the effects of actin cytoskeletal destabilization on cell cycle by cofilin overexpression." Molecular Biotechnology 31(1): 1-10.

Lemaire, C., K. Andreau, et al. (1999). "Specific dual effect of cycloheximide on B lymphocyte apoptosis: involvement of CPP32/caspase-3." Biochem Pharmacol 58(1): 85-93.

Leslie, B. J. and P. J. Hergenrother (2008). "Identification of the cellular targets of bioactive small organic molecules using affinity reagents." Chemical Society Reviews 37(7): 1347-1360.

Li, Q. Y., H. Imataka, et al. (1999). "Eukaryotic translation initiation factor 4AIII (eTF4AIII) is functionally distinct from eIF4AI and eIF4AII." Molecular and Cellular Biology 19(11): 7336-7346.

Li, W., G. J. Belsham, et al. (2001). "Eukaryotic initiation factors 4A (eIF4A) and 4G (eIF4G) mutually interact in a 1:1 ratio in vivo." Journal of Biological Chemistry 276(31): 29111-29115.

Lindegren, C. C., G. Lindegren, et al. (1959). "Gene controlled resistance and sensitivity to caffeine and nicotine in Saccharomyces." Journal of General Microbiology 20(3): 504-\&.

Linder, P. (2003). "Yeast RNA helicases of the DEAD-box family involved in translation initiation." Biology of the Cell 95(3-4): 157-167.

Linder, P. (2003). "Yeast RNA helicases of the DEAD-box family involved in translation initiation." Biological Cell 95(3-4): 157-167.

Linder, P. (2006). "Dead-box proteins: a family affair--active and passive players in RNPremodeling." Nucleic Acids Research 34(15): 4168-4180.

Linder, P. and P. P. Slonimski (1988). "Sequence of the genes TIF1 and TIF2 from Saccharomyces cerevisiae coding for a translation initiation-factor." Nucleic Acids Research 16(21): 10359-10359.

Linder, P. and P. P. Slonimski (1989). "An essential yeast protein, encoded by duplicated genes TIF1 and TIF2 and homologous to the mammalian translation initiationfactor eIF-4A, can suppress a mitochondrial missense mutation." Proceedings of the National Academy of Sciences of the United States of America 86(7): 22862290.

Lindqvist, L., M. Oberer, et al. (2008). "Selective pharmacological targeting of a DEADbox RNA helicase." Plos One 3(2): 11.

Lindqvist, L. and J. Pelletier (2009). "Inhibitors of translation initiation as cancer therapeutics." Future Medicinal Chemistry 1(9): 1709-1722.

Liu, X. S., J. K. Jiang, et al. (2009). "Lycorine induces apoptosis and down-regulation of Mcl-1 in human leukemia cells." Cancer Letters 274(1): 16-24.

Liu, Y. X., Y. C. Hsiung, et al. (1994). "Yeast topoisomerase-II mutants resistant to antitopoisomerase agents - Identification and characterization of new yeast topoisomerase-II mutants selected for resistance to etoposide." Cancer Research 54(11): 2943-2951.

Lodish, H. F. (2003). Molecular cell biology. New York, W.H. Freeman and Company.

Lomenick, B., R. Hao, et al. (2009). "Target identification using drug affinity responsive target stability (DARTS)." Proceedings of the National Academy of Sciences of the United States of America 106(51): 21984-21989. 
Lopes, N. M., H. P. Miller, et al. (1997). "Assessment of microtubule stabilizers by semiautomated in vitro microtubule protein polymerization and mitotic block assays." Cancer Chemotherapy and Pharmacology 41(1): 37-47.

Lopez-Fanarraga, M., J. Avila, et al. (2001). "Review: postchaperonin tubulin folding cofactors and their role in microtubule dynamics." Journal of Structural Biology 135(2): 219-229.

Lorenz, M. C. and J. Heitman (1995). "TOR mutations confer rapamycin resistance by preventing interaction with FKBP12-rapamycin." Journal of Biological Chemistry 270(46): 27531-27537.

Lorsch, J. R. and D. Herschlag (1998). "The DEAD box protein eIF4A. 1. A minimal kinetic and thermodynamic framework reveals coupled binding of RNA and nucleotide." Biochemistry 37(8): 2180-2193.

Low, W. K., Y. J. Dang, et al. (2007). "Substrate-dependent targeting of eukaryotic translation initiation factor $4 \mathrm{~A}$ by pateamine A: Negation of domain-linker regulation of activity." Chemistry and Biology 14(6): 715-727.

Low, W. K., Y. J. Dang, et al. (2005). "Inhibition of eukaryotic translation initiation by the marine natural product pateamine A." Molecular Cell 20(5): 709-722.

Luban, C., M. Beutel, et al. (2005). "Systematic screening of nuclear encoded proteins involved in the splicing metabolism of group II introns in yeast mitochondria." Gene 354: 72-79.

Luduena, R. (1998). "Multiple forms of tubulin: different gene products and covalent modifications." International Review of Cytology 178: 207-275.

Luesch, H. (2006). "Towards high-throughput characterization of small molecule mechanisms of action." Molecular Biosystems 2(12): 609-620.

Lum, P. Y., C. D. Armour, et al. (2004). "Discovering modes of action for therapeutic compounds using a genome-wide screen of yeast heterozygotes." Cell 116(1): 121137.

Madeo, F., E. Herker, et al. (2004). "Apoptosis in yeast." Current Opinion in Microbiology 7(6): 655-660.

Maehle, A. H., C. R. Prull, et al. (2002). "The emergence of the drug receptor theory." Nature Reviews Drug Discovery 1(8): 637-641.

Maere, S., K. Heymans, et al. (2005). "BiNGO: a Cytoscape plugin to assess overrepresentation of Gene Ontology categories in Biological Networks." Bioinformatics 21(16): 3448-3449.

Marissen, W., A. Gradi, et al. (2000). "Cleavage of eukaryotic translation initiation factor 4GII correlates with translation inhibition during apoptosis." Cell Death and Differentiation 7(12): 1234-1243.

Marissen, W. E., Y. Guo, et al. (2000). "Identification of caspase 3-mediated cleavage and functional alteration of eukaryotic initiation factor 2alpha in apoptosis." Journal of Biological Chemistry 275(13): 9314-9323.

Marissen, W. E. and R. E. Lloyd (1998). "Eukaryotic translation initiation factor 4G is targeted for proteolytic cleavage by caspase 3 during inhibition of translation in apoptotic cells." Molecular and Cellular Biology 18(12): 7565-7574.

Markovich, S., A. Yekutiel, et al. (2004). "Genomic approach to identification of mutations affecting caspofungin susceptibility in Saccharomyces cerevisiae." Antimicrobial Agents and Chemotherapy 48(10): 3871-3876.

Martin, S. and P. Leder (2001). "Human MCF10A mammary epithelial cells undergo apoptosis following actin depolymerization that is independent of attachment and rescued by Bcl-2." Molecular and Cellular Biology 21(19): 6529-6536.

Matias, P., C. Soares, et al. (2001). "[NiFe] hydrogenase from Desulfovibrio desulfuricans ATCC 27774: gene sequencing, three-dimensional structure determination and refinement at $1.8 \mathrm{~A}$ and modelling studies of its interaction with the tetrahaem cytochrome c3." Journal of Biological Inorganic Chemistry 6(1): 63-81. 
McCarthy, J. E. G. (1998). "Posttranscriptional control of gene expression in yeast." Microbiology and Molecular Biology Reviews 62(4): 1492-1553.

McCusker, J. H. and J. E. Haber (1988). "Crl mutants of Saccharomyces cerevisiae resemble both mutants affecting general control of amino-acid biosynthesis and omnipotent translational suppressor mutants." Genetics 119(2): 317-327.

McCusker, J. H. and J. E. Haber (1988). "Cycloheximide-resistant temperature-sensitive lethal mutations of Saccharomyces-cerevisiae." Genetics 119(2): 303-315.

Meng, L. H., N. Sin, et al. (1998). "The antiproliferative agent didemnin B uncompetitively inhibits palmitoyl protein thioesterase." Biochemistry 37(29): 10488-10492.

Michels, A. A. and N. Hernandez (2006). "Does Pol I talk to Pol II? Coordination of RNA polymerases in ribosome biogenesis." Genes \& Development 20(15): 1982-1985.

Middlekauff, J. E., S. Hino, et al. (1957). "Gene control of resistance vs. sensitivity to actidione in Saccharomyces." Genetics 42(1): 66-71.

Miller, J., B. Rouwe, et al. (2004). "Peloruside A enhances apoptosis in H-ras-transformed cells and is cytotoxic to proliferating T cells." Apoptosis 9(6): 785-796.

Miyamoto, Y., K. Machida, et al. (2002). "Identification of Saccharomyces cerevisiae isoleucyl-tRNA synthetase as a target of the $\mathrm{G}_{1}$-specific inhibitor reveromycin A." Journal of Biological Chemistry 277(32): 28810-28814.

Mnaimneh, S., A. P. Davierwala, et al. (2004). "Exploration of essential gene functions via titratable promoter alleles." Cell 118(1): 31-44.

Moerke, N., H. Aktas, et al. (2007). "Small-molecule inhibition of the interaction between the translation initiation factors eIF4E and eIF4G." Cell 128(2): 257-267.

Mosmann, T. (1983). "Rapid colorimetric assay for cellular growth and survival: application to proliferation and cytotoxicity assays." Journal of Immunological Methods 65(1-2): 55-63.

Mukhopadhyay, K., A. Kohli, et al. (2002). "Drug susceptibilities of yeast cells are affected by membrane lipid composition." Antimicrobial Agents and Chemotherapy 46(12): 3695-3705.

Neff, C. L. and A. B. Sachs (1999). "Eukaryotic translation initiation factors 4G and 4A from Saccharomyces cerevisiae interact physically and functionally." Molecular and Cellular Biology 19(8): 5557-5564.

$\mathrm{Ng}$, R. and J. Abelson (1980). "Isolation and sequence of the gene for actin in Saccharomyces cerevisiae." Proceedings of the National Academy of Sciences of the United States of America 77(7): 3912-3916.

Nielsen, K. H., H. Chamieh, et al. (2009). "Mechanism of ATP turnover inhibition in the EJC." RNA 15(1): 67-75.

Nielsen, P. and H. Trachsel (1988). "The mouse protein synthesis initiation factor 4A gene family includes two related functional genes which are differentially expressed." EMBO Journal 7(7): 2097-2105.

Nitiss, J. L. and W. T. Beck (1996). "Anti-topoisomerase drug action and resistance." European Journal of Cancer 32A(6): 958-966.

Nogales, E. (2001). "Structural insights into microtubule function." Annual Review of Biophysics and Biomolecular Structure 30: 397-420.

Northcote, P. T., J. W. Blunt, et al. (1991). "Pateamine - a potent cytotoxin from the New Zealand marine sponge, Mycale sp." Tetrahedron Letters 32(44): 6411-6414.

Novac, O., A.-S. Guenier, et al. (2004). "Inhibitors of protein synthesis identified by a high throughput multiplexed translation screen." Nucleic Acids Research 32(3): 902915.

O'Donovan, C., M. J. Martin, et al. (2002). "High-quality protein knowledge resource: SWISS-PROT and TrEMBL." Briefs in Bioinformatics 3(3): 275-284.

Obrig, T. G., W. J. Culp, et al. (1971). "The mechanism by which cycloheximide and related glutarimide antibiotics inhibit peptide synthesis on reticulocyte ribosomes." Journal of Biological Chemistry 246(1): 174-181. 
Oda, Y., T. Owa, et al. (2003). "Quantitative chemical proteomics for identifying candidate drug targets." Analytical Chemistry 75(9): 2159-2165.

Odaka, C., M. L. Sanders, et al. (2000). "Jasplakinolide induces apoptosis in various transformed cell lines by a caspase-3-like protease-dependent pathway." Clinical and Diagnostic Laboratory Immunology 7(6): 947-952.

Ohnishi, T., A. Yamashita, et al. (2003). "Phosphorylation of hUPF1 induces formation of mRNA surveillance complexes containing hSMG-5 and hSMG-7." Molecular Cell 12(5): 1187-1200.

Okada, Y., M. Ogawa, et al. (1973). "Effect of $\mathrm{K}^{+}$on membrane-potential in HeLa-cells." Biochimica Et Biophysica Acta 291(1): 116-126.

Page, M. F., B. Carr, et al. (1999). "SMG-2 is a phosphorylated protein required for mRNA surveillance in Caenorhabditis elegans and related to Upflp of yeast." Molecular and Cellular Biology 19(9): 5943-5951.

Palacios, I., D. Gatfield, et al. (2004). "An eIF4AIII-containing complex required for mRNA localization and nonsense-mediated mRNA decay." Nature 427(6976): 753757.

Pan, Z. Q., A. K. Agarwal, et al. (2008). "Identification of molecular pathways affected by pterostilbene, a natural dimethylether analog of resveratrol." BMC Medical Genomics 1: 13.

Parsons, A., R. Brost, et al. (2004). "Integration of chemical-genetic and genetic interaction data links bioactive compounds to cellular target pathways." Nature Biotechnology 22(1): 62-69.

Parsons, A. B., A. Lopez, et al. (2006). "Exploring the mode-of-action of bioactive compounds by chemical-genetic profiling in yeast." Cell 126(3): 611-625.

Pause, A., N. Methot, et al. (1994). "Dominant negative mutants of mammalian translation initiation factor eIF4A define a critical role for eIF4F in cap-dependent and capindependent initiation of translation." EMBO Journal 13(5): 1205-1215.

Pause, A. and N. Sonenberg (1992). "Mutational analysis of a dead box RNA helicase - the mammalian translation initiation-factor eIF4A." EMBO Journal 11(7): 2643-2654.

Pestka, S. (1971). "Inhibitors of ribosome function." Annual Review of Microbiology 25: 487-562.

Pestova, T. V. and C. U. T. Hellen (2003). "Translation elongation after assembly ribosomes on the Cricket paralysis virus internal ribosomal entry site without initiation factors or initiator tRNA." Genes \& Development 17(2): 181-186.

Pestova, T. V., I. N. Shatsky, et al. (1998). "A prokaryotic-like mode of cytoplasmic eukaryotic ribosome binding to the initiation codon during internal translation initiation of hepatitis C and classical swine fever virus RNAs." Genes \& Development 12(1): 67-83.

Pickerin, W. R. and R. A. Woods (1973). "Genetics of resistance to 4-aminopyrazolo-(3,4d)-pyrimidine in Saccharomyces cerevisiae." Molecular \& General Genetics 122(3): 231-242.

Pierce, S. E., E. L. Fung, et al. (2006). "A unique and universal molecular barcode array." Nature Methods 3(8): 601-603.

Piggott, A. M. and P. Karuso (2004). "Quality, not quantity: The role of natural products and chemical proteomics in modern drug discovery." Combinatorial Chemistry \& High Throughput Screening 7(7): 607-630.

Prat, A., S. R. Schmid, et al. (1990). "Expression of translation initiation factor-4A from yeast and mouse in Saccharomyces cerevisiae." Biochimica Et Biophysica Acta 1050(1-3): 140-145.

Pryor, D. E., A. O'Brate, et al. (2002). "The microtubule stabilizing agent laulimalide does not bind in the taxoid site, kills cells resistant to paclitaxel and epothilones, and may not require its epoxide moiety for activity." Biochemistry 41(29): 9109-9115. 
Rao, J. Y. and N. Li (2004). "Microfilament actin remodeling as a potential target for cancer drug development." Current Cancer Drug Targets 4(4): 345-354.

Ray, B. K., T. G. Lawson, et al. (1985). "ATP-dependent unwinding of messenger-RNA structure by eukaryotic initiation-factors." Journal of Biological Chemistry $\mathbf{2 6 0}(12)$ : 7651-7658.

Richman-Boytas, C. M. and L. W. Parks (1989). "Effects of sterol alterations on nystatin sensitivity in Saccharomyces-cerevisiae." Microbios 59(239): 101-111.

Rine, J., W. Hansen, et al. (1983). "Targeted selection of recombinant clones through gene dosage effects." Proceedings of the National Academy of Sciences of the United States of America 80(22): 6750-6754.

Rix, U., O. Hantschel, et al. (2007). "Chemical proteomic profiles of the BCR-ABL inhibitors imatinib, nilotinib, and dasatinib, reveal novel kinase and nonkinase targets." Blood 110(12): 4055-4063.

Rix, U. and G. Superti-Furga (2009). "Target profiling of small molecules by chemical proteomics." Nature Chemical Biology 5(9): 616-624.

Robinson, L. J. and P. D. Roepe (1996). "Effects of membrane potential versus pH(i) on the cellular retention of doxorubicin analyzed via a comparison between cystic fibrosis transmembrane conductance regulator (CFTR) and multidrug resistance (MDR) transfectants." Biochemical Pharmacology 52(7): 1081-1095.

Rogers, G. W., Jr., N. J. Richter, et al. (2001). "Modulation of the Helicase Activity of eIF4A by eIF4B, eIF4H, and eIF4F." Journal of Biological Chemistry 276(33): 30914-30922.

Romo, D., N. S. Choi, et al. (2004). "Evidence for separate binding and scaffolding domains in the immunosuppressive and antitumor marine natural product, pateamine A: Design, synthesis, and activity studies leading to a potent simplified derivative." Journal of the American Chemical Society 126(34): 10582-10588.

Romo, D., R. M. Rzasa, et al. (1998). "Total synthesis and immunosuppressive activity of (-)-pateamine A and related compounds: Implementation of beta-lactam-based macrocyclization." Journal of the American Chemical Society 120(47): 1223712254.

Rosenbloom, J., R. Endo, et al. (1976). "Termination of procollagen chain synthesis by puromycin. Evidence that assembly and secretion require a $\mathrm{COOH}$-terminal extension." Journal of Biological Chemistry 251(7): 2070-2076.

Sarafianos, S. G., S. H. Hughes, et al. (2004). "Designing anti-AIDS drugs targeting the major mechanism of HIV-1 RT resistance to nucleoside analog drugs." International Journal of Biochemistry \& Cell Biology 36(9): 1706-1715.

Scherer, W. and A. Hoogasian (1954). "Preservation at subzero temperatures of mouse fibroblasts (strain L) and human epithelial cells (strain HeLa)." Proceedings of the Society of Experimental and Biological Medicine 87(2): 480-487.

Schneider-Poetsch, T., J. H. Ju, et al. (2010). "Inhibition of eukaryotic translation elongation by cycloheximide and lactimidomycin." Nature Chemical Biology 6(3): 209-217.

Schneider-Poetsch, T., T. Usui, et al. (2010). "Garbled messages and corrupted translations." Nature Chemical Biology 6(3): 189-198.

Schuldiner, M., S. R. Collins, et al. (2005). "Exploration of the function and organization of the yeast early secretory pathway through an epistatic miniarray profile." Cell 123(3): 507-519.

Schuldiner, M., S. R. Collins, et al. (2006). "Quantitative genetic analysis in Saccharomyces cerevisiae using epistatic miniarray profiles (E-MAPs) and its application to chromatin functions." Methods 40(4): 344-352.

Shannon, P., A. Markiel, et al. (2003). "Cytoscape: A Software Environment for Integrated Models of Biomolecular Interaction Networks." Genome Research 13(11): 24982504. 
Shibuya, T., T. Tange, et al. (2004). "eIF4AIII binds spliced mRNA in the exon junction complex and is essential for nonsense-mediated decay." Nature Structure Molecular Biology 11(4): 346-351.

Shimma, Y.-i. and I. Uno (1990). "Isolation and characterization of neomycin-sensitive mutants in Saccharomyces cerevisiae." Journal of Genetic Microbiology 136(9): 1753-1761.

Shoemaker, D. D., D. A. Lashkari, et al. (1996). "Quantitative phenotypic analysis of yeast deletion mutants using a highly parallel molecular bar-coding strategy." Nature Genetics 14(4): 450-456.

Sin, N., L. H. Meng, et al. (1997). "The anti-angiogenic agent fumagillin covalently binds and inhibits the methionine aminopeptidase, MetAP-2." Proceedings of the National Academy of Sciences of the United States of America 94(12): 6099-6103.

Singh, G., S. Jakob, et al. (2007). "Communication with the Exon-Junction complex and activation of nonsense-mediated decay by human Upf proteins occur in the cytoplasm." Molecular Cell 27(5): 780-792.

Singh, P., K. Rathinasamy, et al. (2008). "Microtubule assembly dynamics: an attractive target for anticancer drugs." IUBMB Life 60(6): 368-375.

Sir Deshpande, B. and P. Toogood (1995). "Mechanism of protein synthesis inhibition by didemnin B in vitro." Biochemistry 34(28): 9177-9184.

Smith, T. and M. Waterman (1981). "Identification of common molecular subsequences." Journal of Molecular Biology 147(1): 195-197.

Sonenberg, N., H. J. W. B., et al., Eds. (2000). Translational Control of Gene Expression. CSHL Monographs, Cold Spring Harbour Laboratory Press.

Sonenberg, N. and A. G. Hinnebusch (2009). "Regulation of translation initiation in eukaryotes: Mechanisms and biological targets." Cell 136(4): 731-745.

Sora, S., O. Ciferri, et al. (1980). "Genetics and biochemistry of resistance to axenomycin in Saccharomyces cerevisiae." Current Genetics 2(1): 61-67.

Spector, I., N. Shochet, et al. (1983). "Latrunculins: novel marine toxins that disrupt microfilament organization in cultured cells." Science 219(4584): 493-495.

Stearns, T., M. A. Hoyt, et al. (1990). "Yeast mutants sensitive to anti-microtubule drugs define 3 genes that affect microtubule function." Genetics 124(2): 251-262.

Stec, B., U. Rao, et al. (1995). "Refinement of purothionins reveals solute particles important for lattice formation and toxicity. Part 2: structure of beta-purothionin at 1.7 A resolution." Acta Crystallogr D Biol Crystallogr 51(Pt 6): 914-924.

Stocklein, W. and W. Piepersberg (1980). "Altered ribosomal-protein L29 in a cycloheximide-resistant strain of Saccharomyces cerevisiae." Current Genetics 1(3): 177-183.

Stocklein, W. and W. Piepersberg (1980). "Binding of cycloheximide to ribosomes from wild-type and mutant strains of Saccharomyces-cerevisiae." Antimicrobial Agents and Chemotherapy 18(6): 863-867.

Stocklein, W., W. Piepersberg, et al. (1981). "Amino-acid replacements in ribosomalprotein YL24 of Saccharomyces-cerevisiae causing resistance to cycloheximide." FEBS Letters 136(2): 265-268.

Strasser, A., L. O'Connor, et al. (2000). "Apoptosis signaling." Annual Review of Biochemistry 69: 217-245.

Struhl, K. (1985). "Nucleotide sequence and transcriptional mapping of the yeast pet56his3-dedl gene region." Nucl. Acids Res. 13(23): 8587-8601.

Sutton, C. A., M. Ares, et al. (1978). "Cycloheximide resistance can be mediated through either ribosomal-subunit." Proceedings of the National Academy of Sciences of the United States of America 75(7): 3158-3162.

Svitkin, Y. V., A. Pause, et al. (2001). "The requirement for eukaryotic initiation factor 4A (eIF4A) in translation is in direct proportion to the degree of mRNA 5 ' secondary structure." Rna-a Publication of the Rna Society 7(3): 382-394. 
Svitkin, Y. V., A. Pause, et al. (2001). "The requirement for eukaryotic initiation factor 4A (eIF4A) in translation is in direct proportion to the degree of mRNA 5 ' secondary structure." RNA 7(3): 382-394.

Tagwerker, C., K. Flick, et al. (2006). "A tandem affinity tag for two-step purification under fully denaturing conditions: application in ubiquitin profiling and protein complex identification combined with in vivo cross-linking." Molecular and Cellular Proteomics 5(4): 737-748.

Tang, D., J. M. Lahti, et al. (1999). "Cycloheximide-induced T-cell Death Is Mediated by a Fas-associated Death Domain-dependent Mechanism." Journal of Biological Chemistry 274(11): 7245-7252.

Tang, R. P., A. M. Faussat, et al. (2006). "Semisynthetic homoharringtonine induces apoptosis via inhibition of protein synthesis and triggers rapid myeloid cell leukemia-1 down-regulation in myeloid leukemia cells." Molecular Cancer Therapeutics 5(3): 723-731.

Tange, T. O., A. Nott, et al. (2004). "The ever-increasing complexities of the exon junction complex." Current Opinion in Cell Biology 16(3): 279-284.

Taunton, J., C. A. Hassig, et al. (1996). "A mammalian histone deacetylase related to the yeast transcriptional regulator Rpd3p." Science 272(5260): 408-411.

Ter Haar, E., R. J. Kowalski, et al. (1996). "Discodermolide, a cytotoxic marine agent that stabilizes microtubules more potently than taxol." Biochemistry 35(1): 243-250.

Tong, A. and C. Boone (2006). "Synthetic genetic array analysis in Saccharomyces cerevisiae." Methods Molecular Biology 313: 171-192.

Tong, A. H. Y., M. Evangelista, et al. (2001). "Systematic genetic analysis with ordered arrays of yeast deletion mutants." Science 294(5550): 2364-2368.

Traut, R. R. and R. E. Monro (1964). "Puromycin reaction and its relation to protein synthesis." Journal of Molecular Biology 10(1): 63-\&.

Tutulan-Cunita, A. C., M. Mikoshi, et al. (2005). "Mutational analysis of the yeast multidrug resistance $\mathrm{ABC}$ transporter Pdr5p with altered drug specificity." Genes to Cells 10(5): 409-420.

Umesono, K., T. Toda, et al. (1983). "Cell division cycle genes nda2 and nda3 of the fission yeast Schizosaccharomyces pombe control microtubular organization and sensitivity to anti-mitotic benzimidazole compounds." Journal of Molecular Biology 168(2): 271-284.

Usui, T., S. Kazami, et al. (2004). "Amphidinolide H, a potent cytotoxic macrolide, covalently binds on actin subdomain 4 and stabilizes actin filament." Chemistry and Biology 11(9): 1269-1277.

Van Eden, M., M. Byrd, et al. (2004). "Translation of cellular inhibitor of apoptosis protein 1 (c-IAP1) mRNA is IRES mediated and regulated during cell stress." 469-481.

Vanduuren, B. L. (1988). "Direct-acting alkylating and acylating agents - DNA adduct formation, structure-activity, and carcinogenesis." Annals of the New York Academy of Sciences 534: 620-634.

Vijayraghavan, U., M. Company, et al. (1989). "Isolation and characterization of premRNA splicing mutants of Saccharomyces cerevisiae." Genes \& Development 3(8): 1206-1216.

von der Haar, T. and J. McCarthy (2002). "Intracellular translation initiation factor levels in Saccharomyces cerevisiae and their role in cap-complex function." Molecular Microbiology 46(2): 531-544.

von der Haar, T. and J. E. G. McCarthy (2002). "Intracellular translation initiation factor levels in Saccharomyces cerevisiae and their role in cap-complex function." Molecular Microbiology 46(2): 531-544.

Wakabaya.K and N. Gunge (1970). "Extrachromosomal inheritance of oligomycin resistance in yeast." FEBS Letters 6(4): 302-\&. 
Walsh, C. (2000). "Molecular mechanisms that confer antibacterial drug resistance." Nature 406(6797): 775-781.

Watanabe, R., M. J. Murai, et al. (2010). "The eukaryotic initiation factor (eIF) 4G heat domain promotes translation re-initiation in yeast both dependent on and independent of eIF4A helicase." Journal of Biological Chemistry 285(29): 2192221933.

Water, R. D. and L. J. Kleinsmith (1976). "Identification of alpha-tubulin and beta-tubulin in yeast." Biochemical and Biophysical Research Communications 70(3): 704-708.

Wendler, F., H. Bergler, et al. (1997). "Diazaborine resistance in the yeast Saccharomyces cerevisiae reveals a link between YAP1 and the pleiotropic drug resistance genes PDR1 and PDR3." Journal of Biological Chemistry 272(43): 27091-27098.

White, T. C., K. A. Marr, et al. (1998). "Clinical, cellular, and molecular factors that contribute to antifungal drug resistance." Clinical Microbiology Reviews 11(2): 382-+.

Wilkie, D. and B. K. Lee (1965). "Genetic analysis of actidione resistance in Saccharomyces cerevisiae." Genetical Research 6(1): 130-\&.

Wilkins, M. R., I. Lindskog, et al. (1997). "Detailed peptide characterization using PEPTIDEMASS - a World-Wide-Web-accessible tool." Electrophoresis 18(3-4): 403-408.

Will, C., H. Urlaub, et al. (2002). "Characterization of novel SF3b and 17S U2 snRNP proteins, including a human Prp5p homologue and an SF3b DEAD-box protein." EMBO J 21(18): 4978-4988.

Williams-Hill, D. M., R. F. Duncan, et al. (1997). "Differential expression of the murine eukaryotic translation initiation factor isogenes eIF4AI and eIF4AIIIs dependent upon cellular growth status." Archives of Biochemistry and Biophysics 338(1): 111-120.

Wilmes, G. M., M. Bergkessel, et al. (2008). "A genetic interaction map of RNAprocessing factors reveals links between Sem1/Dss1-containing complexes and mRNA export and splicing." Molecular Cell 32(5): 735-746.

Wilson, W. A., Z. Wang, et al. (2002). "Systematic identification of the genes affecting glycogen storage in the yeast Saccharomyces cerevisiae - Implication of the vacuole as a determinant of glycogen level." Molecular \& Cellular Proteomics 1(3): 232-242.

Winzeler, E. A., D. D. Shoemaker, et al. (1999). "Functional characterization of the $S$. cerevisiae genome by gene deletion and parallel analysis." Science 285(5429): 901906.

Woo, J. T., M. Kato, et al. (1999). "Reveromycin A induces osteoclast apoptosis and inhibits bone resorption." Journal of Bone and Mineral Research 14: SA207.

Wu, H. I., J. A. Brown, et al. (2004). "Genome-wide identification of genes conferring resistance to the anticancer agents cisplatin, oxaliplatin, and mitomycin C." Cancer Research 64(11): 3940-3948.

Xia, Y.-F., B.-Q. Ye, et al. (2004). "Andrographolide attenuates inflammation by inhibition of NF- $\kappa$ B activation through covalent modification of reduced cysteine 62 of p50." Journal of Immunology 173(6): 4207-4217.

Xie, M. W., F. L. Jin, et al. (2005). "Insights into TOR function and rapamycin response: Chemical genomic profiling by using a high-density cell array method." Proceedings of the National Academy of Sciences of the United States of America 102(20): 7215-7220.

Xu, Y.-Z., C. M. Newnham, et al. (2004). "Prp5 bridges U1 and U2 snRNPs and enables stable U2 snRNP association with intron RNA." EMBO Journal 23(2): 376-385.

Yoder-Hill, J., A. Pause, et al. (1993). "The p46 subunit of eukaryotic initiation-factor (eIF)-4F exchanges with eIF-4A." Journal of Biological Chemistry 268(8): 55665573. 
Yu, L., A. Lopez, et al. (2008). "Chemical-genetic profiling of imidazo[1,2-a]pyridines and -pyrimidines reveals target pathways conserved between yeast and human cells." Plos Genetics 4(11).

Zanchin, N. I. T. and J. E. G. McCarthy (1995). "Characterization of the in vivo phosphorylation sites of the mRNA cap-binding complex proteins eukaryotic initiation factor-4E and p20 in Saccharomyces cerevisiae." Journal of Biological Chemistry 270(44): 26505-26510.

Zewail, A., M. W. Xie, et al. (2003). "Novel functions of the phosphatidylinositol metabolic pathway discovered by a chemical genomics screen with wortmannin." Proceedings of the National Academy of Sciences of the United States of America 100(6): 3345-3350.

Zhang, J., C. Schneider, et al. (2002). "Genomic scale mutant hunt identifies cell size homeostasis genes in S. cerevisiae." Current Biology 12(23): 1992-2001.

Zhang, W. Z. and B. T. Chait (2000). "Profound: An expert system for protein identification using mass spectrometric peptide mapping information." Analytical Chemistry 72(11): 2482-2489.

Zhao, R. M., M. Davey, et al. (2005). "Navigating the chaperone network: An integrative map of physical and genetic interactions mediated by the Hsp90 chaperone." Cell 120(5): 715-727. 